NBS

PUBLICATIONS

A I I I O2 483490

U.S. DEPARTMENT OF COMMERCE National Bureau of Standards

NBS Monograph 173

Fire Behavior of

Upholstered

Furniture

Vytenis Babrauskas and John Krasny

3S NBS NBS NBS NBS NBS NBS NBS NBS NBS NB

3S NBS NBS NBS NBS NBS NBS NBS NBS NBS NE

iS NBS NBS NBS NBS NBS NBS NBS NBS NBS NE

iS NBS NBS NBS NBS NBS NBS NBS NBS NBS NL

3S NBS NBS NBS NBS NBS NBS NBS IRS NBS NB National Bureau of Standards

BS NBS NBS NBS NBS NBS NBS \R4 VBS NBS NL $\sqrt{10}$

100

.4556

No. 173

1985

3S NBS NBS NBS NBS NBS NBS NBS NBS NL

c. 2 
he National Bureau of Standards' was established by an act of Congress on March 3, 1901. The

Bureau's overall goal is to strengthen and advance the nation's science and technology and facilitate their effective application for public benefit. To this end, the Bureau conducts research and provides: (1) a basis for the nation's physical measurement system, (2) scientific and technological services for industry and government, (3) a technical basis for equity in trade, and (4) technical services to promote public safety. The Bureau's technical work is performed by the National Measurement Laboratory, the National Engineering Laboratory, the Institute for Computer Sciences and Technology, and the Institute for Materials Science and Engineering.

\section{The National Measurement Laboratory}

Provides the national system of physical and chemical measurement; coordinates the system with measurement systems of other nations and furnishes essential services leading to accurate and uniform physical and chemical measurement throughout the Nation's scientific community, industry, and commerce; provides advisory and research services to other Government agencies; conducts physical and chemical research; develops, produces, and distributes Standard Reference Materials; and provides calibration services. The Laboratory consists of the following centers:
- Basic Standards ${ }^{2}$

- Radiation Research

- Chemical Physics

- Analytical Chemistry

\section{The National Engineering Laboratory}

Provides technology and technical services to the public and private sectors to address national needs and to solve national problems; conducts research in engineering and applied science in support of these efforts; builds and maintains competence in the necessary disciplines required to carry out this research and technical service; develops engineering data and measurement capabilities; provides engineering measurement traceability services; develops test methods and proposes engineering standards and code changes; develops and proposes new engineering practices; and develops and improves mechanisms to transfer results of its research to the ultimate user. The Laboratory consists of the following centers:
- Applied Mathematics

- Electronics and Electrical Engineering ${ }^{2}$

- Manufacturing Engineering

- Building Technology

- Fire Research

- Chemical Engineering ${ }^{2}$

\section{The Institute for Computer Sciences and Technology}

Conducts research and provides scientific and technical services to aid Federal agencies in the selection, acquisition, application, and use of computer technology to improve effectiveness and economy in Government operations in accordance with Public Law 89-306 (40 U.S.C. 759), relevant Executive Orders, and other directives; carries out this mission by managing the Federal Information Processing Standards Program, developing Federal ADP standards guidelines, and managing Federal participation in ADP voluntary standardization activities; provides scientific and technological advisory services and assistance to Federal agencies; and provides the technical foundation for computer-related policies of the Federal Government. The In-* stitute consists of the following centers:
- Programming Science and Technology

- Computer Systems Engineering

\section{The Institute for Materials Science and Engineering}

Conducts research and provides measurements, data, standards, reference materials, quantitative understanding and other technical information fundamental to the processing, structure, properties and performance of materials; addresses the scientific basis for new advanced materials technologies; plans research around cross-country scientific themes such as nondestructive evaluation and phase diagram development; oversees Bureau-wide technical programs in nuclear reactor radiation research and nondestructive evaluation; and broadly disseminates generic technical information resulting from its programs. The Institute consists of the following Divisions:
- Ceramics

- Fracture and Deformation ${ }^{3}$

- Polymers

- Metallurgy

- Reactor Radiation 


\section{Fire Behavior of \\ Upholstered \\ Furniture}

\section{Vytenis Babrauskas and John Krasny}

National Engineering Laboratory:

Center for Fire Research!

National Bureau of Standards:

Gaithersburg, MD 20899

November 1985

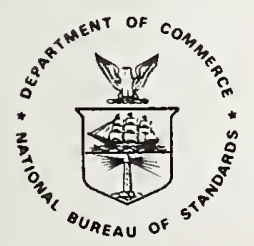

U.S. Department of Commence Maloolm Baldrige, Secretary

National Bureau of Standards

Emest Ambler, Director 
Library of Congress

Catalog Card Number: 85-600620

National Bureau of Standards

Monograph 173

Natl. Bur. Stand. (U.S.),

Monogr. 173,

101 pages (Nov. 1985)

CODEN: NBSMA6
U.S. Government Printing Office Washington: 1985
For sale by the

Superintendent of Documents, U.S. Government Printing Office Washington, DC 20402 


\section{Contents}

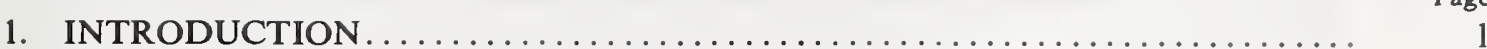

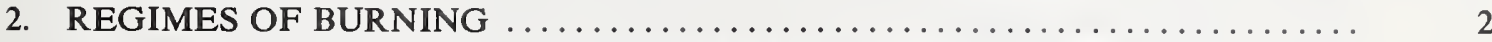

3. CIGARETTE IGNITION OF UPHOLSTERED ITEMS ............... 3

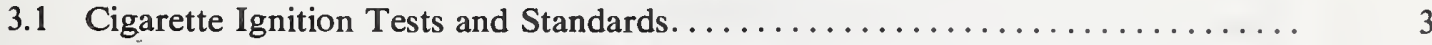

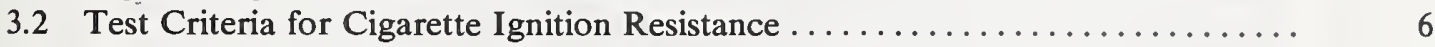

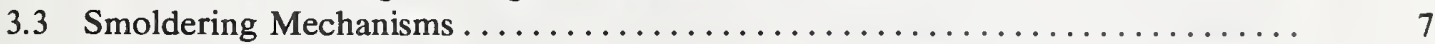

3.3.1 Cellulose Smoldering. ............................... 7

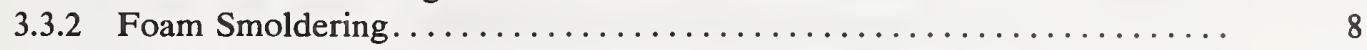

3.3.3 Cigarette-Upholstered Item Interaction . . . . . . . . . . . . . . .

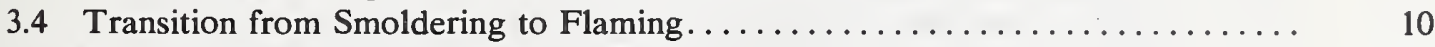

4. FLAMING FIRE BEHAVIOR AND TESTS $\ldots \ldots \ldots \ldots \ldots \ldots \ldots \ldots \ldots \ldots \ldots \ldots \ldots \ldots \ldots \ldots$

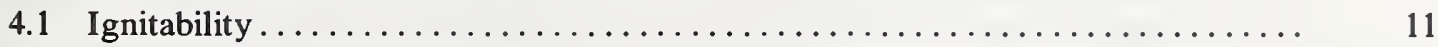

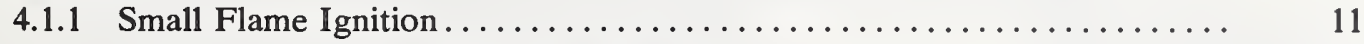

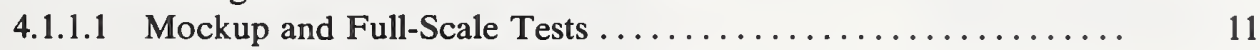

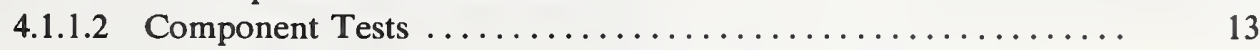

4.1.1.3 Comparison of Component and Mockup Test Results ......... 14

4.2 Ignitability from Large Open-Flame or Radiation Sources............... 15

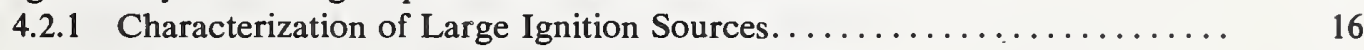

4.2.2 Large Open-Flame and Radiant Ignition Tests................ 16

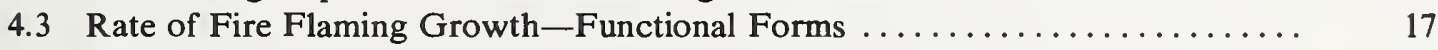

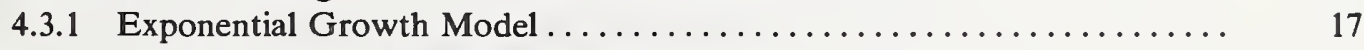

4.3.2 Triangular Rate of Heat Release Model...................... 18

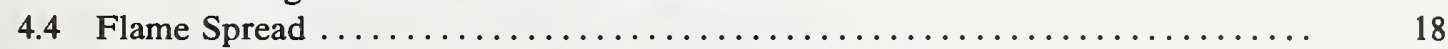

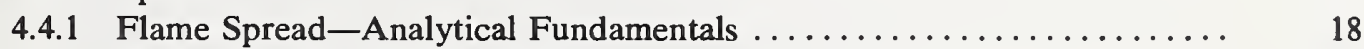

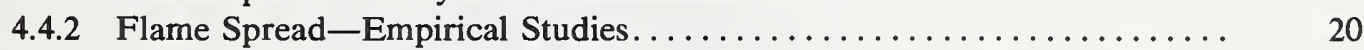

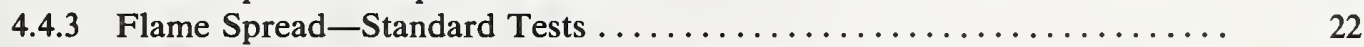

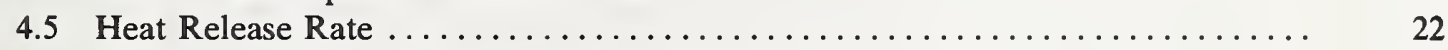

4.5.1 Full-Scale Heat Release Rate Measurement Techniques............ 22

4.5.2 Full-Scale Heat Release Rate Data....................... 23

4.5.3 Bench-Scale Heat Release Rate Measurement Techniques............ 23

4.5.4 Bench-Scale Heat Release Rate Data ........................ 24

4.6 Upholstered Items of Unconventional Construction . . . . . . . . . . . . . . . . . 24

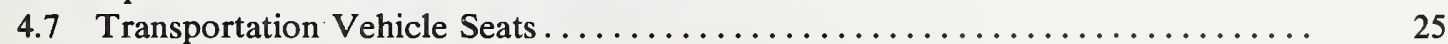

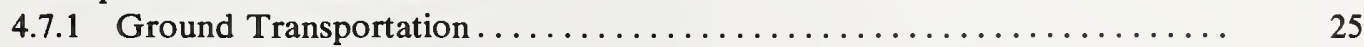

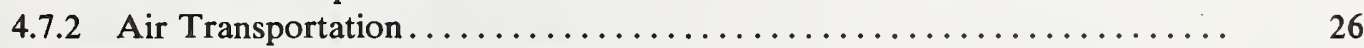

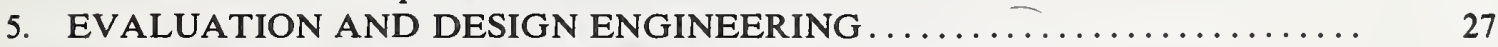

5.1 Flammability Ranking of Upholstered Furniture Components............. 27

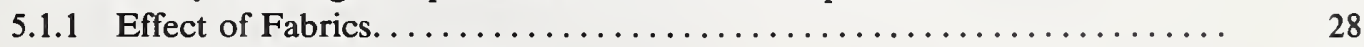

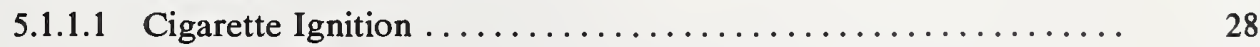

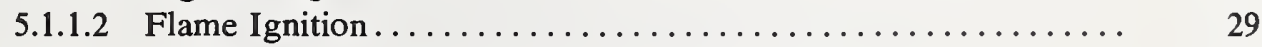

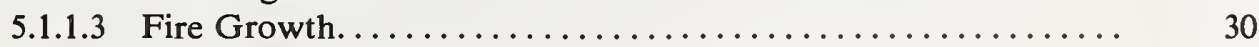

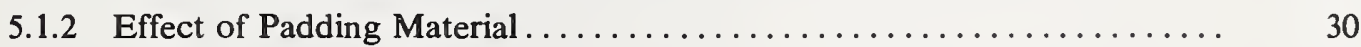

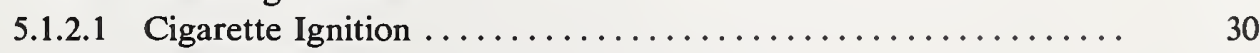

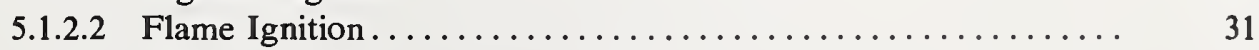

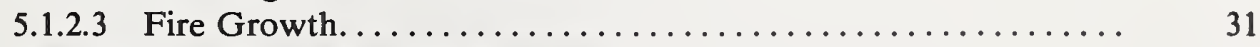

5.1.3 Effect of Interliner or Barrier Materials.................... 32

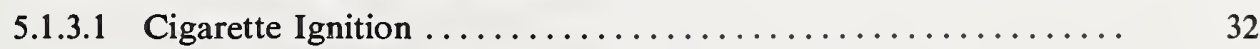

5.1.3.2 Flame Ignition and Fire Growth $\ldots \ldots \ldots \ldots \ldots \ldots \ldots \ldots . \quad 32$ 


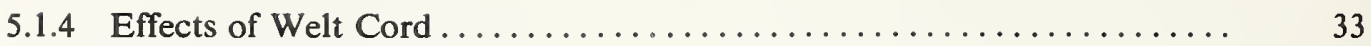

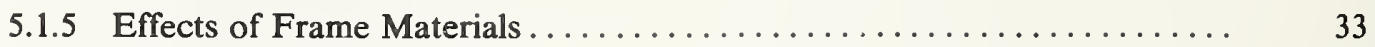

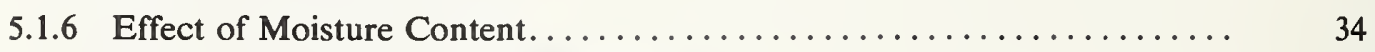

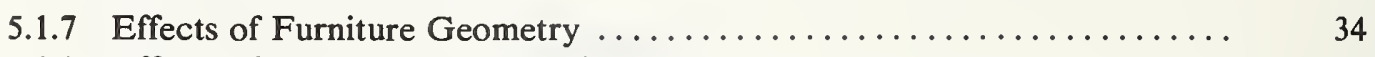

5.1.8 Effects of Fuel Load and Specimen Mass .................. 35

5.2 Estimates of Flammability Based on Generic Materials Identification Only ..... 35

5.3 Estimates of Flammability Based on Bench-Scale Testing ............. 36

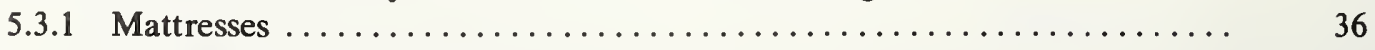

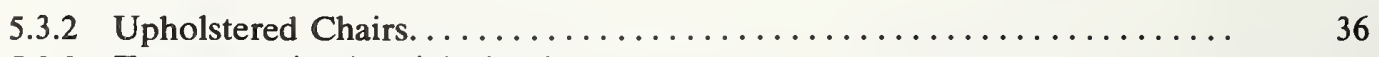

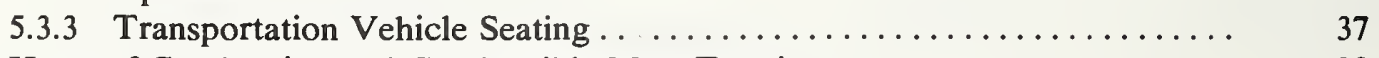

5.4 Heats of Combustion and Combustible Mass Fraction................ 38

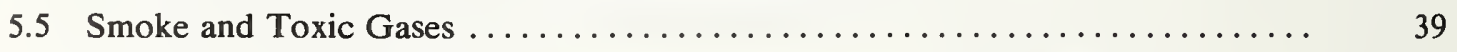

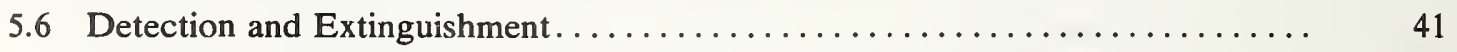

5.7 Behavior in Room Fires . . . . . . . . . . . . . . . . 41

5.7.1 Some Relationships from Room Fire Theory $\ldots \ldots \ldots \ldots \ldots \ldots \ldots \ldots ., 41$

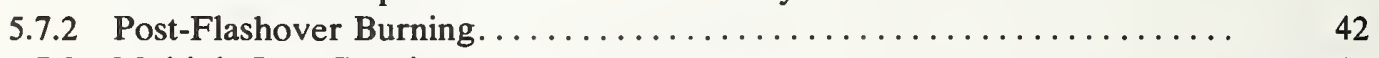

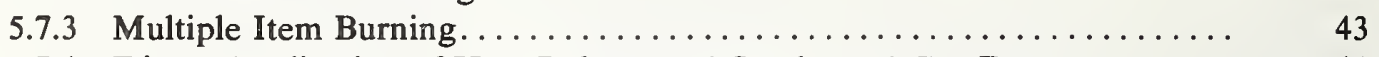

5.7.4 Direct Application of Heat Release and Smoke and Gas Data ........ 44

5.7.5 Applications to Numerical Room Fire Models................ 45

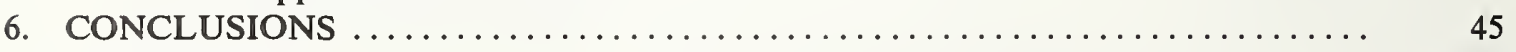

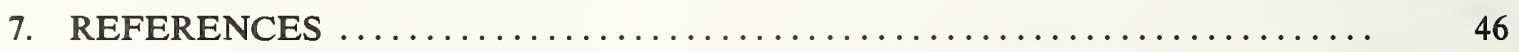


Table 1. Tests for smoldering (cigarette) ignition of upholstered furniture and

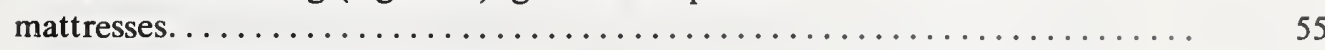

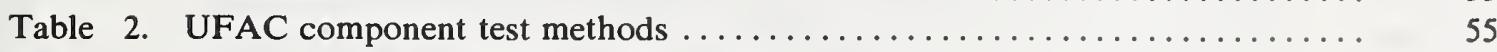

Table 3. British upholstered furniture butane ignition sources............... 55

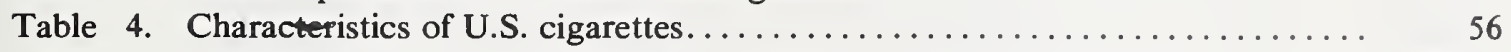

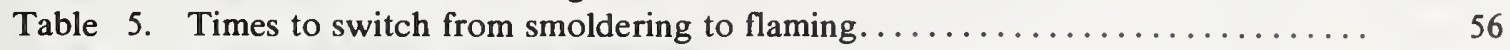

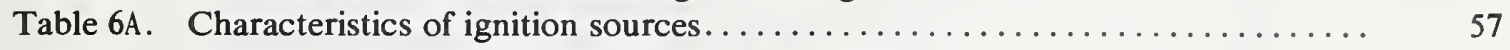

Table 6B. Characteristics of typical furnishings as ignition sources.............. 57

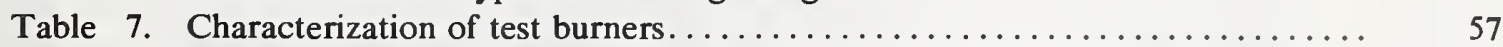

Table 8. Fabric and mockup ignitability test results on 10 upholstery cover fabrics... 58

Table 9. Effect of irradiance levels on polyurethane foam flammability performance... 58

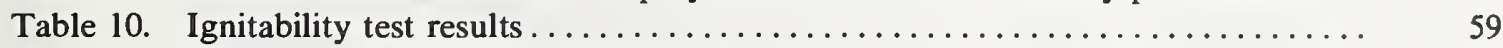

Table 11. Effect of substrate on ignitability......................... 59

Table 12. Triangular representation of heat release rate curves for upholstered chairs... 60

Table 13. Observations during mattress burn experiments ................. 61

Table 14. Flame spread measurements in horizontal flame spread test apparatus over fabric/foam composites . . . . . . . . . . 61

Table 15. Heat release rates of mattresses in NBS tests. . . . . . . . . . . . . . . . 62

Table 16. Heat release rates of mattresses in CSTB tests . . . . . . . . . . . . . . 63

Table 17. Heat release rates of chairs in recent NBS tests .................. 64

Table 18. Full-scale chair mockup results and bench-scale rate of heat release

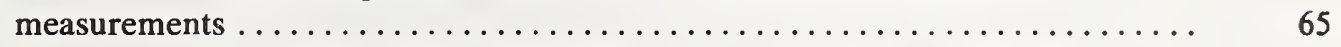

Table 19. Comparison of full-scale to bench-scale heat release rate measurements

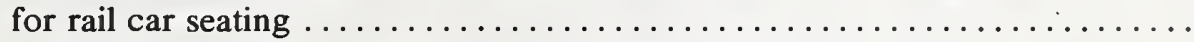

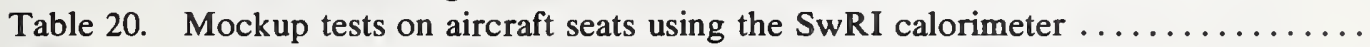

Table 21. Upholstered furniture components listed in approximate order of

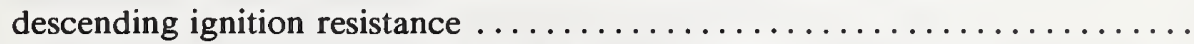

Table 22. Cigarette ignition resistance of typical fabric/padding material combinations. .

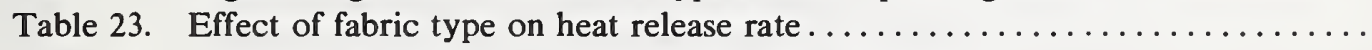

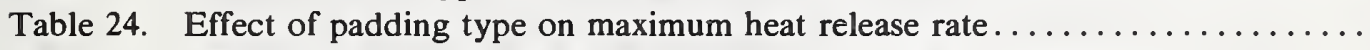

Table 25. Effect of frame material for specimens with NFR PU padding and

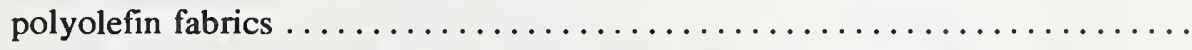

Table 26. Effect of specimen mass on the heat release rate of polyurethane foam

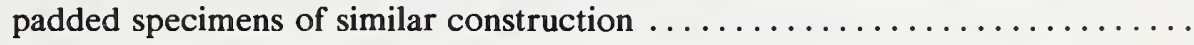

Table 27. Rate of heat release peak values for upholstered chairs-measured and

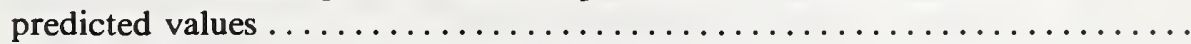

Table 28. Heats of gasification for aircraft seat materials $\ldots \ldots \ldots \ldots \ldots \ldots \ldots \ldots$

Table 29. Comparison of full-scale and bench-scale heat release rate results for

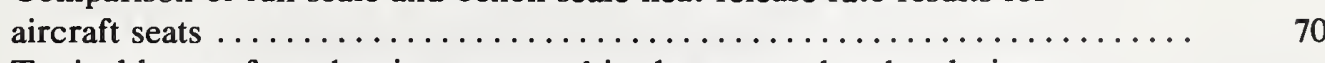

Table 30. Typical heats of combustion measured in the oxygen bomb calorimeter

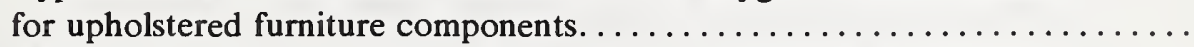

Table 31. Effective heats of combustion as measured in full-scale or bench-scale

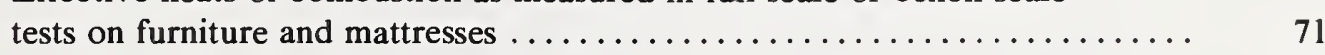

Table 32. Smoke production for a series of mattresses $\ldots \ldots \ldots \ldots \ldots \ldots \ldots \ldots \ldots \ldots \ldots$

Table 33. Comparison of smoke production results for upholstered furniture........ 72 
Figure 1. Upholstered furniture construction details .................. 73

Figure 2. Mockup for testing cigarette ignition resistance of upholstered furniture.... 73

Figure 3. Mini-mockup for determining fabric classification ................ 74

Figure 4. Fabric classification scheme ............................ 74

Figure 5. Mockup for BS 5852 tests............................ 75

Figure 6. Time-temperature relationships for cigarettes burning on various

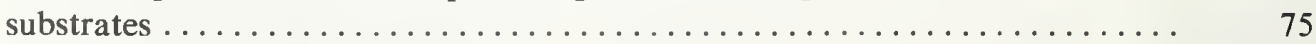

Figure 7. Typical ignition curves for a range of upholstered furniture fabric/padding

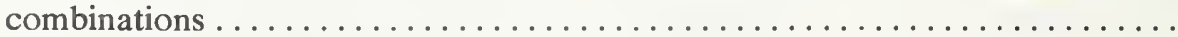

Figure 8. Gage locations for heat flux measurements on ignitability test burners......

Figure 9. Heat fluxes measured at the wastebasket simulation burner .............

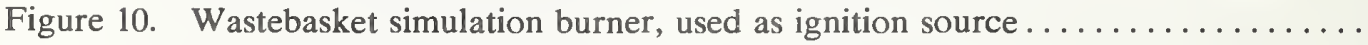

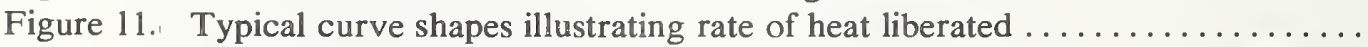

Figure 12. Triangular approximation to an actual heat release rate curve...........

Figure 13. Geometrical configurations possible for one-dimensional flame spread......

Figure 14. Shape of the pyrolysis area on a vertical slab with point ignition, at

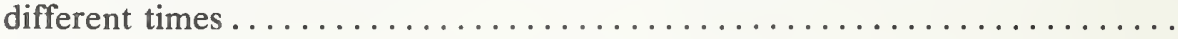

Figure 15. Shapes of pyrolysis zones on polyurethane foam slabs with point ignition....

Figure 16. Pyrolysis zone contours for horizontal polyurethane foam slab, ignited at

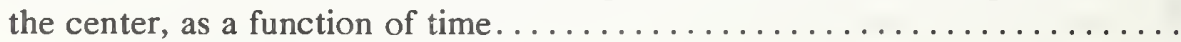

Figure 17. Mockup frame and cushion arrangements $\ldots \ldots \ldots \ldots \ldots \ldots \ldots \ldots \ldots$

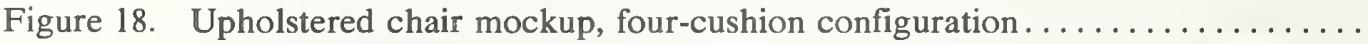

Figure 19. Flame spread over seat cushion surface in four-cushion mockup..........

Figure 20. Rates of heat release for standard-size pillows, covered with polyester/cotton

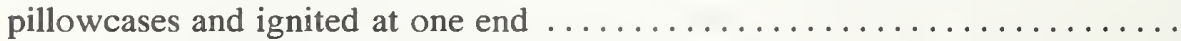

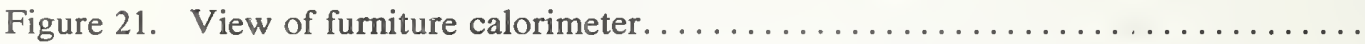

Figure 22. Test bed configuration used for mattress room fire tests . . . . . . . . . .

Figure 23. Typical heat release rate results in the furniture calorimeter $\ldots \ldots \ldots \ldots \ldots$

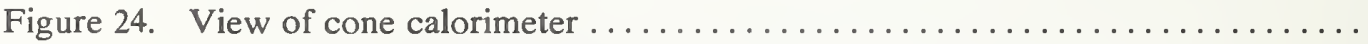

Figure 25. Cone calorimeter measurements of the heat release rate for heavy polyolefin fabric/combustion modified high-resiliency polyurethane

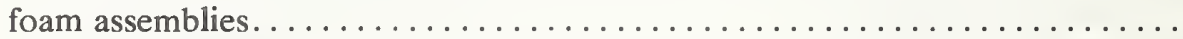

Figure 26. Cone calorimeter measurements of the heat release rate for various fabric/padding combinations, at an irradiance of $25 \mathrm{~kW} / \mathrm{m}^{2} \ldots \ldots \ldots \ldots$

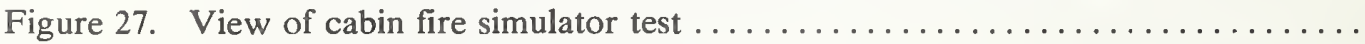

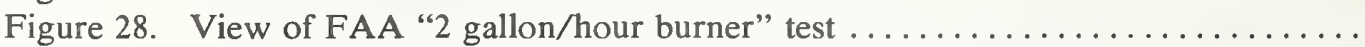

Figure 29. Data for mattresses and upholstered chairs indicating that fuel alone is a

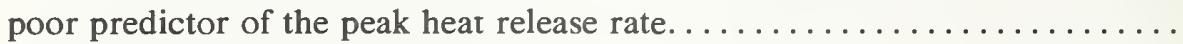

Figure 30. Prediction of full-scale heat release rate based on generic material factors ...

Figure 31. Relationship between full-scale and bench-scale of heat release

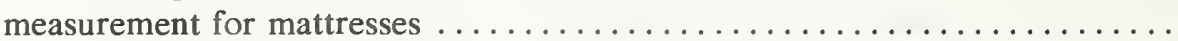

Figure 32. Prediction of full-scale heat release rate based on bench-scale measurements

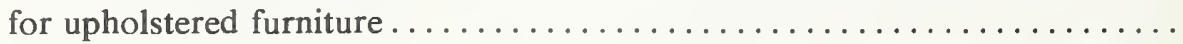

Figure 33. Effective heat of combustion measured for chair F21 .............

Figure 34. Comparison of free burn and room fire results for beds $\ldots \ldots \ldots \ldots \ldots \ldots$

Figure 35. Comparison of furniture calorimeter and room fire results for an

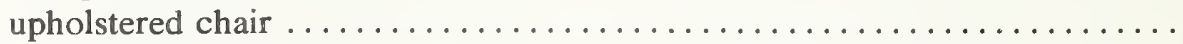

Figure 36. Comparison of furniture calorimeter and room fire results for a loveseat .... Figure 37. Irradiances for wicker couch (F19) measured at peak burning time . . . . . . Figure 38. Irradiances for wicker couch (F19) measured at $0.41 \mathrm{~m}$ height .......... Figure 39. Relationship between mass loss rate of initial item and irradiance to target... Figure 40. Relationship between mass loss rate of initial item and maximum ignitability

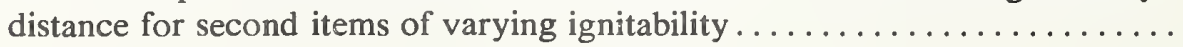




\section{Nomenclature}

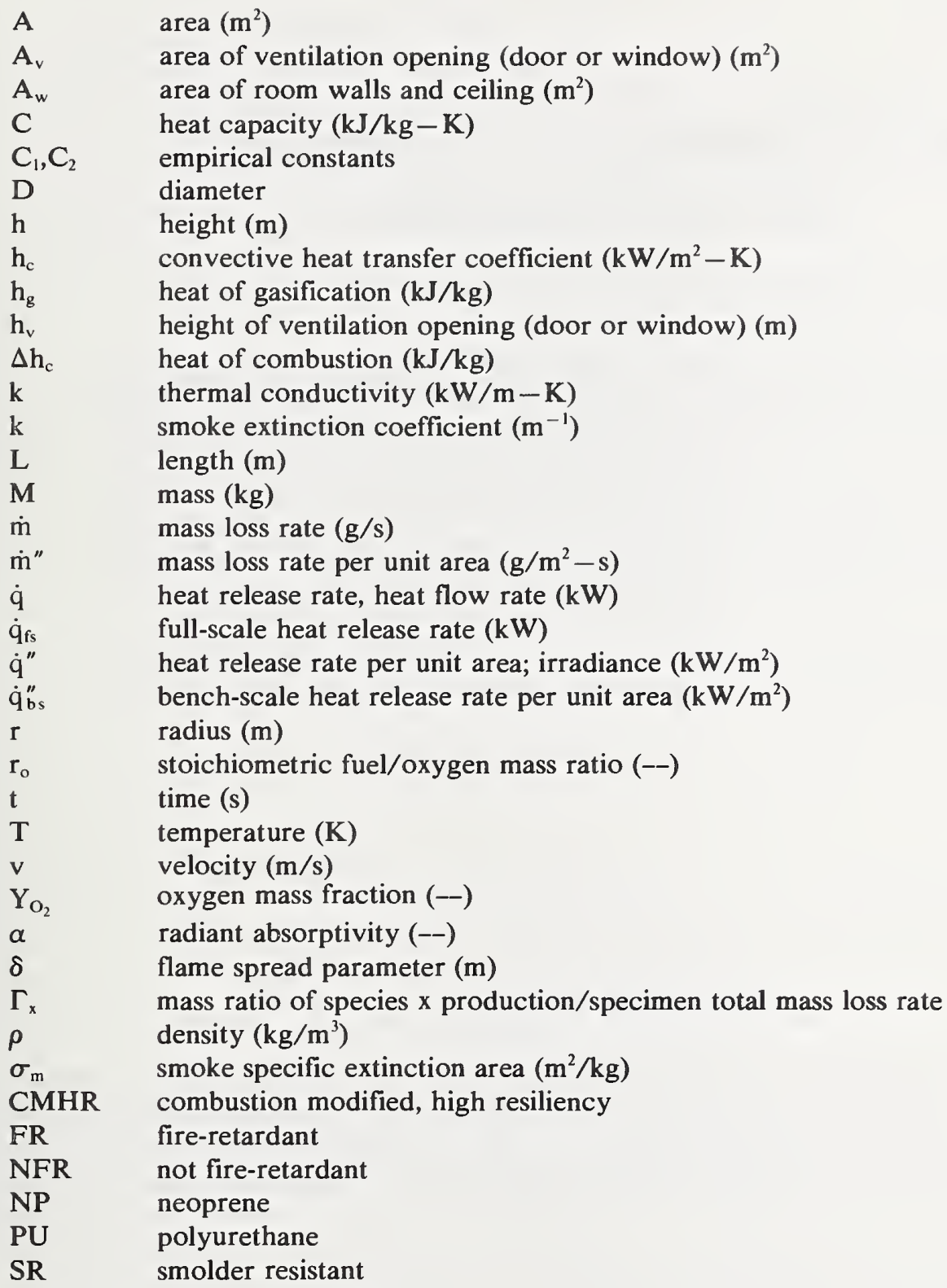





\title{
Fire Behavior of Upholstered Furniture
}

\author{
Vytenis Babrauskas and John F. Krasny \\ Center for Fire Research, National Bureau of Standards, Gaithersburg, MD 20899
}

\begin{abstract}
A systematic review is made of engineering data on the major aspects of upholstered furniture flammability: cigarette ignition, small open flame ignition, radiant ignition, transition from smoldering to flaming, flame spread rates, and heat release and mass loss rates during fully-involved burning. Other areas discussed, but for which less data are available, include smoke production and radiant heat fluxes. Mattresses and transportation vehicle seating are included, along with upholstered chairs, loveseats, and sofas. Test methods for measuring each of these properties are discussed. Where available, relationships are presented which permit the quantitative prediction of full-scale furniture behavior from bench-scale tests. Where such relationships are not available, generalizations of qualitative results of empirical tests are given, even though such relationships give less accurate results than testing. Areas where substantive work is not available are outlined.

Key words: aircraft seats; beds; cigarette ignition; fabric flammability; flame spread; foam; heat release rate; ignitability; mattresses; smoldering; transportation vehicle seats; upholstered furniture.
\end{abstract}

\section{INTRODUCTION}

This monograph is a review of the published literature on fires of upholstered furniture and mattresses, with a few recent, unpublished results included. For the purposes of this monograph, "upholstered items" will include both upholstered furniture and mattresses, as well as upholstered seats used in transportation vehicles. Since this monograph is primarily intended for the fire safety designer, the emphasis is on quantitative methods. Studies which do not lead to engineering conclusions are not discussed here, but can be found in relevant bibliographies $[1,2,3]$.

Residential fire statistics [4-7] indicate the following about upholstered furniture item fires:

- About 65 percent of them are caused by cigarettes; other major causes are matches, electrical appliances, and hot objects.

- Cigarette-initiated fires caused over 30 percent of the fire deaths in the United States, and were the largest single cause of such fire deaths. This situation is similar in some European countries.

- However, cigarette-initiated fires accounted only for 10 percent of residential fires, and 20 percent of the injuries; the morbidity and mortality in cigarette initiated fires is thus inordinately high.

- While the actual number of fires has decreased in recent years, the proportion of cigarette-caused fires appears to be constant.

Because cigarette-initiated fires are much more frequent than small flame ignition source caused fires, prevention of the former is most important. This has been recognized by regulatory measures in the United States, by the International Organization for Standardization (ISO), and many individual countries, as will be discussed later.

Four major characteristics of upholstered item fires should be considered: probability of cigarette ignition; probability of small flame ignition; consequences of such ignitions, in terms of rate of heat release, flame spread, and development of smoke and toxic combustion products; and contribution to the total fire if the upholstered item is not the first item to ignite. Cigarette ignition resistance and flame ignition resistance do not necessarily go hand in hand, e.g., heavy thermoplastic fabrics (nylon, polyester, polypropylene) in combination with 
ignitable padding materials have relatively good cigarette ignition resistance but poor small flame ignition resistance. Similarly, heavy cellulosic materials (cotton, hemp, linen, rayon) generally have poor cigarette ignition resistance but burn at a slower rate than thermoplastic fabrics and polyurethane (PU)* foams.

Many aspects of flammability are similar for upholstered furniture and mattresses. However, the following distinction must be made. Mattresses have predominantly flat surfaces which are not as likely to ignite by cigarettes as furniture crevices, i.e., the juncture of seat cushion and the back or arm-rests of upholstered furniture. Similarly, the horizontal flat surfaces are not as easily ignited from flame ignition sources as the vertical furniture surfaces.

On the other hand, cigarettes on mattresses may be covered inadvertently with sheets, blankets, and/or pillows. This increases the probability of ignition by cigarettes. Also, these intermediary materials may ignite more readily than mattresses from flames, but then expose the mattress to a much more severe fire than the original ignition source, e.g., a match. Consequently, it is more difficult to develop relevant ignition tests and standards for mattresses than for upholstered furniture.

Upholstered furniture is a complex structure, as shown in figure 1. One item can contain 10 or more materials. In the ignition process, whether it be from a cigarette or small flame, the cover fabric and material immediately below it-one or two layers of padding-are important. As the fire progresses, other materials contribute, including the frame and springs, which can affect the manner in which the burning item collapses.

Transportation vehicle upholstered seats are generally constructed in a similar manner as upholstered furniture, albeit with different choices of materials. Since safety requirements are typically higher, different, more stringent tests are usually applied than for commercial furniture. Several sections in this monograph are devoted to an analysis of full-scale and bench-scale tests for transportation vehicle seating. Otherwise, fire phenomena and methods for analysis are identical to those for upholstered chairs.

While fire problems with upholstered furniture have been of concern for some decades, it has been only a few years since systematic, quantitative, and predictive data have been available for common materials in the upholstered furniture category. Rapid progress has been made recently, however, so that one can now start to treat the subject as a design or prediction problem. In a design problem, the designer is typically required to come up with materials and configurations suitable to meet a set objective, which may be resistance to ignition by cigarettes, or a full-scale burning rate of less than a specified amount. One may have access to bench-scale test capabilities but must be able to produce the design without full-scale testing. Conversely, for an article which already exists, its performance may need to be estimated from bench-scale tests alone. In some forms of hazard surveying, even bench-scale fire tests are precluded and the estimate mus! be made solely on material identification and weight and size data. (This should be undertaken only as a last recourse, however.) In this monograph, means to achieve this for major categories of upholstered furniture are outlined. Except in the area of cigarette ignition, only small sets of experimental data are available; thus design methods to prevent flaming are expected to change as more complete data become available.

In the body of this monograph, smoldering (cigarette) ignition of upholstered items will be discussed first. This will be followed by small flame ignition. The major parameters determining the growth of fires in upholstered items, flame spread and heat release rate, will be discussed next. Design considerations to attain cigarette and flame resistance, and to minimize consequences of ignition, will be discussed in the final chapter. The emphasis is on thermal behavior, flaming or smoldering; literature on relative rates of smoke and combustion products release is much less extensive.

\section{REGIMES OF BURNING}

Combustion of solid materials can be of two kinds--either flaming or smoldering. A given material may be capable of only one or both modes of burning. The rates of combustion are very different, being typically $0.1 \mathrm{~g} / \mathrm{s}$ for a smoldering chair and $100 \mathrm{~g} / \mathrm{s}$ for a flaming one. The ignition scenarios are likewise different. A smoldering furniture fire almost invariably starts from a cigarette, whereas a flaming one can be started with matches, lighters, or other, often much larger, flaming objects. Also, the smoldering fire may turn into a flaming one later in its course, or a flaming fire may convert to smoldering due to oxygen depletion. While the heat output of the smoldering fire is very small, its hazards are very significant. Even only partial smoldering of a chair can cause casualties due to suffocation in the room of origin or adjoining rooms.

\footnotetext{
* All nomenclature is listed in Nomenclature Section.

Note: Certain commercial products and materials are identified in this monograph in order to adequately specify the experimental procedure. Such identification does not imply recommendation by the National Bureau of Standards, nor does it imply that these products or materials identified are necessarily the best available for the purpose.
} 


\section{CIGARETTE IGNITION OF UPHOLSTERED ITEMS}

\subsection{Cigarette Ignition Tests and Standards}

Much of the knowledge and experience of cigarette ignitions has been acquired through the running of standardized tests. These tests have also been used in two approaches to limiting ignitions from cigarettes which are in use or under consideration: regulatory and voluntary standards for upholstered furniture and mattresses and, much less advanced, regulatory action concerning cigarettes. The former approaches are listed in table 1, divided into voluntary and regulatory standards. These standards either prescribe mockup or component tests. In mockup tests, cover fabrics, padding materials (also known as filling or stuffing), welt cord, and interior fabrics are arranged as in the planned line of furniture. In component tests, these individual components are subjected to separate tests. The mockup tests require more effort, and must be performed for the numerous combinations of cover fabric and back, side arm, and seat cushion padding materials, and (in some standards) welt cords. However, they provide the only means to evaluate the effects of interaction between materials for cigarette ignition resistance of upholstered furniture assemblies. Component tests can be used to screen the individual materials and to restrict the use of those with low cigarette ignition resistance.

The United States Consumer Product Safety Commission (CPSC) considered a regulatory cigarette ignition standard for upholstered furniture in the years 1976 to 1981 [8]. In 1981, CPSC voted to accept, on a trial basis, the voluntary standards proposed by the pertinent trade group, the Upholstered Furniture Action Council (UFAC) [9]. However, the specialized Business and Institutional Furniture Manufacturers Association (BIFMA) voluntarily adopted the original, proposed CPSC standard [10]. The reasons for the choice of test arrangements in this standard and numerous results, including those of an interlaboratory evaluation of the method, are described in a report prepared for CPSC [11].

The American Society for Testing and Materials (ASTM) is working on a proposed cigarette ignition test for upholstered furniture components which is based on the UFAC standards [12]. The National Fire Protection Association (NFPA) Standard 260A is also based on the UFAC component standards and is intended for residential furniture; NFPA 260B parallels the proposed CPSC test procedure and is intended for public occupancy furniture [13].

Two features of the CPSC procedure have been adopted for all United States cigarette ignition tests: the cigarette and the placement of a piece of sheeting over the cigarette after it is placed into its test position. The cigarette is made from natural tobacco, $85 \pm 2 \mathrm{~mm}$ long, with a tobacco packing density of $0.270 \pm 0.020 \mathrm{~g} / \mathrm{cm}^{3}$ and a total weight of $1.1 \pm 0.1 \mathrm{~g}^{2}$. The proposed ASTM version of the test also specifies that the smoldering rate of the cigarette should be $0.10 \pm 0.01 \mathrm{~mm} / \mathrm{s}$, with the cigarette burning downward in a draft protected area [12]. The sheeting is cotton or polyester/cotton percale, $115 \pm 28 \mathrm{~g} / \mathrm{m}^{2}, 67-79$ threads $/ \mathrm{cm}$, without chemical finish. The presence of this sheeting on top of the smoldering cigarette makes the test slightly more severe and more reproducible $[11,14,15]$.

The mockup and locations for placement of the cigarettes are shown in figure 2. The mockup consists of a horizontal cushion, $450 \times 550 \mathrm{~mm}$, and vertical back and side cushions, approximately $300 \times 500 \mathrm{~mm}$. In addition, the decking (the materials under removable seat cushions) and flat areas on top of the side arms and back are mocked up if they are large enough so cigarettes can rest on them. All these mockup cushions contain the padding material planned for use in the prospective line of furniture, covered by the chosen cover fabric. Three cigarettes each are placed into the two crevices formed by the seat and the back or side cushions, in the flat area of the seat cushion and the welt edge area in its front, and, if applicable, in flat mockups of the decking and back and sidearm tops. The cigarettes are then covered with the above-mentioned sheeting, $125 \times 125 \mathrm{~mm}$. If the resulting char lengths, measured from the nearest point of the original cigarette location, are less than 75 $\mathrm{mm}$, the mockup passes. Provisions are made for retesting if cigarettes go out before burning their whole length, or if only one cigarette per location produces a char length exceeding $75 \mathrm{~mm}$.

A furniture manufacturer may use several thousand fabrics in one year, but relatively few padding material combinations. To eliminate the need for testing these padding material combinations with each fabric, the proposed CSPC and BIFMA tests contain a fabric classification scheme. The mini-mockup testing device used in fabric classification is shown in figure 3. The fabric is tested over glass fiberboard, $200 \times 200 \mathrm{~mm}$ for the horizontal and $200 \times 300 \mathrm{~mm}$ for the vertical piece. The glass fiberboard)(Fed. Spec. HH-I-558B, Form A, Class 1 , plain faced) is approximately $25 \mathrm{~mm}$ thick and has a density of $40 \pm 8 \mathrm{~kg} / \mathrm{m}^{3}$. A cigarette is placed into the crevice formed by the two fabric-covered boards, covered with a piece of sheeting, and allowed to burn completely. The fabric classification scheme shown in figure 4 is used. For example, if the char length is $38 \mathrm{~mm}$

${ }^{a}$ Pall Mall king size cigarettes comply with this specification. 
or less, the fabric is Class A or B. It can then be subjected to an additional test in which the vertical glass fiberboard is replaced with a plywood board covered with $50 \mathrm{~mm}$ cotton batting without any FR treatment. If the char length then is less than $38 \mathrm{~mm}$, the fabric is Class A.

The results of the fabric classification test are used as follows: if a combination of padding material and welt cord passes with a Class A fabric, this combination may be used with all Class $\mathrm{A}$ fabrics. Combinations which pass with the Standard Class B fabric (the above-mentioned sheeting used to cover the cigarettes) can be used with all fabrics classified to be Class A or B. Similarly, combinations which pass with the Standard Class C fabric (Fed. Spec. CCC-C-436D, cloth, ticking, twill, cotton, Type I, Class I, untreated, $305 \pm 14 \mathrm{~g} / \mathrm{m}^{2}$, without finish) can be used with all Class A, B, or C fabrics. However, all furniture which is to be covered with Class D fabric must be tested in mockup form.

Even with this large reduction in testing effort, the furniture industry objected to the proposed CPSC standard. Instead, UFAC offered to develop a voluntary program and this was accepted on a trial basis, with CPSC monitoring the progress. UFAC proceeded to (1) develop voluntary standards for upholstered furniture components, (2) sign up manufacturers to join the program, and (3) initiate a labeling program and educational program covering UFAC labeled furniture. The label states that the furniture "is made in accordance with the new, improved UFAC methods, designed to reduce the likelihood of furniture fires from cigarettes. However, upholstery fires are still possible." The label also recommends use of smoke detectors.

The UFAC tests use the above discussed cigarette, cigarette cover, and mini-mockup test frame. The testing scheme for the individual components is outlined in table 2 [9], together with materials which usually pass the tests. Specifications of the UFAC standard polyurethane (PU) foam and two standard test fabrics and the sheeting used to cover the cigarettes are also shown in the table.

Upholstery fabrics to be classified are placed over the UFAC standard foam in both the horizontal and vertical panel of the mini-mockup and a cigarette is placed into the crevice and covered with the sheeting. If the vertical char length in any of three replicate tests is equal to or exceeds $44 \mathrm{~mm}$, the fabric is "Class II." Class II fabrics must have a UFAC approved barrier material between cover fabric and padding material in the seat cushion. Class I fabrics can be used with any UFAC approved components.

Similarly, padding material is mounted in both parts of the mini-mockup and covered with the UFAC standard ticking which is identical to the CPSC Class C standard fabric. This standard ticking is also used in testing any interior fabric layers, if present over the padding. The welt cord is tested with the more ignitionprone UFAC standard Class II fabric and UFAC standard foam in both panels. The same fabric is used to test barrier and decking materials (the latter are only tested in a horizontal panel).

These choices of test parameters, especially the choices of standard fabrics and foam, which do not represent "worst case" choices*, are apparently compromises made to obtain the best cigarette ignition resistance while using readily available, relatively inexpensive components. The UFAC standards can be readily upgraded, to take advantage of materials with higher cigarette ignition resistance. A case in point is the recent upgrading of the welt cord standard by changing from the more cigarette ignition resistant standard ticking to the more ignition-prone Standard Class II fabric. This change followed development of welt cords containing heat dissipating aluminum foil strips and eliminated the previously acceptable ignition-prone cellulosic welt cords [16].

As discussed in section 5.1.1.1, fabrics vary widely in cigarette ignition resistance. It thus would be desirable that standard fabrics used in the UFAC and California tests (discussed below) would have very low cigarette ignition resistance, to assure that padding, welt cord, etc., which pass with the standard fabric would not ignite with any of the cover fabrics used on upholstery items. Such is not the case, however; the standard fabrics were chosen to eliminate some of the materials with low cigarette ignition resistance, but not to completely change the market by requiring highly cigarette resistant, and, possibly, expensive materials. Similarly, the UFAC standard foam which is used in the qualification of fabrics, welt cords, and interliners is by far not the least cigarette ignition resistant PU foam available. Furthermore, interaction of furniture components in a smoldering situation cannot be predicted from component tests. Many UFAC labeled pieces of furniture procured during the early stages of the program and mockups prepared to UFAC requirements, have been shown to ignite from cigarettes [17,18]. More recently CPSC and UFAC tested 40 furniture items conforming to UFAC standards which were procured in late 1983. Resistance to cigarette ignition was found to have been improved [19].

The State of California has standards requiring cigarette ignition resistance of resilient cellular material (foam) used in upholstered furniture, as well as certain levels of flame resistance of all components [20]. The mini-mockup configuration, standard cigarette, and cigarette cover sheeting are again used in the test. The

* For example, with a worst case fabric (possibly a heavy, unfinished cellulosic fabric) no presently used filling materials would pass the tests. 
foam is tested with a standard fabric (beige, $100 \%$ cotton velvet, $330 \mathrm{~g} / \mathrm{m}^{2}$ ) without backcoating. The test is carried out until obvious combustion or until the system appears to have self-extinguished for 5 minutes, the remains of the fabric and carbonaceous char removed from the foam, and the nonburned portions of the foam weighed. Foam passes if the specimens retain more than 80 percent of their original weight. The background of this standard and its effects on material selection are discussed in a 1981 paper by Damant [21].

Great Britain also has a standard for both cigarette and small flame ignition resistance of upholstered furniture [22]. The standard consists of two parts: the first applies to "smoker's materials," which include both cigarettes and wooden matches (simulated by a butane burner). All furniture sold in Great Britain must have the cigarette ignition resistance required in this part. The second part covers flame ignition with six additional ignition sources and will be discussed under flame ignition. If furniture does not pass the small flame ignition test, it must be so labeled [23].

The British standard specifies a mockup (fig. 5) consisting of a seat cushion $(450 \times 300 \mathrm{~mm})$ and a cushion simulating the back or side $(450 \times 300 \mathrm{~mm}$ for Part $1,450 \times 450 \mathrm{~mm}$ for Part 2 of the standard). The padding material thickness is specified as $75 \mathrm{~mm}$. It is placed into a hinged steel frame while both halves are horizontal. The cover fabric is then placed over the seat padding material, threaded under a bar at the crevice, and then placed over the vertical material. The fabric is clamped on the outside of the frame and the back brought into the upright position. The ignition source-a cigarette or a butane burner-is placed into the crevice. The burner specifications are shown in table 3 . The lowest burner exposure is intended to represent the heat output of a burning wooden match; the specified ignition exposure time, 20 seconds, appears to be long compared to the time an inadvertently dropped match may burn. The criterion for ignition is flaming or progressive smoldering. The remaining two burner sources have not yet been mandated but are available for use in specifications.

The British test has been adopted or is under consideration by ISO [24], Australia (which uses the $150 \mathrm{mg}$ methenamine pill instead of the gas burner and covers cigarettes with sheeting like the United States) [25], Austria [26], Ireland [27], New Zealand [28], two of the Nordic countries, Finland and Norway [29], and Sweden [30]. The specifications for the cigarette ignition source vary for the various countries.

In addition to the upholstered furniture flammability test sponsored by the British Standards Institution (BSI), the British Department of the Environment/Property Services Agency (DOE/PSA) developed specifications for furniture in government facilities [31]. For mockups, a somewhat different arrangement is specified than in the BSI test; cigarettes and a series of flame ignition sources, including matches, gas burners, and wood cribs are used. Samples pass the tests if all flaming, smoldering, and smoking has ceased 2 minutes after the ignition source has stopped burning, and it is judged that no further combustion will take place. If two test items give otherwise similar results, the one producing less smoke is to be chosen. For full-scale tests, ignition sources are placed on top of fully made up beds and on uncovered mattresses and in the corners formed by the seat, back, and side cushions of upholstered furniture. Gas burners are also applied to the front vertical surface, as well as the bottom, of seat cushions. An original feature of the specifications is that bedding is loosened by pushing a block with a $200 \times 400 \mathrm{~mm}$ cross section between the sheets before testing, to simulate a vacated bed. Interliners are tested while mounted over a $300 \times 300 \times 75 \mathrm{~mm}$ foam block. Components can be screened first but must also be tested in assembled mockup or product form.

While the United States lags behind some other countries in regulations for upholstered furniture, its mattress standard has been in place since 1972 [32]. Full-sized prototypes (of planned, new production lines), as well as production mattresses sampled according to regulations which are part of the standard, are tested. One half of the mattress is covered with a sheet, and nine cigarettes are placed on smooth surfaces and near tufts and tape edges, and covered with another sheet. Nine other cigarettes are placed on the same features of the uncovered half of the mattress. Char length exceeding $51 \mathrm{~mm}$ in any one location constitutes failure.

Canada has a mattress cigarette ignition test, requiring a $300 \times 300 \mathrm{~mm}$ piece of mattress fitted tightly into a box to minimize edge effects [33]. The specimen is put under $24.5 \mathrm{kPa}$ pressure by means of an indentation tester. The cigarette is placed on a stitched area near the pressure point. The passing requirement is that the char length not exceed $50 \mathrm{~mm}$, and that there must be no continued combustion 10 minutes after the cigarette burned out. The French standard for mattresses is similar to the U.S. standard [34].

ISO is considering a mattress test in which the cigarette would be covered with a glass fiber or a cotton batting [35]; these are more severe test conditions than obtained with an uncovered cigarette and are intended to simulate the conditions which exist when a blanket covers the cigarette [36].

Some areas where further test development is desirable include the following:

Concerning crevice geometry in all mockups:

- The crevice ignition tests may not be applicable to all possible scenarios. An Australian study indicated that when cigarettes were dropped in an open crevice formed by compression of the seat cushion, and 
the pressure released, sustained smoldering occurred even if the fabric/padding material combination did not produce smoldering in the regular mockup crevice [37].

Concerning the proposed CPSC upholstered furniture method:

- The United States upholstered furniture industry calls this method rather cumbersome and materialconsuming, even with the fabric classification method; however, this also would apply to the U.S. mattress standard and the British furniture mockup, which have been reasonably well accepted.

- The fabric classification method has flaws; when CPSC tested 78 upholstered furniture items both as furniture items and in mockup form, several of the mockup items covered with the standard Class B fabric did not ignite, but the actual items ignited [17]. This and similar experiences indicate that the standard Class $\mathrm{B}$ fabric is not a worst case fabric for its class, and should be replaced with a fabric with less cigarette ignition resistance. This difficulty did not seem to arise with the Class $\mathrm{C}$ standard fabric. In most other cases, the mockup and actual furniture items results agreed very well.

- The use of a cover fabric over the cigarette on upholstered furniture is unrealistic. It makes the test slightly more severe; however, it also makes it more reproducible [11]. It may compensate for the effect of aging and dirt accumulation which has been reported to decrease cigarette ignition resistance [38]. The sheeting should fit tightly over the cigarette to be effective [37].

- The standard eliminates medium to heavy cellulosic fabrics which are important in the United States marketplace; however, many of these fabrics would pass if some of the steps which increase cigarette ignition resistance are taken, as discussed in section 5.

Concerning UFAC and California component test methods:

- The major objection to these methods is that they only test components and that this is not necessarily predictive of furniture items in which the components interact. However, these standards are only designed to reduce cigarette ignition of furniture, not eliminate it completely and they may well achieve this objective.

- Standard cover fabrics and foams are not really "standard": there is considerable variation within fabric rolls and between fabric rolls, as well as differences between fabric and foam lots [39]. Both UFAC and California are working on this problem, aided by industry committees [40]. However, none of these materials represent worst case conditions, as discussed earlier. The standards could be improved from a safety point of view by using more cigarette ignition-prone standard materials.

Concerning the BSI test method:

- Some of the same difficulties described above, especially regarding the crevice modeling, also apply to the British standard. In addition, the requirement that the padding material must be $75 \mathrm{~mm}$ thick, rather than actual thickness, may require splitting of the popular $100 \mathrm{~mm}$ foam, a major operation. Actual thickness could be used with minor adjustments to the test procedure. For use with cigarettes only, the British mockup is unnecessarily large.

- While the backup literature for the test indicates that the present arrangement achieves reproducible tension of the fabrics, it appears that the actual fabric tension depends on the compressibility of the padding material. Constant tension could be applied to the clamps which hold the fabric.

- The British Standard does not address the flammability of welt cords which can significantly affect ignition by cigarettes [14].

\subsection{Test Criteria for Cigarette Ignition Resistance}

Different criteria for cigarette ignition resistance of upholstered items are used in the various standards. UFAC, BIFMA, and the CPSC mattress and proposed upholstered furniture standards use char length criteria, based on the experience that if a certain char length is exceeded, continuous smoldering is likely to occur [8-13,32]. Failure is also recorded if "obvious ignition" occurs. However, a recent paper indicates that continued, slow smoldering may continue in PU foam below the crevice while the cover fabric exhibits only a short char length [41]. This causes doubt about the reliability of use of char length and obvious ignition to determine cigarette ignition resistance. It appears that dismantling and judging the inside of the mockup should be required.

The British and similar standards rely on observation of flaming or progressive smoldering i.e., "exothermic oxidation not accompanied by flames which is self-propagating, i.e., independent of the ignition source." It was found that this observation has to be continued for 1 hour to get reliable results [37]. The California standard prescribes mass loss in 90 minutes as the criterion [20]; this works well with the mini-mockup but has not been tried in routine testing with the much heavier British mockup. A suggestion to use the second derivative of the time-mass loss curve, the change of rate of mass loss, was made but this would require complex 
calculations or sophisticated instrumentation [42]. Furthermore, using that method resulted in fabric rankings similar to the CPSC fabric classification test, which is based on char length. Mini-mockup mass loss of cotton fabrics over untreated and flame retardant (FR) PU foam gave very similar results to the UFAC classification test, and also to the subjective judgment of obvious ignition of the substrates [43]. Time to ignite the substrate is another quantitative measure, but requires removal of cigarettes after $1,2,3, \ldots$ minutes, until an ignition time is obtained [44].

Trying to establish ignition time by observation of the fabric under the cigarettes is difficult because the cigarette and ashes interfere with visible observation and the exact point at which continuous combustion will occur is difficult to judge [44].

\subsection{Smoldering Mechanisms}

This section is a brief review of the literature on smoldering of the major materials in upholstered items: cellulosic materials and PU foams. While there is a considerable body of knowledge of the type of constructions which ignite from cigarettes (sec. 5.1), there exists no model of the actual transfer of smoldering from the tobacco column/cigarette paper system to the fabric/padding system.

\subsubsection{Cellulose Smoldering}

Both the tobacco column and the paper covering a cigarette are essentially cellulose. Experience shows that smolder transfers readily from cigarettes to medium and heavy weight cellulosic and acrylic fabrics and from them to many commercial padding materials, especially cotton batting and PU foam. Certain materials, such as thermoplastic fabrics and batting, wool fabrics, and halogen-containing materials (vinyl-coated fabrics, vinyl-vinylidene backcoatings, or PU with smolder resistance (SR) treatment) interfere with this transfer. This will be discussed in more detail in section 5.1.

There is a plethora of analyses of cigarette (mostly tobacco column) smoldering behavior [e.g., 45,46], and a series of papers analyzing the smoldering behavior of shredded cellulose insulation and PU foam [47-55]. Smolder behavior can be approximately described by the following overall reaction scheme:

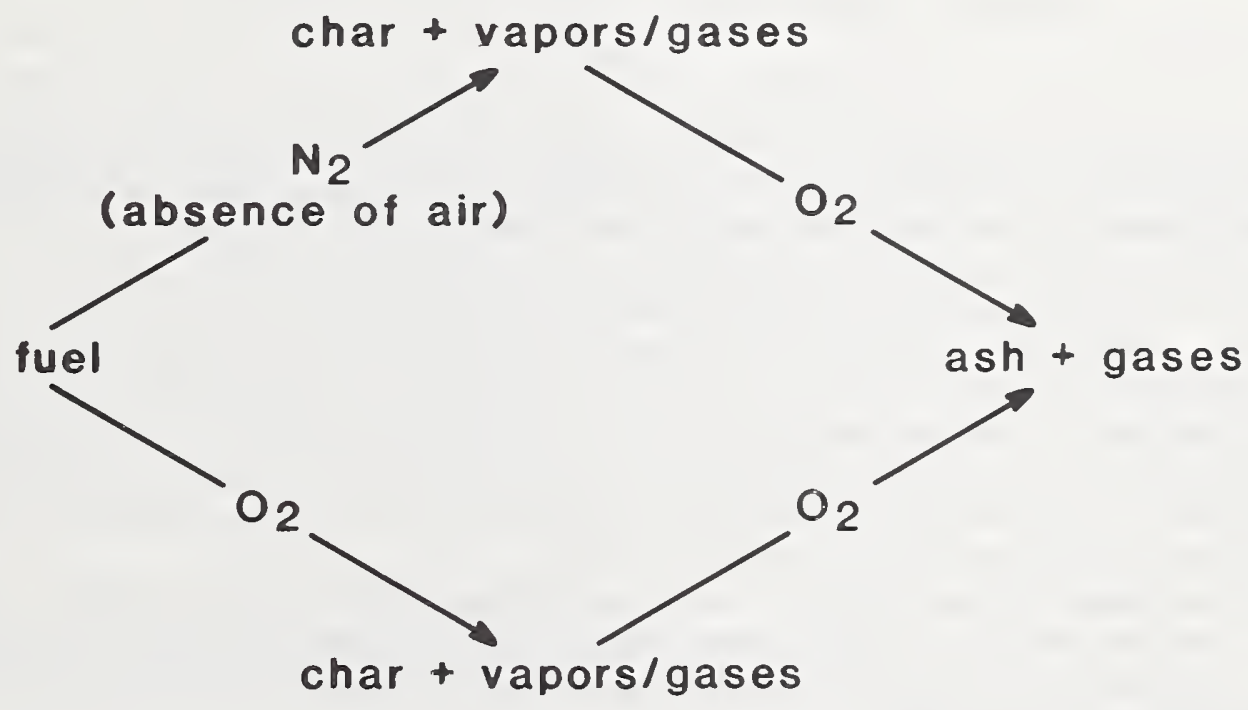

The gases and chars produced by the two different paths may differ in their chemical nature.

This shows that initially there are competing oxidative and pyrolytic reaction pathways; the oxidative pathway can be moderately exothermal (several hundred calories per gram of fuel). Both initial pathways may form a high carbon-containing material (char); the two chars are probably not identical in reactivity or in other properties. These chars are typically somewhat more resistant to oxidation than the initial fuel but ultimately can be completely gasified, releasing a few thousand calories per gram of char. This second oxidation wave can often be visually observed as a glow traveling over a previously charred area. 
In experiments involving shredded cellulose insulation on a heated plate, smoldering could be initiated at temperatures as low as $290^{\circ} \mathrm{C}[48,49]$. This compares with temperatures measured in tobacco columns of up to $900^{\circ} \mathrm{C}[45,56-59]$. Smoldering rate increased with denser packing of the cellulose insulation, thicker insulation beds, oxygen supply, and favorable air current direction. The role of fire retardants, primarily boric acid, is to interfere with the oxidation process; it does not reduce temperatures in the smolder wave.

Much of the literature on cigarettes discusses effects of tobacco type, packing density, cigarette paper porosity, etc., on the linear burning rate (the mass burning rate is less affected by these parameters). It is not clear whether a fast burning cigarette, in which the flame front moves faster over an upholstered item, or a slow burning cigarette, where the flame front dwells on any point of the substrate for a longer period, but which may have a lower temperature, are more apt to cause substrate ignition.

\subsubsection{Foam Smoldering}

Few PU foams were found to smolder in contact with burning cigarettes unless a fabric cover was present [55]. Smolder temperatures were about $400^{\circ} \mathrm{C}$ and smolder front progress in those foams which smoldered was about $0.1 \mathrm{~mm} / \mathrm{s}$ [56-59]. About 5 percent of the combustion products consisted of carbon monoxide (CO). The smoldering process again can be divided into two major competing phases: formation of nonsmoldering tar and formation of smoldering char. A kinetic model of the smoldering process in PU foam is given below [47,52]:

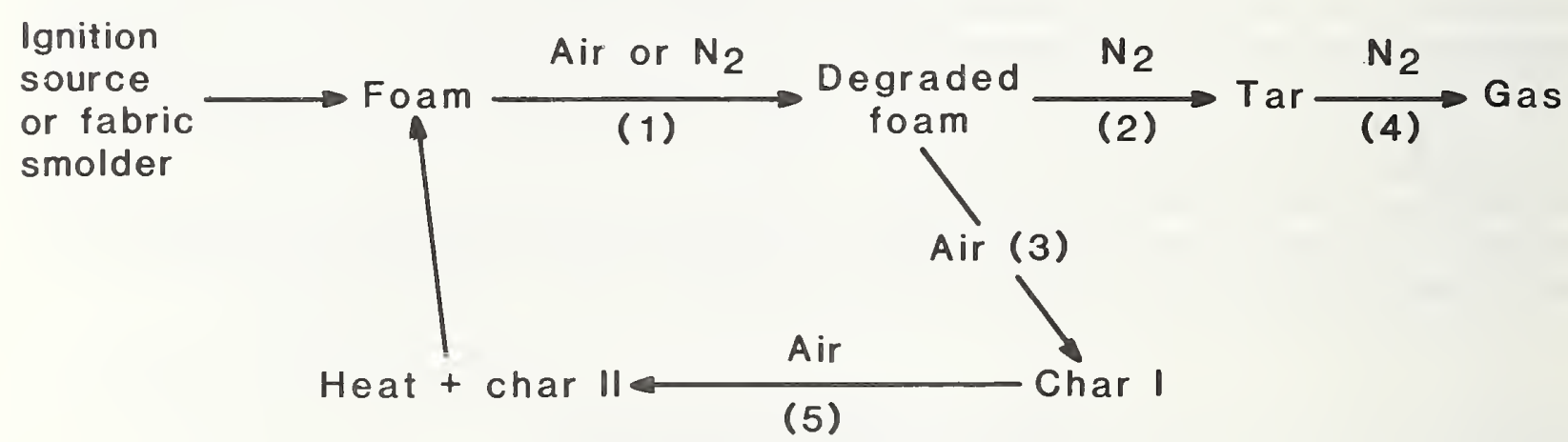

Step (1) The first phase of foam pyrolysis, which involves $10-15 \%$ weight loss, is virtually the same in air or inert atmosphere. The product is colored but still has some of the resiliency of original foam.

Steps (2) and (3) In the absence of air, or when the rate of Step (3) is prohibitively slow, the degraded foam is converted to tar with the loss of cellular structure essential for smolder.

Step (4) In the absence of air the tar is completely gasified leaving a small residue $(1-3 \%)$ at $500^{\circ} \mathrm{C}$.

Step (5) The black cellular char (which retains much of the foam structure) formed in Step (3) undergoes further oxidation in air and provides heat to drive the smolder wave. If Step (5) is sufficiently fast then the rate of heat production may be adequate to replace the outside ignition source so that smoldering becomes self-sustaining. If not, smoldering may still proceed until it recedes so far from the external heat source (e.g., smoldering fabric or cigarette) that its own heat generation can no longer overcome heat losses; it will then extinguish.

Two possible approaches to SR foam are suggested. One is the use of agents which would interfere with steps 2, 3, and 5, above, and, if sufficient volatile agent becomes available, also reduce fabric smoldering. The second is promotion of tar formation by weakening the polyol chain and urethane links. This, however, may increase flaming combustion [54].

Another study provided more specific modeling equations for the smoldering of PU foam and reasonable experimental validation [54]. The difficulties caused by the fact that smoldering is very incomplete combustion are discussed. Both conduction and radiation affect the smoldering rate in open structures, such as flexible PU foams. Smolder intensity was found to be governed by oxygen supply, but smoldering can proceed at oxygen supply rates as low as 5 percent of the stoichiometric one. The threshold oxygen concentrations at which self-extinguishment, continued smoldering, or transition to flame occur was established for three PU foams [55]. This work was performed with an electrical heating coil rather than cigarette ignition source. Such heating coils appear to give different results from cigarettes [14] and seem to lead to faster transition to flaming than cigarette induced smoldering. They obviously present a stationary ignition source, as compared to the moving smolder front of a cigarette. 
Most PU foam formulation variables had little effect on smoldering [52]. A report on an interlaboratory test to establish reproducibility of results obtained with a "standard" foam claims that there was no difference due to location of specimens along the length and from top to bottom of a foam bun [40]. A significant effect of breathability of the foam was found, and it was suggested that foam samples be flexed before testing; this increases breathability and would simulate conditions in actual use.

Some flame retardants increased, others suppressed smoldering. Several studies describe improvement in smoldering resistance of fabric/PU mockups due to use of proprietary smolder and flame retardants [e.g., 60-65]. As discussed later, the beneficial effects of smolder and flame retardants can be overwhelmed by the presence of smoldering or burning medium to heavy weight fabrics which provide substantial amounts of heat, unless concentrations of the retardants are very high.

\subsubsection{Cigarette-Upholstered Item Interaction}

This section reviews the burning characteristics of cigarettes in air, how they are changed when in contact with substrates, and results obtained on upholstered substrates with cigarettes other than the present standard cigarette (see 3.1). The cigarette industry has published extensively in the first area but there is relatively little work available in the two others.

Table 4 shows the ranges of various characteristics of U.S. commercial cigarette brands [11,45,56-59,66,67]. Typical Australian, British, and Japanese cigarettes fall within these ranges [68]. Burning temperatures for 16 U.S. cigarettes did not correlate with heat flux, under dry as well as under typical laboratory conditions ( $55 \%$ R.H., $24^{\circ} \mathrm{C}$ ) [59].

The cigarette chosen for all U.S. upholstered furniture and mattress tests is a non-filter cigarette which was very popular at the time the tests were developed, and fell in the upper range of burning temperature [11]. Its heat flux seems to be intermediate [59]. In spite of the increasing popularity of filter cigarettes, this cigarette has been continued for test use. It was assumed that the easily observable increased glow and burning rate at the very end of the butt of nonfilter cigarettes would present a more severe condition than filter cigarettes. However, in mockup testing of about 120 fabric/padding combinations, results obtained during full length burning of the standard and a filter cigarette were almost identical [18]. One of the reasons may be that upholstery substrates seem to ignite in as little as 2 minutes, long before the end of the cigarette is reached $[15,44]$.

Most of the data given in table 4 were obtained with the cigarettes burning in air. However, burn behavior of cigarettes on fabrics has been shown to be quite different. A comparison of burn time-cigarette core temperatures is given in figure 6 [14]. The cigarette burned in air exhibited a very narrow peak. The timetemperature relationship of cigarettes placed into the crevice of PU mockups and covered with sheeting depended on the weight of cotton fabrics, with the heavier cotton fabric producing prolonged preheating before the peak was reached. The time-temperature curve of covered cigarettes was somewhat broader but showed the same peaks as uncovered cigarettes $[14,15]$. Also, visual observation shows that cigarettes in air burn with a short burn cone, but the smolder at the cigarette/fabric interface moves ahead of the tobacco column burn cone if the fabric substrate smolders at all.

Several investigators measured temperatures with thermocouples placed near the cigarette-upholstered furniture substrate interface or at various distances from it. Peak temperatures measured with glass fiberboard crevices were about $250^{\circ} \mathrm{C}$, those measured with four fabric/glass fiberboard combinations ranged from 320 to $520^{\circ} \mathrm{C}[41,67]$. Cigarette burning rate was $1.3 \mathrm{~mm} / \mathrm{s}$ for the glass fiberboard mockup and between 1.4 and $2.1 \mathrm{~mm} / \mathrm{s}$ for the four fabric mockups. Temperatures and burn rates ranked the fabrics in the same order. Similar dependence of burn temperatures on fabric and foam parameters was demonstrated in another study [14]. However, because neither fabrics nor foams were systematically varied, the results cannot be easily used to predict temperatures as a function of physical parameters of fabrics and foams.

Neither are published cigarette ignition studies in related areas very helpful. Two experimental studies indicate that it is very unlikely that cigarettes will ignite apparel fabrics $[69,70]$. However, wildlife material, including compacted conifer needles, grass, and punk wood can be ignited by cigarettes [66,72]. Conditions which increase the probability of such ignition are [56,57,71,72]: dense packing of material; high ambient temperature and low humidity; and modest winds, especially in the direction of the burn cone travel on the cigarette. Especially in winds, these substrates seem to burst into flames rather rapidly, without lengthy smoldering periods.

In recent years, it has become quite widely known that a few commercial cigarette brands have a relatively low propensity to ignite furniture substrates. This indication that technology exists to lower the ignition propensity of cigarettes has led to submission to the U.S. Congress, as well as at least eight State assemblies, of legislation which would require cigarettes to conform to yet to be developed ignitability standards [e.g.,73]. 
However, none of these bills have become law. Initially, these bills required self-extinguishment of the cigarettes within a certain number of minutes. Later versions of most of these bills were directed towards requiring the lowest propensity of cigarettes to ignite, achieved by whatever means available, and without increasing tar/nicotine delivery to the smoker. (The cigarette industry $\mid$ has claimed that self-extinguishing cigarettes would increase tar/nicotine delivery [58]; however, this delivery in present-day cigarettes is primarily determined by filters and ventilation, i.e., perforations in the paper and ventilation holes near the filter which cause the smoke to be diluted during the dragging on the cigarette [74].) Recently, the "Cigarette Safety Act of 1984" became law, which set up a mechanism to study the feasibility of producing cigarettes with a minimum propensity to ignite upholstered items [75].

Two means to quantitatively measure the propensity of cigarettes to ignite substrates have been suggested. One is to place the cigarettes on mini-mockups made from standard fabric and foam as in the California upholstered furniture test [20], and measure the mass loss rate. The other consists of placing the cigarette on a piece of $\alpha$-cellulose chromatographic analysis paper and again measure the mass loss rate [44]. During development of the latter test, about 30 commercial cigarette brands were placed on flat areas of a number of such substrates, which varied in cigarette ignition propensity, for 1,2 , or $3 \ldots$ minutes and then removed. If the substrate still smolders 10 minutes after the removal of the cigarette, ignition is recorded. Thus the propensity of cigarettes to ignite substrates was defined both by the number of substrates a given cigarette ignited and the time it took to ignite any specific substrate.

This screening work produced several findings:

(1) Most of the cigarettes performed similarly to the standard cigarette, but it was confirmed that several commercial brands ignited fewer of the horizontal substrates and the ignition time on the substrates they ignited was longer. These cigarettes were ranked in the same order by crevice tests using UFAC standard PU foam and the California standard fabric in another laboratory [76].

(2) Propensity to ignite did not relate to burning rate or burn cone temperatures of the cigarettes.

(3) While the commercial cigarettes did not make it possible to conduct an experiment in which such parameters were varied systematically, it appears that measures which lower the fuel content, such as low linear packing density and reducing the diameter, lower the ignition propensity $[44,58]$. Making the burn time of cigarettes shorter, by either making the tobacco column shorter and/or lowering the packing density (which increases linear burn rate) would obviously reduce the time during which a smoker may become sleepy and inadvertently drop the cigarette. If the smoker then increases his cigarette consumption, at least his awareness would be increased every time he has to light a cigarette.

(4) The combined mass loss rate of burning cigarettes and the $\alpha$-cellulose substrate paper was found to correlate with the above ranking of the cigarettes [44]. The $\alpha$-cellulose paper was chosen in the hope that it would be more reproducible than the so-called standard fabrics used in various tests to determine cigarette ignition resistance of upholstered furniture components. The $\alpha$-cellulose does not smolder after the heat source is removed. It seems reasonable to assume that its mass loss is proportional to the heat which is transferred from the cigarette, which in turn should be proportional to the fuel consumption rate and thus the rate of heat transmitted to the substrate.

(5) The validity of this concept of ranking cigarette ignition propensity should be established by testing a wider variety of upholstered furniture and mattress substrates $[44,77]$.

\subsection{Transition from Smoldering to Flaming}

Many, but not all, fires which start as smoldering fires eventually become flaming. This transition is governed by a complex interaction of heat conduction, gas flows, and reaction chemistry and is not well understood [47]. For upholstered items, three main empirical observations can be made:

(1) Oxygen availability and air currents play a major part in this transition. Typically, a smoldering furniture item may flame when a door is opened, assuring new oxygen supply. On the other hand, flaming may revert to smoldering if the oxygen in a room is depleted [78]; however, the rate of weight loss remains fairly constant before and after reversion to smoldering, while it always increases very significantly at flaming. Shredded, tightly packed grass clippings burst into flames most readily when air movement exceeded $0.83 \mathrm{~m} / \mathrm{s}(3 \mathrm{~km} / \mathrm{hr})[56,57,71]$.

(2) When a transition to flaming occurs, the macroscopic variables of interest (heat release, smoke production, etc. are seen to be essentially identical to a fire that would have been started at that instant by flaming means [79]. This principle allows great simplification in practical analysis since it states that the history of the fire does not have a "memory." The limits of validity of this principle have not yet been tested, although it appears to have wide generality. 
(3) The transition to flaming, if it occurs, occurs between about 20 minutes and several hours after smolder initiation $[78,80-82]$ On this point there is a large amount of data. The most extensive source is the Indiana Dunes tests performed in the late 1970's [81,82]. An assortment of commercially available new and second-hand furniture was used and ignited with a glowing heater element. The results are summarized in table 5A. A test series was later conducted at NBS on replicate chairs [83]. The chairs weighed $16 \mathrm{~kg}$ each and were of traditional construction with a hardwood frame, $600 \mathrm{~g} / \mathrm{m}^{2}$ cotton upholstery fabric, and padded with both cotton batting and PU foam. None of the components were fire retarded. The data are shown in table 5B. The relative roles of construction materials versus natural variability can be assessed by comparing the coefficients of variation for the assorted-sample tests against the replicate-sample tests. The values are 0.45 and 0.30 , respectively. This suggests that a careful search for materials effects on smoldering-to-flaming transition might not be rewarding.

A study by Braun et al. [78] suggests that when polyester batting is used as the padding material, the probability of transition to flaming is decreased as compared to PU and cotton batting. The same study shows that the rate of smoldering (for those fabrics which do smolder) may be increased when polyester batting is substituted for PU foam or cotton batting, presumably because more air can reach the fabric as the polyester batting shrinks away from it. The fastest transition from smoldering to flaming ( 22 minutes after placement of the cigarette) was in a chair in which heavy cotton fabric covered cotton batting padding; in chairs with lighter cellulosic fabrics and mostly PU padding, this time was about one hour. Another study identifies PU additives which decrease smoldering but may lead to enhanced tendency to flaming [54].

\section{FLAMING FIRE BEHAVIOR AND TESTS}

In this section, the full range of flaming fire behavior will be considered. Flaming ignition-the transfer of the flame from an ignition source to the upholstered item-will be considered first. This will be followed by flame spread, heat release rate, and full item involvement. For many of these properties, standardized tests have been proposed and will be discussed. A relatively recent development, engineering applications of flaming fire behavior data, will be discussed in chapter 5 .

\subsection{Ignitability}

\subsubsection{Small Flame Ignition}

Only about 25-33 percent of upholstered furniture fires are caused by small flames, the rest by cigarettes [4-7]. Thus, small flame ignition resistance should not be sought to the detriment of cigarette ignition resistance. Prevention of cigarette caused fires has been given priority by the CPSC, several foreign governmental bodies, and ISO.

Upholstered furniture generally has surfaces where the fabric is in close contact with padding materials, such as the seat and the other inside surfaces. In such areas, the small flame ignition resistance depends not only on the ability of the fabric to resist ignition but also on its ability to protect the padding material from heat, as well as the flame resistance of the padding material. Here the thermoplastic fabrics, which generally have good cigarette ignition resistance, perform poorly because they shrink, melt, split open, and expose the padding. In some cases, the molten fabric coagulates into a bead which burns vigorously and can ignite padding material, e.g., FR PU, which would, without a fabric cover, resist a small ignition source, such as a match [83]. Char-forming fabrics perform better than thermoplastics unless they, too, split due to stress caused by heat shrinkage, the original fabric tension of the upholstered item (especially in tufted areas), or due to items lying on them. Heat shrinkage increases with increasing area of the ignition source; this will be discussed in more detail below.

In other places, normally on the outside of the back and sides, as well as in skirts covering the bottom of furniture, fabric is not generally in contact with padding material. Here thermoplastic fabrics (without backcoating) may resist small ignition sources because they tend to shrink away from ignition sources. Such areas thus present an entirely different ignition situation than areas with close fabric/padding material contact.

\subsubsection{Mockup and Full-Scale Tests}

There is no standard procedure for testing the small flame resistance of residential upholstered furniture and mattresses in the United States. However, tests based on the British standard have been adopted or are under consideration in a number of countries and by ISO, as discussed above in section $3[22,30]$. (The British 
test has been discussed under 3.1 since it is used for both cigarette and small flame ignition.) In addition to the small butane flame used in Part 1, Smoker's Materials, it uses two additional gas flames (table 3) and four wood cribs as shown in table 6A. The availability of seven ignition sources makes it possible to use the test for furniture for various occupancy hazards; e.g., residential furniture must have a negative label if it does not pass with the butane ignition source number 1 which is supposed to simulate a match [23]. Contract furniture and children's furniture are tested with ignition source 5 , a $16 \mathrm{~g}$ wood crib. Ignition source 7 is supposed to simulate the heat characteristics of four double sheets of British newspaper. Cribs rather than newspaper were apparently chosen because newspaper ignition sources may be hard to standardize, and the cribs may simulate the pressure on seats caused by tufting, books lying on the cushion, etc.

The cribs consist of pine wood (pinus silvestris), approximately $500 \mathrm{~kg} / \mathrm{m}^{3}$, nominally $20.5 \mathrm{~kJ} / \mathrm{g}$, conditioned under warm, dry conditions for a week. The sticks are glued with a PVA-based or other suitable wood glue. A $40 \times 40 \mathrm{~mm}$ piece of "PC grade surgical lint" (absorbent cotton) weighing $0.3 \mathrm{~g}$ is placed into the center of the crib and soaked with $1.4 \mathrm{ml}$ of isopropanol to facilitate ignition.

An appendix to the British Standard claims good reproducibility and repeatability for the test method [22].

Numerous studies discuss the ignition sources used in the British mockup and for full-scale testing. Many such reports compare the effects of several ignition sources on a number of fabric/padding material combinations. The findings regarding ignition sources can be sumarized as follows:

(1) The butane flame No. 1 is intended to simulate average wooden matches. Matches, even from one manufacturer, were found to be too variable to be used in a standard test [84]. In ISO, the Germans tried hard to introduce the "Rieber" premixed propane flame burner which is used in many German DIN tests [85]. ISO did not accept the use of the much more complex Rieber burner, but permitted use of propane with the British burner. On the other hand, Austria uses the Rieber burner which is used in many other flammability tests [26]. Comparisons of the propane and butane flames are shown in table 7. The British diffusion flame and the Rieber burner, both used as a premixed and as a diffusion burner, gave roughly the same results on several fabric/foam combinations [85].

(2) The methenamine pill (150 mg) is preferred by some countries, especially Australia and the Nordtest ccuntries $[35,86]$. In general, it gives results similar to the butane flame No. $1[68,86,87]$ (table 8 ) and to matches $[36,68,86,88,89]$. In some cases, it ignited substrates which were not ignited by the other ignition sources, particularly when placed on flat surfaces of mattresses where it sinks into the substrate. The pill appeared to be slightly less severe than a $40 \mathrm{~g}$ wood crib [87].

In one study, bone dry and 65 percent R.H. conditioned mockups were exposed to cigarettes, methenamine pills, and matches [89]. Pill (burning time 90 to $120 \mathrm{~s}$ ) and cigarette (burning time about 20 minutes) ignitions were not affected by the moisture content of the substrates, but matches ignited some dry substrates but not the corresponding conditioned ones. This may indicate that longer burning time may make results less sensitive to conditioning, because the substrate may have time to dry out. The use of the pill, instead of the butane burner, may make it possible to use less stringent conditioning, which would be an advantage. This would have to be verified with a variety of hygroscopic fabrics and padding materials.

The methenamine pill can probably be placed reproducibly into the well-defined crevices of the British mockup, but crevice geometry and especially width varies widely in actual furniture (a visit to a furniture store will show an amazing number of gaping and wavy crevices). For use in a test applicable to actual furniture, as well as to mockups, a device to hold pills in gaping crevices would have to be developed. Such crevices may not present as much of a problem to the gas burner tube.

(3) In another study, it was found that matches were more likely to ignite the upholstery substrate when placed near, rather than in, the crevice [89]. However, the rate of flame spread was more rapid when ignition was in the crevice. The butane flame burner results were not affected by position.

(4) The increase in severity of the three butane flames is illustrated in table 8. It is interesting to note that only wool or FR fiber containing fabrics passed with any of the butane flames, and that FR PU foam helped several fabrics pass with butane flames 2 and 3. A Japanese study showed similar fabric behavior [68].

(5) Newspaper sheets, in various arrangements, were used in much of the original work and in full scale room burns [28,90-92]. A number of possible arrangements, their heat output, and reproducibility have been discussed by Australian workers [93]. Obviously, their severity depended on their weight and arrangement and they could not be readily compared to the other ignition sources. More recently, however, newspaper sheets confined in a wire cage have been used in both mattress $[94,95]$ and upholstery furniture mockup tests $[96,97]$ with reportedly good reproducibility. 
(6) The preparation of the wood cribs is time consuming: sticks must be cut to size and grouped by weight to obtain the correct total weight; glued together; dried and conditioned; and ignited by isopropyl alcohol spread on surgical cotton [22].

(7) Much disagreement appears to exist with regard to the proper weight and base area of the wood cribs. The larger the weight and the smaller the base area, the greater the probability of a charred fabric to break open and expose the padding material. This appears to be particularly important for wool. Cover fabrics and innerliners which shrink when heated are more likely to split open when the heated area is large. Different wood species (balsa and an Australian pine) and different dimensions of the cribs have been suggested $[28,98,99]$. Another criticism of the cribs is lack of reproducibility in the burning mode, with the larger ones collapsing to one side.

While the British seem to have settled on the wood cribs, other nations have not finalized this choice; e.g., the proposed ISO draft standard which is otherwise quite similar to the British standard substitutes unspecified ignition sources for the cribs [24]. Nordic countries seem to be following the same route. A recent Australian study describes a procedure differing somewhat from the British Standard, including six wood crib ignition sources varying from 50 to $400 \mathrm{~g}$ and a standard test room, which can be used for mockups as well as actual furniture items [100]. It is hard to imagine that these complicated crib ignition sources would be popular in the United States. It is indeed not clear that similar regulatory purposes could not be achieved with a radiant ignition source. Since these sources are more commonly used to represent larger ignition sources, a discussion is deferred to section 4.2.3.

Some other possible shortcomings of the British mockup arrangements for small flaming ignition sources are similar to the ones for cigarette ignition testing, namely, the tensior $\mathrm{g}$ scheme and the requirements for an arbitrary filling material thickness (sec. 3.2).

The California Bureau of Home Furnishings recently published a draft test procedure for furniture used in high-risk or high-density occupancies [96]. This specifies an instrumented test room, $3.7 \times 3.1 \times 2.5 \mathrm{~m}$, with a door $2.1 \times 0.96 \mathrm{~m}$. The ignition source consists of five loosely wadded double sheets of newspaper, $90 \pm 5 \mathrm{~g}$, placed into the crevice. A steel, cage-like enclosure is placed over it. Furniture fails if one of the following criteria is exceeded:

- temperature of $150^{\circ} \mathrm{C}$ at a thermocouple $25 \mathrm{~mm}$ below the ceiling or $66^{\circ} \mathrm{C}$ at mid-height in the room;

- 75 percent opacity at mid-height and 50 percent at the floor;

- CO concentration of 1000 ppm (height not specified);

- 10 perent mass loss in the first 10 minutes.

Pretesting of back and seat cushions of a line of furniture in a steel frame mockup is suggested but cannot be substituted for testing of actual samples.

A report on the development of the test method indicates that primarily vinyl covered, combustionmodified high-resiliency (CMHR) PU foams (a type of highly FR PU) can pass the above requirements [97].

California also has a full-scale test for institutional mattresses [94,95]. As in the above test, it is a room fire test with the mattress placed on a steel support and ignited from below with a newspaper filled metal wastebasket. Bed linens are not used. Test criteria are: 1) that mass loss be less than 10 percent of the total, (2) that a thermocouple reading at the ceiling not exceed $260^{\circ} \mathrm{C}$, and (3) that peak $\mathrm{CO}$ readings (measurement scheme not described) not exceed $1000 \mathrm{ppm}$ at any point in the room. Both tests are pass/fail tests for screening out items which do not self-extinguish under moderate test conditions and are not intended to be used as a quantitative measure of heat release rate.

\subsubsection{Component Tests}

The state of California [20] and the BIFMA standard [10] require that certain components used in upholstered furniture pass small flame ignition tests. The California objective was to eliminate from the market furniture items with inordinately high ignitability and rapid flame development rather than provide assured resistance to such ignition sources for all of the furniture sold in the state.

Thus, California adopted a modification of Federal Test Method 5903 [101] (vertical specimen, bottom ignition, char length criterion $153 \mathrm{~cm}(6$ in)) for foam. This generally leads to the use of FR PU foam but ones with only a low level of treatment. Such FR foams have been shown to have a lower propensity to ignite from small ignition sources and to burn somewhat more slowly, if ignited, than untreated foam. However, sometimes smoke and CO production is higher [e.g., 83]. Furthermore, with a larger fire exposure these FR foams tend to perform no better than NFR ones [102]; also table 9. California test requirements for other padding materials provide similar modest improvements in ignition resistance.

Both California and BIFMA require that upholstered furniture cover fabrics pass the $45^{\circ}$ orientation test used for apparel fabrics in the United States [103]. Most upholstery fabrics easily pass this requirement, 
including the thermoplastics which have been shown to behave poorly in assemblies with a variety of padding materials because of the poor protection|for the padding.

Another test (Motor Vehicle Safety Standard No. 302 [104]) covers the flammability of interior materials used in passenger cars, multipurpose passenger vehicles, trucks, and buses. It covers essentially all nonmetal parts of the interior of such vehicles, including seat and back cushions. The surface material, i.e., the cover fabric, is tested by itself unless it is bonded, sewn, or otherwise attached to the padding material. Specimens, $356 \times 102 \mathrm{~mm}$, are held in horizontal U-shaped steel frames and a Bunsen burner flame applied to the uncovered specimen end for $15 \mathrm{~s}$. Materials which have a burn rate of less than $1.7 \mathrm{~mm} / \mathrm{s}$ (102 mm/minute) pass the test.

The Federal Aviation Administration (FAA) also uses Federal Test Method 5903 [101] for some materials used in aircraft. The Port Authority of New York and New Jersey sets flammability standards for many public buildings in its area [105]. Upholstery materials, including covering, lining, webbing, cushioning or padding, and self-supporting (rigid) materials are tested as specified by the Federal Aviation Administration [106], i.e., by means of the vertical Bunsen burner test 5903 [101]. Char length must not exceed $153 \mathrm{~mm}$; after flame must be less than 15 seconds for the specimen and 5 seconds for ablated drips. Padding materials thicker than $12 \mathrm{~mm}$ are tested by ASTM E162, the radiant panel test [107]. Materials with flame propagation indices under 100 pass. Materials with higher indices may be covered with self-extinguishing materials, as determined by the 5903 test, if the cover/padding assembly has a flame propagation index of less than 100.

The Boston Fire Department requires approval of furniture items for certain occupancies [108]. The type of occupancy, building construction, and presence or absence of sprinklers and alarm systems are considered. Certain materials are "approved"; e.g., use of a specific polychloroprene interliner over PU foam which passes California requirements is approved. "Plastic foam" cushioning is limited to a thickness of $100 \mathrm{~mm}$.

\subsubsection{Comparison of Component and Mockup Test Results}

Tests by Braun et al. on transportation vehicle mockups [109-111] included a comparison between fullscale results and measurements with the vertical 5903 [101] and horizontúl MVSS 302 tests [104]. Neither of these Bunsen burner tests was found useful in predicting the full-scale hazard.

Several studies compared the results of mockup tests and tests on residential upholstery fabrics alone, e.g., a Finnish study investigating the British test for possible adoption [86]. Twenty-five upholstered furniture cover fabrics were tested with a $45^{\circ}$ fabric test ( 60 second ignition time) [103] and the results compared to results of mini-mockup test in which six padding substrates (glass fiberboard, untreated and FR PU foam, cotton, and untreated and FR polyester batting) were used. Ignition was with the small British butane ignition source. Some of the fabrics were also tested in the British mockup arrangement over untreated and FR PU foams.

For the fabrics in this study (wool blends, cellulosic blends) the $45^{\circ}$ test was somewhat predictive of mockup behavior. The wool blends generally self-extinguished in the fabric test, and did not ignite in any of the mini-mockups, while fabrics which ignited and burned fairly rapidly in the $45^{\circ}$ test also caused ignition in the mini-mockups. Three fabrics, with burn times of 40 to 56 seconds, ignited in some mini-mockups and not in others. However, the one thermoplastic fabric in this series performed poorly in the mini-mockup tests but very well in the fabric test. In a similar study, vertical and $45^{\circ}$ fabric tests did not predict ignition when the fabric was used as a mattress cover [36].

Table 8 shows the results when 10 of these fabrics were tested in the British mockup arrangement, which is much larger than the mini-mockup. The fabrics which self-extinguished in the $45^{\circ}$ test passed the butane ignition source 1 (match simulation) test and performed quite well with the more intense butane flame as well as with the methenamine pill and the "Nordtest" $40 \mathrm{~g}$ wood crib, especially over the FR foam. Among the fabrics which burned in the $45^{\circ}$ test, time to burn $125 \mathrm{~mm}$ was somewhat predictive of behavior in the British mockup. Thus there appears to be a good correlation between the mini-mockup and the larger British mockup results. The $45^{\circ}$ fabric test seems to approximately predict behavior of nonthermoplastic fabrics but fails to predict the poor flame ignition behavior of thermoplastic fabrics. This is an important limitation since thermoplastics are widely used in furniture.

A study carried out in New Zealand [28] compared the results of a variety of fabric tests (horizontal ignition and vertical flame spread tests as well as a "flammability index," a composite of speed, heat, and spread of flame on fabrics), with those in the British mockup, using PU foam as the padding. Ignition sources were wooden matches, $13.2 \mathrm{~g}$ newspaper, and $8.5 \mathrm{~g}$ wood cribs. Again, the fabric tests were reasonably predictive of mockup burning behavior, except for the thermoplastic fabrics. The wool fabrics behaved well in both fabric and mockup tests, while the cellulosic, acrylic, and acrylic/cellulosic blend fabrics generally behaved poorly. The thermoplastic fabrics, however, were intermediate in the fabric tests and poor in the mockup tests.

A similar study, using aircraft seating type fabrics, was designed to find out whether fabric testing by Method 5903 (vertical specimen, bottom edge ignition) as required by the Federal Aviation Administration for 
aircraft upholstery fabric [106], is predictive of behavior of fabrics in aircraft seat assemblies [92]. The small butane flame No. 1, methenamine pills, and $18 \mathrm{~g}$ of newsprint were used as ignition sources. Only three fabrics, FR nylon, FR polyester, and FR wool, passed the vertical fabric test. The FR wool passed the mockup test (with PU foam as the padding) with all three ignition sources; FR nylon and polyester failed when exposed in the same manner. On the other|hand, an/untreated wool fabric which failed the vertical fabric test passed in the mockup test with the butane flame but not the other ignition sources. All other fabrics (nylon, polyester, polypropylene, acrylic, cotton, acrylic/cotton) failed both the fabric and mockup tests.

The discrepancies between the fabric test results and the mockup results are presumably caused by the failure of the fabric test to measure the protection afforded by the fabric to the padding material. With some laboratory effort a fabric test probably could be developed which would take into account both resistance to ignition and resistance to penetration by the flame. The latter feature would eliminate thermoplastic and other fabrics with high heat shrinkage which do not protect padding materials because they open up under the flame. Such a method could specify vertical specimens, under tension similar to that found in furniture, and with flame impingement some distance above the bottom edge. A fabric would have to withstand the exposure without ignition, melt-out, or overly brittle char.

\subsection{Ignitability from Large Open-Flame or Radiation Sources}

For discussion purposes here, a large open-flame source will be taken to be one which is substantially larger than a match, a cigarette lighter, etc. A small polyethylene wastebasket, of about 7 liters capacity, has often been used for testing [112]. This wastebasket, filled with milk cartons, burns at an average of approximately $50 \mathrm{~kW}$ heat output for a time of $200 \mathrm{~s}$ [113]. While much greater than a match, this exposure is much smaller than that of a full-sized upholstered item itself. The results in table 10 show ignition with a small wastebasket, with peak fluxes of about $35 \mathrm{~kW} / \mathrm{m}^{2}$, as discussed below, is easily achievable for almost any common upholstered item [113]. Thus, ignition from large ignition sources is not an important variable for direct hazard assessment. However, as will be discussed later, the consequences of ignition-in terms of rate of heat release, flame spread, smoke, and toxic gas development-differ greatly for various furniture assemblies.

Figure 7 shows irradiance-ignition time curves for essentially the complete range of commercial upholstery assemblies, from the highly fire resistive wool fabric/neoprene padding combination, to the readily ignitable polyolefin/unretarded PU combination [114]. The irradiance at which ignition occurred ranged from 5.6 to $14.5 \mathrm{~kW} / \mathrm{m}^{2}$. The above tests were run in the cone calorimeter described in [115]. The most ignitionresistant composite (wool/neoprene) showed a minimum irradiance for ignition of $14.5 \mathrm{~kW} / \mathrm{m}^{2}$. Exploratory tests were also run on this composite in a larger calorimeter [116]. Despite the fact that both provide uniform, well-characterized irradiances and similar electric spark ignition, the tests in the latter required $65 \mathrm{~kW} / \mathrm{m}^{2}$ for ignition. Both sets of data were reproducible. The explanation lies in detailed observations of the ignition event. In one case, the wool intumesced, pyrolyzed, charred, eventually cracked in the char, and then ignited and burned primarily at the crack. In the second case, ignition was not achieved until the surface was raised enough in temperature to ignite uniformly. Minor differences in specimen size and tension and, consequently, amount of shrinkage and tendency to split open, edge conditions, convective flows, and spark details can be enough to create the different ignition sequences. While no systematic study is yet available on apparatus effects for fabric/padding ignition, observations suggest that significant differences are likely to occur only for a few highly ignition-resistive materials and not for more common furniture materials.

Additional time to ignition data have been obtained by Moulen and Grubits [117]. They investigated a number of fabrics, primarily cellulosics, over five different substrates ranging from mineral fiber to latex foam. The effects of the substrate (table 11) were seen to be small to negligible, and to depend more on substrate density than on its combustibility. The fabric weight and weave (i.e., tight or fuzzy) are likely to be important variables in ignition behavior. These have been studied for fabrics alone [118] but not for fabric/padding composites.

Theories for radiative ignition of solids have been available for many years and are useful in suggesting the relative importance of material properties; however, as a numerical predictive tool, they leave much to be desired. Hallman [119] discussed the theories and also studied empirically an extensive series of simple, homogeneous plastics. Even for these materials, a functional form somewhat different from theoretical was required to fit the data and uncertainties of about a factor of two still remained. His general expression for the ignition time was

$$
\mathrm{t}=\frac{1035\left(\mathrm{~T}_{\mathrm{ig}}-\mathrm{T}_{\mathrm{o}}\right)^{1.04}(\mathrm{k} \rho \mathrm{C})^{3 / 4}}{\left(\alpha \dot{\mathrm{q}}_{\mathrm{i}}^{\prime \prime}\right)^{2}}
$$


where the ignition time $t(s)$ is given as a function of the incident flux $\dot{q}_{i}^{\prime}$ the ignition temperature $T_{i g}$ and the thermal properties of conductivity, $\mathrm{k}$, density $\rho$, heat capacity $\mathrm{C}$, and radiant absorptivity $\alpha$. For a composite material specimen, effective thermal properties would have to be used. These data are nonexistent for furniture composites, although some values for fabrics alone, primarily apparel fabrics, have been measured [e.g., 120].

\subsubsection{Characterization of Large Ignition Sources}

Available data characterizing flaming ignition sources are rather limited. A summary is given in table 6 for natural ignition sources relevant to furniture ignitions and in table 7 and figure 8 for some test burners. Sources are shown ranging four orders of magnitude of heat output-5 W to $50,000 \mathrm{~W}$. Data are from $[59,93,121-123,124]$. Additional data on some sources are given in [125]; these are not directly applicable to a common ignition scenario since they were taken for the source impinging on the underneath of a horizontal surface. A detailed flux mapping for the wastebasket simulation burner, obtained with Gardon-type total and radiant heat flux gages, is shown in figure 9 [102].

An examination of the data in the tables reveals a certain consistency: the peak heat fluxes for all the sources, excluding the methenamine pill, are approximately $15-42 \mathrm{~kW} / \mathrm{m}^{2}$. What differs mainly when ignition source strength is increased is not the peak incident flux, but rather the area over which the flux is applied. In the case of the wastebasket, the area over which fluxes exceed, say, $20 \mathrm{~kW} / \mathrm{m}^{2}$ is about $60 \times 700 \mathrm{~mm}$; for a match this would be approximately $10 \times 30 \mathrm{~mm}$.

The ignition of materials by small-area sources has not been quantified in a systematic way. Physically, there are two effects:

(1) If the target object is heated over only a small area, instead of heating $\mid$ an infinitely large surface, higher heat fluxes are required to bring the small area surface up to the same temperature as compared to a theoretical, infinite plane. Analytical solutions, without radiation, however, have been developed by Thomas [126].

(2) The assumption that ignition occurs at the same surface temperature for the small area heating as for large area heating is probably invalid. A more realistic model may be to consider ignition as occurring as the lower flammability limit of the pyrolysate gases is reached. This is determined both by the pyrolysate mass flux rate from the surface and by the entrainment and mixing conditions. The latter have not been studied as a function of the heated area size.

As indicated above, uniform, large-area irradiance of about $20 \mathrm{~kW} / \mathrm{m}^{2}$ suffices to ignite not only all common constructions but even most fire-improved ones. While higher fluxes may be required to ignite over a small area, even this is normally achieved in typical fire scenarios. Yet, in many practical cases, a small ignition source may cause the material to be ignited locally but the fire will not spread; instead, it will die out once the source goes out. An extreme example of this is the use of a welding torch-with maximum fluxes much greater than the sources in tables 6 and 7-to ignite PU foam. With many foam compositions sustained ignition is impossible; a hole is melted/burned through the foam but sustained ignition does not result. Sustained ignition is, in fact, a manifestation of flame spread and should be considered as such. Reviews of ignition theories have been published by Kanury [127] and Thomas [128].

\subsubsection{Large-Open-Flame and Radiant Ignition Tests}

The following ignition sources have been used for experimental purposes or, rarely, for acceptance testing.

1. "Berkeley Wastebasket." This source was first characterized in [112] and used for igniting a wide variety of furniture and building materials. The specifications are:

7-liter polyethylene wastebasket, $M=0.285 \mathrm{~kg} ; 12$ paper/polyethylene milk cartons, 6 upright, 6 shredded, total $\mathrm{M}=0.390 \mathrm{~kg}$

Total heat content (lower) $=19.7 \mathrm{MJ}$

The rate of heat release characteristics were examined in [113]. The average heat release during flaming combustion was $50 \mathrm{~kW}$ for $200 \mathrm{~s}$; the heat content realized during the later slow burning, or not at all=9.7 MJ.

The burning rate is, unfortunately, somewhat operator-dependent and is affected by packing and ignition procedures. Ignition variability with the wastebasket simulation burner sometimes arises when the basket collapses to one side instead of burning down uniformly. This tends to open up a gap between the basket and the test piece, thereby greatly reducing the heat flux. 
2. Wastebasket simulation burner. This source was developed to simulate the characteristics of the Berkeley wastebasket, but intended to be more reproducible. The burner is placed flush against the test piece and does not move as the wastebasket does in collapsing.

The burner has been described in [102]. The construction is illustrated in figure 10, while heat flux measurements are given in figure 9 . It is noteworthy that the peak heat fluxes are only $35 \mathrm{~kW} / \mathrm{m}^{2}$, but that the area covered by the $20 \mathrm{~kW} / \mathrm{m}^{2}$ contours is substantial.

3. Wire mesh paper basket. This ignition source was proposed by Moulen and Grubits of Australia [93]. They used a cubical $0.25 \times 0.25 \times 0.25 \mathrm{~m}$ wire mesh basket filled with shredded paper. Because of varying packing densities, combustible loads of 50 to $150 \mathrm{~g}$ gave approximately $15-25 \mathrm{~kW}$ heat release rates, lasting for 30 to $90 \mathrm{~s}$. A similar newspaper ignition source has been developed by the California Bureau of Home Furnishings and is described in section 4.1.1.1 [96,97].

4. Galvanized metal circular wastebasket. This ignition source was developed by the California Bureau of Home Furnishings [94] and is now specified in a California mattress test standard [95]. The basket is filled with $21 \mathrm{~g}$ of loosely wadded newspaper. Used as an ignition source for institutional mattresses, it is placed underneath the center of the mattress. The heat output is substantially less than for the other wastebaskets discussed; details of burning characteristics are not available.

5. Balled up newspaper. Balled up pieces of newspaper, spread over the test article, have been commonly used. This source, unfortunately, shows extreme variability and it would be difficult to assign a unique heat output to it [129].

6. ISO Ignition Apparatus. The ISO apparatus uses a conical heater to impose a radiant flux on a bench-scale sample [130]. The flux can be varied over the range of $10-50 \mathrm{~kW} / \mathrm{m}^{2}$. A gas pilot is used.

7. Cone Calorimeter. This apparatus, discussed in detail below, under heat release rate (sec. 4.5), is used also in ignitability testing [115]. A conical heater, similar to the one in the ISO apparatus is used, but with a flux capability up to $100 \mathrm{~kW} / \mathrm{m}^{2}$. An electric spark pilot is used.

8. A group of Finnish workers have studied the burning behavior of common furnishing items which are often the first item to ignite and may serve as an ignition source for upholstered furniture: polyethylene waste paper baskets, cellulosic curtains, commercial chair and chair mockups built according to the British standard with cellulosic fabric and PU foam; television sets; and Christmas trees [131]. Room size was $3.6 \times 2.4 \times 2.4 \mathrm{~m}$, with a $2.0 \times 0.8 \mathrm{~m}$ door. The results are shown in table 6B. The items could be grouped according to maximum rate of heat release as follows: below $100 \mathrm{~kW}$ waste paper baskets which could only ignite items very near or above them; heat release rates of 100-200 kW, from TV sets (which burned for a long time), curtains, and chairs (the latter with much shorter burning times); and dry Christmas trees, 500-600 kW, with such rapid heat evolution that escape would be difficult.

\subsection{Rate of Fire Flaming Growth-Functional Forms}

\subsubsection{Exponential Growth Model}

In recent years some consideration has been given to describing, analytically, a generalized fire growth process. The conceptual model is the following. Initial fire spread is considered as a growth in the fire area. This is reasonable for large surfaces, such as upholstered chairs, or for arrays of fuel items, progressively becoming involved. In a process of this sort, it is often observed that the rate at which new material becomes fire involved is proportional to the amount already burning. That is

$$
\frac{\mathrm{dA}}{\mathrm{dt}} \sim \mathrm{A}
$$

This can be integrated to give the involved area, as a function of time, as

$$
A(t)=C_{1} e^{C_{2} t}
$$

(where $\mathrm{C}_{1}, \mathrm{C}_{2}$ are empirical constants)

which is "exponential growth." For practical applications, one would wish to consider heat release rate or mass loss rate as a more convenient measure than involved area. Such an approach was proposed by Friedman [132] and Huggett [133]. The tabulation below shows growth constants found by a number of workers for a variety .of materials, in a variety of forms [132-135]. The range is $C_{2}=0.003$ to $0.03 \mathrm{~s}^{-1}$. 
Slow burning commodities on pallets

PU foam slab

Beds, burning rapidly

0.15

Sofas

Upholstered chairs and sofas, overall range

0.01 most data, typically

For upholstered furniture a correlation between the value for the growth constant and the properties of the specimen was not evident [135].

The main application of fire growth models, suggested by Friedman [132], is for studying detection, alarm, and sprinkler activation situations, since there, the time to an event (detection, etc.) is of essence. These aspects will not be discussed in detail here. It is of importance in assessing fire hazard to determine the time from ignition to some critical event. The exponential growth model, however, does not offer a complete answer since (1) the fire growth process may have to be described by not one, but two or more growth constants [134]; and (2) the total time to a given fire stage will depend not only on the growth constant, $k$, which is primarily a measure of flame spread rate and is determinable only for a fire beyond a certain minimum measurable size, but also on the ignition period, which is highly dependent on the exact ignition details. The method becomes useful when the objective is to determine fire growth from a nonzero start (e.g., from detection) to a later event (e.g., sprinkler activation).

\subsubsection{Triangular Rate of Heat Release Model}

The actual form of upholstered furniture fire heat release or mass loss rates vs time plots is important to consider. In figure 11 are shown some typical forms noted in practice. It bears emphasis that quasi-steady burning is rare and not a good conceptual model. Figure 12 is an illustration of the fact that while an exponential fire growth may be a slightly better representation of the actual burning process, a simpler linear, triangular representation can be an adequate approximation [136]. Computations are shown in table 12 for the upholstered chair fires tested in full scale [111,137]. An active burning time can be directly taken from this representation. These times ranged from $200 \mathrm{~s}$ to $800 \mathrm{~s}$, excluding cases where a triangular fit is a poor representation. For chairs with combustible frames, the heat released in such a triangular representation averaged 63 percent of the total released during the whole combustion process, with a range of 46 to 83 percent. The remaining 37 percent would be accounted for by the slow burning final stages of the fire where primarily the frame is burning, with a slight additional contribution during the very early part of the fire. In the case of chairs with noncombustible frames, the triangular area represents, on the average, 91 percent of the total heat content. The triangular representation allows a simple yet useful design representation to be made. Using this model, the active burning time can be computed without conducting a specific full-scale test if the total heat content (see sec. 5.4) and peak rate of heat release (secs. 5.2 and 5.3) can be determined. The method is not appropriate to highly fire resistive constructions (e.g., wool fabric, neoprene foam) which do not burn to completion in a flaming manner. Based on data in table 12 and additional data on specimens with plastic frames [136], the burning time, $t_{b}$, is estimated as

$$
\mathrm{t}_{\mathrm{b}}=\mathrm{C}_{3} \frac{\text { [total heat content] }}{\dot{\mathrm{q}}}
$$

where $\mathrm{C}_{3}=1.3$ for items with wood frames and 1.8 for items with metal frames or plastic frames; $\dot{\mathrm{q}}$ is the peak full-scale heat release rate $(\mathrm{kW})$ estimated by the techniques given in section 5.3 or 5.2; and the total heat content $(\mathrm{kJ})$ is determined as described in section 5.4.

\subsection{Flame Spread}

\subsubsection{Flame Spread-Analytical Fundamentals}

Typical upholstered item dimensions range from 0.5 to $2.0 \mathrm{~m}$. Fires of this scale are large enough so that flame spread and heat release behaviors are dominated by radiative, rather than convective, mechanisms. It can further be specified that in a room fire, only natural convection and not forced convection flows need 
to be considered. Figure 13 shows the geometric arrangements that need to be considered. It will be shown later from experimental observations that the primary patterns which need to be considered are the ones where the flame travel is "against-the-wind," i.e., in the opposite direction of the draft (which is induced by the fire itself, due to its buoyancy). A theory is available due to Rockett [138] which considers the calculational basis for determining against-the-wind flame spread when radiation is the primary mechanism and convection-which can never be ignored-is small enough that a simple treatment is adequate. The flame spread process is assumed to be one-dimensional, i.e., spreading from a line source, not a point source. This theory has been applied in a somewhat simplified way, to a test method for wall paneling materials [139]. More recently, a test apparatus has also been constructed at NBS for making against-the-wind flame spread measurements of fabric/padding composites with the goal of obtaining data suitable for analysis with Rockett's theory. Dipert [140] had made initial calibrations and this work is continuing.

Dipert's measurements indicate that a suitable form for a flame spread expression, which has both predictive value and theoretical justification, is

$$
\mathrm{v}(\mathrm{t})=\frac{\delta}{\mathrm{k} \rho \mathrm{C}}\left[\frac{\dot{\mathrm{q}}_{\text {foot }}^{\prime \prime}+\dot{\mathrm{q}}_{\text {plume }}^{\prime \prime}}{\mathrm{T}_{\mathrm{ig}}-\mathrm{T}_{\mathrm{s}}(\mathrm{t})}\right]^{2}
$$

where $\mathrm{v}$ is given as a function of the thermal properties of the solid, $\mathrm{k}, \rho$, and $\mathrm{C}$; the ignition temperature $\mathrm{T}_{\mathrm{ig}}$; the convective/conductive flux $\dot{q}_{\text {f oot }}^{\prime}$ at the foot of the flame; the radiative flux $\dot{q}_{\text {plume }}^{\prime \prime}$ from the fire plume to the base of the flame; and $T_{s}(t)$ which is the instantaneous surface temperature, computed only from the heating due to external irradiances (radiant panels in the case of a test apparatus). The distance $\delta$ is an experimentally determined distance for $1 /$ e falloff of plume radiation at the base of the flame.

The theory for one-dimensional flame spread [138] predicts that there is a minimum flame flux, $\dot{\mathrm{q}}_{\mathrm{fc}}^{\prime \prime}$ from the flame to its spreading edge for achieving sustained flame propagation. This value depends on material thermal properties, external heating and convective effects,

$$
\dot{\mathrm{q}}_{\mathrm{f}}^{\prime \prime}=\mathrm{h}_{\mathrm{c}}\left(\mathrm{T}_{\mathrm{ig}}-\mathrm{T}_{\mathrm{s}}(\mathrm{t})\right)
$$

where $T_{s}(t)$ is the surface temperature which would be derived solely from external heating. For no external flux, $T_{s}=$ ambient temperature $T_{0}$. An ignition temperature, $T_{i g}$, and an effective convective heat transfer coefficient, $\mathbf{h}_{c}$, are also needed. In practice, small ignition sources are point sources, not line sources; therefore, on horizontal surfaces, axi-symmetric flame spread, rather than one-dimensional flame spread, is seen. With a small ignition source, once material in the immediate proximity has melted or burned away, the external heating at the flame spread circle becomes negligible. Whether flame spread will continue or die out then depends on whether the burning at the flame front is vigorous enough to generate a $\dot{\mathrm{q}}_{\mathrm{f}}^{\prime \prime}>\dot{\mathrm{q}}_{\mathrm{fc}}^{\prime \prime}$. No theoretical or experimental data are available on this point. Indeed, even for one-dimensional spread, neither measurements nor computations are available to evaluate $\dot{\mathrm{q}}_{\mathrm{f}}^{\prime \prime}$ for upholstered items, although some data have been obtained for carpets [141]. On parts of a burning upholstered chair, flame spread can be materially aided by radiation from a burning nearby surface of the same chair; this is "external" radiation in the context of the flame spread theory.

Somewhat more empirical but closed-form expressions for mattress flame spread were sought by Pagni $e t$ al. [142]. They tested one half-size PU foam mattress $(0.89 \mathrm{~m}$ by $0.89 \mathrm{~m})$ with a cotton/polyester sheet in two configurations-intact, and with a $100 \mathrm{~mm}$ hole cut out of the ticking and sheet, surrounding the methenamine pill ignition point. For the specimens with the hole, they found three burning regimes: (1) for the first $30 \mathrm{~s}$, flame spread was traveling across the surface, up to the edge of the cut hole; (2) in the next $100 \mathrm{~s}$, there was little horizontal flame spread-instead, the burning surface regressed downward until the bottom burned through; (3) in the final period, there was a steady, somewhat accelerating radial spread. However, this was not surface spread alone, but rather a progressively enlarging cylindrical consumed area. The interior of the cylindrical void was filled with a luminous turbulent flame. The uncut-cover case was generally similar, but with less distinct regimes. (Similar observations also were made with specimens subjected to a linear ignition source on the apparatus described in [140].) Flame spread and mass loss rates, as well as flame base diameters for various time from ignition are listed in table 13. An expression for flame height, measured above the specimen top, was obtained as:

$$
\frac{h_{f l}}{D}=0.36\left(\frac{\dot{m}^{2}}{D^{5}}\right)^{1 / 4}
$$


where $D$ is the instantaneous flame base diameter $(\mathrm{m})$. The above results are not predictive, in the sense that they are not based on fundamental material properties. They are dealt with in detail here, however, to illustrate that describing flame spread in a detailed way is not straightforward.

Other curve-fit results have also been reported in the literature for similar, but not identical, PU foam mattresses by Land [143] and Mizuno [144]. Land found a significant effect of foam moisture absorption on the flame spread-higher moisture contents giving lower flame spread rates, smoke, and flame heights. The mass loss rates of samples conditioned to 92 percent R.H. were 50 percent or less than those conditioned to 35 percent R.H. These limited observations by Land constitute the only data to be found in the literature on the effects of moisture on flame spread over upholstered items. Other moisture eifects will be discussed 'i 5.1.6.

Mizuno [144] studied mattress foams, without ticking, in two sizes: $0.50 \mathrm{~m}$ by $0.50 \mathrm{~m}$ by $\mathrm{s} .14 \mathrm{~m}$ thick, and $0.90 \mathrm{~m}$ by $0.90 \mathrm{~m}$ by $0.12 \mathrm{~m}$ thick. The foams were ignited in the center with a methenamine pill. Flame radius (m) was measured as:

$$
\begin{aligned}
& r=2.3 \times 10^{-3} t \\
& r=3.5 \times 10^{-2} e^{0.026 t} \text { for the smaller specimens } \\
& r=4.0 \times 10^{-2} e^{0.02 t t} \text { for the larger specimens }
\end{aligned}
$$

$$
\begin{gathered}
0<\mathrm{t}<30 \mathrm{~s} \\
30<\mathrm{t}<70 \mathrm{~s} \\
30<\mathrm{t}<130 \mathrm{~s}
\end{gathered}
$$

The mass loss rate $(\mathrm{g} / \mathrm{s})$ from $\mathrm{t}=20 \mathrm{~s}$ to total surface involvement $(\mathrm{t}=90 \mathrm{~s}$ for the smaller specimens) was evaluated as a function of instantaneous radius:

$$
\dot{\mathrm{m}}=46.1 \mathrm{r}^{2.23}
$$

It also was noted that at the time of full surface involvement, 14 percent of the mass was lost.

On a horizontal surface, as considered above, a point source ignition leads to radially axi-symmetric (circular) spread. While vertical surface flame spread is usually of less importance, there is one study where the flame spread from a point ignition on a vertical surface was explored [145]. The fuel:was solid polymethylmethacrylate, so the numerical values of the results would not be directly applicable to upholstered items; however, qualitatively similar development could be expected. Figure 14 shows the shape of the pyrolysis region - the spread pattern is no longer axi-symmetric, and a fully three-dimensional burning problem has to be considered.The mass loss rate for this case was found to be expressible as a power law,

$$
\dot{\mathrm{m}} \propto \mathbf{t}^{1.8}
$$

Additional illustrations of flame spread over vertical PU foam slabs are available [146]. In one configuration a single slab was ignited at the top with a point source. Melting, dripping, and cratering was seen. The basic burn pattern was V-shaped, with some additional burning at the top (fig. 15). In the case of a corner-top ignition of two slabs, the predominant flame pattern was straight down.

\section{Thermally Thick and Thermally Thin}

The work of Mizuno [144] quantitatively illustrates the very difficult aspect of studies of furniture flame spread. For reasons of tractability, theories of flame spread are invariably based on one of two simplifying assumptions-the fuel is taken to be either thermally thick or thermally thin $[138,147]$. For the thick case, a negligible fraction of the mass is lost during flame spread; after initial flame involvement the burning surface regresses parallel to its original plane. For the thin case (e.g., a burning card) the fuel regresses perpendicularly to the original plane. Actual measurements on PU foams (fig. 16), however, show a behavior which does not conform to either of these limiting cases. For fabric/foam composites the reality is usually somewhat closer to the thermally thick case; nonetheless, some errors can be expected in forcing this simplification.

\subsubsection{Flame Spread-Empirical Studies}

There are few published studies on comparative, quantitative flame spread rate measurements over upholstered fabric/padding composites. Semi-quantitative studies are reported by several authors [e.g., 91,148]. Lee and Wiltshire [149] constructed a bench-scale apparatus to measure flame spread over fabric/padding composites. The experimental setup did not include a source of external radiant heating. A horizontal specimen, $150 \mathrm{~mm}$ wide by $450 \mathrm{~mm}$ long, was ignited at one end with kerosene and the flame travel was timed. Initial tests using fabrics with no padding showed approximately the inverse dependence of flame spread rate on specimen mass-per-unit-area predicted from theory [147]. The bulk of the measurements was taken with fabric over a 
$25 \mathrm{~mm}$ thick layer of PU foam. The variations were surprisingly small, covering a range of 0.7 to $1.1 \mathrm{~mm} / \mathrm{s}$, with only the acetate fabrics tending towards the higher end. Cellulosic fabrics tested over cotton batting showed flame spread rates about $1 / 2$ those over PU foams. Sensitivity to specimen width and thickness effects was also briefly explored. Increasing specimen width by a factor of three increased the flame spread rate by about 30 percent. Increasing specimen thickness six-fold resulted in a barely noticeable further flame spread increase.

Some 12 years later, Krasny and Babrauskas [150] reported on a series of measurements using full-sized chair mockups, that is, simulated chairs using realistic cushions to form seat, sides, and back, but with a steel frame and with no additional combustibles beyond the cushions (fig. 17). These measurements were done in order to help establish a data base for validation of a bench-scale test procedure [140]. Small flame ignition sources were used. Thermoplastic and cellulosic fabrics, each in light and heavy weights, and ordinary PU foam, FR PU, and neoprene foam padding were used. Typical flame spread is illustrated in figure 18.

Visual observations indicated major differences between the thermoplastics and the cellulosics. The cellulosics charred ahead of the flaming area. The thermoplastics pyrolyzed visibly and then melted and peeled back and the thus formed melt bead burned ahead of the PU fire front, causing more PU ignition. This somewhat periodic progression of flaming could be observed only on the horizontal (seat) cushion. Since the ignition source was towards the back of the seat area, the chair back became rapidly exposed to a high plume of fire. Flame spread and ignition on this surface, bathed with flame, was difficult to identify. The burning of the side (arm) cushions was generally in the form of unpiloted ignition, in distinct steps on one arm and almost simultaneously over the whole surface on the other arm, rather than a flame progression. Neoprene foam padding generally did not burn, once its fabric had burnt away, although it continued smoldering in crevices. The FR PU foams showed two flame fronts: a faster moving one associated with the fabric burning, and a later one for the foam itself. Typical results are illustrated in figure 19. The ranking of the various materials is discussed in section 5.1.1.3.

Mockup geometry affected the flame spread results. Increasing the number of cushions from one (single seat) to two (seat and back) to three (plus arm) to four (two arms) increased the overall flame involvement rate, so that for the last case, full seat involvement of the first ignited cushion was about 40 percent faster than in the first. Expanding the mockup to six cushions, to simulate a loveseat, brought about a substantial spread rate decrease of the first ignited cushion, so that times were more similar to the three-cushion case. This can be understood as a reduction in the radiative feedback of the more open geometry during the early burning stages. The second seat cushion showed the peeling of the olefin fabric generally observed only on vertical surfaces, with subsequent flaming ignition simultaneously over the whole surface. On the other hand, varying cushion thickness from $50 \mathrm{~mm}$ to $100 \mathrm{~mm}$ had no effect on flame spread rates, although it did affect the heat release rate.

For mattresses, flame spread is normally not an issue. In use, mattresses are covered by mattress pads, sheets, blankets, and other bedding. Since these bedding items comprise the outer exposed layers, it is their properties, rather than those of the mattress, which determine the flame spread behavior. Bed linens are not customarily made in fire retarded grades. Thus, flame spread variations due to bed linen differences will be limited. Three additional observations can be made on bed linen effects on flame spread:

(1) Bedding can affect both the cigarette ignition resistance and flame behavior of mattresses in a major manner. Cigarettes can ignite blankets (except wool and thermoplastics) but are unlikely to ignite sheets $[80,36]$. The probability of ignition is increased if additional layers of sheets and blankets are placed on top of the cigarette, rather than between the cigarette and the mattress $[36,150]$.

(2) A tightly made up bed, as for military inspection, will spread flame much slower than an unmade or loosely draped bed. For realistic fire testing it is important to disturb and/or pull back the covers to permit easy flame spread [31].

(3) Among common bedding materials, wool blankets have been shown to be hard to ignite and have low flame spread, as compared to other blanket materials [151,152,36].

(4) Pillows can have a major effect on bed fires. The NBS mattress test series [153] was conducted using shredded PU foam pillows. These were chosen as being both commercial and fast-burning. Much better behavior can be obtained from pillows filled with down, feathers, or polyester padding or when covered with pillow covers of FR fabrics. Since the pillow fire can serve as a major driving force for flame spread over the rest of the bedding, its behavior should be considered. Rate of heat release measurements on pillows have been recently made [154] and are shown in figure 20.

In hospital beds, decubitus (bedsore) pads are sometimes necessary. The pads may be typically foam plastic or pneumatic. No fire incidents are known to ever have occurred with the foam plastic type; nonetheless, a test series has been reported [155] where ignitability and mass loss values were examined. 


\subsubsection{Flame Spread-Standard Tests}

Flame spread measurements traditionally have been considered adequate characterization of the postignition burning behavior of building materials [e.g., 107], apparel fabrics [103], and even automobile upholstery [104]. In recent years, it has been recognized that this does not adequately characterize flammability hazards, and methods for rate of heat release are also being adopted by standards groups [e.g, 156]. The role of flame spread measurements on mattresses has been questioned above because in real-life bedding fires, the effect of bedding masks mattress flame spread properties. The role of flame spread over upholstered furniture is not yet well understood, and the results of the mockup test program [83], discussed in section 4.4.2 above, indicate that flame spread rate is related to heat release rate during the early stages of the upholstered chair fire.

Most commonly, U.S. standards and regulations [e.g., 157,158] refer to the ASTM E162 flame spread test [107]. Since the specimen is held at an angle from vertical in this test, melting materials can drip out during the course of test. A variant of this is the ASTM D3675 test [159] designed for retaining foam plastics in the holder by the use of wire mesh; a slightly different burner is also prescribed. Composite fabric/padding assemblies can be accommodated in this apparatus; nonetheless, most tests and requirements have been for padding alone. The available flame spread research, as discussed above, however, suggests that an end-use composite must be evaluated and that little meaning can be attached to flame spread measurements over separate components, especially subsurface components.

Attempts have occasionally been made to gather flame spread data on the Ohio State University (OSU) rate of heat release apparatus [156] and on the ISO ignitability apparatus [160,161]. In such cases, circularly spreading rates based on a center point ignition have been considered.

A suitable flame spread test for upholstered furniture should meet certain minimum requirements. It should have a provision for retaining composite specimens and preventing them from curling on the side during test. It should use a horizontal face-up orientation to enable melting and dripping materials to be tested. To enable analysis with available theory, the specimen should be subjected to a uniform radiant heating, with a flux of up to about $10 \mathrm{~kW} / \mathrm{m}^{2}$. The design of an apparatus to these requirements is not difficult and a test rig of this nature has been constructed [140]. Some preliminary measurements [124] are shown in table 14.

Several observations can be made: (1) at zero irradiance, spread rates ranged from zero to $3.7 \mathrm{~mm} / \mathrm{s}$; (2) at $2.5 \mathrm{~kW} / \mathrm{m}^{2}$ irradiance, spread rates were typically about doubled, except for those cases which fell below 1.0 $\mathrm{mm} / \mathrm{s}$ at zero flux; (3) PU foam with no fabric showed high flame spread rates, exceeded only by a light olefin fabric/PU composite; and (4) general ranking followed similar trends to the results from mockup tests. This work is still going on and test procedures are not yet developed.

\subsection{Heat Release Rate}

The rate of heat release of very simple materials, e.g., organic liquids, can be computed from known thermochemical properties and some applications-related data (boundary conditions). For upholstered furniture, and for other more complex combustibles, such is not the case. Unless rate of heat release itself is considered a "property," a deduction from properties cannot be made and detailed measurements have to be taken. A role is seen for both bench-scale and full-scale measurements.

\subsubsection{Full-Scale Heat Release Rate Measurement Techniques}

The importance of the heat release rate as a dominant variable was not recognized until a few years ago. Thus, until very recently, no attempts were made to evaluate the heat release rate in most full-scale fire tests. Temperatures were the primary variable measured; these tests had little generality and did not yield any properties specific to the test article. Once it became clear that heat release rate measurements were needed, a suitable measurement method had to be found. The most obvious way is to attempt to measure the sensible enthalpy of the fire gas outflow. A technique of this kind was tried by Fitzgerald [162,163], who built a test room with a blower air supply and a ceiling exhaust duct. Thermocouples located in the exhaust duct give the primary indication of heat output. Since a large amount of heat is lost to the room walls, however, additional thermocouples were installed in these surfaces. These were used to provide an empirical correction for wall losses. This correction, even after calibration with a test gas, could only be very approximate since the fraction of heat lost to different surfaces depends on soot radiation, plume combustion, and other variables differing for different fuels. The amount of heat released within this calorimeter was limited by the air supply rate of 0.22 $\mathrm{kg} / \mathrm{s}$ to $\dot{\mathrm{q}}=680 \mathrm{~kW}$. The inability to achieve a universal calibration is the most serious limitation of any such thermocouple measurement scheme. The pioneering unit designed by Fitzgerald was, furthermore, limited to heat release values much smaller than necessary to characterize common upholstered furniture items. 
The presence of an enclosed chamber itself can be a limitation to obtaining general $\dot{q}$ values. Since heat release rates can, in general, be influenced by wall heating and re-radiation effects, air vitiation effects, and effects due to nonsymmetric air inflow patterns, these factors must be quantified or, alternatively, free-burn measurements can be sought. A measurement apparatus became feasible with the development of the oxygen consumption principle in the late 1970's [164]. This principle states that, to within about \pm 5 percent, for most common combustible species, the combustion heat released is proportional to the amount of oxygen consumed. The proportionality constant is $13.1 \times 10^{3} \mathrm{~kJ}$ per $\mathrm{kg}$ of $\mathrm{O}_{2}$ consumed.\} Note, by contrast, that the heat of combustion of a fuel is given as the heat released per $\mathrm{kg}$ of fuel. Detailed equations for applying this principle are given in [165]. The application of the oxygen consumption principle allowed a simple apparatus to be built where the open, or free-burn, rate could be determined. This has been termed the furniture calorimeter and is shown in figure 21 [102]. Heat release rates up to about $7000 \mathrm{~kW}$ can be measured at NBS in this way. Similar devices have also been implemented at the Factory Mutual Research Corporation [166] and in Sweden [167].

A standardized full-scale test method for upholstered furniture has not yet been proposed. Full-scale testing is costly and difficult. Nonetheless, it might be necessary to develop a standard test method if that were the only way of assessing burning rate hazards. As is shown in section 5.3 below, however, full-scale/benchscale correlations offer a much more useful method. Once a basic correlation is established for a product class, bench-scale data can be used, which are both less costly and more reproducible. Full-scale testing then remains desirable only for those classes of articles where such a predictive correlation has not been established. This full-scale testing would be done in the furniture calorimeter.

\subsubsection{Full-Scale Heat Rellease Rate Data}

Prior to the development of calorimeter techniques for heat release rate measurements, upholstered furniture items were generally tested by conducting full-scale room fires. If load cell measurements were taken, an estimate of the heat release rate could be made by multiplying the $\dot{m}$ values by a presumed heat of combustion. In many test series, however, only temperature data were taken; this did not yield any property value characteristic of the specimen. Almost all available earlier systematic measurements have been references discussed in [153] for mattresses, up to 1977, and in [79] for upholstered chairs, up to 1979. Some newer studies are referenced in [1,2, and 3].

Recent measurements using the furniture calorimeter have established a quantitative data base. To that can be added some earlier results where heat release rate values have been computed from m records or by estimates from gas analysis. Table 15 gives results for mattresses tested at NBS [153]. These were early room fires with standard bed linens and noncombustible bed frames, as shown in figure 22. Another set of mattress data was taken at the Centre Scientifique et Technique du Batiment (CSTB) $[168,169]$ and is given in table 16. Full-scale data on upholstered chairs were taken at NBS during three different test series $[79,102,137,171]$ and are given in table 17. Typical heat release rate curves are illustrated in figure 23.

The latest available data are from a series of chair mockup burns discussed in section 4.4.2 [83]. In these tests a steel framework was used and the combustibles consisted solely of cushions, $0.61 \mathrm{~m}$ by $0.61 \mathrm{~m}$ in size, and of several thicknesses. Five arrangements were used as shown in figure 17: a single seat cushion; seat and back; seat, back and one arm; seat, back and two arms (standard easy chair); and six cushions simulating a loveseat (two seat, two back, both arms). The results are shown in table 18 and will be discussed in more detail in section 5.1.

In addition to the above systematic test series, there have been other studies in recent years where at least peak m values and, in some cases, also heat release values, were obtained. In Sweden and Finland, upholstered chairs [131,171-173] and beds [167] were tested. At the Science University of Tokyo, a series of upholstered chairs were burned [135]. Finally, in the United States a brief report is given [175] of a series of chair tests. For some newer, more fire-resistive materials, full-scale heat release rate data are not available but semi-quantitative observations are available $[176,177]$ which tend to corroborate bench-scale findings of relatively fire safe performance.

\subsubsection{Bench-Scale Heat Release Rate Measurement Techniques}

A number of laboratory techniques have been developed for making heat release rate measurements. The simplest consist of some arrangement to measure directly the sensible heat output of a burning specimen. To do this adequately an adiabatic test chamber would be required. This can be possible with the use of guard heaters; however, it would be very costly and has never been attempted. More simply, one can insulate the test box and then attempt to correct for heat losses by empirical means. A device of this nature, the OSU heat 
release rate apparatus [156], has been in use since the late 1960's. Its conformance to ideal behavior has more recently been examined $[178,179]$.

An improved way of making heat measurements is with an isothermal, instead of adiabatic, design. In that case, the apparatus measuring chamber contains a temperature sensor and a substitution burner. The substitution burner injects fuel into the chamber at such a rate as to maintain a constant temperature, irrespective of specimen rate of heat release. By metering the required substitution burner fuel flow, a measurement of the specimen heat release rate is obtained. Instruments of this nature have been built at NBS, designated NBS-I [180] and NBS-II [116]. Isothermal instruments of this sort avoid the first order errors due to heat losses. There is some residual error, however, since specimen burning, substitution burner, and temperature sensing cannot be at the same point, but must, in fact, be rather widely separated. The costs are high enough for this approach that no commercial instrument has resulted.

The development of the oxygen consumption principle discussed above in connection with full-scale testing, has also changed the nature of bench-scale rate of heat release tests. This method can be retrofitted to existing sensible-enthalpy instruments for an improved accuracy in measurement $[178,179]$. Recently, however, an apparatus was developed based on a design specifically optimized for the use of the oxygen consumption method [115]. It has been termed the Cone Calorimeter (fig. 24) and is simple enough in construction to be useful for routine product testing applications. The more recent data taken at NBS, discussed below, have been measured with this apparatus.

In addition to the apparatus discussed above, there have been a number of other heat release rate devices developed, most of them being variants of the three basic types. Janssens has reviewed in detail the features of over a dozen different apparatuses [181]; the specific merits and drawbacks of the various apparatus will not be reviewed in more detail here. For making measurements on upholstered furniture, any unit which accommodates square or rectangular specimens (circular specimens of composite materials are difficult to prepare) in a horizontal orientation can be utilized.

A feature in which rate of heat release apparatus differ substantially is specimen size. Specimen areas from $0.007 \mathrm{~m}^{2}$ to $0.28 \mathrm{~m}^{2}$ have been used. There is some effect on heat release rate but the effect is minor. For vertical specimens, a factor of three size variation was seen to have a 10 percent or less effect on heat release rate [182]. For the horizontal orientation, the effect is slightly more pronounced; each doubling of specimen area for polymethylmethacrylate slab specimens was seen to yield about a 15 percent increase in the heat release rate [124]. For certain mattress specimens, a 225 percent increase in specimen area did not yield significantly different heat release rates [183]. However, specimen size may be of importance for cover materials which melt, shrink and char, because the higher tension set up in a large specimen may increase the chance of splitting and exposing the padding material.

For testing upholstered furniture materials, some details of specimen preparation must be considered. At NBS the most consistent results were achieved with the following technique [115]. The padding material is cut to a size slightly smaller than the finished sample size $(100 \mathrm{~mm} \times 100 \mathrm{~mm} \times 50 \mathrm{~mm}$ thick, in the case of the Cone Calorimeter). The interliner, if any, is cut in a cruciform shape to cover the top and the four sides. The upholstery cover fabric is cut in a similar cruciform shape. The sample is assembled and held together by stapling the sides through at an angle, near the bottom. The specimen is then wrapped in a single piece of aluminum foil, covering sides and bottom, with corners folded and not cut.

Suitable conditions of specimen irradiance and proper analysis of data cannot be prescribed $a$ priori. Such conditions can only be established for a specific fire scenario and product class on the basis of correlations between full and bench-scale measurements (see sec. 5.3 below).

\subsubsection{Bench-Scale Heat Release Rate Data}

Typical measurements made in the cone calorimeter are shown in figures 25 and 26 . Figure 25 shows heavy polyolefin fabric/combustion modified high-resiliency PU specimens tested at three different irradiances-25, 50 and $75 \mathrm{~kW} / \mathrm{m}^{2}$. The curve shows two peaks, an initial one mainly due to fabric, and a later one attributable to the foam. Figure 26 shows data at one irradiance, $25 \mathrm{~kW} / \mathrm{m}^{2}$, for a number of fabric/padding combinations.

Bench-scale heat release rate data become useful only when a correlation to full-scale is achieved. This is examined under the engineering approaches considered in chapter 5.

\subsection{Upholstered Items of Unconventional Construction}

"Conventional" furniture items can be taken to include normal mattresses and those upholstered chair items which either have a traditional wood frame or a plastic frame of similar shape and function. Uncon- 
ventional furniture, by contrast, can include bean bag chairs, foam block chair-beds, and single-piece molded items. These types of furniture are more difficult to evaluate since bench-scale flame spread (sec. 4.4.3) and heat release rate (sec. 4.5.3) testing procedures for conventional frame upholstered chairs have not been correlated with results on unconventional construction chairs. Some full-scale test data are available, however. In one NBS study [79] a number of these chairs were burned in rooms (table 17). These included a polystyrene bean bag chair, a molded PU foam block chair and foam block chair-lounger, and molded PU and polyethylene pedestal chairs. These ranged in heat release from $370 \mathrm{~kW}$ for the bean bag chair, to $2480 \mathrm{~kW}$ for the large chair-lounger. Use of bench-scale procedures for the evaluation of this type of furniture will be difficult, due to the possible geometric complexities, both in the basic design and as caused by melting and collapsing during the fire.

One test had been reported [184] on an auditorium (fold-down) seat with a steel frame, wood back and seat structural panels $(8.0 \mathrm{~kg})$, PU foam padding $(1.23 \mathrm{~kg})$, and PVC fabric $(2.2 \mathrm{~kg})$, with a total mass of $22 \mathrm{~kg}$ and a combustible mass of $11.4 \mathrm{~kg}$. The peak rate of heat release was found to be $300 \mathrm{~kW}$.

\subsection{Transportation Vehicle Seats}

\subsubsection{Ground Transportation}

Under the general category of transportation vehicle seats, buses, subways, interurban rail cars, and aircraft will be considered. The problems associated with buses and rail cars are very similar and so is materials usage. Aircraft seat design involves similar concerns but additional fire safety is often desired while weight has to be minimized. Thus the actual materials used in aircraft seating differ substantially from those on ground vehicles; to a certain extent test procedures and criteria are also different. Passenger car and truck seating has not been restricted in the United States except by the minimal MVSS 302 test [104], section 4.1.2.2; correspondingly, there has not been a history of studies on car and truck seats.

A number of programs involving full-scale fire tests or full-scale mockups of buses and rail cars, and full-scale seat tests have been reported. Hawthorne conducted tests on a full-scale rail car mockup [185]. Braun studied urban buses [111] and subway cars [109,110]. Nelson tested sectional mockups of rail car and bus configurations [186]. Williamson and Fisher tested subway car seats [187]. Peacock and Braun recently tested interurban rail car interiors [188], including seating in a full-sized sectional mockup. Their tests were the first where rate of heat release measurements were made in the full scale, on pairs of seats alone in the furniture calorimeter, and on bench-scale specimens of seat construction. A comparison of the furniture calorimeter data obtained with fabric covers to the bench-scale data obtained on the foam only is shown in table 19. Even with these procedural differences, the bench-scale test is somewhat predictive of full scale behavior. A number of fully-furnished railcar section mockup tests were also conducted in this program. Their results cannot be directly correlated to data on seating since other variables were not kept constant, except for one case. In that case, the mockup performance (with CMHR PU and neoprene foams) reflected the bench-scale performance. One important conclusion from this test series, which would be difficult to establish in bench scale, was that PU foam padded armrests acted as a significant fire growth mechanism, compared to slower burning ones.

Specific tests to verify that interliner protection should not be relied on in those transporation modes where vandalism is a problem have been run on bus seats [189]. In these full-scale mockup tests a neoprene interliner was highly effective in reducing burning rates and smoke on a vinyl fabric/PU foam assembly, giving a performance very similar to vinyl fabric/neoprene foam assembly. When the seats were slashed, however, the improvement was only slight.

Regulations in the United States for ground transportation vehicles have typically prescribed bunsen burner tests, such as the Motor Vehicle Safety Standard (MVSS) No. 302 [104] which has been described in section 4.1.2.2. This test is very easy to pass. However, a proposal currently exists within ASTM Committee E5 to standardize a room fire test with a sectional mockup for two pairs of seats, with ignition being by wood cribs. This follows roughly the experimental setup of Nelson [186].

A number of studies were undertaken primarily to establish the need for improvement of railroad fire safety regulations, and to determine the path which such regulations should follow. Rakaczky has reviewed rail car flammability studies prior to 1980 [190]. Hathaway surveyed a number of topics of interest, including a listing of fire development scenarios [191], a comparison of regulations for different classes of transportation vehicles [192], and a background for proposed Department of Transportation regulations [193]. A review of subway car fires in six U.S. subway systems was published by the American Iron and Steel Institute [194]. Following the BART fire of 1979 , the general fire safety effectiveness of existing subway systems was examined $[109,110,195]$. Some additional studies of land transportation vehicle seating are reviewed in [196]. As could be 
expected, these studies generally pointed out the problems arising from replacing wood and metal with plastic materials.

\subsubsection{Air Transportation}

The earliest full-scale tests on aircraft cabin interiors, including seating, were conducted at the Federal Aviation Administration (FAA) facilities in Atlantic City [197]. Active full-scale testing is continuing there through the present [e.g., 198,199]. Other early cabin tests were reported by the Airline Pilots Association in 1966 [200,201] and by the Aerospace Industries Association in 1968 [202]. A full-scale testing program was conducted at the NASA Johnson Space Center during 1974-76 to compare the performance of existing cabin materials with new improved or experimental materials [203-205]. Full-scale aircraft fire tests were more recently conducted at Johnson Space Center in a new test series which includes improved PU foams and polyimide foams [206].

In the 1960's, aircraft seats generally had either latex or PU foam padding and an assortment of fabrics, including nylon, modacrylic, nylon/wool/rayon, and a PVC warp/wool filling yarn fabric. By about 1970 the latex foams were dropped in favor of PU and a 90 percent wool/10 percent nylon upholstery fabric became dominant. This offered some improvement over earlier combinations; nonetheless it still was evident that seats were a major potential contributor to cabin fires. Thus, a development program, organized at NASA-Ames by J. A. Parker and D. Kourtides for improved aircraft materials entailed a significant amount of work on seating, much of it done by contract at the major airframe manufacturers. This program was started in the late 60's. Early research work was reported in a conference in 1976 [207], followed by a second conference in 1978 [208].

The development program work on seats was completed in 1983 with the publication of a final report, summarizing tests during the latter part of the project and issuing final recommendations [209,175,211]. The recommendations focused heavily on the use of optimally-designed interliners, as a means of achieving a high performance/weight ratio. The recommended assembly retains the wool/nylon fabric and uses NFR PU foam (which is lighter than FR foam). The improved performance results from the use of, e.g., an aluminized, heat resistant interliner fabric (Norfab R11HT-26-AL), consisting of 70 percent Kevlar, 25 percent Nomex and 5 percent Kynol fibers. The aluminized interliner prevents pyrolysis gases from feeding the fire; the seats enclosed in this fabric are vented in the back, and it is assumed that the fire will impinge on them from the aisle. Other interliners and coatings for the cushion, as well as the backside of the cover fabrics, are under consideration at the time of this writing. Two cost-benefit studies of fire-blocking interliners in aircraft seats have been published recently $[212,213]$. The second reference contains an analysis of aircraft accident data.

By contrast, improved seating assemblies recommended in recent years for ground transportation vehicles have generally comprised a wool/nylon fabric and a (much heavier) neoprene foam padding, with no interliner.

The earliest bench-scale test developed specifically for aircraft materials, including seating, was the "T-3" test developed at NASA in the late 1960's [214]. This test comprised a small furnace fed by an oil burner, in which specimens $229 \mathrm{~mm} \times 229 \mathrm{~mm}$ in size are exposed at openings in the top of the furnace. The furnace fire rate is adjusted to produce specimen irradiance of 85 or $113 \mathrm{~kW} / \mathrm{m}^{2}$ [210]. Criteria involve primarily measurement of specimen back face or internal temperatures. In recent work it was concluded that the flux levels are too high in the T-3 test to adequately distinguish behavior of seating materials [210].

Recent testing of aircraft seat assemblies in full-scale mockups has been centered around the cabin fire simulator (CFS) developed by Douglas Aircraft [215]. The CFS (fig. 27) consists of a test chamber containing a steel frame for a double-seat mockup. Two each of seat cushions $460 \mathrm{~mm}$ by $500 \mathrm{~mm}$ by $80 \mathrm{~mm}$ thick and back cushions $430 \mathrm{~mm}$ by $610 \mathrm{~mm}$ by $50 \mathrm{~mm}$ thick are used. This assembly is heated by a large radiant panel located parallel to one side and $150 \mathrm{~mm}$ away. The panel imposes a maximum flux of $100 \mathrm{~kW} / \mathrm{m}^{2}$ on the edge of the cushions next to it. Fluxes incident on the front face of the back cushion range from $48 \mathrm{~kW} / \mathrm{m}^{2}$ to less than $3 \mathrm{~kW} / \mathrm{m}^{2}$ at the far side. The peak on the seat cushion face is $53 \mathrm{~kW} / \mathrm{m}^{2}$. Ignition is with a propane torch held to the side edge. Temperatures and other variables are measured, but the primary determination is of specimen mass loss. This method does not appear to be propoșed as a standard test. The test would meet most requirements for a quantitative full-scale method if rate of heat release were the main measured output. Some comparison of data is discussed in sections 5.1.1 and 5.1.2.

Grand and Valys [216] reported on a series of full-scale mockup tests of aircraft seats in the Southwest Research Institute (SwRI) calorimeter [162], where rate of heat release values were measured. The test rig comprised a seat and a back cushion placed on a metal frame. The specimen was heated with radiant panels placed parallel to the seat and to the back, giving fluxes in the range of $31-99 \mathrm{~kW} / \mathrm{m}^{2}$; ignition was with a gas pilot. The results for those seven tests where some material identification is available are shown in table 20. The magnitudes of the peak full-scale heat release values are similar to those for railroad seating (table 19). The 
"improved" constructions show a modest improvement in heat release characteristics. Bench-scale data are not available for comparison.

While the oil burner test, T-3, did not achieve acceptance for bench-scale seat assembly testing, a similar but not identical, oil burner alone has recently been proposed for a full-scale test to be used in a new standard for airplane seating, in addition to FAR 25.853 [217]. In this FAA test (and a similar ASTM draft method) a "2-gallon/hour" oil burner is fitted with a discharge cone and aimed on a seat mockup assembly (fig. 28). The mockup comprises a $457 \mathrm{~mm}$ by $508 \mathrm{~mm}$ by $102 \mathrm{~mm}$ seat cushion and a $432 \mathrm{~mm}$ by $635 \mathrm{~mm}$ by $51 \mathrm{~mm}$ back cushion, placed on a steel mockup frame. The assembly is exposed to the burner flame for $120 \mathrm{~s}$. Assemblies fail if they lose more than 10 percent weight, if the flame spread reaches the side opposite the ignition flame, or if there is flaming drip. Brown and Johnson [218] recommend this test on the basis of adequate agreement to full-scale results. In the same study, however, they found a better agreement for OSU calorimeter results. The OSU tests [156], however, showed poor inter-laboratory agreement; no inter-laboratory data were obtained on the "2-gallon/hour" burner, but within-laboratory coefficients of variation for three assemblies were 6 to 10 percent. The "2-gallon/hour" burner test is functionally a Bunsen burner test, although areas of flame coverage and peak fluxes $\left(115 \mathrm{~kW} / \mathrm{m}^{2}\right)$ are substantially higher. This increased heating suffices to ignite aircraft materials and, to an extent, to differentiate among them. In common with more typical Bunsen burner tests, however, it does not yield measurements of analyzable material properties, though it may well be a good pass/fail test for state-of-the-art aircraft seats.

Until the development of this test, the only requirements for aircraft seating officially part of U.S. regulations is the FAR 25.853 Bunsen burner test [106], a test which is neither severe nor discriminating. Improvement in aircraft cabin materials has historically been accomplished indirectly-the FAA suggests that it will institute new, severe tests, while NASA and industry cooperate in developing advanced materials. Together, this has resulted in improved materials being adopted of a much better level of performance than would be suggested by the regulations.

General reviews of aircraft fires, fire scenarios, materials usage and similar subjects have been published by an FAA advisory committee [219], a National Academy of Sciences Committee [220], NBS [213] and by AGARD [221]. A detailed survey of details of aircraft fire incidents prior to 1975 was compiled by Stanford Research Institute [222].

\section{EVALUATION AND DESIGN ENGINEERING}

The designer concerned with the flammability of upholstered items may need performance information to varying degrees of specificity. In the simplest case, generic information on the relative performance of various proposed component materials and their interaction may be sufficient. In the first several sections below, this information is presented in a consolidated form. At the next level of detail, standard tests may need to be run on the materials and composites under consideration. The available standard tests for this have been examined in the prior sections. At the most detailed level, a state-of-the-art engineering analysis may need to be made. The pertinent techniques available so far for this are examined in the concluding sections.

\subsection{Flammability Ranking of Upholstered Furniture Components}

A bibliography of papers on cigarette and flame ignition of upholstered furniture contains 149 references [1]; and a general discussion of cigarette ignition resistance summarizes the state of the art up to 1981 [60]. The following adds the findings of the more recent papers on the ignition behavior of upholstered furniture and mattresses. The results are based on experiments with mini-mockups, mockups, or full-scale furniture; no papers on ignition resistance of fabrics or padding materials alone are included. A substantial part of the experimental work with cigarette ignition was performed at the California Bureau of Home Furnishings, while most of the work with small flame ignition was performed in Australia, England, Finland, and New Zealand.

Table 21 summarizes the findings of many such studies. The materials in the table are listed from top to bottom in the approximate order of decreasing resistance to ignition for cigarette ignition source (Part A) $[1-3,14-18,21,28,36-43,55,60-62,67,76,78,80,86,150,223-242]$ and in order of decreasing resistance to small flames and increasing fire growth after ignition $[28,36,63-65,83,86-93,97,131,148,149,151,173,175,183,185-190$, 210,243-246]. In many cases, there is considerable overlap between these characteristics of materials listed near each other, depending on such factors as density, amount of SR or FR agent, fabric finish and backcoating, and other factors. 
Recall that some materials which have good cigarette ignition resistance do not necessarily have good small flame ignition resistance, and vice versa, e.g., thermoplastic fabrics tend to resist cigarette ignition because some of the heat transferred to the fabric causes melting. On the other hand, cigarettes induce smoldering in medium to heavy weight cellulosic fabrics, with consequent heat transfer to the padding. However, the thermoplastics shrink and curl away from an open flame and expose the padding, while cellulosic fabrics char and, until the char breaks, protect the padding. Similarly, some flame retardants for PU reduce resistance to smoldering, while others improve both flame and cigarette ignition behavior.

To prevent ignition by cigarettes, it is not necessary to use only the materials listed on top of each column in table 21. For example, the combination of a medium weight thermoplastic with ordinary PU foam or the combination of light to medium weight cellulosic fabric with a layer of polyester batting over the PU may not ignite. Many wool and medium to heavy PVC-coated fabrics can be used with FR or ordinary PU foam or mixed batting. Material combinations which are, for all practical purposes, cigarette ignition resistant in a crevice configuration, can be chosen on the basis of a few trials in a qualified laboratory. The number of such trials can be held small by using the information from the table.

Unfortunately, no such simple scheme can be recommended for assuring the flame resistance of materials listed in Part B. Here, even the materials listed on top of each column will ignite if the flame is large enough or applied long enough, or both. However, Part B may be helpful in choosing material combinations with a low probability of ignition from, e.g., matches, and which may have lower rates of flame growth, when ignited with a larger source.

As examples for use of Part B, medium to heavy weight wool and vinyl coated cellulosic fabrics (vinyl coated thermoplastics that open up and expose the padding to the flame) have been shown to resist match ignition, regardless of padding material, but ignite with larger flame exposure. Heavy cotton fabric over neoprene padding burned and then smoldered, while the neoprene did not enter the combustion process except for smoldering in the crevice. Total rates of heat release and combustion product formation were negligible after the fabrics stopped burning. Aircraft seats constructed with wool/nylon fabric, an aluminized aramid fabric interliner, and NFR PU foam self-extinguished even after a severe flame exposure for 2 minutes [211-247].

The flammability characteristics of the individual materials are discussed in detail below.

\subsubsection{Effect of Fabrics}

\subsubsection{Cigarette Ignition}

Fiber content and weight: Tables 8 and 22 are examples of data on which the following discussion will be based. Table 22 summarizes two studies by the California Bureau of Home Furnishings. In one, conducted in 1976, over 80 upholstery fabrics popular in California at that time were tested over 10 padding materials each, in the mini-mockup configuration [223,224]. The other study covered 171 commercial furniture items sampled in 1981/82, to check compliance with the California standard [225].

These and other studies indicate that increasing the mass of cellulosic materials (cotton, rayon, linen, hemp in fabrics, cotton in batting) decreases cigarette ignition resistance. Increasing the mass of thermoplastics (nylon, polyester, and polyolefin in fabrics and thermoplastic fibers, usually polyester, in batting) increases the cigarette ignition resistance, because a large portion of the heat from the cigarette is consumed in melting the thermoplastic fibers and the thermoplastics do not smolder along with the cigarette.

Besides that, table 21 shows that the highest cigarette ignition resistance is obtained with wool and PVC-coated fabrics $[11,28,36,86]$; their efficacy increases with fabric weight and thickness of coating. The opposite effects of fabric weight for thermoplastics and cellulosic fabrics has been mentioned. Blending of thermoplastic fibers with cellulosic fibers increases cigarette ignition resistance; the data shown in table 22 imply that fabrics with 20 to 50 percent thermoplastic content rarely ignite from cigarettes [223-224]. However, no systematic study of such blends to optimize the retention of the appearance and feel of cellulosic fabrics, as well as cigarette ignition resistance, has been undertaken. Possible variables in such a study would be: location of the thermoplastic fibers-e.g., by placing them in the filling in weaves where mostly the filling appears on the surface; amounts needed in intimate yarn blends to obtain cigarette ignition resistance; type of thermoplastic-nylon, olefin, polypropylene, etc.

Finish: Permanent (non-water-soluble) flame retardant treatments of fabrics do not necessarily increase smolder resistance and can, in fact, exacerbate the smolder tendency of cellulosic fabrics [223]. Treatment of cellulosic fabrics and cotton batting with some nonpermanent materials, e.g., borax and boric acid, can increase both flame and smolder resistance [15,225,229-234,241]. Higher concentrations are often needed for smolder than for flame resistance. Such treatments can affect the color and feel of fabrics but have been successfully 
used in batting for prison mattresses, for example. Proprietary spray products claimed to make possible cigarette and flame ignition resistance of uphostered items by retrofit are occasionally promoted; tests with three such sprays indicated that this is indeed possible but that the amount of spraying necessary is very large, and the fabrics appeared discolored and harsh to the hand [242].

Most commercial backcoatings either did not affect the cigarette ignition resistance or else seemed to improve it $[18,39,223,225,228,237]$. A vinyl vinylidene latex backcoating and certain organophosphorous compounds improved furniture fabric cigarette ignition resistance [235-237].

Contamination of cellulosic fabrics and battings: Presence of alkali metal ions, such as sodium and potassium, decreases smoldering ignition resistance $[50,51,238,248]$. Such ions are always present on unscoured cotton. On finished fabrics, they may be detergent, softener, dyes, or dye auxiliaries deposits. Rinsing such fabrics in clean water often causes dramatic improvements in cigarette ignition resistance $[18,60,238]$. In spite of the publication of these results, little seems to be done by industry to remove these contaminants.

Tension: No systematic study of the effect of fabric tension on cigarette ignition resistance is available, but a few observations can be reported. When tension is low, as in old furniture or certain styles, the fabric may make little or no contact with the padding and cigarette ignition will be determined entirely by the fabric (table 21, first column). With higher tension, intimate contact between the fabric and padding is achieved and the padding can act either as a heat sink (e.g., SR PU), absorb heat during melting (polyester batting), or smolder along with smoldering fabrics (cellulosic batting)

The effect of fabric weight has already been discussed. No systematic study of the effect of other fabric parameters, such as weave, yarn size and density, pile vs. nonpile, etc., have been carried out. In nonfabric substrates, e.g., grass clippings and foam, denser packing has increased the smolder tendency $[55,66]$. This indicates that not only weight but dense packing of fibers and other cellulosic materials promotes smoldering. Lowering air permeability has been reported to increase cigarette ignition resistance but in some of these experiments, this was achieved by applying latex backcoatings, which introduces extraneous factors and increases the weight $[39,40]$. Increasing the air permeability by making slits in the fabric increased smoldering rate but not smoldering temperature and char areas [239].

\subsubsection{Flame Ignition}

A comparison of Parts A and B of table 21 shows that materials do not rank in the same order for cigarette and flame ignition resistance. Furthermore, while a furniture item combining materials from the upper to medium range of the listings can be considered essentially cigarette ignition resistant, even a combination of the materials ranking at the top in flame resistance will ignite if the flames are large enough and applied long enough.

The difference in the relative resistance to cigarettes and flames can be explained in terms of char forming and thermoplastic materials. Char forming can be initiated by low energy, e.g., that of a cigarette, in cellulosic and acrylic but not most wool materials. If enough cellulose is present, the char will grow. However, in flame exposures, such chars protect the padding from the flames, at least until they split due to fabric tension. Heavy cellulosic fabrics are thus preferable for flame ignition resistance, but lighter fabrics for cigarette ignition resistance. The flame resistance of wool fabrics also increases with weight. Acrylic fabrics are susceptible to both cigarette and flame ignition, but an effect of weight has not been established.

On the other hand, the heat from a cigarette only suffices to melt medium or light weight thermoplastic fabrics in the area of contact and cannot spread to the padding. However, upon flame exposure, the thermoplastic fabrics melt and shrink, rapidly exposing the padding. The molten area tends to form a burning bead which often constitutes a secondary ignition source with more available heat than the original one, e.g., a match. One often can observe two flame fronts: one, the foam burning, and a burning molten, thermoplastic bead in front of it $[83,91]$.

Most small flame ignition studies on upholstered furniture items were performed with the butane flame No. 1 of the British test [22] (secs. 4.1, 4.2) which simulates a wood match, on mini-mockups, large mockups, or actual furniture. Many such studies also used larger ignition sources. Examples of such data are shown in table 8 . This and similar studies provide the following ranking of fabrics according to fiber content with respect to small flame ignition resistance.

Generally, only fabrics containing wool or FR cellulosic fibers, as well as heavily PVC coated fabrics, had satisfactory resistance to butane flame No. 1 and matches. Fortunately, such fabrics, except the FR cellulosics, also tend to have good cigarette ignition resistance. Untreated cellulosic fabrics, acrylic fabrics, acrylic/cotton blends (apparently popular in Europe), and thermoplastic fabrics (nylon, polyester, polypropylene, untreated or FR treated) performed poorly. As a rough estimate, at least 40-60 percent wool or FR cellulosic fiber 
(viscose) may be necessary to pass the butane flame No. 1 test. FR treated wool and cellulose tends to resist even larger ignition sources [28,36,86,88-92,148, 149,151,175,183,243,244].

Heavier fabrics generally have better small flame ignition resistance than lighter fabrics, and smooth fabrics perform better than pile fabrics. Natural leather has relatively good resistance to flames (but is less effective in preventing cigarette ignition). PVC coated fabrics have considerably better flame resistance if the coating is applied to cellulosic rather than thermoplastic base fabric. Figure 7 shows that time to ignition at various irradiances was shorter for polyolefin fabric over PU foam of two densities than for similar cotton covered specimens. A wool/neoprene combination had relatively long ignition times in this study. FR treament of wool, cotton, and polyester increased the small flame ignition resistance of cover fabrics. These differences were less apparent when the ignition sources were relatively large (tables 9 and 10).

\subsubsection{Fire Growth}

Here fire growth means post-ignition behavior, in terms of heat release and flame spread rate. The relative ranking of fabrics by fire growth is, not surprisingly, similar to that with respect to flame ignition.

The quantitative effects of fabric material on the heat release rate are shown in table 23. The largest data set (group 3) comes from the mockup test series [83]. The rank ordering, best to worst, with FR PU filling, is heavy cotton, no fabric, light cotton, heavy olefin, light olefin. This is almost exactly the inverse of the ordering by cigarette ignitability, with the exception of thermoplastic fabrics, where heavier weight is preferable in both cases.

Typical heat release curves are shown in figure 23 (furniture calorimeter) and figure 26 (cone calorimeter). In both cases, the maximum heat release rate was lower and occurred at a longer time after ignition when FR PU and cotton batting were covered with a cotton than with a polyolefin fabric [102].

The effect of normally used fabric (ticking) is much less important for the rate of heat release behavior of mattresses than it is for upholstered chairs. To understand this, one must consider the use environment. Chairs are normally used without further covering over the upholstery fabric. Conversely, a mattress is covered with sheets, pillows, and blankets; therefore, the bedding behavior tends to dominate flame spread behavior. Rapid exposing of the padding by a thermoplastic ticking is also less important in the case of the mattress (tables 15 and 16) $[36,153,168,169,183]$.

Section 4.2.2 on empirical flame spread studies described an early flame spread test series in which little difference between cellulosic fabrics was found, but acetate fabric burned more rapidly [149]. In two studies, time to full involvement of chairs varied by only about 5 minutes for a large variety of fabrics. Exceptions were PVC and PU coated FR cotton and FR wool/viscose fabrics [91,148]. In a later study, flame spread measurements over chair mockups were estimated visually and determined by trip cords [83]. Figure 19 shows the results of the flame spread estimates on the horizontal cushion of chair mockups. This and other flame spread estimates (the time at which the other cushions got fully involved, the times at which the trip threads were burned through, and the time at which the rate of heat release reached $100 \mathrm{~kW}$ ) ranked the materials as follows, from best to worst:

- Heavy cotton fabric covered assemblies

- FR PU without fabric; also light cotton fabric or heavy polyolefin fabric or light polyolefin fabric

- PU without fabric

This ranking is essentially the same as in the bench-scale test discussed earlier (sec. 4.4.2, table 14 [124]).

FR treatment of wool and cotton reduced flame growth, though it increased smoke development $[89,148]$. Use of wool comforters and wool ticking greatly improved the small flame ignition resistance of mattresses [246].

\subsubsection{Effect of Padding Material}

\subsubsection{Cigarette Ignition}

The effects of padding material on cigarette ignition resistance is illustrated in table $21 \mathrm{~A}$. Smolder resistant neoprene and the CMHR PU foams rank high. Polyester batting absorbs heat during melting. Earlier FR treatment for PU did little or nothing to improve smolder resistance but in the last few years, mainly in response to the California requirements [20], FR treatments which improve both smolder and flame resistance of PU have been marketed. The efficacy of the SR (boric acid treatment) mixed or cotton batting depends on the boric acid concentration; some of this can be lost in handling the batting since the material does not stick well to the fibers. Untreated cellulosic batting smolders badly $[9,11,14-18,28,86,223-229,240]$. Choice of fabric/padding combinations with very low probability of cigarette ignition has been discussed above, as have the relative small effects of foam breathability and position in the bun and effect of contamination of cotton batting, which 
increases smoldering tendency (sec. 3.3). Sheets and blankets can increase the probability of mattress ignition when they are placed on top of a cigarette, but generally do not ignite from cigarettes [36].

\subsubsection{Flame Ignition}

In general, resistance to small Mames of upholstered items depends more on the fabric than the padding. However, self-extinguishment after small flame ignition of fabrics is more likely with the padding materials at the top of table 21B than with those lower down. Several studies have been performed in which upholstered items were subjected to a number of ignition sources increasing in size (e.g., table $8[28,31,36,83,86,88,90,92$, $151,175,243,244])$. Latex had the lowest small flame ignition resistance; among PU foams, FR treatment and use of high-resilency, dense foam improved the resistance. Interestingly, the difference between foams appeared to be masked when a highly small flame resistant, FR wool fabric was used [28]. The effect of foam density was not as well defined. The use of larger ignition sources generally masked the effect of FR treatment of PU $[102,183]$; this effect is illustrated in bench-scale by the measurements in table 9 .

Radiative ignition of a variety of fabrics, each with mineral fiber batt, wool and cotton batting, and PU and latex foam padding was discussed in table 11 [117]. As discussed earlier, the fabric had more effect on the results in this than in other ignition tests. No clear superiority of any of these paddings could be established.

\subsubsection{Fire Growth}

The effect of padding material on fire growth is much more important. Table 24 summarizes maximum heat release rate results $[83,102]$. The FR PU foams were formulated to pass the California State test [20], but passing just barely. It is seen that there is no significant difference between those FR foams tested and the untreated ones. However, a major improvement could be seen when cotton batting was substituted, and yet a further improvement with neoprene. It has also been shown $[83,137]$ that there is a similar effect of the improved padding materials in delaying the time to peak. Actual chairs, unlike the chairs and mockups considered here, often incorporate a variety of padding materials in one chair. There are some indications that such a mixed construction type shows peak heat release rate values close to the worst-performing element's behavior [137].

Additional materials have been evaluated in detail in full and bench-scale heat release rate tests. Table 15 shows a comparative series of results for mattresses, many with PVC tickings [183]. The worst heat release rate behavior is seen to be with latex foam padding. Dense PU foams, such as used in M01 $\left(25\right.$ and $\left.64 \mathrm{~kg} / \mathrm{m}^{3}\right)$, behave worse than lightweight ones, such as used in M20 $\left(18 \mathrm{~kg} / \mathrm{m}^{3}\right)$. This, however, is not necessarily a manifestation of a density effect, per se, since chemical foam composition has to be changed to produce foams of substantially different densities. Small amounts of fire retardant, such as in M14, are again seen to have little benefit. It is striking, however, that very low rates of heat release can be achieved by special PU formulations incorporating large amounts of fillers and fire retardants (M15, M22, M25). Some aspects of this combined effectiveness have been studied in detail [65]; full-scale tests also qualitatively verify the bench-scale findings [249]. Table 9 shows comparative bench-scale data for ordinary PU foams and PU foams treated to California State requirements. These verify the full-scale observations that a much more effective treatment is needed to significantly reduce heat release rates, as opposed to simply improving bunsen burner ignitability behavior.

Upholstered items using the highly FR treated PU foams behave similarly to ones using neoprene, with one major exception-the neoprene foam cores support smoldering combustion and will often burn up completely, albeit slowly. A smoldering neoprene article is often impossible to extinguish, except by total submersion under water. The highly FR treated PU specimens, by contrast, do not tend to smolder; lacking a strong external source, the fire tends to go out $[94,124]$.

Numerous natural fiber materials are becoming infrequent in use-these include kapok, horsehair, wool batting, jute, and other similar products. Available data (table 11) [79,119] suggest that, very roughly, these behave similarly to cotton batting. A few measurements have been made showing that when cotton batting treated with boric acid (to reduce cigarette smoldering and small flame ignition) is compared to NFR batting, about a 15 percent increase in heat release rate is seen [124]. For practical purposes, this effect is not significant.

Mixed fiber batting is widely used today; it contains mostly cotton but also various amounts of other fibers, primarily polyester. This has been found to release heat substantially more rapidly than comparable all-cotton batting, but its smoldering tendency is reduced $[9,183]$. All-polyester batting is used frequently in a layer between cover fabric and PU foam in seats and in sides of upholstered furniture. It showed low heat release rates, comparable to those of all-cotton [183]. Smolder rate over polyester batting has been found to be faster than over PU foam [241]; 
There is little general information on padding density effects, partly because many paddings cannot be made in a wide density range; even PU foams normally cannot be varied in density without changing the chemical composition. However, maximum heat release rate generally increases with specimen mass.

The following is an approximate best to worst ranking of padding material contribution to flame spread, based on three studies [83,91,141]: neoprene, rubberized hair, PU, and latex. Among PU foams, the order seems to be: highly retardant treated and filled foams, combustion modified (CMHR) foams, cold cure foams, ordinary FR formulations and ordinary high resiliency foams, ordinary PU.

\subsubsection{Effect of Interliner or Barrier Materials}

\subsubsection{Cigarette Ignition}

The UFAC program [9] requires that all fabrics be tested, and those which are more ignition prone (Class II) must be used with a barrier material between fabric and padding in the seat surface. The most common barrier material is polyester batting. However, many fabrics, especially medium to heavy cellulosics, ignite even with such polyester barriers $[17,18]$. Aluminized barrier materials have been shown to be very effective in increasing cigarette ignition resistance of such fabrics [11]. UFAC also introduced a test for "interior fabrics," which are called interliners in this monograph, i.e., fabrics which are used between cover fabric and padding. The test fails cotton fabrics but passes thermoplastic woven and nonwoven fabrics. Other interliners which increase cigarette ignition resistance are neoprene and CMHR PU sheets.

\subsubsection{Flame Ignition and Fire Growth}

Interliners have been discussed under Transportation Vehicle Seats, section 4.7 above. They are probably not appropriate for use in furniture intended for prisons, hospital alcoholic and psychiatric wards, buses, subway cars and other situations where vandalism or malicious fire setting can be expected. In other applications, however, interliners can offer increased design options for achieving good fire performance. Interliners have been studied as a means of reducing the cigarette ignitability, flaming ignitability, and also the rate of heat release. Systematic engineering data are not available; however, enough studies have now been reported to enable some generalizations to be made $[11,14,60,79,88,90,91,93-95,209]$. For flaming behavior improvement, Kourtides et al. [210] have classified the possible retardant mechanisms.

1. Transpiration cooling. This occurs if the interliner contains substances which gasify rapidly but are nonflammable. Typically $\mathrm{Al}_{2} \mathrm{O}_{3} \cdot 3 \mathrm{H}_{2} \mathrm{O}$, which releases water vapor, can be used as a filler for foams

2. Re-radiation. This effect is noted for materials of low thermal conductivity and good high temperature stability.

3. Thermal insulation. This mechanism is effective if the barrier is thermally stable, of low conductivity and density, and-if cellular-of closed-cell form. Effectiveness increases with thickness.

4. Reflection. Typically, aluminum foil or aluminized fabrics are useful materials for this, but this effect would be much more noticeable if the reflective surface were on the outside than when it is in contact with other surfaces on both sides.

5. Local heat dissipation. A material of high density and thermal conductivity can limit small-scale ignitability by dissipating heat over a wide area. Cigarette ignitability can also be improved. Aluminum is a suitable material for this.

6. Barrier to pyrolysates. A dense, nonporous substance is required for this. Additional benefits can be derived from limiting oxygen access to the pyrolysis region and frnm thermal cracking of the retained pyrolysates.

Commonly proposed interliners can be grouped into several categories.

- Interliners which improve flaming properties if they do not split due to.tension, but which sacrifice cigarette ignitability.

- FR cotton cambric has been tested $[91,148,151]$ for this purpose. The behavior appears to be typical of cellulosic fabrics; increasing interliner weight improves the heat release rate behavior but worsens cigarette ignitability [16]. Its effect on flaming ignitability is presumed to be small.

- Interliners which improve both flaming and cigarette ignition resistance behavior.

- Polychloroprene (neoprene) foam barriers (e.g., Vonar). These are seen to offer an improved behavior in all three aspects (cigarette ignitability, flaming ignitability, heat release rate). Performance is improved with barrier thickness (density is usually constant) [78,210]. A neoprene foam interliner was considered to be completely satisfactory even for the fire environment in aircraft; however, its weight precludes its use in that application [209]. The neoprene foam interliner derives a significant fraction of its effectiveness from the action of the filler, 
$\mathrm{Al}_{2} \mathrm{O}_{3} \cdot 3 \mathrm{H}_{2} \mathrm{O}$, in releasing water as a cooling mechanism. This feature has not been utilized in most other interliner materials.

- Fiberglass cloth [148]. This is porous (after burn-off of any readily combustible film) and not practical in larger thicknesses. Thus, it may offer less protection than a thicker layer of a neoprene-type material. Its mechanical strength under heating can be usefully exploited in multilayer constructions;

- Novoloid felt (e.g., Kynol). This was seen to be effective in some full-scale chair tests [244] where it reduced the peak heat release rate from $600 \mathrm{~kW}$ to $150 \mathrm{~kW}$.

- Aluminized material layers. These are highly effective in cigarette ignition resistance if they are in close contact with the cover fabric, due to their high thermal conductivity. The cigarette heat output becomes less concentrated at a point and more spread out over a larger area, effectively stopping smolder propagation. In flaming fires there is a two-fold effect: (1) localized heat is dissipated, enabling small open flame sources to be better resisted and (2) due to the impervious nature of the aluminum layer, pyrolysate vapors from the padding cannot as readily leave the surface and contribute to the fire [210]. A fully-impervious layer, however, may have impaired comfort due to mechanical and moisture retention properties.

- Specialized fabrics. Kourtides [209,210] found that the best interliner for aircraft use, taking weight factors into account, was a material consisting of 70 percent Kevlar, 25 percent Nomex, and 5 percent Kynol, aluminized on the outer side. This has a weight of $400 \mathrm{~g} / \mathrm{m}^{2}$ and resists splitting under stress, even at high temperatures. Similar aluminized aramid (Nomex/Kevlar) fabrics were found effective in subsequent work [211,212,250]. With an impermeable envelope of this material, it is necessary to provide pressure vents on the backside of the cushion to avoid rupturing $[212,250]$ (sec. 4.7.2).

- Interliners of uncertain benefit.

- Layers of FR-treated PU foams have been tested occasionally as barrier materials [88]. Such a barrier could not be expected to be better than a solid FR foam core, a design with limited benefits, unless a very highly treated FR formulation is considered.

Present interliners can provide added resistance to fabric ignition and spread from a small flaming source primarily by mechanisms $\# 1,5$, and 6 proposed by Kourtides. No interliners are currently known which would give significant improvement in the performance for flaming ignitability from large sources. This is not unexpected since this behavior is largely governed by surface layer behavior. Also, constructions involving, say, a readily flammable fabric over a slow burning padding would gain little benefit from an interliner. After a flaming ignition, a properly chosen interliner can again be highly useful in reducing the rate of pyrolysis product generation and the rate of heat release.

As in the case of smoldering resistance, an interliner which breaks open or which does not have sound bonding at the edges and seams can readily let the padding become involved at an early stage and lose most of its protective value. Tendency to break open can be examined only in full-scale tests. Interliners seem to reduce flame spread, but differences between flame spread behavior of various interliner materials were found to be minor $[91,148]$.

\subsubsection{Effects of Welt Cord}

Aluminum foil twisted into welt cords has been shown to have better cigarette ignition resistance than untreated and FR treated cellulosic welt cords [16]. UFAC has recently upgraded its welt cord standard to eliminate the latter. Some thermoplastic and PVC welt cords also conform to the upgraded welt cord standard. The effects of welt cord on flaming fire behavior are considered negligible.

\subsubsection{Effects of Frame Materials}

Frame material obviously has no effect on the ignitability or the early stages of the fire. It can have a substantial effect on the peak heat release rate, however. Table 25 iliustrates this for a series of chair burns where frame material was varied, with all other construction features kept constant [137]. The analysis is simplified if the heat release rate values are normalized by the specimen mass. On that basis, it is seen that the PU foam frame chair shows a per-unit-mass burning rate about half that of the wood frame unit, while the polypropylene foam frame chair burning rate is about double. Tentatively, the following explanation is offered, although it is understood that this is on the basis of these very limited tests. The wood frames fail when the frame connections give way. These connections are normally not designed to be fire resistive and fail early in the fire. When the frame starts falling apart, large quantities of fresh padding material are rapidly exposed to fire involvement. The PU foam frame is a rigid, charring, monolithic assembly. It does eventually burn through 
and fail, but the process takes longer. The polypropylene frame, by contrast, is a melting thermoplastic unit, melting and collapsing early in the fire. In the particular case of the specimens in table 25, the polypropylene frame was very lightweight, so that while the per-unit-mass burning rate was much greater, the actual burning rate of the chair was very similar to that of the heavier woodframe chair.

Frame material effects clearly need to be further studied. This is made difficult by the fact that bench-scale techniques are not applicable and that actual full-sized or at least fairly realistic specimens, must be tested.

\subsubsection{Effect of Moisture Content}

Moisture content can affect test results in some cases and this must be considered when using test results in engineering design. Most synthetic polymer materials are not hygroscopic. The amount of moisture contained in such a specimen will not exceed the amount present in the air and the effects of the moisture on flame spread or heat release can be ignored. Cellulosic materials-cotton, rayon, wood products, etc.--and also wool can, however, absorb large amounts of moisture.

In one study, bone dry and 65 percent R.H. conditioned mockups were exposed to cigarettes, methenamine pills, and matches [89]. Pill (burning time 90 to $120 \mathrm{~s}$ ) and cigarette (burning time about 20 minutes) ignitions were not affected by the moisture content of the substrates, but matches ignited some dry cellulosic fabric substrates but not the corresponding conditioned ones. This may indicate that longer burning time may make results less sensitive to conditioning, because the substrate may have time to dry out. However, the heat flux of cigarettes was found to be larger under dry than under normal ambient conditions [59].

Most fire tests prescribe conditioning temperatures of around $20-24^{\circ} \mathrm{C}$ and R.H. of $50-65$ percent. This may be very different from actual use conditions. Data are available on the moisture sorption properties of wood [196,251,253]. Some data also are available on the effects of moisture on wood fire performance. Moisture effects on flame spread over cellulosic boards [254] and effects on rate of heat release [255] have been reported. It was found that, for fiber-board, changing specimen conditioning R.H. from 0 to 100 percent changed the moisture content from 1 percent to 25 percent and the flame spread rate was cut roughly in half. This was attributed to the increase in thermal inertia by about 2-1/2 times. A more recent theoretical study [256] considered also the effect of the heat of vaporization of water as a heat loss term in the flame spread equation. For the rate of heat release of solid wood, Chamberlain [255] concludes that each 10 percent rise in R.H. decreases the rate of heat release by about 4 percent. He also tabulates data on the effect in increasing ignition time and time to peak heat release rate.

Land [143] found a substantial effect of moisture on flame spread rates, flame heights, and smoke development for mattresses. The mass loss rate was reduced to half for R.H. $=92$ percent, compared to R.H. $=35$ percent Hägglund [171] conducted tests on chairs at R.H. $=20$ percent and R.H. $=60$ percent. For thermoplastic fabrics and PU foams, no effect was seen. In the case of cellulosic fabrics and padding, however, an effect was observed. The process of fire development took substantially longer at the higher R.H.; the peak mass loss rates were not affected, however. The disagreement between these findings and those of Land may be attributed to the specific R.H. levels used-Land's upper value of 92 percent was much higher than Hägglund's 60 percent This is plausible since cellulose sorption curves are roughly linear in the range of 20-80 percent R.H., but increase steeply past about 80 percent R.H.

\subsubsection{Effects of Furniture Geometry}

For any combination of fabric and padding material, cigarette ignition resistance is better in flat areas than in crevices $[11,16,17,18]$. Several factors may contribute: re-radiation of heat from two rather than one surface in the crevice; a chimney effect of air in the channel below the cigarette [11,14]; and in the case of cellulosic fabrics, increase in the mass of cellulosic fibers due to multiple layers at the seams. Tufted areas also may have lower cigarette ignition resistance than flat areas and are usually tested separątely, as are areas near the welt edge outside the crevices [11].

For flaming fires, there is little information on the effects of furniture geometry. Observations suggest that flame spread over curved and convoluted surfaces can be slower initially but may be appreciably accelerated when larger, radiatively-driven flames come to dominate. Peak heat release rate, per unit mass, was found to increase when simulated furniture geometry was changed from a single cushion to two, three, and four sides of a cube, with ignition in the enclosed space [83]. When cushion thickness was varied, it was found that the peak rate of heat release was not quite proportional to specimen mass, but was somewhat higher, per unit mass, for thinner cushions [83]. 


\subsubsection{Effects of Fuel Load and Specimen Mass}

Very rough estimates of fire hazard potential are sometimes based on fuel load numbers alone. This is an unsatisfactory measure in all but the crudest sense. Figure 29 shows chair and mattress data from $[129,170,183]$. It is seen that any correlation between fuel load and peak rate of heat release is poor, at best. Total fuel content can be used as one measure for estimating a fire's duration; however, the active hazard to occupants is related to how big the fire gets, at what rate it grows, as well as how long it lasts.

If all other factors are accounted for, however, then a direct proportionality of peak rate of heat release to total combustible specimen mass is seen. Table 26 illustrates this for the case of upholstered furniture where fabric, padding, frame type, and style of design were all fixed and only size and total mass were varied [137]. A similar relationship can also be seen in the case of data from mockups [83].

\subsection{Estimates of Flammability Based on Generic Materials Identification Only}

Performance of upholstered items can be very approximately assessed without specific testing, but merely on the basis of generic materials identification. This approach is not appropriate for final design or for acceptance procedures. It can be useful, however, for preliminary design and for hazards surveying of existing buildings where destructive testing is not feasible.

Cigarette ignitability can be assessed on a generic basis with the use of table $21 \mathrm{~A}$ and the discussion in section 5.1. No resistance to match ignition can be assumed unless the upholstery fabric is heavy wool or PVC. For rate of heat release performance of upholstered furniture, a more quantitative estimation technique has been developed $[137,257]$. The experimental study involved full-scale tests on a number of upholstered furniture specimens where various features were systematically and individually varied These variances included fabric material, padding, frame, style, and size. Considerations of the role of each of those variables led to the development of an approximate rule (based on experiments with a limited number of variables and replicates) for estimating the peak full-scale heat release rate, $\dot{\mathrm{q}}_{\mathrm{f}}$, of an upholstered furniture piece:

$$
\dot{\mathrm{q}}_{\mathrm{fs}}=210\left[\begin{array}{c}
\text { fabric } \\
\text { factor }
\end{array}\right]\left[\begin{array}{c}
\text { padding } \\
\text { factor }
\end{array}\right]\left[\begin{array}{c}
\text { mass } \\
\text { factor }
\end{array}\right]\left[\begin{array}{c}
\text { frame } \\
\text { factor }
\end{array}\right]\left[\begin{array}{c}
\text { style } \\
\text { factor }
\end{array}\right]
$$

with each term evaluated as follows:

fabric factor $=\left\{\begin{array}{l}1.0 \text { for thermoplastic fabrics (fabrics such as polyolefin and nylon which melt prior to } \\ \text { burning) } \\ 0.4 \text { for cellulosic fabrics (cotton; also rayon, linen, etc.) } \\ 0.25 \text { for PVC/PU type coverings }\end{array}\right.$ padding factor $=\left\{\begin{array}{l}1.0 \text { for PU foam or latex foam } \\ 0.4 \text { for cotton batting } \\ 1.0 \text { for mixed materials } \\ 0.4 \text { for neoprene foam }\end{array}\right.$

mass factor $=$ total combustion mass, $\mathrm{kg}$

frame factor $=\left\{\begin{array}{l}1.66 \text { for noncombustible frames } \\ 0.58 \text { for melting plastic frames } \\ 0.30 \text { for wood frames } \\ 0.18 \text { for charring plastic frames }\end{array}\right.$

style factor $=\left\{\begin{array}{l}1.0 \text { for plain, primarily rectilinear construction } \\ 1.5 \text { for ornate, convoluted shapes } \\ \text { [with intermediate values for intermediate shapes] }\end{array}\right.$

(this rule was given in a slightly different form in [137]).

There are serious limitations on a rule of this kind. Only chairs with a conventional frame construction should be considered, since a data base is lacking for other types. Also, the data base is for chairs which are not highly fire resistive, specifically where not only is most of the combustible mass consumed, but that this takes 
place primarily during the rapid flaming portion and not during subsequent smoldering. Thus, heat release rates would be much overestimated if the rule were applied for heavy items with low fabric and padding flammability. Figure 30 shows the agreement between the above rule and actual heat release values, as listed in table 27 for three test series of chairs. A reasonable agreement is seen.

\subsection{Estimates of Flammability Based on Bench-Scale Testing}

For the majority of design and acceptance testing applications, it is desirable to obtain data from benchscale tests on fabric/padding composites as actually used in the upholstered item. Bench-scale, instead of full-scale, testing is made desirable for both cost and reproducibility reasons. Bench-scale test procedures, however, have to be validated initially against full-scale performance to establish a credible correlation. In the case of cigarette and small-flame ignitability this correlation is automatic, since the phenomena are intrinsically of small scale. Determining the full-scale heat release rate behavior from bench-scale data is not simple. The following describes a start in that direction for both mattresses and for upholstered chairs of conventional construction.

\subsubsection{Mattresses}

Mattresses are the simplest case of upholstered items to be considered, since geometric and frame considerations are not necessary and mattresses are all of similar shape, use, and orientation. A predictive correlation was achieved for mattresses in 1980 [183]. These results were initially presented in terms of four performance groups. A more quantitative analysis is possible by using estimated full-scale $\dot{\mathrm{q}}$ values, as given in table 15 . Bench-scale results (in the NBS-II calorimeter) are also indicated in table 15. The comparison is plotted in figure 31. The relationship is not linear but is adequately predictive. Bench-scale rate of heat release values below about $75 \mathrm{~kW} / \mathrm{m}^{2}$ imply full-scale fires with very small heat/release rates, less than $100 \mathrm{~kW}$. The test data on which figure 31 is based were from mattresses of approximately "twin" size. The effects from varying specimen size cannot, therefore, be predicted. Furthermore, it is interesting to note that for this data base, the predictability is not improved if a specimen mass factor is added. Clearly additional experimental work would be desirable.

\subsubsection{Upholstered Chairs}

For upholstered chairs, more extensive data are available for determining a correlation between full and bench-scale results [83,257]. These data are shown in tables 17 and 27. The correlation model uses the same mass, frame, and style factors as discussed above (sec. 5.2). For determining the effect of the padding and the fabric, however, instead of generic factors, a bench-scale measurement, $\dot{\mathrm{q}}_{\mathrm{b} s}^{\prime \prime}$, of the actual fabric/padding composite is used. The data shown have been taken in the cone calorimeter at $25 \mathrm{~kW} / \mathrm{m}^{2}$ irradiance and averaged over $180 \mathrm{~s}$ after ignition [257]. The proper irradiance and averaging period values to be used were determined by data correlation, which has been described in detail [257]. The model used is then

$$
\dot{\mathrm{q}}_{\mathrm{fs}}=0.63\left[\dot{\mathrm{q}}_{\mathrm{bs}}^{\prime \prime}\right]\left[\begin{array}{c}
\text { mass } \\
\text { factor }
\end{array}\right]\left[\begin{array}{c}
\text { frame } \\
\text { factor }
\end{array}\right]\left[\begin{array}{c}
\text { style } \\
\text { factor }
\end{array}\right]
$$

where the mass, frame, and style factors are as before. The factor 0.63 is the factor needed to provide the optimum correlation. Figure 32 shows the agreement between predicted and actual values.

Since bench-scale rate of heat release rate values are determined on a per-area basis, it might seem appropriate to base the correlation model on a full-scale area factor, instead of a mass factor. While this is fundamentally more sound, in most cases it is impractical, since the actual exposed area of the full-scale item cannot be readily determined. It is, however, possible in the case of the rectilinear mockups [83]. A comparison was made which showed that, for that data set, the coefficient of variation for the area basis is 0.048 , compared to 0.071 for the mass basis method. Thus, while the area basis method would, for idealized rectilinear items, offer improved predictability, the mass basis method is, nonetheless, adequate.

It is evident that the rule based on measured $\dot{q}_{b s}^{n}$ values is a more sensitive measure than the one based simply on generic fabric and padding factors. Specifically, it is not limited to materials of chemical compositions already tested in full scale. Neither of the upholstered chair estimating rules is useful for evaluating very low rate of heat release constructions, such as, for instance, certain cotton fabrics over neoprene foam [83]. Since rapid, complete combustion does not occur with such an assembly, the mass factor will greatly over-estimate the output for heavy items. An appropriate guideline is that eq (10) is applicable if $\dot{\mathrm{q}}_{\mathrm{bs}}^{\prime \prime} \geqslant 75 \mathrm{~kW} / \mathrm{m}^{2}$. Also, they 
are not applicable to constructions deviating substantially from the data base of items with a more or less conventional frame.

It can be. observed that, while the relationships for estimating upholstered chair heat release rates are directly proportional to specimen mass, such is not the case for mattresses (fig. 31). This may be explainable in terms of the differences in flame spread processes that occur over the differing geometries; it can be shown, however, that adding a mass factor to the mattress correlation would decrease rather than improve the predictability.

Flame spread is not directly accounted for in the prediction relationships above. While bench-scale measurement of flame spread and heat release rate are correlated, the correlation is not complete [83,257]. Thus, it might reasonably be expected that a separate flame spread factor would have to be included in the prediction model. This is presumably true, but the means for doing that and the increase in the predictability to be thereby gained have not yet been investigated.

The test conditions for the NBS bench-scale $\dot{q}_{b s}^{\prime \prime}$ measurements for both mattresses and upholstered chairs involved a $25 \mathrm{~kW} / \mathrm{m}^{2}$ test irradiance and a $180 \mathrm{~s}$ averaging period to determine the $\dot{\mathrm{q}}_{\mathrm{bs}}^{\prime \prime}$. This was independently determined for mattresses [183] and for upholstered chair mockups [257]. In both cases, numerous irradiances and averaging periods were explored. The above conditions were selected because they yielded the best correlations with full-scale tests. The fact that they were identical may be fortuitous or may indicate a certain commonality of behavior for furniture item rate of heat release.

\subsubsection{Transportation Vehicle Seating}

For transportation vehicle seating, similar full-scale/bench-scale correlations can be sought; there are some differences, however. The irradiance level of $25 \mathrm{~kW} / \mathrm{m}^{2}$ established for bench-scale testing of primarily residential type furniture is not necessarily appropriate for institutional uses or transportation vehicle applications. Many materials intended for use in these applications only flash-ignite at $25 \mathrm{~kW} / \mathrm{m}^{2}$ [258] and release a negligible amount of heat. In one typical aircraft cabin fire scenario (an external fuel pool), irradiance values of 17 to $140 \mathrm{~kW} / \mathrm{m}^{2}$ may be expected [259]. Much of aircraft materials bench-scale heat release rate testing has been done at 25,35 , and $50 \mathrm{~kW} / \mathrm{m}^{2}$ irradiance levels.

Materials for BART subway car seats have recently been tested in full-scale and in bench-scale. Williamson and Fisher [187] ran tests on full-sized seat assemblies. PU foam cushioning and vinyl/nylon upholstery ignited from a trash bag source and totally burned out. Improved material seats consisting of neoprene foam padding and 90 percent wool/10 percent nylon fabric were ignited with trash bag, gas burner, and flammable liquid sources. In none of these cases did the fire propagate beyond the immediate vicinity of the source. Spieth and Trabold [260] conducted bench-scale tests on the same assemblies. At an irradiance of $35 \mathrm{~kW} / \mathrm{m}^{2}$, they obtained the following values:

$\begin{array}{lcc}\text { polyurethane, vinyl/nylon fabric } & \begin{array}{c}\text { Peak } \dot{\mathrm{q}}^{\prime \prime} \\ \left(\mathrm{kW} / \mathrm{m}^{2}\right)\end{array} & \begin{array}{c}180 \mathrm{~s} \text { average } \dot{\mathrm{q}}^{\prime \prime} \\ \left(\mathrm{kW} / \mathrm{m}^{2}\right)\end{array} \\ & 99 & 69 \\ \text { neoprene, wool/nylon fabric } & 57 & 19\end{array}$

Thus, the bench-scale test could adequately be used to distinguish levels of performance. Full-scale $\dot{q}$ values were not measured, however, so a direct numerical correlation cannot be made.

The rate of heat release and the rate of mass loss are related by the heat of combustion. For evaluation of interliners, the heat of combustion of the foam padding is determined by its own composition, while the effect of the interliner is to reduce the pyrolysis mass rate. The effect of the interliner on the heat of combustion of the pyrolysates would be expected to be minor. In consequence, Kourtides [210] suggested that interliner efficacy can be evaluated essentially by measuring the effective heat of gasification of the assembly in a bench-scale apparatus. The effective heat of gasification, $h_{g}$, can be defined as the applied heat required to gasify a unit mass of specimen

$$
\mathrm{h}_{\mathrm{g}}=\frac{\dot{\mathrm{q}}_{\mathrm{i}}^{\prime \prime}}{\dot{\mathrm{m}}_{\mathrm{p}}^{\prime \prime}}
$$

and has the units of $(\mathrm{kJ} / \mathrm{kg})$. Higher heats of gasification mean the material is more difficult to pyrolyze.

Table 28 shows the heat of gasification measurements for a number of aircraft seat assemblies measured in a modified NBS smoke chamber [261]. Kourtides recommends that assemblies showing $\mathrm{h}_{\mathrm{g}}>50 \times 10^{3} \mathrm{~kJ} / \mathrm{kg}$ at $25 \mathrm{~kW} / \mathrm{m}^{2}$ irradiance be considered satisfactory for aircraft use, based on rough correlation to full-scale 
performance. For a simple material, such as a liquid, and assuming negligible re-radiation, the heat of gasification would be independent of the value of irradiance. The materials listed in table 27 instead show values which drop substantially at $50 \mathrm{~kW} / \mathrm{m}^{2}$ and then remain roughly constant at $75 \mathrm{~kW} / \mathrm{m}^{2}$. A quantitative gasification model is not available to explain these details.

A more conventional study was conducted on the same series of aircraft materials by Brown and Johnson [218]. They correlated full-scale seat fire results to rate of heat release measurements taken in the OSU apparatus [156]. The full-scale measurements did not include heat release rates; analysis was based on absolute and fractional mass loss measurements for the total burning time. Table 29 shows the results. The three sets of bench-scale results were all obtained in the OSU apparatus, but with minor specimen size and operational variations. Brown concludes that the FAA bench-scale results at a $50 \mathrm{~kW} / \mathrm{m}^{2}$ irradiance are well-correlated to the full-scale data. The lack of agreement with the other laboratories was not elucidated.

The above findings suggest that an irradiance of 35 to $50 \mathrm{~kW} / \mathrm{m}^{2}$ should be considered for transportation vehicle applications based on limited available data. For all applications, existing data thus far suggest that an averaging interval of approximately $180 \mathrm{~s}$ is appropriate. Detailed quantitative data for the performance of transportation vehicle seating are as yet not extensive, so future applications will probably require additional full-scale validations, not just solely bench-scale tests. Proper heat release rate measurements for transportation vehicles in full-scale, especially, are almost nonexistent. Since appropriate techniques for making such measurements are now available, this situation should improve.

\subsection{Heats of Combustion and Combustible Mass Fraction}

Heats of combustion for pure materials are readily determinable by oxygen bomb calorimetry. These measurements have been tabulated for a large number of materials [262]; they are not, however, applicable to upholstered furniture problems. For furniture specimens, the effective heat of combustion can be determined as the (time-dependent) ratio of the heat release rate to the mass loss rate. Not only are upholstered furniture items intrinsically composite, also, some materials (such as cellulosics) do not show a constant apparent heat of combustion over the duration of the combustion process. Thus, effective heats of combustion are rarely constant. Chair F21 [137], for instance, which was constructed of a wood frame, PU foam padding and polyolefin fabric, shows distinct regimes (fig. 33). During peak burning the $\Delta \mathrm{h}_{\mathrm{c}}$ rises from 15 to $30 \mathrm{MJ} / \mathrm{kg}$. After flaming subsides and the frame and residues burn slowly, a $\Delta \mathrm{h}_{\mathrm{c}}$ of around $10 \mathrm{MJ} / \mathrm{kg}$ is seen. The jagged nature of the curve is due to noise in the weighing system.

Table 30 gives heats of combustion of individual materials, measured in a bomb calorimeter, while table 31 shows a compilation of measurements from a number of test series of actual furniture items $[124,137,173,183]$. The trends conform roughly to expectations based on heats of combustion for individual component materials. The widest range of variations can be attributed to PU foams of varying degrees of fire retardancy. This can be seen to a much lesser extent in the table 30 measurements on PU foams. Presumably the low values for some FR, but not hydrophilic, PU foam formulations in table 31 are due to incomplete combustion.

In the relationships of sections 5.2 and 5.3, above, values are needed for the specimen combustible mass. For conventional upholstered chairs as used in residences, the bulk of the mass may be made up of the frame, which in the typical case will be wood. For this type of chair, typically about 55 percent of the mass may be comprised of the frame and an additional 6-7 percent of metal parts, primarily springs [79]. For a highly modern design frameless chair, both of these may be small or absent. Conversely, for waiting room furniture, the frame may be all-metal and the combustible content very small.

For purposes of engineering calculations, the following rule may be reasonably adopted. For conventional easy chairs and such, with wood or plastic frames, ignore the small difference between total mass and combustible mass. For chairs with a metal frame, the combustible mass and the total mass must be distinguished-rules for estimating heat release properties must be based on the combustible mass alone.

With conventional, nonfire retarded materials (i.e., not neoprene or other similar padding) and with suitable ignition which results in flame involvement of the whole item, almost all organic content is eventually burned out. A $30-\mathrm{kg}$ easy chair after several hours of burning typically loses all but the weight of the springs and 0.5 or $1 \mathrm{~kg}$ of its original mass.

Mattress noncombustible content consists of innersprings, if any. These generally comprise 40-60 percent of the total mass [183] and so have to be accounted for. 


\subsection{Smoke and Toxic Gases}

Human incapacitation or fatalities due to direct thermal effects in fires are often overwhelmed by smoke and toxic effects. Thus, a logical way of characterizing fire hazard would be according to the time for incapacitation. This approach is natural for analyzing standardized room fires, given suitable measurements of toxic gases and a pertinent set of tenability criteria. Such an approach was taken for mattresses [80,153], where tenability criteria for $\mathrm{CO}, \mathrm{CO}_{2}, \mathrm{O}_{2}$ depletion, heat flux, and smoke were established and applied. This approach remains appealing for cases where a fixed compartment scenario is to be involved. Transporation vehicles are a natural example; recent evaluations of aircraft cabin performance have been assessed in terms of available escape time. In the evaluation of movable furnishings, however, there is no unique possible compartment configuration. However, a recently developed California test for high-risk, high-density occupancy furniture prescribes pass-fail criteria for smoke and CO concentration (sec. 4.1.1) [96].

The most tractable model for toxic gas evolution postulates that a fixed fraction of the specimen mass is realized as any given gas species (or smoke particulates). Thus, the mass rate of production of species is

$$
\dot{\mathrm{m}}_{\mathrm{x}}(\mathrm{t})=\dot{\mathrm{m}}(\mathrm{t}) \Gamma_{\mathrm{x}} .
$$

Here the production of any quantity ( $x=$ soot, $\mathrm{CO}$, etc.) is expressed as the fraction, $\Gamma_{\mathrm{x}}$, of specimen mass loss that becomes the species $x$, multiplied by the specimen pyrolysis rate $\dot{m}(t)$. The concentration at any point in a room can then be solved for, if air flow rates are known and suitable assumptions on mixing (or stratification) are made [263]. The assumption that the fraction of specimen mass becoming a given gas species is constant, is according to Tewarson [264], reasonable where fires are not ventilation limited. When fires do become oxygen limited, the most noticeable effect is a rise in $\mathrm{CO}$ production, increasing with oxygen depletion; this has already been quantified for some simple materials [265], although not yet for upholstered furniture.

The effect of smoke obscuration on lethality is not direct; nonetheless it is real in that escape can be hindered or precluded where visibility does not exist. The conversion of specimen mass into soot mass, just as for toxic gas species, is presumably dependent on ventilation and other effects. An examination of the limited available data, however, suggests that the assumption of a constant soot mass ratio is not a bad one [266]. Bench-scale measurements of smoke have typically been made in the NBS smoke chamber [261], where an optical beam attenuation is measured in a sealed chamber. To enable a determination of the proper per-unitmass quantities, the chamber must be fitted with a mass loss measuring transducer [267]. The specific extinction area $\sigma_{\mathrm{m}}\left(\mathrm{m}^{2} / \mathrm{kg}\right.$ pyrolyzed) can then be determined. Using that, a value for the soot particulate mass fraction, $\Gamma_{\mathrm{s}}$, can be derived. The relationships are [266,267]:

$$
\begin{aligned}
\mathrm{k} & =\frac{1}{\mathrm{~L}} \ln (100 / \mathrm{T}) \quad\left(\mathrm{m}^{-1}\right) \\
\sigma_{\mathrm{m}} & =\mathrm{V}_{\mathrm{ch}} \frac{\mathrm{dk} / \mathrm{dt}}{\dot{\mathrm{m}}} \quad\left(\mathrm{m}^{2} / \mathrm{kg}\right) \\
\Gamma_{\mathrm{s}} & =\frac{1}{7600} \sigma_{\mathrm{m}}
\end{aligned}
$$

Here the specific extinction area, $\sigma_{\mathrm{m}}$, is expressed as a function of the chamber volume, $\mathrm{V}_{\mathrm{ch}}$, the specimen mass loss rate, $\dot{m}$, and the indicated extinction coefficient, $\mathrm{k}$, which in turn depends on the optical path length, $\mathrm{L}$, and the percent transmission, T. Similar measurements can be made in the dynamic, flow-through environment of the furniture calorimeter or the cone calorimeter. In that case,

$$
\sigma_{\mathrm{m}}=\frac{\dot{\mathrm{V}} \mathrm{k}}{\dot{\mathrm{m}}}
$$

where $V$ is the exhaust flow rate $\left(\mathrm{m}^{3} / \mathrm{s}\right)$ and other terms are as before. The relationships for $\mathrm{k}$ and $\Gamma_{\mathrm{s}}$ are also as before.

For upholstered furniture the amount of smoke data available is rather small. One of the few test series where bench-scale smoke data were validated against full-scale measurements was for a series of mattresses, table $32[183,267]$. Because of significant mass differences, these values tend to be determined largely by the core and not by the ticking. Latex foam is seen to constitute the worst case, with 20 percent of the specimen 
mass becoming smoke particulates. PU foams typically yield 10-15 percent smoke, although some specimens yield values as low as $2-5$ percent. Cotton batting mattresses illustrate, that with a low smoke producing core, the composition of the ticking can be important. M03, at 5 percent, had a PVC ticking, while M07, at 0.5 percent, had a cotton fabric ticking. Neoprene smoke production depends on the foam formulation, while polyester and mixed fibers battings show low values, similar to cotton battings.

Additional smoke data have been measured for upholstered furniture and mattress cover fabric/padding assemblies under a variety of conditions, both in bench-scale and full-scale experiments [83,89-91,131,148,151,173,183, 244,245]. Typical upholstered furniture data are shown in table 33. In general, smoke production was affected more by the padding materials than by the cover fabric, unlike ignitability and flame spread. Wool tended to release relatively little smoke at a low rate. Next in order were cellulosic fabrics, thermoplastic fabrics, and, worst, PVC cover fabrics. Similarly, the order from best to worst padding was wool, cotton and other vegetable fibers, and PU foams. FR interliners reduced and delayed smoke release.

Modacrylic fabrics produced high values, while aramide fabrics produced low smoke release results [91]. Acrylic/cellulosic blends seemed to be worse than all-cellulosic fabrics [91]. Among interliners, there seemed to be little difference between aluminized, glass, and FR cotton fabrics [91,244].

FR PU foam generally released more smoke than NFR PU, but at a somewhat lower rate $[83,173,244]$. High resiliency PU released smoke at a yet lower rate. Woolley et al. reported smoke release from mockups consisting of four normal size cushions in room fires [148]. Wool/PU foam and FR cotton/PU foam assemblies showed similar low smoke production values, thermoplastic fabrics increased the smoke production by 50 percent to 200 percent, while a PVC covering increased the rate by about six-fold. Substituting latex foam for PU foam increased the rate by roughly an order of magnitude.

The major toxic products expected to be found in upholstered item fires are $\mathrm{CO}, \mathrm{CO}_{2}, \mathrm{HCN}, \mathrm{HCl}$, and $\mathrm{NO}_{x}$; depletion of oxygen also has a toxic effect. Perhaps more than in other fields, there is no agreement on relevant test conditions and evaluation of results. A recent review of test methods is given in [268]. It is quite widely accepted that significant differences in toxic effects are expressed by differences in order of magnitude in $\mathrm{LC}_{50}$. On that basis, the differences between most upholstery materials are not significant. However, materials may show a better toxic effect behavior by showing a slower burning rate, not just lower per-massburned toxicity. Based on such a fuller understanding of toxic effects, differences in furniture materials can be seen, even though the $\mathrm{LC}_{50}$ 's do not differ by an order of magnitude. It is beyond the scope of this monograph to deal with differences in toxic effect of upholstery items in detail; typical, recent publications in this area are [268-277].

In aircraft seating applications additional extensive testing for smoke and toxicity have been reported, although predictive correlations are as yet wanting. Brown [278] tested a number of aircraft foams and fabrics in a modified NBS smoke chamber, but individually, not as composites. The modifications included a highirradiance heater, up $114 \mathrm{~kW} / \mathrm{m}^{2}$, and a load cell for mass loss measurements. The data were not reduced into the form of a mass-weighted measure, such as $\sigma_{\mathrm{m}}$. Smoke measurements were made on composites a few years later, using the smoke device in the OSU apparatus [218].

For overall performance evaluation, the FAA along with their contractors, have promoted the concept of a "combined hazards index" (CHI) [199]. This is a reasonable concept for determining the actual fire tenability time as the time when the combined toxic hazards would produce incapacitation. It was proposed as a way of determining the overall hazard as early as 1969 by Sumi and Williams-Leir [269]. Data for justifying a model of toxins being additive are scarce and so a partial summation rule was adopted by FAA; only very recently has some experimental verification of additivity been obtained [277,278]. For extrapolating benchscale toxicity and smoke measurements, it was assumed that the release rates, per unit area, will be the same in full-scale as in bench-scale (that is, flame spread, burnout, and irradiance nonuniformity are ignored). Smoke and toxic gas measurements were made in a modified OSU apparatus. Evaluation of the aircraft cabin atmosphere entailed the use of a numerical compartment model of multiple zones. Thermal incapacitation was included as one of the toxic terms. For this problem formulation, involving a large number of toxic gas species and toxic-action submodels, a total of four full-scale mockup tests comprised the entire validation effort [280]. The initial test series included only wall, not seating materials. Additional tests were then performed in a full-scale aircraft cabin by the FAA to examine seating material variables. Four comparisons for padding were made, in each case with a wool/nylon fabric: (1) FR PU foam; (2) the aluminized high-temperature fabric interliner (Norfab) recommended for aircraft seats by Kourtides [210], over FR PU foam (note that in addition to lower weight, Kourtides found a better fire performance for this barrier installed over NFR PU, as opposed to FR PU, for reasons of detailed pyrolysis chemistry not fully understood); (3) Vonar interliner over FR PU foam; and (4) noncombustible refractory batting. The incapacitation time, as measured in a given cabin location by gas analysis in the full-scale tests and analyzed according to the CHI rule was $166 \mathrm{~s}$ for case (1), increasing in $209 \mathrm{~s}$ for the Norfab interliner, somewhat improved yet for the heavier, Vonar interliner at $226 \mathrm{~s}$, and 
reaching a limit of $233 \mathrm{~s}$ for the noncombustible padding case (4) $[199,247]$. Smoke visibility was evaluated separately, and it appeared that in all three cases, visibility limits would be exceeded before the CHI toxicity limits were reached.

\subsection{Detection and Extinguishment}

In the Indiana Dunes tests [81,82], a wide variety of upholstered items were tested, under varying conditions of ventilation and placement of the items in rooms. Smoke detectors were placed at various locations of the residential buildings involved. In general, these detectors activated before the fires went from smoldering to flaming. Furthermore, in many cases of flaming furniture ignitions, smoke detectors are activated by the ignition source itself, prior to the upholstered item ignition. Thus, time to smoke detector actuation cannot be considered to be a property of the upholstered item. Heat detectors operate much more slowly in comparison to smoke detectors. Thus, in principle, it might be possible to consider heat detector actuation as a property. The data quoted in section 4.3.1 suggest, however, that these times would be highly similar even for dissimilar construction types.

Extinguishment of furniture items presents a problem. All too frequently, a small smoldering fire is detected and "extinguished" with water by the persons in the house. After the inhabitants retire, the smolder continues, and often leads to casualties. We have heard of cotton mattresses which still smoldered after 24 hour immersion in water. We ourselves have "extinguished" a small smolder cavity in PU foam by both flooding and removal of char, but returned about 30 minutes later only to find that smoldering had burrowed about a 100 $\mathrm{mm}$ tunnel into the foam. When this tunnel reaches a cushion edge, it may well go into flaming. Taking a smoldering item apart, and putting small pieces into a water bucket and placing a lid on the latter seems to be the only safe way to dispose of smoldering furniture items. Some fire departments use detergents to disperse water throughout upholstered items.

Ames and Thorne of the British Fire Research Station [281] performed a number of furniture item tests in which they related sprinkler actuation time to heat output and sprinkler locations. Sprinklers considered appropriate for "ordinary hazard" in Britain discharged when the fire size reached from 220 to $700 \mathrm{~kW}$ with the sprinkler directly above the furniture item in a $2.5 \mathrm{~m}$ high, $300 \mathrm{~m}^{3} \mathrm{room}$. With the sprinkler mounted 2.5 $\mathrm{m}$ from the fire axis, the sprinkler often did not operate in these fires, if total fire size was below about $650 \mathrm{~kW}$ (with one exception where it did not operate in a $720 \mathrm{~kW}$ fire). The sprinkler put out fires in the horizontal part of the furniture in about 10 seconds. Vertical fires were controlled soon thereafter except when the seat was sheltered from the sprinkler. In such cases, the fire burned until all dry fuel was consumed. Smoke increased during such controlled fires.

A Swedish study of room fires of bedding varying in pillow, bed clothing, and mattress materials included attempts to extinguish the fire with a hand fire extinguisher [174]. The latest time, after the start of fire, at which such attempts would be effective were estimated, and for three materials combinations, ranged from 5 to 25 minutes.

\subsection{Behavior in Room Fires}

Up to this point the burning behavior of upholstered items alone has been considered-it was assumed that the presence of a room surrounding the item was ignorable and that there were no other combustibles which could interact in the burning process. In actual applications these additional factors do have to be considered. Thus some of the most important room fire effects will be considered here.

\subsubsection{Some Relationships from Room Fire Theory}

It is not within the scope of this monograph to review the theory of room fires. Nonetheless, a few general findings must be summarized in order to make the ensuing presentation comprehensible. In the context of this discussion, a room fire is understood to take place in a single compartment, with no forced ventilation and with a single window or doorway providing natural ventilation. The maximum air flow through the opening, of height $h_{v}$ and area $A_{v}$, is [262]

$$
\dot{\mathrm{m}}_{\mathrm{a}} \simeq 0.5 \mathrm{~A}_{\mathrm{v}}{\sqrt{\mathrm{h}_{\mathrm{v}}}}_{\mathrm{v}}
$$


The maximum heat that can be released within the room proper is [165]

$$
\dot{\mathrm{q}}=\left(\frac{\Delta \mathrm{h}_{\mathrm{c}}}{\mathrm{r}_{\mathrm{o}}}\right) \mathrm{Y}_{\mathrm{O}_{2}} \dot{\mathrm{m}}_{\mathrm{a}} .
$$

At maximum air flow rate this yields the stoichiometric limit

$$
\dot{\mathrm{q}}_{\mathrm{st}} \cong 1500 \mathrm{~A}_{\mathrm{v}} \sqrt{\mathrm{h}}_{\mathrm{v}} \text {. }
$$

This simple expression is possible since $\left(\Delta \mathrm{h}_{\mathrm{c}} / \mathrm{r}_{\mathrm{o}}\right)$ is nearly constant for most fuels, $13.1 \times 10^{3} \mathrm{~kJ} / \mathrm{kg} \mathrm{O}_{2}$ [164]. The relation between fuel mass pyrolyzed and available heat release is

$$
\dot{\mathrm{q}}=\Delta \mathrm{h}_{\mathrm{c}} \dot{\mathrm{m}}_{\mathrm{p}}
$$

If fuel is being released at $\dot{\mathrm{m}}_{\mathrm{p}}>\dot{\mathrm{q}}_{\mathrm{st}} / \Delta \mathrm{h}_{\mathrm{c}}$, the excess pyrolysate cannot be burned within the room, but is available for burning outside the room.

Flashover conditions can be predicted on the basis of heat release. Very roughly, about 50 percent of $\dot{\mathrm{q}}_{\mathrm{st}}$ must be supplied by the burning combustibles to cause flashover [282]. In a more precise estimate, wall loss details are taken into account. A review and evaluation of these procedures has been published [283]. Briefly, a suitable expression is that flashover can be expected if the peak $\dot{q}$ value exceeds a value which depends on ventilation and wall area,

$$
\dot{\mathrm{q}} \geqslant 378 \mathrm{~A}_{\mathrm{v}} \sqrt{\mathrm{h}_{\mathrm{v}}}+7.8 \mathrm{~A}_{\mathrm{w}} .
$$

Before flashover and also sometime towards the end of a fire, it must, perforce, be in a fuel-limited regime, i.e., that the fuel pyrolysis rate, relative to $\dot{\mathrm{m}}_{a}$, is not so large as to use up all incoming oxygen. Some time after flashover a vigorously burning fire may enter a ventilation-limited regime, where all the oxygen minus a small unmixed fraction, is used up and excess unburnt pyrolysate is discharged.

\subsubsection{Post-Flashover Burning}

Through the years some tests have been conducted in which a single upholstered furniture item was burned in a room and led to flashover. Extensive bibliographies are included in $[79,153]$. These data lack generality since comparative free-burn rates were not known. The lack of knowledge of post-flashover fire effects is not confined to upholstered furniture alone. For many years suitable models for post-flashover burning existed for only two fuels: pools of liquids or thermoplastics, and cribs of wood or charring plastics [262]. These two simple fuel types show opposite extremes of behavior. The wood crib fire is largely selfcontained and little affected by externally applied radiant heat or room ventilation, unless the ventilation is highly restricted. Beyond about 30 percent fuel rich conditions, fuel release rates diminish in direct proportion to the ventilation provided. Liquid pool fires show opposite behavior-fuel release rate is directly proportional to incident radiant heat. Upholstered items are, however, not closely related to either of these fuel types.

So far, there have been only two studies designed to yield comparisons between free-burn rates and rates in room fires, including post-flashover fires, for upholstered furniture; one for chairs [282], and one for beds [196]. In the latter study the furnishings included, in addition to a bed (mattress, box spring, and bedding), a plywood headboard and night table. The room tests were done in a $2.4 \mathrm{~m} \times 3.7 \mathrm{~m} \times 2.4 \mathrm{~m}$ high room with a 0.76 $\mathrm{m}$ wide by $2.03 \mathrm{~m}$ high doorway. Thus, a minimum expected flashover level (eq 20) would be $1130 \mathrm{~kW}$. The open burning rate was determined with a technique similar to that described in [102] and is shown in figure 34. Two peaks are seen - an initial one corresponding to a rapid burning of the bed linens, at 480-720 kW; and a second one corresponding to mattress involvement, at 1090-1210 kW. The room fire data, also shown in figure 3.1, are somewhat difficult to interpret since the test room was not fully noncombustible, but had a paper lining oü gypsum wallboard. This paper lining, when ignited, burns rapidly and can contribute a relatively high rate of heat release spike. This generally occurs very shortly after ignition. The spikes at 2000-2040 kW are attributed to wallboard paper flaming (the time sequence was sensitive to very minor test differences). Ignoring the peaks due to paper burning, the initial bedding peak is at $440 \mathrm{~kW}$, i.e, not showing any radiative augmeniation. The second peak is at $1430 \mathrm{~kW}$, compared to $1090-1210 \mathrm{~kW}$ in the open burns, suggesting a $15-30$ percent augmentation. Finally, there is a third peak seen in one of the room burns, not seen in the replicate or in the open burns. This is believed to be due to an earlier dying-down in the second peak for that test. Thus, the heat output seen in the third peak is divided in other room burns between increased duration of the second 
peak and increased heat liberated during the final, smoldering period. Such differences indicate the variability to be anticipated in room tests of more complex fuel arrangements. The conclusion is that, for bed fires, an augmentation of 15-30 percent may be expected after flashover.

In the above test series, flashover was noted at a heat release rate of $180-640 \mathrm{~kW}$ in one room fire and at $380-1350 \mathrm{~kW}$ in the replicate. (The wide error bars in these estimates come from assuming a time uncertainty of \pm 10 s.) Ventilation-limiting, which would require $\mathrm{Q} \simeq 1500 \mathrm{~A} \sqrt{\mathrm{h}}=300 \mathrm{~kW}$, was not reached.

The second test series [283] was for an upholstered armchair and a loveseat. These items were tested earlier in the furniture calorimeter [137]. The corresponding room fires were in a room similar to, but slightly different from, the bed tests [196]. The size was $3.94 \mathrm{~m}$ by $2.26 \mathrm{~m}$ by $2.31 \mathrm{~m}$ high. The armchair (F21) was tested with a single ventilation opening, while the loveseat (F31) was tested with three ventilation configurations. In each case the openings were so sized as to produce flashover, but not ventilation-limiting. Peak heat release values ranged from 0.42 to 0.68 of the maximum stoichiometric limit. The results are shown in figures 35 and 36 . To within the scatter of the data (roughly $\pm 15 \%$ ), there does not appear to be a significant burning rate enhancement in the room fires, compared to free-burn furniture calorimeter measurements (the time shift is due to differences in ignition).

While clearly much more work needs to be done in this area, the following hypothesis can be offered that is consistent with the available measurements. During the period after flashover and short of reaching ventilation-limited conditions, the main effect of an enclosure on the burning rate is expected to be radiative augmentation. A burning item already has a fire plume above or around it due to its own combustion. For the external radiation to affect the fuel release rate, it must be transmitted through this flame volume. If the flame layer is thin, this is not difficult, and can be envisioned as occurring on a mattress. A burning chair, on the other hand, tends to partially surround the flame volume, which will tend to make it less sensitive to external radiation levels.

While there are no upholstered furniture studies relevant to the ventilation-limited regime, a few general observations are expected to hold. Radiative augmentation, or lack thereof, should behave similarly as in the fuel-limited regime. However, in the fuel-limited regime, excess oxygen still exists and so oxygen diminution effects are not expected. In the ventilation-limited regime, potentially a major decrease in the fuel release rate could be expected from this effect. It bears emphasis that, while $\dot{q} \cong 1500 \mathrm{~A} \sqrt{\mathrm{h}}$ represents the maximum limit of heat released within a compartment, it does not necessarily place a proportional limit on the amount of fuel which can be pyrolyzed. The excess fuel will, in general, burn outside the window of the compartment. This excess pyrolysate fraction can be very large for pool fires; for wood cribs, it is empirically observed to be limited to $\sim 30$ percent; for upholstered furniture, it is still an open question.

\subsubsection{Multiple Item Burning}

Real fires rarely occur in rooms with only one combustible item. More commonly, there are many combustibles, some contiguous, some separate, and also combustible materials on walls, floors, and ceilings. The latter is outside the scope of this review; the question of multiple furniture items must be considered, however.

A concept useful for analysis is the fuel package. Items which are placed contiguously, or are stacked, are presumed to burn as one discrete item. Thus, they would be tested in say, the furniture calorimeter as a single item. On the other hand, bench-scale techniques to characterize a fuel package have not yet been explored or developed. In treating the room fire, a fuel package would be treated no differently than a single item.

Items which are not contiguous do not constitute a fuel package. They may, nonetheless, show interactions. The simplest interaction is for one item to ignite a second. There then may be no burning rate interaction and the total burning rate may be just the sum of the individual, isolated rates. In that case, the only new requirement is the ability to predict the ignition, and its time of occurrence, for the second item. Interactions may also be more extensive. The radiation levels may be sufficient to significantly increase the pyrolysis rate of one or both objects. Fluid flow aspects also may be effected; eventually the two fires can merge. This problem has been studied for simple fuel arrays [284], in which case flames merge when the clear spacing is less than about 0.2 of the flame height. Since flame heights tend to be about 1-5 times object width for sizeable furniture items, some estimates of flame merging are possible. Empirical studies of the burning of two chairs, separated by $0.1 \mathrm{~m}$, with the first chair acting as a potential ignition source for the second have been conducted [91].

Radiant augmentation of one burning item from another-without flame merging-is, conceptually, a simple process. Its quantification for actual furniture items, however, has not yet been attempted.

Before radiant augmentation or flame merging effects can take place, the second item must ignite. This is experimentally simple, but unrewarding, to determine, since a huge variety of tests would have to be run, e.g., 
the sort of program attempted by RAPRA [91]. (Irradiances and heat flux from burning furnishings items have been investigated in $[112,131]$.) The former reference illustrates a simplified approach, which separates the effects of radiant flux generation and second item ignition. According to this procedure, the radiant fluxes generated by the first burning item are determined in full-scale, as a function of height and lateral distance. The second item is then tested only in bench-scale, in an ignitability test. For upholstered furniture ignition, the minimum irradiance levels shown in figure 7 are indicative. The times to ignition are of less importance since, for upholstered furniture materials, they are generally short compared to the duration of the peak fluxes from the first item. Representing the fluxes from the first item in a simple way is not trivial, however. Figures 37 and 38 show the results from [112] for a wicker couch $(\mathrm{F} 19)$. Note especially that the $1 / \mathrm{r}^{2}$ representation of fluxes is not appropriate except at large r. For upholstered furniture, peak fluxes are seen to occur typically at a height of about $0.5 \mathrm{~m}$. A fair number of measurements have been collected for a height of $0.5 \mathrm{~m}$ and a lateral distance of $0.5 \mathrm{~m}[83,137]$. The latter are shown in figure 39 , where it is shown that there is an approximate dependence of radiant flux on the burning rate of the item. Since there are many geometric and flame spread variables ignored in this type of correlation, one would not expect a precise fit. If the second item is located not $0.5 \mathrm{~m}$ away, then additional relationships are needed. Typical plots are given in figure 40 [112]. These data suggest that about $1.5 \mathrm{~m}$ is a limit beyond which second item involvement will be unlikely prior to flashover. Initial item fires with greater $\dot{m}_{\mathrm{p}}$ or heat release beyond those shown are likely to (a) ignite objects due to long flames which fold over and continue along the ceiling [285], or (b) lead to flashover.

For vertical targets in the far field, i.e., farther than about 1 or $1.5 \mathrm{~m}$, a power law relationship is reasonable. Mizuno and Kawagoe [135] have derived a relationship for $\dot{q}^{\prime \prime}\left(\mathrm{kW} / \mathrm{m}^{2}\right)$ as

$$
\dot{\mathrm{q}}^{\prime \prime}=0.32 \dot{\mathrm{m}} / \mathrm{r}^{1.8}, \text { for } \mathrm{r}>1.3 \mathrm{~m}
$$

This should not be extrapolated to smaller $\mathrm{r}$ distances, since excessive $\dot{\mathrm{q}}^{\prime \prime}$ values would be predicted.

For targets oriented horizontally, less data are available. The findings of Ahonen et al. [131] can be expressed in the form

$$
\dot{\mathrm{q}}=0.46 \dot{\mathrm{m}} / \mathrm{r}^{2}
$$

Interactions between burning items of upholstered furniture and combustible room walls have not been studied for a general case. One study has been reported [184] as part of a fire investigation where detailed measurements were made.

In addition to the above major effects of the room fire back upon the burning object, there are two minor effects to consider. The air inflow velocities in a room will no longer be axially symmetric as in the case of open burning. Airflow direction and magnitude can affect the flame spread rates. The second effect is noted when the burning object is located close to a wall. The wall surface will be heated up and in turn re-radiate to the burning item, with a possible increase in burning rate. If the item is flush against, or nearly flush against, a wall, the flame will attach to the wall and become taller [285]. This effect can decrease the radiation to the item since the flame zone gets extended farther away from the burning surface.

\subsubsection{Direct Application of Heat Release and Smoke and Gas Data .}

Data on rates of heat release and released smoke and gas for upholstered furniture can be used directly to obtain some hazard assessment. So far, the application most intensively explored has been in the prediction of whether or not a room can be driven to flashover by a given furniture item. As considered earlier, a very rough estimate of the minimum $\dot{q}$ required for flashover is

$$
\dot{\mathrm{q}}=750 \mathrm{~A}_{\mathrm{v}} \sqrt{\mathrm{h}_{\mathrm{v}}}(\mathrm{kW}) .
$$

If the room dimensions are known, then a better estimate can be made by using

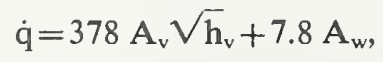

where $A_{w}$ is the area of the walls and ceiling [283]. It is useful to consider an example.

(1) Consider a room $2.5 \mathrm{~m}$ by $3.7 \mathrm{~m}$ by $2.5 \mathrm{~m}$ high. It has a window opening with $\mathrm{h}=0.8 \mathrm{~m}$ and $\mathrm{A}_{\mathrm{v}}=1.25$ $\mathrm{m}^{2}$. Then the minimum heat release rate for flashover is $\dot{\mathrm{q}}=740 \mathrm{~kW}$. From table 17 , one can observe that a traditional easy chair is not likely to flash the room over if either the fabric or the padding, or both, consist of cellulosic or similarly slow burning materials. 
(2) Consider the same room with a door opening $2.0 \mathrm{~m}$ high with an area $\mathrm{A}_{\mathrm{v}}=1.8 \mathrm{~m}^{2}$. Then the minimum $\dot{\mathrm{q}}=1280 \mathrm{~kW}$ is seen. Table 17 suggests some additional designs which may not cause flashover in this higher ventilation condition. The limiting case chair can also be compared from the estimating rule given above. Assume the chair used conventional PU foam padding, polyolefin upholstery, a wood frame, and rectilinear construction. Then, according to the expression given in section 5.2,

$$
1280=210(1.0)(1.0) \mathrm{M}(0.30)(1.0)
$$

giving $\mathbf{M}=20 \mathrm{~kg}$ as the minimum chair mass estimate to cause flashover.

Concentrations of combustion products in the gas outflow stream can also be estimated in an approximate way. The total mass outflow is taken as

$$
\dot{\mathrm{m}}_{\mathrm{f}}=0.5 \mathrm{~A}_{\mathrm{v}} \sqrt{\mathrm{h}_{\mathrm{v}}} \quad(\mathrm{kg} / \mathrm{s}) .
$$

The product generation rate is

$$
\dot{\mathrm{m}}_{\mathrm{x}}(\mathrm{t})=\dot{\mathrm{m}}(\mathrm{t}) \Gamma_{\mathrm{x}},
$$

where $\dot{m}$ without subscript denotes the total specimen mass loss rate, and is identical to $\dot{\mathrm{m}}_{\mathrm{p}}$, used earlier. This gives a product mass concentration, $\mathrm{Y}_{\mathrm{x}}$, as

$$
\mathrm{Y}_{\mathrm{x}}(\mathrm{t})=\frac{\dot{\mathrm{m}}(\mathrm{t}) \Gamma_{\mathrm{x}}}{0.5 \mathrm{~A}_{\mathrm{v}} \bar{V}_{\mathrm{h}}}
$$

The value for $\dot{m}(\mathrm{t})$ can be taken from furniture calorimeter results, or a peak value can be estimated from bench-scale test results as

$$
\dot{\mathrm{m}}=\dot{\mathrm{q}} / \Delta \mathbf{h}_{\mathrm{c}},
$$

where $\Delta \mathrm{h}_{\mathrm{c}}$ is the appropriate effective heat of combustion for the materials in question.

\subsubsection{Applications to Numerical Room Fire Models}

For estimating flashover, only the peak values of heat release were needed. If it is desired to model numerically a complete room fire, then the whole $\dot{q}$ curve as a function of time is needed. For items measured in the furniture calorimeter or other similar apparatus, such a curve is available and can be used directly. Rockett has examined this, using the Harvard Computer Fire Code [286].

Bench-scale measurements have been developed, so far, only to estimate the full-scale peak $\dot{\mathrm{q}}$, and not the whole $\dot{q}$ curve. The difficulties in attempting this are somewhat daunting. An initial approach to this problem might be based on a triangular representation of the $\dot{q}$ curve, as discussed earlier in section 4.3.

\section{CONCLUSIONS}

For characterizing cigarette ignitability there is essentially no theory available. Testing procedures vary greatly in fine details, but are all conceptually similar and yield generally similar results. Most commercial categories of frames and of paddings have been tested and generic performance guidelines are available.

Some regulatory bodies have been adopting or considering requirements for small open-flame ignitability. These can be effective in screening out easily ignited material combinations; they do not differentiate according to hazards from fast-developing flaming fires, however. The most widely referenced of these tests, the British one, is strict enough that it screens out most fabrics, except heavy wools, PVC coated ones and some FR cottons.

Significant advances have been made in recent years in measuring the full-scale behavior of upholstered items undergoing flaming combustion. Test apparatus have been developed which allow a much simpler open-burn testing, compared to room fire tests. The necessity for open-burn full-scale testing may be lessened in some cases by the development of empirical relationships for predicting the full-scale behavior on the basis of bench-scale tests. Numerical design guidelines now permit the prediction of flashover conditions in a room if the upholstered item is the only significant item burning, and if the ventilation-door or window sizing-is 
known. Prediction of more than one item burning in a room is complex, and design methods are not available. Smoke and toxic gas computations can be made, if bench-scale property test results are available. The new predictive capabilities are not yet reflected in regulatory requirements; such requirements for flaming combustion behavior are still few in number and not based on current capabilities.

Bench-scale measurements of heat release rate are essential for the prediction of full-scale heat release rates. Bench-scale measurements of flame spread would, in principle, also be necessary; however, flame spread differences are less important than heat release rate differences and so additional bench-scale testing for flame spread is usually not necessary to achieve a good full-scale predictability.

Some common fabrics and paddings behave well in either smoldering resistance or open flame conditions, but not both. A few commercial materials are available which are good for both. Interliners may, in many cases, be used to successfully achieve a good performance for both smoldering resistance and open flame behavior.

In principle, the behavior of transportation vehicle seating in fire is not different from upholstered furniture. Research in this area, however, has generally not been tied closely to other upholstered furniture work. In consequence, test methods and procedures have been developed which are different. As the unifying principles of both full-scale combustion and bench-scale testing are becoming better understood, more unified methods of testing and analysis become possible. When this process is complete, only different test criteria are likely to need to be applied for transportation vehicle seating testing.

While great progress has been already made in quantifying upholstered furniture fires, certain aspects remain not well explored. A theoretical model of smoldering ignition is not available; neither is a suitable model for small flame ignition. Flame spread has not been investigated yet to the point of yielding a suitable test procedure. Frame material and geometric style effects have been examined only over a small range of variations. Multiple-item burning has yet to be examined beyond prediction of the ignition of the second item. Toxicity testing and toxic hazard evaluation are still relatively new but promising fields.

\section{REFERENCES}

[ 1] Damant, G. H., A Bibliography of Published Information on Furniture Flammability, J. Consumer Product Flammability, Part I, 5, 245-248 (Dec. 1978); Part II, 7, 127-129 (June 1980); Part III (coauthor; Wortman, P. S.), 8, 235-238 (Dec. 1981).

[2] References to Literature on the Fire Hazards of Furniture and Furnishings (Library Bibliography No. 182)] Fire Research Station, Borehamwood (1979). Also supplement (June 1982).

[3] Fires in Furniture (Building Research Establishment Digest No. 285). Fire Research Station, Borehamwood (1984).

[4] Tinsworth, D. K. and Kelly, S., Hazard Analysis, Fires in Mattresses and Bedding, U.S. Consumer Product Safety Commission (July 1984).

[ 5] Tinsworth, D. K., National Estimates of 1982 Fire Losses Associated with Upholstered Furniture, U.S. Consumer Product Safety Commission (Feb. 1984).

[ 6] Eighth Annual Flammable Fabrics Report, U.S. Consumer Product Safety Commission (Dec. 1980).

[ 7] Clarke, F., II, and Ottoson, J., Fire Death Scenario and Firesafety Planning, Fire Journal. 70, 20-22, 117,118 (May 1976).

[ 8] Code of Federal Regulations, Part 1633, Proposed Standards for the Flammability (Cigarette Ignition) of Upholstered Furniture (PFF 6-81), U. S. Consumer Product Safety Commission (1981).

[9] Important Consumer Information from UFAC, Upholstered Furniture Action Council, High Point, NC (1984).

[10] The Business and Institutional Furniture Manufacturer's Association First Generation Voluntary Upholstered Furniture Flammability Standard for Business and Institutional Markets, BIFMA, Grand Rapids (1980).

[11] Loftus, J. J., Back-Up Report for the Proposed Standard for the Flammability (Cigarette Ignition) of Upholstered Furniture, (NBSIR 78-1438). [U.S.] Natl. Bur. Stand. (June 1976).

[12] Proposed Standard Test Method for Assessing the Resistance of Mock-Up Upholstered Furniture to Combustion after Exposure to Smoldering Cigarettes, American Society for Testing and Materials (ASTM) (1982).

[13] Standard Methods of Tests and Classification System for Cigarette Ignition Resistance of Components of Upholstered Furniture (NFPA 260 A), Standard Method of Test for Determining Resistance of Mock-Up Upholstered Furniture Material Assemblies to Ignition by Smoldering Cigarettes (NFPA 260 B), National Fire Protection Association (NFPA) (1982).

[14] Salig, R. J., The Smoldering Behavior of Upholstered Polyurethane Cushionings and Its Relevance to Home Furnishing Fires (Master's Thesis), Mass. Institute of Technology, Cambridge, MA (1981).

[15] Donaldson, D. J., Yeadon, D. A., and Harper, Jr., R. J., Smoldering Characteristics of Cotton Upholstery Fabrics, Textile Research J. 51, 196-202 (Mar. 1981).

[16] Report of 1982 Test Series to Evaluate UFAC Construction Modifications, Guilford Laboratories, Inc., Greensboro, NC (Nov. 1982).

[17] Upholstered Furniture Flammability Briefing Package: Reference 14: Fairall, P., and Madison, R., Analysis of Upholstered Furniture Test Program; Reference 15: Pressler, C., and Oakley, M., Upholstered Furniture Test Methods and Data Summary; Reference 41: Fairall, P., Relationship of Small Scale Testing to Full Scale Furniture Performance, U.S. Consumer Product Safety Commission (June 1981).

[18] Damant, G. H., Williams, S. S. and Krasny, J. F., Cigarette Ignition Behavior of Commercial Upholstery Cover Fabrics, J. Consumer Product Flammability, 9, 31-46 (Mar. 1982). 
[19] Upholstered Furniture Flammability, Briefing Package, U.S. Consumer Product Safety Commission, Washington, DC (Sept. 1984).

[20] Flammability Information Package, State of California, Department of Consumer Affairs, Bureau of Home Furnishings, North Highlands, CA (1983).

[21] Damant, G. H., California Upholstered Furniture Combustibility Standard: 1981 Update, J. Consumer Product Flammability. 8. 209-220 (Dec. 1981).

[22] Fire Tests for Furniture, Part 1., Methods of Test for the Ignitability by Smoker's Materials of Upholstered Composites for Seating (1979), Part 2. Methods of Test for the Ignitability of Upholstered Composites for Seating by Flaming Sources (1982). British Standard BS 5852, British Standards Institution, London.

[23] The Upholstered Furniture (Safety) (Amendment) Regulations, 1983, No. 519, Consumer Protection, Her Majesty's Stationery Office, London (1983).

[24] Upholstered Furniture-Burning Behavior-Ignitability of Upholstered Composites-Methods of Test. Part 1, Smokers Materials. Section 1, Cigarette, Section 2, Small Flame 1, Part 3, Ignition Sources, Butane Flames, Part 4, Larger Ignition Sources (ISO/TC 136/SC1/WG4) Publ. by British Standards Institution, Manchester, England (1982).

[25] Draft Australian Standard Method of Test for the Ignitability of Upholstered Seating (DR 80 123) North Sidney, N.S.W. (1980). Method of test for the ignitability of upholstered seating of the low fire hazard type (DR 80-124) Standards Association of Australia, North Sidney, N.S.W. (1980).

[26] Austrian Standard 5410-A 1606, Part I. Specification for Furniture: Testing Inflammability of Furniture Surfaces. Oesterreichisches Normungungsinstitut, Vienna, Austria.

[27] Irish Standard Specification, Requirement for Smolder and Flame Resistant Upholstery, I.S. 244: 1980, Institute for Industrial Research and Standards, Dublin (1980).

[28] A: Ingham, P. E., Goddard, J. M. and Grueber, A. L., The Influence of Fabric Coverings on the Flammability of Polyurethane Upholstered Furniture, (1979); B: Ingham, P. E., The Flammability of Polyurethane Upholstered Furniture, Part II. Tests with Larger Ignition Sources and "Improved" Foams (1981); C: Ingham, P. E., The Flammability of Polyurethane Upholstered Furniture, Part III. House Fire Tests (1981) Wool Research Organization of New Zealand, Christchurch.

[29] Nordtest Fire 014, NordTest, SF 00340, Helsingfors 34, Finland.

[30] Furniture Upholstered Seating Method of Test for the Ignitability (by a Smoldering Cigarette), Svensk Standard SS 839130, SIS Standardiseringgrupp, Stockholm, Sweden.

[31] DOE/PSA Fire Retardant Specifications, No. 3: Fire Barrier Standards for Upholstery (Seating and Bedding); No. 4 (Composite Upholstery Ignition Standard (Seating and Bedding); No. 5: Flammability of Beds and Bedding; No. 6: Ignition Standard for Seating. Department of the Environment/Public Service Agency, London (Apr. 1978).

[32] Code of Federal Regulations, Part 1632, Standard for the Flammmability of Mattresses (and Mattress Pads), FF 4-72 (1983).

[33] Method of Test for the Combustion Resistance of Mattress; Cigarette Test. Canadian Government Specification Board, Ottawa, Ont. Canada, No. 27.7 (1977).

[34] Behavior of Mattresses in Fire: Cigarette Test. Bulletin Official des Services des Prix, Annexe a la Recommendation No. D1-78 Direction General de la Concurrence et de la Confirmation, Paris (Dec. 1978).

[35] ISO TC 136/TC document.

[36] Pakkala, L., Ignitability of Beds and Bedding, Research Report No. 247, Technical Research Center of Finland, Espoo, Finland (Jan. 1984).

[37] Ramsay, G. C. and Cerra, A. P., A Progress Report on the Assessment of Test Methods for the Ignitabililty of Upholstery Combinations by Small Ignition Sources-Cigarette Ignition. ISO/TC136 document (Apr. 1982).

[38] Harabin, D., Ostrander, E. R., and Stout, E. E., Properties of Textile Upholstery Fabrics and Their Importance to Consumer Satisfaction, (Bulletin 1032). Cornell University Agricultural Experiment Station, Ithaca, NY (May 1973).

[39] Fesman, G., A Study in Smoldering Test Behavior Versus Air Flow Variations in Fabric, pp. 303-307 in Proc. of the 6th International SPI Technical/Marketing Conference (Nov. 1983).

[40] Toner, H. P., Ignition of Foam/Fabric Composites in Residential Upholstered Furniture, J. Consumer Product Flammability. 9, 85-94 (June 1982).

[41] Shaw, A. and Gill, J. T., The Smoldering Behavior of Selected 100 Percent Cotton Fabrics in Combination with Three Different Batting Materials, AATCC International Conference, Chicago, IL (Oct. 1984).

[42] Gill, J. T., Howerton, R. D., and Werner, P. M., Combustion Acceleration as a Measure of Upholstery Fabric Flammability, Textile Chemist and Colorist. 13, 3-33 (Mar. 1981).

[43] Baitinger, W. F. and Konopasek, L., Smoldering Combustion of Cotton Fabric/Urethane Foam Composites, pp. 11-22 in Proc. of the 7th International Conference on Fire Safety, Stanford Research Institute, Menlo Park, CA (1982).

[44] Krasny, J. F., Allen, P. J., Maldonado, A., Juarez, N., Development of a Candidate Test Method for the Measurement of the Propensity of Cigarettes to Cause Snioldering Ignition of Upholstered Furniture and Mattresses, (NBSIR 81-2363). [U.S.] Nat1. Bur. Stand. (1981).

[45] Baker, R. D., Combustion and Thermal Decomposition Regions Inside a Burning Cigarette, Combustion and Flame. 30, 21-32 (1977).

[46] Summerfield, M., Ohlemiller, T. J. and Sandusky, H. W., A Thermophysical Mathematical Model of Steady Draw Smoking and Predictions of Overall Smoking Behavior, Combustion and Flame. 33, 263-279 (1978).

[47] Ohlemiller, T. J., Modeling of Smoldering Combustion Propagation, (NBSIR 84-2895). [U.S.] Natl. Bur. Stand. (1984).

[48] Rogers, F. E. and Ohlemiller, T. J., Cellulosic Insulation Material 1. Overall Degradation Kinetics and Reaction Heats, Combustion Science and Technology, 24, 129-137 (1980); II. Effect of Additives on Some Smolder Characteristics, 139-152; III: Effects of Heat Flow Geometry on Smolder Initiation, 26, 89-105 (1981).

[49] Ohlemiller, T. J. and Lucca, T. A., An Experimental Comparison of Forward and Reverse Smolder Propagation in Permeable Fuel Beds, Combustion and Flame. 54, 131-147 (1983).

[50] Shafizadeh, F. and Bradbury, A. G. W., Smoldering Combustion of Cellulosic Materials, Journal of Thermal Insulation. 2, 153 (Jan. 1979).

[51] Shafizadeh, F., Bradbury, A. G. W., deGroot, W. F. and Aanerud, T. W., Role of Inorganic Additives in the Smoldering Combustion of Cotton Cellulose, Industrial and Engineering Chemistry, Product Research and Development. 21, 97-101 (1982). 
[52] Rogers, F. E., Ohlemiller, T. J., Kurtz, A., and Summerfield, M., Studies of the Smoldering Combustion of Flexible Polyurethane Materials, J. Fire and Flammability. 9, 5-13 (Jan. 1978).

[53] Ohlemiller, T. J. and Rogers, F. E., A Survey of Several Factors Influencing Smoldering Combustion in Flexible and Rigid Polymer Foams, J. Fire and Flammability. 9, 489-509 (Oct. 1978).

[54] Ohlemiller, T. J., Bellan, J., and Rogers, F., A Model of Smoldering Combustion Applied to Flexible Polyurethane Foams, Combustion and Flame. 36, 197-215 (1979).

[55] Ortiz-Molina, M. G., Toong, T. Y., Moussa, N. A., and Tesoro, G. C., Smoldering Combustion of Flexible Polyurethane Foams and Its Transition to Flaming or Extinguishment, pp. 1191-1200 in 17th Symposium (International) on Combustion, The Combustion Institute, Pittsburgh (1978).

[56] Sale, P. D. and Hoffheins, F. M., Cigarettes and Cigars, Fire Hazard Tests, Quarterly of the National Fire Protection Association. 21, 237-246 (Jan. 1928).

[57] Hoffheins, F. M., Fire Hazard Tests with Cigarettes, Quarterly of the National Fire Protection Association. 27, 132-140 (Oct. 1933).

[58] Spears, A. W., A Technical Analysis of the Problems Relating to Upholstered Furniture and Mattress Fires Relative to Proposed Cigarette Legislation Including A Review of Relevant Patents, Testimony, Subcommittee on Health and the Environment, Committee on Energy and Commerce, U. S. House of Representatives (Mar. 21, 1983).

[59] Behnke, W., Cigarette Study; Heat Flux and Ember Temperatures, unpublished document prepared for ASTM Committee D-13 (1969).

[60] Tesoro, G. C., The Fire Safety of Upholstered Furniture: An Evaluation of the State-of-the-Art and Potential Improvements, J. Consumer Product Flammability. 8, 132-143 (June 1981).

[61] Rua, L., Condit, D. A., Nakos, S. T., and Orsi, J., Evaluations of the Fire Performance of Flame Retarded Flexible Polyurethane Foams in an Upholstered Furniture Application, J. Consumer Product Flammability. 7, 99-126 (June 1980).

[62] Eicher, W. J. and Szabat, J. F., Response of Polyurethane Foams to Cigarette Ignition Tests, J. Consumer Product Flammability. 7, 172-188 (Sept. 1980).

[63] Szabat,J. F., Combustibility Aspects of Polyurethane Foams for Mattresses, J. Consumer Product Flammability. 5, 82-95 (June 1978).

[64] Keating, J. Z., Use of Hydrated Alumina as a Flame and Smoke Suppressant Filler for Flexible Urethane Foams, J. Fire Retardant Chemistry, 9, 215-220 (Nov. 1982).

[65] Schuhmann, J. G., Improved Furniture and Mattress Fire Safety Through the Use of Combustion Modifying Polyurethane Foam, pp. 307-315 in Proc. of 6th International SPI Technical/Marketing Conference. Technomic Publ., Lancaster, PA (1983).

[66] Countryman, C. M., Some Physical Characteristics of Cigarettes as Firebrands; Cigarette Temperatures and Burning Rates. Pacific Southwest Forest and Range Experiment Station, U.S. Department of Agriculture Forest Service (1981).

[67] Olsen, N. F. and Bollinger, J. R., Filtered and Nonfiltered Cigarette Ignition of Cotton Upholstery Fabrics, Textile Research J. 50, 310-315 (May 1980).

[68] Study on Fire Test Procedures for Upholstered Furniture, ISO/TC 136 document (1983).

[69] Yockers, J. R. and Segal, L., Cigarette Fire Mechanisms, Quarterly of the National Fire Protection Association . 49, 213-222 (Jan. 1956).

[70]' Blankenbaker, S., Cigarettes and Electric Heating Elements as Ignition Sources, pp. 97-113 in Proc. of the Thirteenth Annual Meeting, Information Council on Fabric Flammability, Atlanta (Dec. 1979).

[71] Fons, W. L. and Stromberg, R. W., Fire Ignition Report No. 1, California Forest Range Experiment Station, U.S. Forest Service, Riverdale, CA (1941).

[72] Blackmarr, W. H., Moisture Content Influences Ignitability. USDA Forest Service Research Note SE8-8173, Southeastern Forest Experiment Station, Asheville, NC (May 1972).

[73] Cigarette Safety Act, Congressional Record, E 828-829 (Mar. 3, 1983).

[74] Keigh, C. H., Physical Methods for the Modification of Tobacco Smoke, Banbury Report: A Safe Cigarette; Gori, G. B., ed., Cold Spring Harbor Laboratory (1980).

[75] Cigarette Safety Act of 1984, Publ. L. No. 98567 (HR 1880) (1984).

[76] Macaluso, C., Cigarette Ignition Studies, Testimony, Subcommittee on Health and Environment, House Energy and Commerce Committee (Mar. 21, 1983).

[77] Tesoro, G. C., Some Reflections on a Proposed Test Relating to Ignition Hazard in Upholstered Furniture, Textile Chemist and Colorist. 15, 40, 44 (Apr. 1983).

[78] Braun, E., Krasny, J. F., Peacock, R. C., Paabo, M., Smith, G. F., and Stolte, A., Cigarette Ignition of Upholstered Chairs, J. Consumer Product Flammability. 9, 167-183 (Dec. 1982).

[79] Babrauskas, V., Full-Scale Burning Behavior of Upholstered Chairs, (Tech. Note 1103). [U.S.] Natl. Bur. Stand. (1979).

[80] Hafer, C. A., and Yuill, C. H., Characterization of Bedding and Upholstery Fires, Southwest Research Institute, San Antonio, TX (Mar. 1970).

[81] Bukowski, R. W., Christian, W. J., and Waterman, T. E., Detector Sensitivity and Siting Requirements for Dwellings, (Publ. SPP-43). Natl. Fire Protection Assn., Boston (1977).

[82] Harpe, S. W., Waterman, T. E., and Christian, W. J., Detector Sensitivity and Siting Requirements for Dwellings, Phase 2, (Publ. SPP-43A). Natl. Fire Protection Assn., Boston (1977).

[83] Bukowski, R. W., Investigation of the Effects of Heating and Air Conditioning on the Performance of Smoke Detectors in Mobile Homes, (NBSIR 79-1915). [U.S.] Natl. Bur. Stand. (1979).

[84] Hoschke, B. N., Development of Textile Standards in Australia, J. Consumer Product Flammability. 7, 133-146 (1980).

[85] Letter report by Deutsches Teppich-Forschungsinstitut (German Carpet Research Institute), submitted to ISO/TC 136 (1983).

[86] Pakkala, L., Kortekallio, E. L., and Ulmanen, M., Ignitability of Upholstered Furniture, Nordtest Project 186-79, VTT Research Note 69/1982, Technical Research Center of Finland, Espoo, Finland (1982).

[87] Pakkala, L. and Ikonen, S., Methenamine Tablet Ignition Test Method for Interior Materials and Sleeping Bags, Technical Research Center, Espoo, Finland (1982).

[88] Schultz, B., Flammability Testing of Combinations of Furniture Cover Fabric, Interliners, and Filling Materials, Swedish Textile Research Institute, Gothenberg, Sweden, TFB 78002 FR (1978) TFB 790001 FR (1979).

[89] Benisek, L. and Phillips, W. A., The Importance and Relevance of Burning Behavior, Smoke, and CO Emission from Upholstered Seating, J. Consumer Product Flammability. 5, 96-110 (1978). 
[90] Woolley, W. D., Ames, S. A., Pitt, A. F., and Murrell, J. V., Fire Behavior of Beds and Bedding Materials, Fire and Materials. 1, 63-73 (1976).

[91] Prager, F. H. and Wood, J. F., Full Scale Investigation of the Fire Performance of Upholstered Furniture, Part I (RAPRA 4), International Isocyanate Institute (1979).

[92] Benisek, L., Realistic and Fair Flammability Test Methods for Upholstered Seating, J. Consumer Product Flammability. 8, 239-244 (1981).

[93] Moulen, A. W. and Grubits, S. J., Paper Ignition Sources Used to Examine the Fire Behavior of Seating and Bedding, Technical Record 474, Experimental Building Station, Department of Housing and Construction, Chatswood, N.S.W., Australia.

[94] Damant, G. H., McCormack, J. A., and Williams, S. U., A Fire Safety Study of Penal Institution Mattresses, J. Consumer Product Flammability. 1, 71-98 (June 1980).

[95] Flammability Test Procedure for Mattresses for Use in High Risk Occupancies (Tech. Bul. 121). Bur. of Home Furnishings, State of California, Sacramento (1980).

[96] Technical Bulletin No. 133, Flammability Test Procedure for Seating Furniture for Use in High Risk and Public Occupancies, Bureau of Home Furnishings, California State Department of Consumer Affairs, North Highlands, CA (1984).

[97] Wortman, P. S., Williams, S. S. and Damant, G. H., Development of a Fire Test for Furniture for High Risk and Public Occupancies, Bureau of Home Furnishings, California State Department of Consumer Affairs, North Highlands, CA (1984).

[98] Benisek, L. and Craven, P. C., Alternative Balsa Wood Ignition Sources 4-7 for DD 58: 1978 and DOE/PSA F.R. 10, Laboratory Report SF-284, International Wool Secretariat, Ilkley, York, England (1980).

[99] ISO/TC 136 documents (1980, 1981).

[100] Ramsay, G. C. and Dowling, V. P., A Protocol for the Assessment of Fire Behavior of Furniture Using Large Ignition Sources, Part 1: Upholstery Combinations; Part 2: Actual Furniture Items, Division of Building Research, Commonwealth Scientific and Industrial Research Organization, Highett, Victoria, Australia (1983).

[101] Flame Resistance of Cloth; Vertical Methods 5903.2, Federal Test Standard No. 191, General Services Administration, Washington (1971).

[102] Babrauskas, V., Lawson, J. R., Walton, W. D., and Twilley, W. H., Upholstered Furniture Heat Release Rates Measured with a Furniture Calorimeter, (NBSIR 82-2604). [U.S.] Natl. Bur. Stand. (1982).

[103] Code of Federal Regulations, Part 1610, Standard for the Flammability of Clothing Textiles (1983).

[104] Motor Vehicle Safety Standard No. 302, Flammabillity of Interior Materials-Passenger Cars, Multipurpose Passenger Vehicles, Trucks, and Buses. Federal Register. 35 (Nov. 28, 1975).

[105] The Port Authority of New York and New Jersey, Specifications Governing the Flammability of Upholstery Materials and Plastic Furniture, New York, NY (1981).

[106] Part 25, Airworthiness: Standards: Transport Category and Airplanes, Para. 25.853, Appendix F., Federal Register, 37 , No. 37 (Feb. 1972).

[107] Standard Test Method for Surface Flammability of Materials Using a Radiant Heat Energy Source, ASTM E162, American Society for Testing and Materials, Philadelphia, PA (1978).

[108] Regulations Controlling Decorations, Furnishings and Interiors, Boston Fire Department, Boston, MA 02118 (1983).

[109] Braun, E., Fire Hazard Evaluation on BART Vehicles, (NBSIR 78-1421). [U.S.] Natl. Bur. Stand. (1978).

[110] Braun, E., A Fire Hazard Evaluation of the Interior of WMATA Metrorail Cars (NBSIR 75-971). [U.S.] Natl. Bur. Stand. (1975).

[111] Braun, E., Report of Fire Test on an AMC General Metro Bus. (NBSIR 75-718). [U.S.] Natl. Bur. Stand. (1975).

[112] Klitgaard, P. S., Williamson, R. B., The Impact of Contents on Building Fires, J. of Fire and Flammability/Consumer Product Flammability Supplement. 2, 84-113 (Mar. 1975).

[113] Babrauskas, V., Will the Second Item Ignite? Fire Safety J. 4, 287-292 (1982).

[114] Babrauskas, V., Fire Engineering Test Development: Bench-Scale Tests to Predict Full-Scale Behavior, presented at the 7th UJNR Panel on Fire Research and Safety, Washington (Oct. 1983).

[115] Babrauskas, V., Development of the Cone Calorimeter-A Bench-Scale Heat Release Apparatus Based on Oxygen Consumption, (NBSIR 82-2611). [U.S.] Natl. Bur. Stand. (1982).

[116] Tordella, J. and Twilley, W. H., Development of a Calorimeter for Simultaneously Measuring Heat Release and Mass Loss Rates, (NBSIR 83-2708). [U.S.] Natl. Bur. Stand. (1983).

[117] Moulen, A. W. and Grubits, S., Fire Properties of Some Commonly Used Upholstered Materials (TR 44/153/412). Commonwealth Experimental Building Station, North Ryde, Australia (1973).

[118] Hilado, C. J. and Brauer, D. P., Effect of Construction, Substrate, and Piloting on Ignitability of Furniture Upholstery Fabrics, $J$. Fire and Flammability 10, 26-40 (1979).

[119] Hallman, J. R., Ignition Characteristics of Plastics and Rubber (Ph.D. Dissertation), University of Oklahoma, Norman (1971).

[120] Wulff, W. et al., Study of Hazards from Burning Apparel and the Relations of Hazards to Test Methods, Georgia Institute of Tech., Atlanta (1971), NTIS No. COM-73-10954.

[121] Tu, K. M. and Davis, S., Flame Spread of Carpet Systems Involved in Room Fires, (NBSIR 76-1013). [U.S.] Natl. Bur. Stand. (1976).

[122] Paul, K. T. and Clevely, W. P., unpublished studies, Rubber and Plastics Research Assn. of Great Britain (1983).

[123] Paul, K. T, Development and Evaluation of Improved Wooden Cribs for Ignitability Standards in Upholstery and Related Specifications, unpublished report, Building Research Establishment, Borehamwood (1981).

[124] Unpublished NBS data. [U.S.] Natl. Bur. Stand., Washington, DC.

[125] Durbetaki, P. et al, Fabric Ignition, Third Annual Report, Georgia Institute of Technology, Atlanta (1974), NTIS No. PB 242740 A/S.

[126] Thomas, P. H., Some Conduction Problems in the Heating of Small Areas on Large Solids, Quart. J. Mech. and Applied Math. 10, 482-493 (1957).

[127] Kanury, A. M., Ignition of Cellulosic Solids A Review, Fire Research Abstracts and Reviews. 14, 24-52 (1972).

[128] Thomas, P., Factors Affecting Ignition of Combustible Materials and Their Behavior in Fire, pp. 84-99 in Fire Safety of Combustible Materials, International Symposium, Edinburgh (1975). 
[129] Palmer, K. N., Taylor, W. and Paul, K. T., Fire Hazards of Plastics in Furniture and Furnishings: Characteristics of the Burning, (CP 3/75). Building Research Establishment, Borehamwood (1975).

[130] Fire Tests-Reaction to Fire--Ignitability of Building Products (ISO/TR-5657-1982), Intl. Org. for Standardization, Geneva (1982).

[131] Ahonen, A., Kokkala, M. and Weckman, H., Burning Characteristics of Potential Ignition Sources of Room Fires (Research Report 285), Technical Research Centre, Espoo, Finland (June 1984).

[132] Friedman, R., Quantification of Threat from a Rapidly Growing Fire in Terms of Relative Material Properties, Fire and Materials. 2, 27-33 (1978).

[133] Huggett, C., Time-Dependent Fire Behavior of Aircraft Cabin Materials, (Report FAA-RD-77-99). Federal Aviation Admin., Washington (1977).

[134] Pape, R., Burn Rate Data, IIT Research Institute, Chicago (ca. 1977).

[135] Mizuno, T., and Kawagoe, K., Burning Behavior of Upholstered Chairs, Fire Science and Technology. 4, 37-45 (June 1984).

[136] Babrauskas, V. and Walton, W. D., A Simplified Characterization for Upholstered Furniture Heat Releae Rates, to be published.

[137] Babrauskas, V., Upholstered Furniture Heat Release Rates: Measurements and Estimation. J. of Fire Sciences. 1, 9-32 (Jan/Feb. 1983).

[138] Rockett, J. A., Mathematical Modeling of Radiant Panel Test Methods, pp. 90-96 in Fire Safety Research (SP 411), M. J. Butler and J. A. Slater, eds. [U.S.] Natl. Bur. Stand. (1974).

[139] Quintiere, J., Harkleroad, M. and Walton, W. D., Measurement of Material Flame Spread Properties, Comb. Sci. and Tech. 32, 67-89 (1983).

[140] Dipert, R. A., Applications of Flame Spread Modeling to Flame Spread on Horizontal Samples, M.S. Thesis, Dept. of Fire Protection Engineering, Worcester Polytechnic Institute, Worcester, MA (1984).

[141] Kashiwagi, T., A Study of Flame Spread Over a Porous Material Under External Radiation Fluxes, pp. 255-265 in 15th Symp. (Intl.) on Combustion. The Combustion Institute, Pittsburgh (1974).

[142] Pagni, P. J., Clow, K. H., Heffner, G. and Bard, S., Observations on the Burning of Urethane Mattresses (UCB-FRG-76-2). Univ. of California, Mech. Eng. Dept., Berkeley (1976).

[143] Land, R. I., Test Burns of Mattresses and Bedclothes (Home Fire Project Report 24) Harvard Univ., Dept. of Appl. Sci., Cambridge (1981).

[144] Mizuno, T., Sasagawa, F., Horiuchi, and Kawagoe, K., Burning Behavior of Urethane Foam Mattresses, Fire Sci. and Tech. 1, 33-44 (1981).

[145] Hanson, A., Sibulkin, M., Flame Spreading from a Point Source on a Vertical Fuel Surface, Comb. Sci. and Tech. 9, 173-176 (1974).

[146] Pape, R., Preflashover Room Fire Model: Parametric Sensitivity Analysis and Development of a Submodel for Burning Furniture Items, (NBS-GCR-81-300). [U.S.] Natl. Bur. Stand. (1981).

[147] DeRis, J. N., Spread of a Laminar Diffusion Flame, pp. 241-252 in Twelfth Symp. (Intl.) on Combustion. The Combustion Institute, Pittsburgh (1968).

[148] Woolley, W. D., Ames, S. A., Pitts, A. I., and Buckland, K., The Ignition and Burning Characteristics of Fabric Covered Foams, Fire Safety Journal. 2, 39-59, 1979/80.

[149] Lee, B. T. and Wiltshire, L. W., Fire Spread Models of Upholstered Furniture, J. Fire and Fiammability. 3, 164-175 (Apr. 1972).

[150] Krasny, J. F. and Babrauskas, V., Burning Behavior of Upholstered Furniture Mockups, J. of Fire Sciences, 2, 205-235 (May/June 1984).

[151] Palmer, K. N., Taylor, W., and Paul, K. T., Fire Hazard of Plastics in Furniture and Furnishings; Fires in Furnished Rooms (CP 21/76), Building Research Establishment, Borehanwood (1976).

[152] Flammability Tests for Blankets-Statistical Analysis of Interlaboratory Results, [U.S.] Natl. Bur. Stand. (1972).

[153] Babrauskas, V., Combustion of Mattresses Exposed to Flaming Ignition Sources, Part 1. Full-Scale Tests and Hazard Analysis, (NBSIR 77-1290). [U.S.] Natl. Bur. Stand. (1977).

[154] Babrauskas, V., Pillow Burning Rates, Fire Safety J. 8, 199-200 (1985).

[155] Stone, H. and Pcolinsky, M. P., Jr., Burning Behavior of Decubitus Ulcer Pads, pp. 134-158 in Proc. of the 8th Intl. Conf. on Fire Safety, Millbrae, CA (1983).

[156] Standard Test Method for Heat and Visible Smoke Release Rates for Materials and Products (ASTM E 906). American Society for Testing and Materials (1983).

[157] Standard for Fixed Guidance Transit Systems (NFPA 130), National Fire Protection Association, Quincy, MA (1983).

[158] Recommended Fire Safety Practices for Rail Transit Materials Selection. Urban Mass Transportation Administration. Federal Register. 47, 53559-63.

[159] Standard Test Method for Surface Flammability of Flexible Cellular Materials Using a Radiant Heat Energy Source (ASTM D 3675). American Society for Testing and Materials (1979).

[160] Fire Tests-Reaction to Fire-Ignitability of Building Products (ISO/TR-5657-1982). Intl. Org. for Standardization, Geneva (1982).

[161] Moulen, A. W., Grubits, S. J., and Miles, P. A., Tests on Upholstery to Grade Horizontal Flame Spread (Technical Record 450). Experimental Bldg. Sta., North Ryde, NSW, Australia (1979).

[162] Fitzgerald, W. E., Quantification of Fires: 1. Energy Kinetics of Burning in a Dynamic Room Size Calorimeter, J. Fire and Flammability. 9, 510-527 (Oct. 1978).

[163] Fitzgerald, W. E. and Kanakia, M., Calorimetric Evaluation of the Role of Fire Retardants in Selected Polymers, pp. 21-30 in Fire Retardant Chemicals Assn. Conference Workshop, March 12-15, 1978, Technomic Publ., Westport, CT.

[164] Huggett, C., Estimation of Rate of Heat Release by Means of Oxygen Consumption Measurements. Fire and Materials. 4, 61-65 (1980).

[165] Parker, W. J., Calculations of the Heat Release Rate by Oxygen Consumption for Various Applications, (NBSIR 81-2427). [U.S.] Natl. Bur. Stand. (1982).

[166] Heskestad, G., A Fire Products Collector for Calorimetry into the MW Range (FMRC J. I. OC2E1.RA). Factory Mutual Research Corp., Norwood (1981).

[167] Holmstedt, G., Kaiser, I., Brand i Vordbaddar (SP-RAPP 1983:04) Statens Provningsanstalt, Boras, Sweden (1983). 
[168] Essais sur Matelas (CR 74), Service Feu, Division Recherche, Centre Scientifique et Technique du Batiment, Champs sur Marne (ca 1974).

[169] Tourrette, J. C., Toyer, M., Debit Calorifique en Fonction de la Geometrie du Combustible (Contract 75.60.110, Articles 1.3.2b) Service Feu, Division Recherche, Centre Scientifique et Technique du Bâtiment, Champs sûr Marne (ca. 1975).

[170] Lawson, J. R., Walton, W. D., and Twilley, W. H., Fire Performance of Furnishings as Measured in the NBS Furniture Calorimeter, Part I. (NBSIR 83-2787). [U.S.] Natl. Bur. Stand. (1984).

[171] Hagglund, B., Janssons, R., Onnermark, B., Fire Development in Residential Rooms After Ignition From Nuclear Explosions, (FOA Rapport C20016-D6-A3). Försvarets Forskningsanstalt, Stockholm (1974).

[172] Jansson, R. Nireus, K., Hansson, S. G., and Onnermark, B., Brandspridning Mellan Möbler (FOA Rapport C20049-D6-A3). Försvarets Forskningsanstalt, Stockholm (1975).

[173] Andersson, B., Fire Behavior of Upholstered Furniture-An Experimental Study, Lund Institute of Technology, Lund, Sweden (Oct. 1984).

[174] Testing of Materials-Burning Behavior of Materials-Burner (DIN 50051) Deutsches Institut fur Normung, Berlin (1977).

[175] Schuhmann, J. G., The Flaming Combustion Characteristics of Residential Upholstered Furniture: An SPI Research Project. pp. 98-105 in Proc. of the SPI 27th Annual Technical/Marketing Conference, Polyurethane Div., Society of the Plastics Industry, Inc., Technomics Publ. (1982).

[176] Anolick, C., et al., Flammability Characteristics of Healthcare Mattresses, paper presented at the August 1977 American Hospital Assn. Annual Convention, Atlanta (E. I. DuPont de Nemours \& Co., Wilmington) (1979).

[177] Fish, D. K., Tobey, R. S., and Galloway, J. R., Prison Mattress Cushioning Materials Evaluation: Durability and Fire Test Data. Elastomer Chemicals Dept., E. I. DuPont de Nemours \& Co., Wilmington (1979).

[178] Krause, R. F., and Gann, R. G., Rate of Heat Release Measurements Using Oxygen Consumption, J. Fire and Flammability. 11, 117-130 (Apr. 1980).

[179] Babrauskas, V., Performance of the Ohio State University Rate of Heat Release Apparatus Using Polymethylmethacrylate and Gaseous Fuels. Fire Safety J. 5, 9-20 (1982).

[180] Parker, W. J. and Long, M. E., Development of a Heat Release Rate Calorimeter at NBS, pp. 135-151 in Ignition, Heat Release and Non-Combustability of Materials (STP 502). American Society for Testing and Materials, Philadelphia (1972).

[181] Janssens, M., Survey of Rate of Heat Release Test Methods and Apparatuses, Fire Safety J. (1985).

[182] Martin, S. B., Characterization of the Stanford Research Institute Large-Scale Heat-Release-Rate Calorimeter, (NBS-GCR 76-54). [U.S.] Natl. Bur. Stand. (1975).

[183] Babrauskas, V., Combustion of Mattresses Exposed to Flaming Ignition Sources, Part II, Bench-Scale Tests and Recommended Standard Test, (NBSIR 80-2186). [U.S.] Natl. Bur. Stand. (1980).

[184] Report to the Artane Fire Tribunal, Fire Research Station, Borehamwood (1982).

185] Hawthorne, B. J., Fire Resistance of Plastics in Railway Coaches, Fire, 58, 649-651 (May 1966).

[186] Nelson, G. L., et al, Material Performance in Transportation Vehicle Interiors, J. Fire and Flammability. 8, 262-278 (July 1977).

[187] Williamson, R. B. and Fisher F., Fire Tests and Criteria for Mass Transportation Seats (SAE Paper 810013). Society of Automotive Engineers (1981).

[188] Peacock, R. D., and Braun, E., Fire Tests of Amtrak Passenger Rail Vehicle Interiors, (Tech. Note 1193). [U.S.] Natl. Bur. Stand. (1984).

[189] Barecki, C. J., Ignition of Bus Seats, paper presented at the May 1976 Nat. Fire Prot. Assn. Meeting. (American Seating Co., Grand Rapids).

[190] Rakaczky, J. A., Fire and Flammability Characteristics of Materials Used in Rail Passenger Cars. A Literature Survey. Aberdeen Proving Ground (1980). NTIS No. AD A084-028.

[191] Hathaway, W. T., Identification of the Fire Threat in Urban Transit Vehicles, (UMTA-MA-06-0051-80-1). Dept. of Transportation, Cambridge, MA (1980).

[192] Hathaway, W. T., Commonalities in Transportation Fire Safety: Regulations, Research and Development, and Data Bases, (DOT-TSC-OST-80-5). Dept. of Transportation, Cambridge, MA (1980).

[193] Hathaway, W. T., Rationale for Proposed Materials Fire Safety, Transportation Systems Center, Dept. of Transportation, Cambridge, MA (1981).

[194] Fire Experience and Exposure in Fixed-Guideway Transit Systems, American Iron and Steel Institute (1980).

[195] Safety Effectiveness Evaluation of Rail Rapid Transit Safety, (NTSB-SEE-81-1). National Transportation Safety Board, Washington, DC (1981).

[196] Lee, B. T., Effect of Wall and Room Surf cees on the Rate of Heat, Smoke, and Carbon Monoxide Production in a Park Lodging Bedroom Fire, (NBSIR 85-2998). [U.S.] Natl. Bur. Stand. (1985).

[197] Marcy, J. F., A Study of Air Transport Passenger Cabin Fires and Materials (FAA-ADS-44). Federal Aviation Administration, Atlantic City (1965).

[198] Marcy, J. F., Air Transport Cabin Mockup Fire Experiments (FAA-RD-70-81). Federal Aviation Admin., Atlantic City (1970).

[199] Sarkos, C. P., Hill, R. G., and Howell, W. O., The Development and Application of a Full-Scale Wide Body Test Article to Study the Behavior of Interior Materials During a Postcrash Fuel Fire, in AGARD Lecture Series No. 123-Aircraft Fire Safety (AGARD-LS-123). AGARD (1982).

[200] Heine, D., and Brennerman, J., ALPA Cleveland Fire Test Results, Processed at the 13th ALPA Air Safety Forum, Oct. 4-5, 1966, Airline Pilots Assn.

[201] Heine, D., and Brennerman, J., Cleveland Fire Tests, Airline Pilot. 36, 4-5, 49 (Aug. 1966), 8-11, 18 (Oct. 1966).

[202] Fire Suppression, and Smoke and Fume Protection (Report AIA CDP-2). Aerospace Association of America, Inc., Washington (1968).

[203] Stuckey, R. N., Supkis, D. E., and Price, L. J., Full-Scale Aircraft Cabin Flammability Tests of Improved FireResistant Materials(NASA TM X-58141). NASA (1974).

[204] Stuckey, R. N., et al., Full-Scale Aircraft Cabin Flammability Tests of Improved Fire-Resistant Materials-Test Series II, (NASA TM X-58172). NASA (1976).

[205] Bricker, T W., Aircraft Seat Cushion Mattress Tests (NASA TM-X-74632), NASA (1975). 
[206] Kuminecz, J. F., and Bricker, R. W., Full-Scale Flammability Test Data for Validation of Aircraft Fire Mathematical Models (NASA TM-58244), NASA (1982).

[207] Fewell, L. L., et al., Conference on the Development of Fire-Resistant Aircraft Passenger Seats (NASA TM-X-73144), NASA (1976).

[208] Kourtides, D. A., ed., Conference on Fire Resistant Materials (Firemen). NASA Tech. Memo, 78523 (1978).

[209] Parker, J. A. and Kourtides, D. A., Optimization of Fire Blocking Layers for Aircraft Seating, pp. $83-106$ in Proc. of the 7th International Conference on Fire Safety, Stanford Research Institute, Menlo Park, CA (Jan. 1982).

[210] Kourtides, D. A. et al, Optimization of Aircraft Seat Cushion Fire Blocking Layers (DOT/FAA/CT-82/132). Federal Aviation Administration, Atlantic City (1983).

[211] Kourtides, D. A. and Parker, J. A., Test Methodology for Evaluation of Fireworthy Aircraft Seat Cushions, J. Fire Flammability. 15, 56-76 (Jan. 1982).

[212] Hill, R. G., et al., Aircraft Seat Fire Blocking Layers: Effectiveness and Benefits Under Various Scenarios (DOT/FAA/CT-83/ 43). Fed. Aviation Admin., Atlantic City (1984).

[213] Hall, J. R., Jr. and Stiefel, S. W., Decision Analysis Model for Passenger Aircraft Safety with Application to Fire-Blocking of Seats, (NBSIR 84-2817). [U.S.] Natl. Bur. Stand. (1984).

[214] Fish, R. H., The Performance of Lightweight Plastic Foams Developed for Fire Safety, pp. 103-110 in Conference on Materials for Improved Fire Safety (NASA SP. 5096), NASA (1971).

[215] Scutter, K. J. and Duskin, F. E., The Optimization of Aircraft Seat Cushion Fire-Blocking Layers. Full-Scale: Test Description and Results (NASA CR-166418). NASA (1982).

[216] Grand, A. F. and Valys, A. J., Assessment of Burning Characteristics of Aircraft Interior Materials, Task I-Analog Seat (NASA-CR-166390), NASA (1982).

[217] Flammability Requirements for Aircraft Seat Cushion, Federal Register. 48, $46250-7$ (Oct. 11, 1983). Federal Aviation Administration.

[218] Brown, L. J., Jr. and Johnson, R. M., Correlation of Laboratory-Scale Fire Test Methods for Seat Blocking Layer Materials with Large-Scale Test Results (DPT/FAA/CT-83/29). Federal Aviation Administration, Atlantic City (1983).

[219] Enders, J. H., and Wood, E. C., Special A viation Fire and Explosion Reduction (SAFER) Advisory Committee, Final Report, Vol 1. (FAA-ASF-80-4 Vol. 1), NTIS No. AD-A092016. Vol. 2A (FAA-ASF-80-4-Vol. 2A), NTIS No. AD-A099147 (1980). Vol. 2B (FAA-A SF-80-4-Vol. 2B), NTIS No. AD-4099176 (1980).

[220] Fire Safety Aspects of Polymeric Materials, Vol. 6-Aircraft: Civil and Military. Technomic Publ., Westport, CT (1977).

[221] Snyder, R. G., Advanced Techniques in Crash Impact Protection and Emergency Egress from Air Transport Aircraft (AGARDOGRAPH-221). June 1976. NTIS No. AD A029375/3.

[222] Lucua, G. V., Robertson, M. A., and Schooley, F. A., An Analysis of Aircraft Accidents Involving Fires (NASA CR-137690). NASA (1975).

[223] Damant, G. H. and Young, M. A., Smoldering Characteristic of Fabrics Used as Upholstered Furniture Coverings, J. Consumer Product Flammability. 4, 60-113 (Mar. 1977).

[224] Damant, G. H. and Young, M. A., Flammability Classification of Fabrics Used as Upholstered Furniture Coverings, J. Consumer Product Flammability. 4, 329-345 (Dec. 1977).

[225] Damant, G. H., Williams, S. S., and McCormack, J. A., The Role of Fabric in the Cigarette Ignition of Upholstered Furniture (Laboratory Report No. SP-83-2) Bureau of Home Furnishings, Department of Consumer Affairs, North Highlands, CA (July 1983).

[226] Damant, G. H., McCormack, J. A., and Williams, S. S., California Enforcement Tests on Commercial Chairs, pp. 2-10 in Proc. of the 7th International Conference of Fire Safety, Stanford Research Institute, Menlo Park, CA (Jan. 1982).

[227] Damant, G. H., Home Furnishings Fire Retardant Requirements: The California Experience, J. Consumer Product Flammability. 6, 95-104 (June 1979).

[228] Williams, S. S. and Damant, G. H., Rate of Weight Loss as an Aid to Evaluate the Smoldering Propensity of Upholstered Fabrics, J. Consumer Product Flammability. 8, 89-104, (June 1981).

[229] Baitinger, W. F., Fire Retardance Treatment of Fabrics for the '80s; Smolder Resistant Cotton Treated with Boric Acid, Textile Research J. 52, 82-86 (Jan. 1982).

[230] Knoepfler, N. B., Neumeyer, J. P., and Madasci, J. P., Meeting the Mattress Flammability Standard FF 4-72 with Boron Treated Cotton Batting Products, J. Consumer Product Flammability. 1, 240-264 (Sept. 1974).

[231] Madasci, J. P. and Knoepfler, N. B., Upgrading Classification of Upholstery Fabrics via Vapor-Phase Deposition of Boric Acid, Textile Research J. 49, 176-190 (Mar. 1979).

[232] Verburg, G. B. and Lambert, A. H., Smolder-Resistant, Oil- and Water-Repellent Cotton Upholstery Fabrics, J. Fire Retardant Chemistry. 7, 136-153 (Aug. 1980).

[233] Madasci, J. P. and Neumeyer, J. P., A Comparison of Smolder Resistance Standards for Boric Acid Treated Cotton Battings, J. Consumer Product Flammability. 9, 3-10 (Mar. 1982).

[234] Madasci, J. P. and Neumeyer, J. P., Chemical Additives to the Boric Acid Treatment of Cotton Filling Materials Used in Mattress and Upholstered Furniture, J. Fire Retardant Chemistry. 9, 70-83 (Mar. 1982).

[235] Leitner, G. J., Reactive Organophosporus Additives as Smólder Retardant Agents in Furniture Fabric Backcoatings, J. Consumer Product Flammability. 8, 158-168 (Sept. 1981).

[236] Williams, S. S. and Damant, G. H., Evaluation of Three Methods of Rendering Upholstery Fabrics Smolder Resistant, Laboratory Report No. SP-82-2, Bureau of Home Furnishings, North Highlands, CA (Dec. 1982).

[237] Knoepfler, N. B., Neumeyer, J. P., and Koenig, P. A., "Backcoated Mattress Tickings as a Factor in Meeting Mattress Flammability Standard FF 4-72", Part I. Polymer Backcoating. J. Fire \& Flammability, Consumer Product Flammability Supplement. 2, 70-83 (1975), Part II. Compound Polymer Backcoating, 2, 123-139 (June 1975).

[238] McCarter, R. J., Smoldering Combustion of Cotton and Rayon, J. Consumer Product Flammability. 4, $346-358$ (Dec. 1977).

[239] Travers, E. B. and Olsen, N. F., Effect of Air Permeability on Smoldering, Characteristics of Cotton Upholstery Fabrics, Textile Research J. 52, 598-604 (Sept. 1982). 
[240] Damant, G. H., Cigarette Induced Smoldering of Uncovered Flexible Polyurethane Foams, J. Consumer Product Flammability. 2, 140-153 (June 1975).

[241] Donaldson, D. J., Yeadon, D. A. and Harper, R. J., Jr., Smoldering Phenomenon Associated with Cotton, Textile Research J. 53, 160-164 (Mar. 1983).

[242] Krasny, J. F., Evaluation of the Effectiveness of Retrofit Products for Increasing the Cigarette Ignition Resistance of Upholstered Furniture, NBS Letter to CPSC (1984).

[243] Palmer, K. N., Paul, K. T., and Taylor, W., Test Specifications for Fire Properties of Bedding and Upholstered Furniture, Building Research Establishment Report (ISBN 011670663 1) Her Majesty's Stationery Office, London (1979).

[244] Andersson, B. and Magnusson, S. E., Fire Behavior of Upholstered Furniture-An Experimental Study (Report No. R80-4, TVBB-0005) Lund Institute of Technology, Lund, Sweden (1982).

[245] Woolley, W. D., Lunt, M. G., Smith, P. G. and Fardell, P. J., Fire Test of Beds and Bedding-Warlingham Park Hospital Fire, Oct. 1981, Fire Safety Journal. 6, 81-95 (1983).

[246] Pingham, P. E. and Edwards, R. J., The Flammability of Bedding Materials, Wool Research Organization of New Zealand, Christcliurch (1984).

[247] Sarkos, C. P. and Hill, R. G., Effectiveness of Seat Cushion Blocking Layer Materials Against Cabin Fires, presented at 182nd SAE Aerospace Congress and Exposition, Anaheim, CA (Oct. 25-28, 1982).

[248] McCarter, R. J., Combustion Inhibition of Cellulose by Powders: Preliminary Data and Hypotheses, Fire and Materials. 5, 66-72 (June 1981).

[249] Murch, R. M., Testing of Mattress Core Materials Under Severe Fire Conditions, J. Consumer Product Flammabililty. 8, 3-15 (Mar. 1981).

[250] Aerospace Industries Association of America, Inc., Fire Resistant Seat Cushions (Project 210-9), (1983).

[251] Simpson, W., Sorption Theories Applied to Wood, Wood and Fiber. 12, 183-195 (1980).

[252] Sereda, P. J., and Hutcheon, N. B., Moisture Equilibrium and Migration in Building Materials, pp. 3-18 in Moisture in Materials in Relation to Fire Tests (ASTM STP 385), American Society for Testing and Materials, Philadelphia (1965).

[253] Skaar, C., Water in Wood, Syracuse Univ. Press, Syracuse (1972).

[254] Lee, T. G., Loftus, J. J., and Gross, D., Effect of Moisture on Surface Flammability of Coated and Uncoated Cellulosic Materials, pp. 112-123 in Moisture in Materials in Relation to Fire Tests (ASTM STP 385). American Society for Testing and Materials, Philadelphia (1965).

[255] Chamberlain, D. L., Heat Release Rate Properties of Wood-Based Materials. (NBSIR 82-2597). [U.S.] Natl. Bur. Stand (1983).

[256] Ying, S. J., Flame Propagation of Burning Solid Materials with Moisture, Fire Technology. 7, 243-250 (1971).

[257] Babrauskas, V. and Krasny, J. F., Prediction of Upholstered Chair Heat Release Rates from Bench-Scale Measurements, (ASTM STP) to be published.

[258] Trabold, E. L., Study to Develop Improved Fire Resistant Aircraft Passenger Seat Materials, Phase 1. NASA CR-152056 (1977)

[259] Hill, R. B. and Sarkos, C. P., Postcrash Fuel Fire Hazard Measurements in a Wide Body Aircraft Cabin, J. Fire and Flammability. 11, 151-163 (Apr. 1980).

[260] Spieth, H. H. and Trabold, E. L., Methodology for Fire Hazard Analysis of Multilayer Seat Constructions, Textile Research Journal. 51, 202-216 (Mar. 1981).

[261] Standard Test Method for Specific Optical Density of Smoke Generated by Solid Materials (ASTM E662-79). American Society for Testing and Materials.

[262] Babrauskas, V., A Closed-Form Approximation for Post-Flashover Compartment Fire Temperatures, Fire Safety J. 4, 63-73 (1981).

[263] Fang, J. B., Fire Buildup in a Room and the Role of Interior Finish Materials, (Tech. Note 879). [U.S.] Natl. Bur. Stand. (1975).

[264] Tewarson, A., Identification of Fire Properties Relevant to the Prediction of Fire Growth (Paper RC83-TP-11) Factory Mutual Research Corp., Norwood, presented at 7th UJNR Panel Meeting, Washington, October 1983.

[265] Tewarson, A., Physico-Chemical and Combusion/Pyrolysis Properties of Polymeric Materials, (NBS-GCR-80-295). [U.S.] Natl Bur. Stand. (1982).

[266] Quintiere, J. G., An Assessment of Correlations Between Laboratory and Fire-Scale Experiments for the FAA Aircraft Fire Safety Program, Part 1: Smoke, (NBSIR 82-2508). [U.S.] Natl. Bur. Stand. (1982).

[267] Babrauskas, V., Applications of Predictive Smoke Measurements, J. Fire and Flammability. 12, 51-64 (Jan. 1981$).$

[268] Kaplan, H. L., Grand, A. F. and Hartzell, G. E., Combustion Toxicology: Principles and Methods, Technomic Publishing Co., Lancaster, PA 17604 (1983).

[269] Sumi, K. and Williams-Leir, C., Lethal Effects of Mattress Fires, Proc. 2nd Annual Meeting, Information Council on Fabric Flammability, pp. 204-229 (Dec. 1968).

[270] Wooley, F. D. and Fardell, P. J., The Prediction of Combustion Products, Fire Research. 1, 11-21 (1977).

[271] Alarie, Y. C. and Anderson, R. C., Toxicological and Acute Lethal Hazard Evaluation of Thermal Decomposition Products of Synthetic and Natural Polymers, Tox. Appl. Pharm. 51, 34l-362 (1979).

[272] Levin, B. C., Fowell, A. J., Birky, M. M., Paabo, M., Stolte, A. and Malek, D., Further Development of a Test Method for the Assessment of the Acute Inhalation Toxicity of Combustion Products, (NBSIR 82-2532) \{U.S.] Natl. Bur. Stand. (1982).

[273] Birky, M., Malek, D. and Paabo, M., Study of Biological Samples Obtained from Victims of MGM Grand Hotel Fire, J. Anal. Toxicology. 7, 265-271 (1983) .

[274] Levin, B. C., Paabo, M., Fultz, M. L., Bailey, C., Yin, W. and Harris, S. E., An Acute Inhalation Toxicological Evaluation of Combustion Products from Fire Retarded and Non-Fire Retarded Flexible Polyurethane Foam and Polyester, (NBSIR 83-2791) [U.S.] Natl. Bur. Stand., Gaithersburg, MD (Nov. 1983).

[275] Levin, B. C., Paabo, M., Fultz, M. L. and Bailey, C., Conditions Conducive to the Generation of Hydrogen Cyanide from Flexible Polyurethane Foam, 7th Joint Meeting, U.S.-Japan Panel on Fire Research and Safety, Washington, DC (Oct. 1983).

[276] Alarie, Y., Stock, M. F., Matijak Schaper, M. and Birky, M., Toxicity of Smoke During Chair Smoldering Tests and Small Scale Tests Using the Same Materials, Fundamental and Applied Toxicology. 3, 619-626 (1983).

[277] Levin, B. C., Bailey, S., Gorman, J. L. and Paabo, M., Effects of Exposure to Single or Multiple Combinations of the Predominant Toxic Gases and Low Oxygen Atmospheres Produced in Fires, Tox. Appl. Pharm. in preparation. 
[278] Brown, L. J., Jr., Smoke Emissions From Aircraft Interior Materials at Elevated Heat Flux Levels Using Modified NBS Smoke Chamber (FAA-RD-79-26). Federal Aviation Administration, Atlantic City (1979).

[279] Yamamoto, K. and Kuwahara, C., A Study on the Combined Action of CO and HCN in Terms of Concentration-Time Products, Z. RechtsMedizine. 86, 287-294 (1981).

[280] Spieth, H. H., et al. A Combined Hazard Index Fire Test Methodology for Aircraft Cabin Materials. Vol, 1 (DOT/FAA/CT-82/ 36-1) NTIS No. AD-A117448. Vol. 2 (DOT/FAA/CT-82/36-2) NTIS No. AD-A117449 (1982).

[281] Ames, S. and Thorne, P. F., A Preliminary Report on the Effect of a Sprinkler System on Fires Involving Displayed Furniture, British Fire Research Station, Borehamwood, (1981).

[282] Babrauskas, V., Estimating Room Flashover Potential, Fire Technology. 16, 94-103, 112 (May 1980).

[283] Babrauskas, V., Upholstered Furniture Room Fires-Measurements, Comparison with Furniture Calorimeter Data, and Flashover Predictions, J. Fire Sciences. 2, 5-19 (1984).

[284] Baldwin, R., Flame Merging in Multiple Fires, Combustion and Flame. 12, 318-324 (1968).

[285] Babrauskas, V., Flame Lengths Under Ceilings, Fire and Materials. 4, 119-126 (1980).

[286] Rockett, J. A., Modeling of NBS Mattress Tests with the Harvard Mark V Fire Simulation, Fire and Materials. 6, 80-95 (June 1982).

[287] Van Volkinburg, D. R., et al., Toward a Standard Ignition Source, LBL-8306, Lawrence Berkeley Laboratory, Berkeley (1978).

[288] Cline, D. D., Von Riesemann, W. A. and Chavez, J. M., Investigation of a Twenty-Foot Separation Distance as a Fire Protection Method as Specified in 10 CFR 50, Appendix R (NUREG/CR-3192, SAND 83-0306 RP). Sandia Natl. Lab., Albuquerque (1983) 
Table 1. Tests for smoldering (cigarette) ignition of upholstered furniture and mattresses.

\begin{tabular}{|c|c|c|c|}
\hline & Sponsor & Test Arrangement & Reference \\
\hline \multirow[t]{6}{*}{ A. } & Voluntary Standards & & \\
\hline & BIFMA $^{a}$ & mockup & 18 \\
\hline & UFAC & component & 17 \\
\hline & ASTM (proposed) & component & 12 \\
\hline & NFPA $260 \mathrm{~A}$ & component & 13 \\
\hline & NFPA $260 \mathrm{~B}$ & mockup & 13 \\
\hline \multirow[t]{7}{*}{ B. } & Regulatory Standards & & \\
\hline & California $^{a}$ & component & 20 \\
\hline & British ${ }^{a, b, c}$ & mockup & 22 \\
\hline & Proposed CPSC & mockup & 8 \\
\hline & U.S. mattress & actual mattress & 32 \\
\hline & Canadian mattress & piece of actual mattress & 33 \\
\hline & French mattress & actual mattress & 34 \\
\hline
\end{tabular}

a Includes tests for small flame ignition

'For'ns the basis for ISO, and many national standards [24-30].

c Welt cord is not included in mockup

Table 2. UFAC component test methods [9].

\begin{tabular}{|c|c|c|c|c|c|c|}
\hline \multirow[b]{2}{*}{ Location of materials } & \multicolumn{6}{|c|}{ Component to be tested } \\
\hline & $\begin{array}{l}\text { Cover fabric } \\
\text { classification }\end{array}$ & Filling/Padding & Welt cord“ & Barrier & Interior Fabric & Decking ${ }^{\mathrm{b}}$ \\
\hline $\begin{array}{l}\text { Horizontal panel } \\
\text { fabric }\end{array}$ & test fabric & std. ticking & std. class II & std. class II & $\begin{array}{l}\text { std. ticking } \\
\text { test fabric }\end{array}$ & std. class II \\
\hline filling & std. foam & test filling & std. foam & $\begin{array}{l}\text { test barrier } \\
\text { over std. foam }\end{array}$ & std. foam & test material \\
\hline $\begin{array}{l}\text { Vertical panel } \\
\text { fabric } \\
\text { filling }\end{array}$ & $\begin{array}{l}\text { test fabric } \\
\text { std. foam }\end{array}$ & $\begin{array}{l}\text { std. ticking } \\
\text { test filling }\end{array}$ & $\begin{array}{l}\text { std. class II } \\
\text { std. foam }\end{array}$ & $\begin{array}{l}\text { std. class II } \\
\text { std. foam }\end{array}$ & $\begin{array}{l}\text { std. ticking } \\
\text { std. foam }\end{array}$ & - \\
\hline $\begin{array}{l}\text { Vertical char length } \\
\mathrm{mm} \\
\text { in }\end{array}$ & $\begin{array}{l}44 \\
1.75\end{array}$ & $\begin{array}{l}38 \\
1.5\end{array}$ & $\begin{array}{l}38 \\
1.5\end{array}$ & $\begin{array}{l}51 \\
2.0\end{array}$ & $\begin{array}{l}38 \\
1.5\end{array}$ & $\begin{array}{l}38 \\
1.5^{\circ}\end{array}$ \\
\hline $\begin{array}{r}\text { Materials which } \\
\text { generally pass }\end{array}$ & $\begin{array}{l}\text { Class I: most } \\
\text { tp's, wool, PVC } \\
\text { light cell. } \\
\text { Class II: med. } \\
\text { weight and } \\
\text { heavy cell. }\end{array}$ & $\begin{array}{l}\text { most PU SR } \\
\text { cotton batting } \\
\text { cell./tp batting } \\
(\min .70 \% \text { tp) }\end{array}$ & $\begin{array}{l}\text { some tp, PVC } \\
\text { aluminized } \\
\text { cell. }\end{array}$ & $\begin{array}{l}\text { pe batting } \\
\text { special pu }\end{array}$ & tp & $\begin{array}{l}\text { similar to } \\
\text { filling mat. }\end{array}$ \\
\hline
\end{tabular}

tp-thermoplastic fibers (nylon, olefin, polyester); pu-polyurethane; pe-polyester; cell--cellulosics (cotton, rayon, linen, hemp)

Standard materials: $100 \%$ mattress ticking fabric, Fed. Spec. CCC-C-436-D, cloth (14.5 oz/yd $\left.\mathrm{d}^{2}\right)$, ticking, twill, cotton: Type I, laundered and tumble dried once. Standard class II fabric: $100 \%$ cotton velvet, $490 \mathrm{~g} / \mathrm{m}^{2} \pm 14 \mathrm{~g}$, undyed, containing no flame retardant finishes of backcoating. Sheeting used to cover cigarettes: $124 \pm 28 \mathrm{~g} / \mathrm{m}^{2}$ ), white, not treated with flame retardants. Standard foam polyester type polyurethane foam, containing no inorganic fillers or flame retardant, $24 \pm 1.6 \mathrm{~kg} / \mathrm{m}^{3}$, hand crushed before use.

a Placed into crevice.

${ }^{b}$ Tested as horizontal specimen only.

cMeasured in any direction.

Table 3. British upholstered furniture butane ignition sources [22].

\begin{tabular}{lccc}
\hline & Source 1 & Source 2 & Source 3 \\
\hline Butane flow rate at $25^{\circ} \mathrm{C}, \mathrm{ml} / \mathrm{min}$ & $45 \pm 2$ & $160 \pm 5$ & $350 \pm 10$ \\
Specimen exposure time, $\mathrm{s}$ & $20 \pm 1$ & $40 \pm 1$ & $70 \pm 1$ \\
Failure criteria & flames, afterglow, smoking or smoldering & \\
& $120 \mathrm{~s}$ after removal of burner & \\
Flame length, approx. $\mathrm{mm}$ & 35 & 145 & 240 \\
\hline
\end{tabular}


Table 4. Characteristics of U.S. cigarettes $[11,45,56-59,66,67]$.

Tobacco column length: $60-85 \mathrm{~mm}$

Circumference: $21-26 \mathrm{~mm}$

Packing density: $0.18-0.26 \mathrm{mg} / \mathrm{mm}^{3}$

Paper weight: most brands approximately $6 \%$, range $2-8 \%$ of total cigarette weight

Moisture content, unopened pack: $12 \%$

Linear burning rate, horizontal, in air: $0.08-0.12 \mathrm{~mm} / \mathrm{s}$

Mass burning rate, horizontal, in air: $0.75-1.2 \mathrm{mg} / \mathrm{s}$

Burning temperature, horizontal, in air: $700-800{ }^{\circ} \mathrm{C}$

Heat of combustion (oxygen bomb): tobacco: 16,000 J/g; paper: 11,000 J/g

Heat of combustion (actual): $4600 \mathrm{~J} / \mathrm{g}$

Heat flux, measured on $0.75 \mathrm{~mm}$ copper plate: bone dry: $42 \mathrm{~kW} / \mathrm{m}^{2}$; conditioned: $35 \mathrm{~kW} / \mathrm{m}^{2}$

Table 5. Times to switch from smoldering to flaming.

A. Indiana Dunes Tests $[81,82]$

sofas/chairs (assorted)

mattresses/box springs (assorted)

B. NBS Mobile Home Tests [83]

chairs (identical) mean

standard deviation

coefficient of variation

number

plus,

shortest time

longest time

plus,

shortest time

longest time

shortest time

longest time

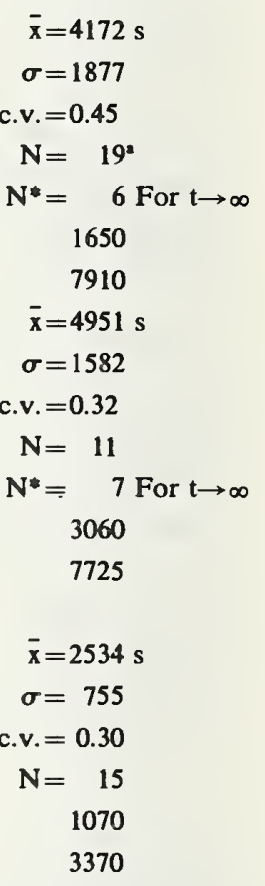

${ }^{a}$ Excludes one test where events unclear.

* Excluded tests where no transition to flaming. 
Table 6A. Characteristics of ignition sources [59,93,121-124,287-288].

\begin{tabular}{|c|c|c|c|c|c|}
\hline & $\begin{array}{l}\text { Typical heat } \\
\text { output }(\mathrm{W})\end{array}$ & $\begin{array}{l}\text { Burn time } \\
\text { (s) }\end{array}$ & $\begin{array}{l}\text { Maximum flame } \\
\text { Height } \\
(\mathrm{mm})\end{array}$ & $\begin{array}{l}\text { Flame } \\
\text { Width } \\
(\mathrm{mm})\end{array}$ & $\begin{array}{c}\text { Maximum heat } \\
\text { flux } \\
\left(\mathrm{kW} / \mathrm{m}^{2}\right)\end{array}$ \\
\hline \multicolumn{6}{|l|}{ Cigarette $1.1 \mathrm{~g}$ (not puffed, laid on solid } \\
\hline surface), bone dry, & 5 & 1200 & - & - & 42 \\
\hline conditioned to $50 \%$ R.H. & 5 & 1200 & - & - & 35 \\
\hline Methenamine pill, $0.15 \mathrm{~g}$ & 45 & 90 & & & 4 \\
\hline Match, wooden (laid on solid surface) & 80 & $20-30$ & 30 & 14 & $18-20$ \\
\hline \multicolumn{6}{|l|}{ Wood cribs, BS 5852 Part 2} \\
\hline No. 4 crib, $8.5 \mathrm{~g}$ & 1000 & 190 & & & $15^{\mathrm{d}}$ \\
\hline No. 5 crib, $17 \mathrm{~g}$ & 1900 & 200 & & & $17^{\mathrm{d}}$ \\
\hline No. 6 crib, $60 \mathrm{~g}$ & 2600 & 190 & & & $20^{\mathrm{d}}$ \\
\hline No. $7 \mathrm{crib}, 126 \mathrm{~g}$ & 6400 & 350 & & & $25^{\mathrm{d}}$ \\
\hline Crumpled brown lunch bag, $6 \mathrm{~g}$ & 1200 & 80 & & & \\
\hline Crumpled wax paper, $4.5 \mathrm{~g}$ (tight) & 1800 & 25 & & & \\
\hline Crumpled wax paper, $4.5 \mathrm{~g}$ (loose) & 5300 & 20 & & & \\
\hline $\begin{array}{l}\text { Folded double-sheet newspaper, } 22 \mathrm{~g} \\
\text { (bottom ignition) }\end{array}$ & 4000 & 100 & & & \\
\hline $\begin{array}{l}\text { Crumpled double-sheet newspaper, } 22 \mathrm{~g} \\
\text { (top ignition) }\end{array}$ & 7400 & 40 & & & \\
\hline $\begin{array}{l}\text { Crumpled double-sheet newspaper, } 22 \mathrm{~g} \\
\text { (bottom ignition) }\end{array}$ & 17,000 & 20 & & & \\
\hline $\begin{array}{l}\text { Polyethylene wastebasket, } 285 \mathrm{~g} \text {, filled } \\
\text { with } 12 \text { milk cartons }(390 \mathrm{~g})\end{array}$ & 50,000 & $200^{\mathrm{b}}$ & 550 & 200 & $35^{c}$ \\
\hline $\begin{array}{l}\text { Plastic trash bags, filled with cellulosic } \\
\text { trash }(1.2-14 \mathrm{~kg})^{c}\end{array}$ & $\begin{array}{c}120,000 \\
\text { to } \\
350,000\end{array}$ & $200^{\mathrm{b}}$ & & & \\
\hline
\end{tabular}

${ }^{\text {a }}$ Time duration of significant flaming.

b Total burn time in excess of $1800 \mathrm{~s}$.

${ }^{c}$ As measured on simulation burner.

${ }^{d}$ Measured from $25 \mathrm{~mm}$ away.

${ }^{\mathrm{e}}$ Results vary greatly with packing density.

Table 6B. Characteristics of typical furnishings as ignition sources [131].

\begin{tabular}{lcccc}
\hline & $\begin{array}{c}\text { Total mass } \\
(\mathrm{kg})\end{array}$ & $\begin{array}{c}\text { Total heat content } \\
(\mathrm{MJ})\end{array}$ & $\begin{array}{c}\text { Maximum rate of heat } \\
\text { release }(\mathrm{kW})\end{array}$ & $\begin{array}{c}\text { Maximum thermal radiation } \\
\text { to center of floor }\end{array}$ \\
\hline waste paper baskets & $0.73-1.04$ & $0.7-7.3$ & $4-18$ & 0.1 \\
curtains, velvet, cotton & 1.9 & 24 & $160-240$ & $1.3-3.4$ \\
curtains, acrylic/cotton & 1.4 & $15-16$ & $130-150$ & $0.9-1.2$ \\
TV sets & $27-33$ & $145-150$ & $120-290$ & $0.3-2.6$ \\
chair mockups & 1.36 & $21-22$ & $63-66$ & $0.4-0.5$ \\
sofa mockup & 2.8 & 42 & 130 & 0.9 \\
arm chair & 26 & 18 & 160 & 1.2 \\
Christmas trees, dry & $6.5-7.4$ & $11-41$ & $500-650$ & $3.4-14$ \\
\hline
\end{tabular}

${ }^{a}$ Measured at approximately $2 \mathrm{~m}$ away from the burning object.

Table 7. Characterization of test burners [122].

\begin{tabular}{|c|c|c|c|c|c|c|c|c|c|c|c|c|}
\hline \multirow[b]{2}{*}{ Burner type } & \multirow{2}{*}{$\begin{array}{c}\text { Tube } \\
\text { diameter } \\
(\mathrm{mm})\end{array}$} & \multirow[b]{2}{*}{ Fuel } & \multirow{2}{*}{$\begin{array}{l}\text { Supply } \\
\text { rate } \\
\text { (W) }\end{array}$} & \multirow{2}{*}{$\begin{array}{c}\text { Maximum } \\
\text { flame height } \\
(\mathrm{mm})\end{array}$} & \multirow{2}{*}{$\begin{array}{c}\text { Maximum } \\
\text { flame width } \\
(\mathrm{mm})\end{array}$} & \multicolumn{2}{|c|}{ Maximum } & \multicolumn{2}{|c|}{$\begin{array}{l}\text { measured } \\
\text { at location }\end{array}$} & \multirow{2}{*}{$\begin{array}{l}\text { flux } \\
\mathrm{R}_{2} \\
\end{array}$} & \multicolumn{2}{|c|}{$\left(\mathrm{kW} / \mathrm{m}^{2}\right)$} \\
\hline & & & & & & $\mathbf{P}_{1}$ & $\mathbf{P}_{2}$ & $\mathbf{P}_{3}$ & $\mathrm{R}_{1}$ & & $\mathbf{R}_{3}$ & $\mathrm{R}_{4}$ \\
\hline straight tube & 6.4 & butane & 315 & 49 & 9.1 & 34 & 35 & 42 & 34 & 38 & 25 & 29 \\
\hline straight tube & 6.4 & propane & 305 & 59 & 8.4 & 40 & 34 & 48 & 34 & 31 & 37 & 28 \\
\hline straight tube & 7.0 & propane & 305 & 42 & 9.0 & 33 & 30 & 41 & 35 & 42 & 26 & 19 \\
\hline straight tube & 7.4 & propane & 305 & 41 & 8.7 & 31 & 43 & 48 & 43 & 43 & 34 & 23 \\
\hline Rieber [174] & - & propane & 305 & 45 & 9.9 & 30 & 35 & 47 & 32 & 29 & 45 & 32 \\
\hline
\end{tabular}

${ }^{a}$ See figure 8. 
Table 8. Fabric and mockup ignitability test results on 10 upholstery cover fabrics [86].

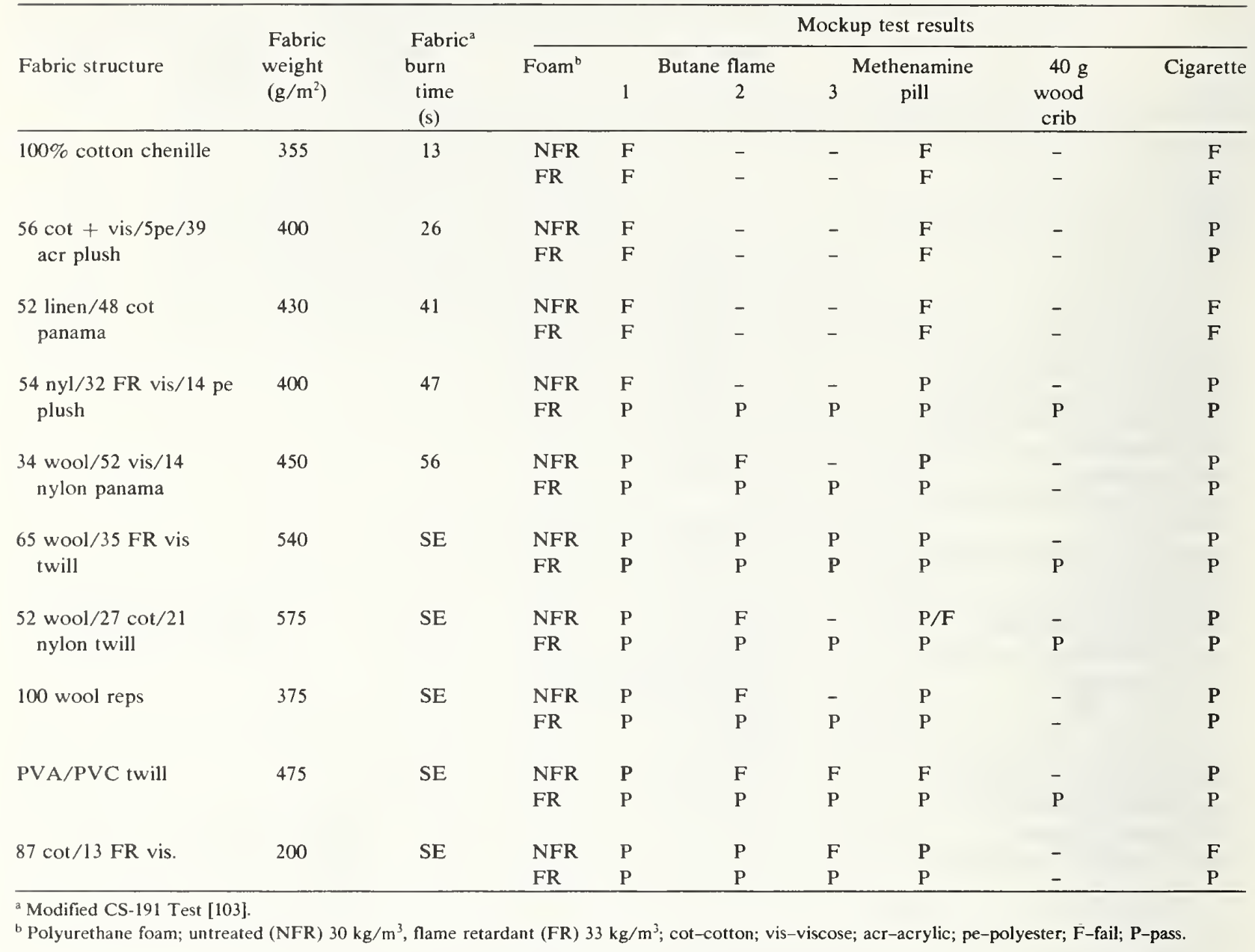

Table 9. Effect of irradiance levels on polyurethane foam flammability performance [124].

\begin{tabular}{|c|c|c|c|c|}
\hline \multirow[b]{2}{*}{ Density } & \multicolumn{2}{|c|}{ NFR PU foams } & \multicolumn{2}{|c|}{ FR PU foams } \\
\hline & $21 \mathrm{~kg} / \mathrm{m}$ & $25 \mathrm{~kg} / \mathrm{m}^{3}$ & $25 \mathrm{~kg} / \mathrm{m}^{3}$ & $28 \mathrm{~kg} / \mathrm{m}^{3}$ \\
\hline \multicolumn{5}{|l|}{ Irradiance $=25 \mathrm{~kW} / \mathrm{m}^{2 *}$} \\
\hline Ignition time (s) & 5.5 & 5.2 & 39.2 & 15.0 \\
\hline Peak heat release $\left(\mathrm{kW} / \mathrm{m}^{2}\right)$ & 433 & 466 & 438 & 467 \\
\hline $60 \mathrm{~s}$ avg. heat release $\left(\mathrm{kW} / \mathrm{m}^{2}\right)$ & 278 & 272 & 276 & 230 \\
\hline \multicolumn{5}{|l|}{ Irradiance $=50 \mathrm{~kW} / \mathrm{m}^{2}$} \\
\hline Ignition time (s) & 3.3 & 3.3 & 4.1 & 4.1 \\
\hline Peak heat release $\left(\mathrm{kW} / \mathrm{m}^{2}\right)$ & 1059 & 876 & 1029 & 844 \\
\hline $60 \mathrm{~s}$ avg. heat release $\left(\mathrm{kW} / \mathrm{m}^{2}\right)$ & 443 & 470 & 456 & 428 \\
\hline \multicolumn{5}{|l|}{ Irradiance $=75 \mathrm{~kW} / \mathrm{m}^{2}$} \\
\hline Ignition time (s) & 1.3 & NA & 2.7 & 2.9 \\
\hline Peak heat release $\left(\mathrm{kW} / \mathrm{m}^{2}\right)$ & 1773 & 1810 & 1429 & 1862 \\
\hline $60 \mathrm{~s}$ avg. heat release $\left(\mathrm{kW} / \mathrm{m}^{2}\right)$ & 501 & 646 & 545 & 561 \\
\hline
\end{tabular}

All tests conducted in the cone calorimeter [115]. Horizontal orientation, $100 \times 100 \times 50 \mathrm{~mm}$ thick samples. 
Table 10. Ignitability test results [113].

\begin{tabular}{|c|c|c|c|c|c|c|c|c|}
\hline Specimen & Type & Frame & Fabric & Padding & $\begin{array}{c}\text { Total } \\
\text { mass } \\
(\mathrm{kg}) \\
\end{array}$ & $\begin{array}{c}\text { Wastebasket } \\
\text { ignition }\end{array}$ & $\begin{array}{l}\text { Ignition time } \\
\text { at } 20 \mathrm{~kW} / \mathrm{m}^{2} \\
\text { irradiance } \\
\text { (s) }\end{array}$ & $\begin{array}{l}\text { Ignition time } \\
\text { at } 40 \mathrm{~kW} / \mathrm{m}^{2} \\
\text { irradiance } \\
\text { (s) }\end{array}$ \\
\hline F02 & "tulip chair" & $\begin{array}{c}\text { molded } \\
\text { thermoplastic }\end{array}$ & cotton & $\begin{array}{l}\text { polyurethane } \\
\text { foam }\end{array}$ & 8.5 & Yes & 29 & 14 \\
\hline F16 & $\begin{array}{l}\text { traditional } \\
\text { armchair }\end{array}$ & wood & polypropylene & $\begin{array}{l}\text { polyurethane } \\
\text { foam }\end{array}$ & 23.4 & Yes & 38 & 14.5 \\
\hline F08 & $\begin{array}{r}\text { side chair } \\
\text { (Breuer) }\end{array}$ & chromed steel & nylon & polyurethane & 9.4 & Yes & $\infty$ & 41 \\
\hline F03 & armchair & chromed steel & PVC & $\begin{array}{l}\text { polyurethane } \\
\text { foam }\end{array}$ & 13.2 & Yes & 25 & 14 \\
\hline F04 & armchair & oak (exposed) & PVC & $\begin{array}{l}\text { polyurethane } \\
\text { foam }\end{array}$ & 27.8 & Yes & $18,31^{3}$ & $11,9.3$ \\
\hline F05 & loveseat & oak (exposed) & PVC & $\begin{array}{l}\text { polyurethane } \\
\text { foam }\end{array}$ & 45.9 & Yes & 29 & 11 \\
\hline F12 & armchair & chromed steel & PVC & $\begin{array}{l}\text { polyurethane } \\
\text { foam }\end{array}$ & 17.1 & Yes & 24 & 11.4 \\
\hline F13 & side chair & oak (exposed) & PVC & $\begin{array}{l}\text { polyurethane } \\
\text { foam }\end{array}$ & 7.3 & Yes & 41 & 18.5 \\
\hline F15 & armchair & oak (exposed) & PVC & $\begin{array}{l}\text { polyurethane } \\
\text { foam }\end{array}$ & 18.5 & Yes & 22 & 15.3 \\
\hline F17 & $\begin{array}{l}\text { molded pedestal } \\
\text { chair }\end{array}$ & polyethylene & PVC & $\begin{array}{l}\text { polyurethane } \\
\text { foam }\end{array}$ & 18.0 & Yes & 20,31 & $12.0,17.3$ \\
\hline $\mathbf{F} 20$ & stacking chair & metal & PVC & $\begin{array}{l}\text { polyurethane } \\
\text { foam }\end{array}$ & 7.7 & Yes & 32,32 & $12.4,11.3$ \\
\hline F18 & prison chair & FR polyurethane & Nomex & $\begin{array}{l}\text { neoprene } \\
\text { foam }\end{array}$ & 35.6 & No & $\infty$ & $\therefore$ \\
\hline
\end{tabular}

${ }^{a}$ Denotes values for seat and back, respectively.

$\infty-$ No ignition.

NA-not a vailable.

Table 11. Effect of substrate on ignitability [117].

\begin{tabular}{|c|c|c|c|c|c|c|c|c|c|c|c|c|c|c|c|c|}
\hline \multirow[b]{2}{*}{ Fabric } & \multirow[b]{2}{*}{$\begin{array}{l}\text { Weight } \\
\left(\mathrm{g} / \mathrm{m}^{2}\right)\end{array}$} & \multicolumn{3}{|c|}{ Mineral fiber batt } & \multicolumn{3}{|c|}{ Wool waste, teased } & \multicolumn{3}{|c|}{ Cotton batting } & \multicolumn{3}{|c|}{$\begin{array}{c}\text { PU foam } \\
\left(23.5 \mathrm{~kg} / \mathrm{m}^{3}\right)\end{array}$} & \multicolumn{3}{|c|}{$\begin{array}{l}\text { Latex foam } \\
\left(61.7 \mathrm{~kg} / \mathrm{m}^{3}\right)\end{array}$} \\
\hline & & $\begin{array}{l}t_{50} \\
(s) \\
\end{array}$ & $\begin{array}{l}\mathbf{t}_{20} \\
(\mathrm{~s}) \\
\end{array}$ & $\begin{array}{c}\dot{q}_{\mathrm{cr}} \\
\left(\mathrm{kW} / \mathrm{m}^{2}\right)\end{array}$ & $\begin{array}{l}t_{s,} \\
(s)\end{array}$ & $\begin{array}{l}t_{20} \\
(s) \\
\end{array}$ & $\begin{array}{c}\dot{q}_{\mathrm{cr}} \\
\left(\mathrm{kW} / \mathrm{m}^{2}\right)\end{array}$ & $\begin{array}{l}t_{50} \\
(s)\end{array}$ & $\begin{array}{l}t_{20} \\
\text { (s) }\end{array}$ & $\begin{array}{c}\dot{q}_{\mathrm{cr}} \\
\left(\mathrm{kW} / \mathrm{m}^{2}\right) \\
\end{array}$ & $\begin{array}{l}t_{50} \\
(s)\end{array}$ & $\begin{array}{l}t_{20} \\
(s)\end{array}$ & $\begin{array}{c}\dot{q}_{\mathrm{cr}} \\
\left(\mathrm{kW} / \mathrm{m}^{2}\right)\end{array}$ & $\begin{array}{l}t_{51} \\
(s)\end{array}$ & $\begin{array}{l}t_{20} \\
(s)\end{array}$ & $\begin{array}{c}\dot{\mathrm{q}}_{\mathrm{cr}} \\
\left(\mathrm{kW} / \mathrm{m}^{2}\right)\end{array}$ \\
\hline none (substrate alone) & - & $\infty$ & $\infty$ & - & 10 & $\infty$ & 25 & 4 & 37 & 11 & 5 & 30 & 16 & 5 & 23 & 12 \\
\hline cotton & 149 & 7 & 31 & 11 & 7 & 37 & 12 & 7 & 28 & 11 & 7 & 28 & 11 & 8 & 25 & 11 \\
\hline cotton & 319 & 10 & 39 & 10 & 9 & 52 & 10 & 11 & 40 & 10 & 9 & 41 & 12 & 11 & 46 & 10 \\
\hline $55 \%$ cotton $/ 45 \%$ linen & 348 & 12 & 56 & 11 & 11 & 48 & 12 & 13 & 54 & 11 & 11 & 50 & 11 & 13 & 54 & 11 \\
\hline rayon & 438 & 17 & 57 & 10 & 12 & 70 & 10 & 13 & 67 & 10 & 16 & 51 & 10 & 17 & 57 & 10 \\
\hline $54 \%$ rayon $/ 46 \%$ wool & 773 & 32 & 83 & 10 & 8 & 116 & 10 & 24 & 89 & 9 & 28 & 80 & 11 & 22 & 103 & 9 \\
\hline $\begin{array}{l}\text { wool } \\
\text { polyurethane; cotton }\end{array}$ & 458 & 20 & $\infty$ & 25 & 19 & $\infty$ & 25 & 21 & 69 & 12 & 19 & $\infty$ & 24 & 20 & $\infty$ & 32 \\
\hline scrim & 383 & 11 & 40 & 11 & 11 & 43 & 11 & 11 & 40 & 11 & 11 & 40 & 11 & 11 & 44 & 11 \\
\hline PVC; cotton scrim & 661 & 7 & 33 & 8 & 6 & 32 & 8 & 6 & 40 & 8 & 8 & 34 & 9 & 7 & 35 & 8 \\
\hline
\end{tabular}

$\mathrm{t}_{50}$-time to ignition at irradiance $\dot{q}^{\prime \prime}=50 \mathrm{~kW} / \mathrm{m}^{2}$.

$\mathrm{t}_{20}$-time to ignition at irradiance $\dot{\mathrm{q}}^{\prime \prime}=20 \mathrm{~kW} / \mathrm{m}^{2}$.

$\mathrm{q}_{\mathrm{cr}}$-minimum irradiance for ignition. 
Table 12. Triangular representation of heat release rate curves for upholstered chairs.

\begin{tabular}{|c|c|c|c|c|c|}
\hline Specimen & $\begin{array}{c}\text { Peak } \\
\dot{q}(k W)\end{array}$ & $\begin{array}{c}\text { Triangle } \\
\text { base width } \\
\text { (s) }\end{array}$ & $\begin{array}{c}\text { Triangle } \\
\text { heat release } \\
(\mathrm{MJ})\end{array}$ & $\begin{array}{c}\text { Actual } \\
\text { heat release } \\
(\mathrm{MJ})\end{array}$ & $\begin{array}{c}\text { Triangle } \\
\quad \div \\
\text { Actual }\end{array}$ \\
\hline \multicolumn{6}{|c|}{ A. Chairs with Combustible Frames [137]. } \\
\hline $\mathrm{F} 21$ & 1970 & 240 & 236 & 440 & 0.54 \\
\hline $\mathrm{F} 22$ & 370 & a & -- & 425 & - \\
\hline $\mathrm{F} 23$ & 700 & 746 & 261 & 461 & 0.57 \\
\hline $\mathrm{F} 24$ & 700 & 490 & 171 & 369 & 0.46 \\
\hline $\mathrm{F} 25$ & 1990 & 234 & 233 & 419 & 0.56 \\
\hline $\mathrm{F} 26$ & 810 & 388 & 157 & 300 & 0.52 \\
\hline $\mathrm{F} 27$ & 920 & 820 & 377 & 519 & 0.73 \\
\hline $\mathrm{F} 28$ & 730 & 600 & 219 & 369 & 0.59 \\
\hline $\mathrm{F} 29$ & 1950 & 381 & 371 & 446 & 0.83 \\
\hline F30 & 1060 & a & -- & 363 & -- \\
\hline F31 & 2890 & 278 & 402 & 614 & 0.65 \\
\hline F32 & 3120 & 359 & 560 & 714 & 0.78 \\
\hline \multirow[t]{2}{*}{ F33 } & 940 & 637 & 300 & 453 & $\underline{0.66}$ \\
\hline & & & & \multicolumn{2}{|r|}{ Average $0.63 \pm 0.12$} \\
\hline $\begin{array}{l}\text { Test } \\
\text { No. }\end{array}$ & $\begin{array}{l}\text { Peak } \\
\dot{q}(k W)\end{array}$ & $\begin{array}{l}\text { Triangle } \\
\text { base width } \\
\text { (s) }\end{array}$ & $\begin{array}{c}\text { Triangle } \\
\text { heat release } \\
(\mathrm{MJ})\end{array}$ & $\begin{array}{c}\text { Actual } \\
\text { heat release } \\
(\mathrm{MJ})\end{array}$ & $\begin{array}{c}\text { Triangle } \\
\div \\
\text { Actual } \\
\end{array}$ \\
\hline \multicolumn{6}{|c|}{ B. Chairs with Non-Combustible Frames [181]. } \\
\hline 1 & 320 & 145 & 23 & 29 & 0.79 \\
\hline 2 & 540 & 160 & 43 & 53 & 0.81 \\
\hline 3 & 260 & 135 & 18 & 22 & 0.82 \\
\hline 4 & 410 & 235 & 48 & 53 & 0.91 \\
\hline 5 & 690 & 220 & 76 & 76 & 1.00 \\
\hline 8 & 890 & 175 & 78 & $83^{\circ}$ & 0.94 \\
\hline 6 & 1460 & 210 & 153 & 155 & 0.99 \\
\hline 7 & 1440 & 170 & 122 & 144 & 0.85 \\
\hline 19 & 1230 & 190 & 117 & 118 & 0.99 \\
\hline 9 & 660 & 135 & 44 & 54 & 0.81 \\
\hline 10 & 870 & 155 & 67 & 74 & 0.91 \\
\hline 23 & 990 & 125 & 62 & 73 & 0.85 \\
\hline 11 & 1120 & 135 & 76 & 84 & 0.90 \\
\hline 12 & 1430 & 155 & 111 & 111 & 1.00 \\
\hline 27 & 1490 & 150 & 112 & 111 & 1.01 \\
\hline 13 & 1050 & 125 & 66 & 71 & 0.93 \\
\hline 14 & 1020 & 315 & 161 & 156 & 1.03 \\
\hline 15 & 120 & 210 & 13 & 28 & 0.46 \\
\hline 16 & 1430 & 140 & 100 & 120 & 0.83 \\
\hline 17 & 530 & 405 & 107 & 108 & 1.00 \\
\hline 18 & 110 & a & $\ldots$ & 22 & - \\
\hline 20 & 430 & a & -- & 107 & -- \\
\hline 21 & 900 & 170 & 77 & 75 & 1.03 \\
\hline 22 & $\sim 0$ & a & -- & $<5$ & -. \\
\hline 24 & 1160 & 155 & 90 & 111 & 0.81 \\
\hline 25 & 1370 & 155 & 106 & 107 & 0.99 \\
\hline 26 & 1460 & 145 & 106 & 115 & 0.92 \\
\hline 28 & 760 & 185 & 70 & 72 & 0.97 \\
\hline \multirow[t]{2}{*}{29} & 1210 & 120 & 73 & 73 & 1.01 \\
\hline & & & & \multicolumn{2}{|r|}{ Average $0.91 \pm 0.12$} \\
\hline
\end{tabular}

"Poor fit. 
Table 13. Observations during mattress burn experiments [144].

\begin{tabular}{cccc}
\hline $\begin{array}{c}\text { Time from ignition } \\
(\mathrm{s})\end{array}$ & $\begin{array}{c}\text { Flame spread rates } \\
(\mathrm{mm} / \mathrm{s})\end{array}$ & $\begin{array}{c}\text { Mass loss rates } \\
(\mathrm{g} / \mathrm{s})\end{array}$ & $\begin{array}{c}\text { Flame base diameters } \\
(\mathrm{m})\end{array}$ \\
\hline $0<\mathrm{t}<30 \mathrm{~s}$ & 1.82 & $\approx 0$ & $3.84 \times 10^{-3} \mathrm{t}$ \\
$30<\mathrm{t}<130 \mathrm{~s}$ & 0.51 & $=0.028 \mathrm{e}^{0.024 \mathrm{t}}$ & $1.02 \times 10^{-3} \mathrm{t}+0.061$ \\
$130<\mathrm{t}<220 \mathrm{~s}$ & $9.0 \times 10^{-3} \mathrm{t}-0.68$ & $=0.099 \mathrm{e}^{0.014 t}$ & $9.0 \times 10^{-6} \mathrm{t}^{2}-1.36 \times 10^{3} \mathrm{t}+0.222$ \\
$220<\mathrm{t}<360 \mathrm{~s}$ & $1.69-1.58 \times 10^{-3} \mathrm{t}$ & $=0.099 \mathrm{e}^{0.014 \mathrm{t}}$ & $-1.58 \times 10^{-6} \mathrm{t}^{2}+3.38 \times 10^{-3} \mathrm{t}-0.300$ \\
\hline
\end{tabular}

Table 14. Flame spread measurements in horizontal flame spread test apparatus over fabric/foam composites [124].

\begin{tabular}{lcccc}
\hline Type & Fabric & & \multicolumn{2}{c}{$\begin{array}{c}\text { Flame spread rate }(\mathrm{mm} / \mathrm{s}) \text { for } \\
\text { external irradiance of }\end{array}$} \\
& $\begin{array}{c}\text { Weight } \\
\left(\mathrm{g} / \mathrm{m}^{2}\right)\end{array}$ & Foam & 0 & $2.5 \mathrm{~kW} / \mathrm{m}^{2}$ \\
\hline olefin & 360 & NFR PU & 3.4 & 7.2 \\
& & FR PU & 3.0 & 5.3 \\
& & NP & $1.4^{\mathrm{b}}$ & 3.8 \\
olefin & 560 & FR PU & $1.0^{\mathrm{b}}$ & 1.8 \\
cotton & 110 & FR PU & 0.6 & 1.5 \\
cotton & 650 & NFR PU & 0.1 & 0.8 \\
& & FR PU & 0 & 0.7 \\
none & & NP & 0 & 0 \\
& & NFR PU & 3.7 & 6.1 \\
& & FR PU & $2.1^{\mathrm{c}}$ & 2.8 \\
\hline
\end{tabular}

a NR PU = ordinary polyurethane.

$F R=$ fire retarded polyurethane.

$\mathrm{NP}=$ neoprene.

b Irregular.

Not constant-flames accelerated along whole specimen length. 
Table 15. Heat release rates of mattresses in NBS tests [153,183].

\begin{tabular}{|c|c|c|c|c|c|c|c|}
\hline Specimen & $\begin{array}{r}\text { Mass } \\
(\mathrm{kg})\end{array}$ & $\begin{array}{l}\text { Combustible } \\
\text { mass } \\
(\mathrm{kg})\end{array}$ & Padding & Ticking & $\begin{array}{l}\text { Peak m } \\
(\mathrm{g} / \mathrm{s})\end{array}$ & $\begin{array}{c}\text { Full-scale } \\
\text { peak q } \\
(\mathrm{kW})\end{array}$ & $\begin{array}{c}\text { Bench-scalec } \\
\dot{\mathrm{q}}^{\prime \prime} \\
\left(\mathrm{kW} / \mathrm{m}^{2}\right)\end{array}$ \\
\hline M04 & 19 & 19 & latex & PVC & NA & $2720^{\mathrm{b} \cdot}$ & 479 \\
\hline M01 & 14 & 14 & PU & PVC & NA & $2630^{\mathrm{b*}}$ & 399 \\
\hline M05 & 6 & 6 & PU & rayon & 46 & $1580^{\mathrm{b}}$ & 179 \\
\hline M09 & 3.2 & 3.2 & PU & PVC & 25 & $810^{b}$ & 152 \\
\hline M20 & 6 & 6 & PU & PVC & & & 175 \\
\hline M02 & 15 & 6 & PU & PVC & 54 & $1620^{b}$ & 138 \\
\hline M 14 & 13 & 13 & FR PU & PVC & - & - & 245 \\
\hline M25 & 17 & 17 & hydrophylic PU & PVC & - & - & 63 \\
\hline M15 & NA & NA & hydrophylic PU & PVC & - & - & 51 \\
\hline M22 & 17 & 17 & hydrophylic PU & PVC & - & & 21 \\
\hline M08 & 18 & 18 & neoprene & cotton (FR) & 7 & $70^{\mathrm{a}}$ & 89 \\
\hline M10 & 6 & 6 & neoprene & PVC & 8 & $70^{a}$ & 83 \\
\hline M07 & 25 & 13 & cotton/jute & cotton (FR) & 6 & $40^{a}$ & 43 \\
\hline M03 & 20 & 11 & cotton (FR) & PVC & 4 & $30^{2}$ & 60 \\
\hline M06 & 20 & 12 & $\begin{array}{l}\text { cotton, } \\
\text { polyester/nylon (FR) }\end{array}$ & polyester & 43 & $970^{b}$ & 127 \\
\hline $\mathrm{T} 67$ & 62.4 & NA & $\begin{array}{l}\text { cotton } / \mathrm{PU} / \text { sisal, } \\
\text { with box spring }\end{array}$ & NA & NA & 660 & NA \\
\hline $\mathrm{T} 74$ & NA & NA & PU/fiber batting & NA & NA & 1700 & NA \\
\hline M21 & 16 & 8 & $\begin{array}{l}\text { neoprene interliner } \\
\text { PU foam, cotton } \\
\text { batting, jute }\end{array}$ & PVC & - & - & 27 \\
\hline
\end{tabular}

${ }^{a}$ Estimaled from mass loss records and $\Delta h_{c}$.

${ }^{\mathrm{b}}$ Estimated from doorway gas concentration

'NBS II calorimer.

* Flashover occurred.

NA-Not available 
Table 16. Heat release rates of mattresses in CSTB tests $[168,169]$.

\begin{tabular}{|c|c|c|c|c|c|c|}
\hline Test & $\begin{array}{r}\text { Mass } \\
(\mathrm{kg}) \\
\end{array}$ & $\begin{array}{c}\text { Combustible } \\
\text { mass } \\
(\mathrm{kg})\end{array}$ & Padding & $\begin{array}{c}\text { Covering } \\
\text { (ticking, sheet, cover) }\end{array}$ & $\begin{array}{c}\text { Peak m } \\
(\mathrm{g} / \mathrm{s})\end{array}$ & $\begin{array}{l}\text { Peak q } \\
(\mathrm{kW})^{2}\end{array}$ \\
\hline 1 & NA & 4.0 & PU & rayon & 26 & 760 \\
\hline 2 & NA & 8.0 & PU & polyester & 9.0 & 240 \\
\hline 10 & 6.8 & 6.8 & PU & rayon, cotton/linen, wool & 17.5 & 460 \\
\hline 11 & 6.4 & 6.4 & PU & $\begin{array}{l}\text { cotton/linen, rayon, } \\
\text { polyester/cotton, acrylic/cotton }\end{array}$ & 60 & 1580 \\
\hline 3 & NA & 8.4 & PU (HD) & polyester, rayon (FR) & 16.7 & 430 \\
\hline 4 & NA & 8.4 & PU (HD) & linen/cotton (FR) & 0.6 & 15 \\
\hline 8 & 11.9 & 11.9 & PU (HD) (FR) & $\begin{array}{l}\text { cotton/linen, polyester (FR), } \\
\text { cotton/linen, wool }\end{array}$ & 6.9 & 180 \\
\hline $9 b$ & 11.4 & 11.4 & PU (FR) & $\begin{array}{l}\text { polyester (FR), polyester/cotton, } \\
\text { acrylic/cotton }\end{array}$ & 1.9 & 50 \\
\hline 5 & 20. & 13.2 & kapok & cotton/linen & 1.4 & 20 \\
\hline 6 & 22.8 & 16.0 & kapok & cotton/linen, wool & 1.0 & 15 \\
\hline 7 & 22.4 & 15.6 & kapok & $\begin{array}{c}\text { cotton, linen, polyester/cotton, } \\
\text { acrylic/cotton }\end{array}$ & 0.95 & 15 \\
\hline
\end{tabular}

${ }^{a}$ Estimated from mass loss records and $\Delta h_{c}$. HD-high density.

NA-Not available. 
Table 17. Heat release rates of chairs in recent NBS tests $[79,102,137,170]$

\begin{tabular}{|c|c|c|c|c|c|c|c|c|c|}
\hline Specimen & $\begin{array}{c}\text { Mass } \\
(\mathrm{kg})\end{array}$ & $\begin{array}{c}\text { Combustible } \\
(\mathrm{kg})\end{array}$ & Style & Frame & Padding & Fabric & Interliner & $\begin{array}{c}\text { Peak m } \\
(\mathrm{g} / \mathrm{s})\end{array}$ & $\begin{array}{c}\text { Peak } \dot{q} \\
(k W)\end{array}$ \\
\hline $\mathrm{C} 12$ & 17.9 & 17.0 & traditional easy chair & wood & cotton & nylon & - & 19.0 & $290^{4}$ \\
\hline F22 & 31.9 & & traditional easy chair & wood & cotton (FR) & cotton & - & 25.0 & 370 \\
\hline F23 & 31.2 & & traditional easy chair & wood & cotton (FR) & olefin & - & 42. & 700 \\
\hline F27 & 29.0 & & traditional easy chair & wood & mixed & cotton & - & 58. & 920 \\
\hline F28 & 29.2 & & traditional easy chair & wood & mixed & cotton & - & 42. & 730 \\
\hline $\mathrm{CO} 2$ & 13.1 & 12.2 & traditional easy chair & wood & cotton, PU & olefin & - & 13.2 & $800^{n}$ \\
\hline $\mathrm{CO3}$ & 13.6 & 12.7 & traditional easy chair & wood & cotton, PU & cotton & - & 17.5 & $460^{3}$ \\
\hline $\mathrm{CO} 1$ & 12.6 & 11.7 & traditional easy chair & wood & cotton, PU & cottom & - & 17.5 & $260^{4}$ \\
\hline $\mathrm{CO} 4$ & 12.2 & 11.3 & tradtional easy chair & wood & PL & nylon & - & 75.7 & $1350^{k}$ \\
\hline $\mathrm{C} 16$ & 19.1 & 18.2 & traditional easy chair & wood & $\mathrm{PL}$ & nylon & neoprene & NA & 180 \\
\hline $\mathrm{F} 25$ & 27.8 & & traditional easy chair & wood & $\mathrm{PL}$ & olefin & - & 80. & 1990 \\
\hline T66 & 23.0 & & traditional easy chair & wood & $\mathrm{PL}$, polyester & cottom & - & 27.7 & 640 \\
\hline $\mathrm{F} 21$ & 28.3 & & traditional easy chair & wood & PU (FR) & olefin & - & 83. & 1970 \\
\hline F24 & 28.3 & & traditional easy chair & wood & $P L^{\prime}(F R)$ & cotton & - & 46. & 700 \\
\hline $\mathrm{C} 13$ & 19.1 & 18.2 & traditional easy chair & wood & $\mathrm{PC}$ & nylon & neoprene & 15.0 & $230^{3}$ \\
\hline $\mathrm{C} 14$ & 21.8 & 20.9 & traditional easy chair & wood & $\mathbf{P U}$ & olefin & neoprene & 13.7 & $220^{3}$ \\
\hline $\mathrm{C} 15$ & 21.8 & 20.9 & traditional easy chair & wood & PU & olefin & neoprene & 13.1 & $210^{\mathrm{b}}$ \\
\hline $\mathrm{T} 49$ & 15.7 & & easy chair & wood & $\mathrm{PL}$ & cotton & - & 14.3 & 210 \\
\hline F26 & 19.2 & & thinner easy chair & wood & PL' (FR) & olefin & - & 61. & 810 \\
\hline F33 & 39.2 & & traditional loveseat & wood & mixed & cotton & - & 75. & 940 \\
\hline F31 & 40.0 & & traditional loveseat & wood & PL' (FR) & olefin & - & 130. & 2890 \\
\hline F32 & 51.5 & & traditional sofa & wood & PU (FR) & olefin & - & 145 . & 3120 \\
\hline T57 & 54.6 & & loveseat & wood & PU. cotton & PVC & - & 61.9 & 1100 \\
\hline T56 & 11.2 & & office chair & wood & latex & PVC & - & 3.1 & 80 \\
\hline $\mathrm{CO} 9 / \mathrm{T} 64$ & 16.6 & 16.2 & foam block chair & wood (part) & $\mathrm{Pu}$, polyester & $\mathrm{PU}$ & - & 19.9 & 460 \\
\hline $\mathrm{CO} 7 / \mathrm{T} 48$ & 11.4 & 11.2 & modern easy chair & polystyrene foam & $\mathrm{PU}$ & PU & - & 38. & 960 \\
\hline $\mathrm{C} 10$ & 12.1 & 8.6 & pedestal chair & rigid $\mathrm{PU}$ foam & $\mathrm{PL}$ & $\mathrm{PU}$ & - & 15.2 & $240^{3}$ \\
\hline $\mathrm{C} 11$ & 14.3 & 14.3 & foam block chair & - & $\mathrm{PU}$ & nỵlon & - & NA & $1810^{b}$ \\
\hline F29 & 14.0 & & traditional easy chair & polypropylene foam & $\mathrm{PU}$ & olefin & - & 72. & 1950 \\
\hline F30 & 25.2 & & traditional easy chair & rigid $\mathrm{PU}$ foam & PU & olefin & - & 41. & 1060 \\
\hline $\mathrm{CO} 8$ & 16.3 & 15.4 & pedestal swivel chair & molded polyethylene & $\mathrm{PU}$ & PVC & - & 112. & $830^{\mathrm{b}}$ \\
\hline $\mathrm{CO} 5$ & 7.3 & 7.3 & bean bag cjaor & - & polystyrene & PVC & - & 22.2 & $370^{-1}$ \\
\hline $\mathrm{CO} 6$ & 20.4 & 20.4 & frameless foam back chair & - & $\mathrm{PU}$ & acrỵlic & - & 151. & $2480^{\mathrm{b}}$ \\
\hline T50 & 16.5 & & waiting room chair & metal & cotton & PVC & - & NA & $<10$ \\
\hline T53 & 15.5 & 1.9 & waiting room chair & metal & $\mathrm{PU}$ & PVC & - & 13.1 & 270 \\
\hline T54 & 27.3 & 5.8 & metal frame loveseat & metal & PU & PVC & - & 19.9 & 370 \\
\hline $\mathrm{T} 75 / \mathrm{F} 20$ & $7.5(x 4)$ & 4) 2.6 & stacking chairs (4) & metal & PU & PVC & - & 7.2 & 160 \\
\hline
\end{tabular}

"Estimated from mass loss records and assumed $\Delta h$."

hEstimated from doorway gas concentrations. 
Table 18. Full-scale chair mockup results and bench-scale rate of heat release measurements [83].

\begin{tabular}{|c|c|c|c|c|c|c|c|}
\hline Test & Foam & Fabric & $\begin{array}{c}\text { Combustible } \\
\text { mass } \\
(\mathrm{kg})\end{array}$ & $\begin{array}{c}\text { Number } \\
\text { of } \\
\text { cushions }\end{array}$ & $\begin{array}{c}\text { Bench-scale } \\
\dot{q}^{\prime \prime} \\
\left(\mathrm{kW} / \mathrm{m}^{2}\right) \\
\end{array}$ & $\begin{array}{c}\text { Actual } \\
\text { Full-scale } \\
\text { peak } \mathrm{q} \\
(\mathrm{kW})\end{array}$ & $\begin{array}{c}\text { Predicted } \\
\text { Full-scale } \\
\text { peak } \dot{\mathrm{q}} \\
(\mathrm{kW}) \\
\end{array}$ \\
\hline 1 & NFR PU & It. olefin & 1.00 & 1 & 259 & 320 & 270 \\
\hline 2 & NFR PU & 1t. olefin & 2.00 & 2 & 259 & 540 & 540 \\
\hline 11 & NFR PU & lt. olefin & 3.11 & 3 & 259 & 1120 & 850 \\
\hline 12.27 & NFR PU & lt. olefin & 4.14 & 4 & 259 & 1460 & 1130 \\
\hline 25 & NFR PU & 1t. olefin & 4.06 & 4 & 259 & 1370 & 1100 \\
\hline $13^{b}$ & NFR PU & 1t. olefin & 2.60 & 4 & 259 & 1050 & 710 \\
\hline 20 & NFR PU & hv. cotton & 5.32 & 4 & 113 & 430 & 630 \\
\hline 3 & FR PU & lt. olefin & 1.17 & 1 & 265 & 260 & 330 \\
\hline 4 & FR PU & lt. olefin & 2.38 & 2 & 265 & 410 & 660 \\
\hline 5,8 & FR PU & It. olefin & 3.53 & 3 & 265 & 790 & 980 \\
\hline $9^{b}$ & FR PU & It. olefin & 2.26 & 3 & 265 & 660 & 630 \\
\hline $7,19^{c}$ & FR PU & It. olefin & 4.77 & 4 & 265 & 1340 & 1330 \\
\hline $26^{c}$ & FR PU & lt. olefin & 4.74 & 4 & 265 & 1460 & 1320 \\
\hline $24^{c}$ & FR PU & 1t. olefin & 4.72 & 4 & 265 & 1160 & 1310 \\
\hline $16^{c}$ & FR PU & lt. olefin & 4.70 & 4 & 265 & 1430 & 1310 \\
\hline $10,23^{b}$ & FR PU & It. olefin & 2.98 & 4 & 265 & 930 & 830 \\
\hline 6 & FR PU & It. olefin & 7.02 & 6 & 265 & 1360 & 1950 \\
\hline 14 & FR PU & hv. olefin & 5.84 & 4 & 304 & 1020 & 1860 \\
\hline 21 & FR PU & lt. cotton & 3.62 & 4 & 137 & 900 & 520 \\
\hline 17 & FR PU & hv. cotton & 5.84 & 4 & 132 & 530 & 810 \\
\hline 15 & NP & It. olefin & 20.08 & 4 & 64 & 120 & a \\
\hline 18 & NP & It. olefin & 9.92 & 4 & 64 & 110 & a \\
\hline 22 & NP & hv. cotton & 21.34 & 4 & 49 & $\sim 0$ & a \\
\hline 29 & NFR PU & none & 2.52 & 4 & & 1210 & d \\
\hline 28 & FR PU & none & 3.02 & 4 & & 760 & d \\
\hline
\end{tabular}

a Prediction method not suitable for high mass, low rate of heat release constructions.

${ }^{\mathrm{b}}$ Half thickness cushions.

c Ignition source variations.

Prediction method not intended for bare foams.

Table 19. Comparison of full-scale to bench-scale heat release rate measurements for rail car seating [188].

\begin{tabular}{|c|c|c|c|c|}
\hline \multirow[b]{2}{*}{$\begin{array}{c}\text { Padding } \\
\text { foam }\end{array}$} & \multirow[b]{2}{*}{ Fabric } & \multicolumn{2}{|c|}{ Bench-scale } & \multirow{2}{*}{$\begin{array}{c}\text { Full-scale }^{b} \\
\text { peak } \dot{q} \\
(\mathrm{~kW})\end{array}$} \\
\hline & & $\begin{array}{c}180 \text { s average } \dot{q}^{\prime \prime} \\
\left(\mathrm{kW} / \mathrm{m}^{2}\right)\end{array}$ & $\begin{array}{l}\text { Peak } \dot{q}^{\prime \prime} \\
\left(k W /{ }^{2}\right)\end{array}$ & \\
\hline PU & none & 139 & 116 & 600 \\
\hline CMHR PU & none & 30 & 77 & 210 \\
\hline neoprene & none & 45 & 10 & 32 \\
\hline neoprene $\mathbf{L S}^{\mathbf{a}}$ & none & 31 & 10 & 27 \\
\hline neoprene & wool/nylon & - & 66 & 220 \\
\hline
\end{tabular}

${ }^{\mathrm{a}}$ Improved, low smoke formulation.

${ }^{\text {b }}$ For tests which included a wool/nylon fabric; furniture calorimeter data. 
Table 20. Mockup tests on aircraft seats using the SwRI calorimeter [216]

\begin{tabular}{|c|c|c|c|c|c|c|}
\hline \multirow[b]{2}{*}{ Specimen } & \multirow{2}{*}{$\begin{array}{c}\text { Combustible } \\
\text { mass } \\
(\mathrm{kg})\end{array}$} & \multirow[b]{2}{*}{ Fabric } & \multirow[b]{2}{*}{ Interliner } & \multirow[b]{2}{*}{ Padding } & \multicolumn{2}{|c|}{ Rate of heat release } \\
\hline & & & & & $\begin{array}{l}\text { Peak } \\
(\mathrm{kW})\end{array}$ & $\begin{array}{c}180 \mathrm{~s} \text { average } \\
(\mathrm{kW})\end{array}$ \\
\hline 1 & 3.6 & wool/nylon & none & PU foam & 107 & 75 \\
\hline 2 & 4.8 & wool/nylon & durette fabric & PU foam & 90 & 61 \\
\hline 4 & 6.6 & kermel/wool & $\begin{array}{l}\text { Nomex fabric over } \\
12 \mathrm{~mm} \text { neoprene }\end{array}$ & PU foam & 70 & 56 \\
\hline 5 & 6.9 & kermel/wool & $\begin{array}{l}\text { Nomex fabric over } \\
12 \mathrm{~mm} \text { neoprene }\end{array}$ & PU foam & 86 & 39 \\
\hline 6 & 4.0 & kermel/wool & none & polyimide foam & 62 & 39 \\
\hline 7 & 2.5 & wool & none & polyimide foam & 65 & 50 \\
\hline 8 & 3.0 & wool & none & polyimide foam & 62 & 56 \\
\hline
\end{tabular}

Table 21. Upholstered furniture components listed in approximate order of descending ignition resistance.

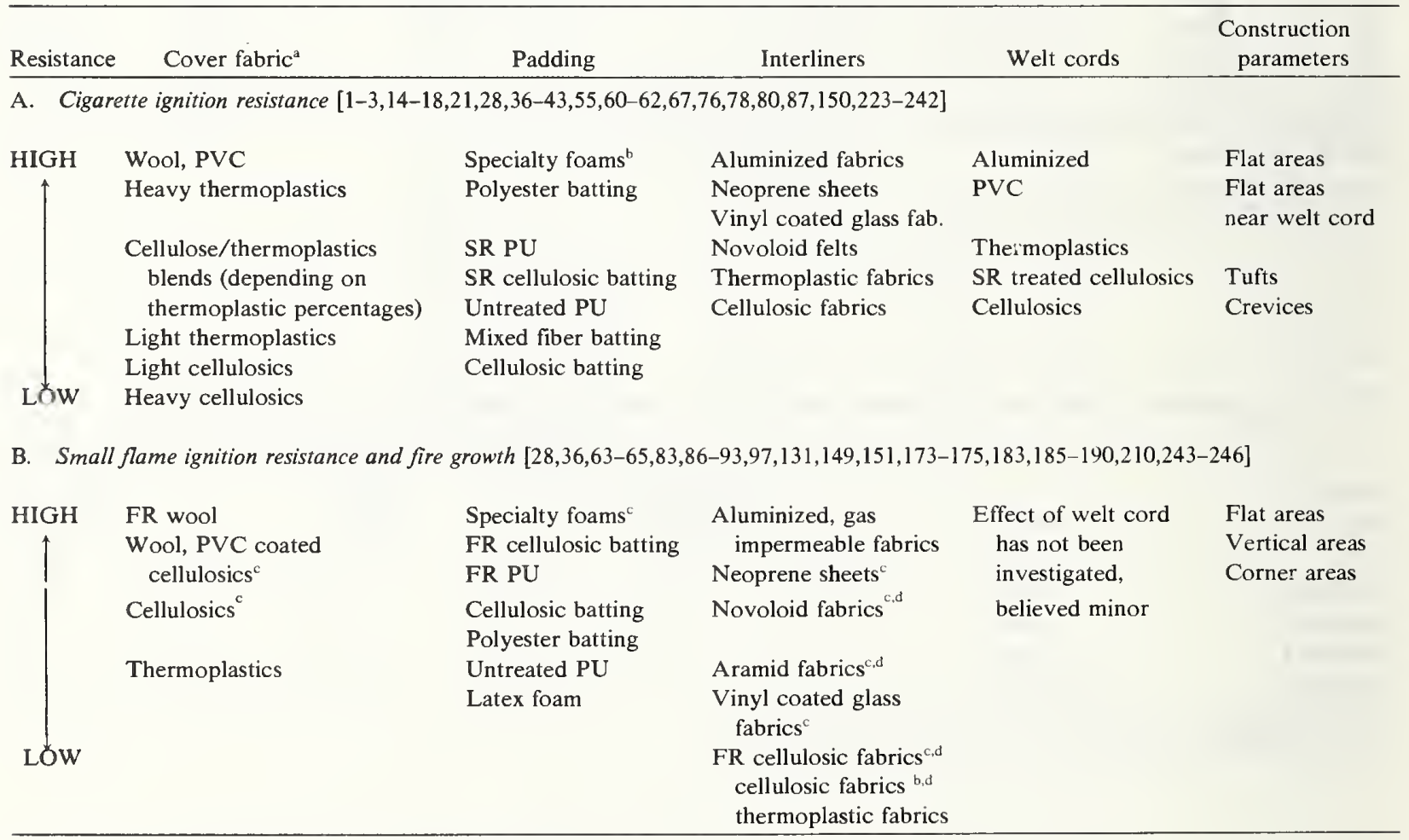

SR-smolder resistant; FR-flame resistant; PU-polyurethane foam.

${ }^{a}$ Data on the behavior of acrylic are sparse but it seems to act more like cellulosics (smolder) than thermoplastics.

${ }^{\mathrm{b}}$ Neoprene; combustion modified, high resiliency PU.

${ }^{c}$ Heavier materiais have higher ignition resistance and generally higher heat release and lower flame spread rate.

${ }^{d}$ Fabrics here includes woven, knitted and rewoven structures. 
Table 22. Cigarette ignition resistance of typical fabric/padding material combinations

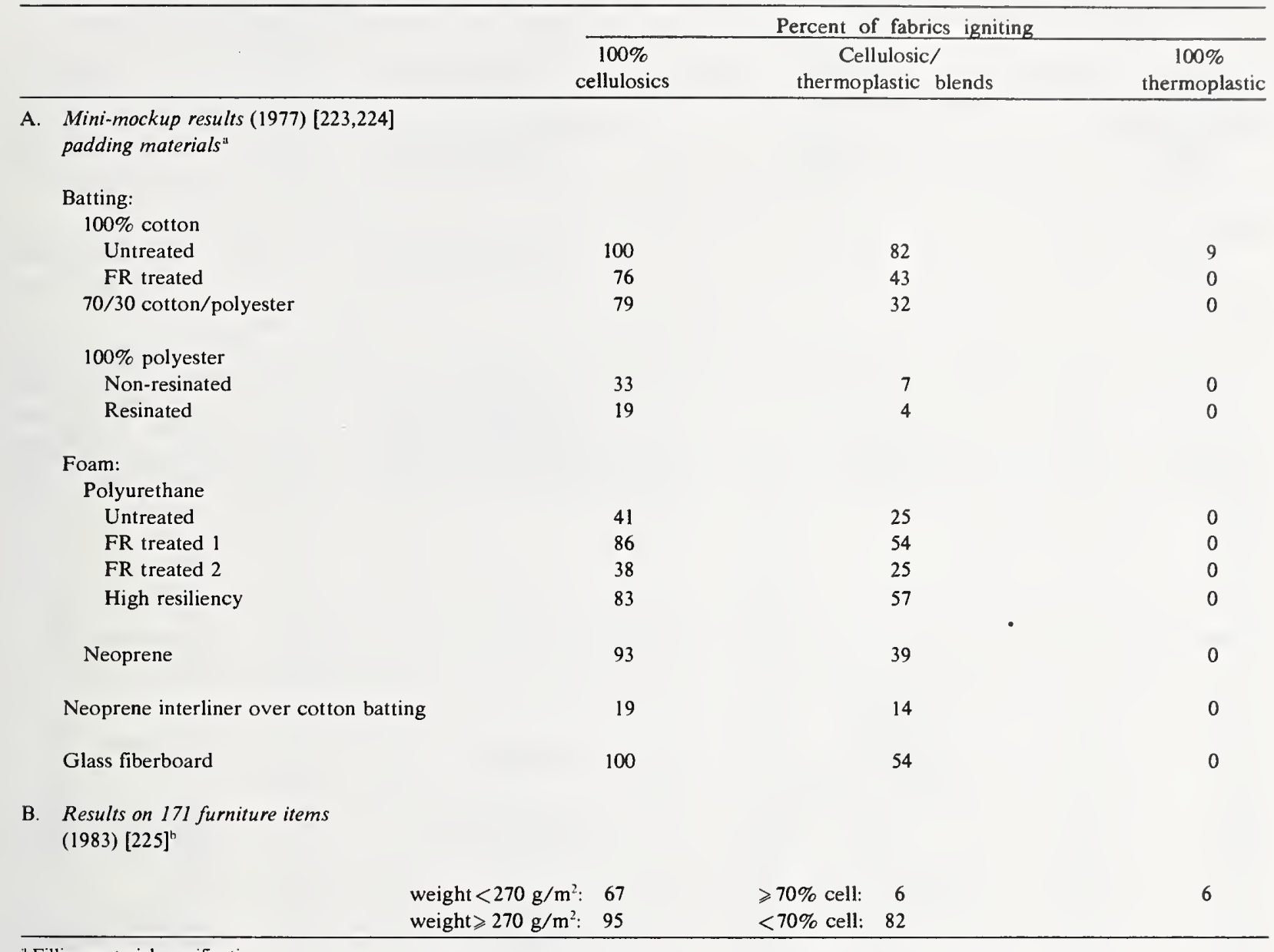

"Filling material specifications:

Materials

1. Batting:

$100 \%$ cotton, untreated

Density, $\mathrm{kg} / \mathrm{m}^{3}$

FR cotton (12-15\% boric acid)

$70 / 30$ cotton polyester, bonded

$100 \%$ polyester, resinated ( $28 \%$ acrylic resin)

$100 \%$ polyester, non-resinated (with polyester scrim)

2. Foam:

Untreated PU

FR PU 1 (antimony trioxide and PVC)

FR PU 2 (brominated biphenyl)

High resiliency PU (brominated organophosphate)

Neoprene ( $4 \%$ antimony trioxide, $16 \%$ alumina trihydrate)

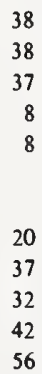

3. Neoprene interliner: $5 \mathrm{~mm}$ thick with cotton scrim backing $950 \mathrm{~g} / \mathrm{m}^{2}$

${ }^{\mathrm{b}}$ Various filling materials 
Table 23. Effect of fabric type on heat release rate (within each group all other construction features were kept constant).

\begin{tabular}{|c|c|c|c|}
\hline Specimen & $\begin{array}{c}\text { Full-scale } \\
\text { peak } \dot{\mathrm{q}} \\
(\mathrm{kW})\end{array}$ & Fabric & Padding \\
\hline \multicolumn{4}{|l|}{ Group 1 [102] } \\
\hline F24 & 700 & cotton $\left(750 \mathrm{~g} / \mathrm{m}^{2}\right)$ & FR PU foam \\
\hline F21 & 1970 & polyolefin $\left(560 \mathrm{~g} / \mathrm{m}^{2}\right)$ & FR PU foam \\
\hline \multicolumn{4}{|l|}{ Group 2 [102] } \\
\hline $\mathrm{F} 22$ & 370 & cotton $\left(750 \mathrm{~g} / \mathrm{m}^{2}\right)$ & cotton batting \\
\hline F23 & 700 & polyolefin $\left(560 \mathrm{~g} / \mathrm{m}^{2}\right)$ & cotton batting \\
\hline \multicolumn{4}{|l|}{ Group 3 [83] } \\
\hline 28 & 760 & none & FR PU foam \\
\hline 17 & 530 & cotton $\left(650 \mathrm{~g} / \mathrm{m}^{2}\right)$ & FR PU foam \\
\hline 21 & 900 & cotton $\left(110 \mathrm{~g} / \mathrm{m}^{2}\right)$ & FR PU foam \\
\hline 14 & 1020 & polyolefin $\left(650 \mathrm{~g} / \mathrm{m}^{2}\right)$ & FR PU foam \\
\hline 7,19 & 1340 & polyolefin $\left(360 \mathrm{~g} / \mathrm{m}^{2}\right)$ & FR PU foam \\
\hline
\end{tabular}

Table 24. Effect of padding type on maximum heat release rate (within each group all other construction features were kept constant).

\begin{tabular}{|c|c|c|c|}
\hline Specimen & $\begin{array}{c}\text { Full-scale } \\
\text { peak } \dot{\mathrm{q}} \\
(\mathrm{kW})\end{array}$ & Padding & Fabric \\
\hline & Group 1 [102] & & \\
\hline F21 & 1970 & FR PU foam & polyolefin $\left(560 \mathrm{~g} / \mathrm{m}^{2}\right)$ \\
\hline \multirow[t]{2}{*}{ F25 } & 1990 & NFR PU foam & polyolefin $\left(560 \mathrm{~g} / \mathrm{m}^{2}\right)$ \\
\hline & Group 2 [102] & & \\
\hline F21 & 1970 & FR PU foam & polyolefin $\left(560 \mathrm{~g} / \mathrm{m}^{2}\right)$ \\
\hline \multirow[t]{2}{*}{ F23 } & 700 & cotton batting & polyolefin $\left(560 \mathrm{~g} / \mathrm{m}^{2}\right)$ \\
\hline & Group 3 [102] & & \\
\hline F24 & 700 & FR PU foam & cotton $\left(750 \mathrm{~g} / \mathrm{m}^{2}\right)$ \\
\hline \multirow[t]{2}{*}{ F22 } & 370 & cotton batting & cotton $\left(750 \mathrm{~g} / \mathrm{m}^{2}\right)$ \\
\hline & Group 4 [83] & & \\
\hline 12,27 & $1460^{\circ}$ & NFR PU foam & polyolefin $\left(360 \mathrm{~g} / \mathrm{m}^{2}\right)$ \\
\hline 7,19 & 1340 & FR PU foam & polyolefin $\left(360 \mathrm{~g} / \mathrm{m}^{2}\right)$ \\
\hline \multirow[t]{2}{*}{15} & 120 & neoprene foam & polyolefin $\left(360 \mathrm{~g} / \mathrm{m}^{2}\right)$ \\
\hline & Group 5 [83] & & \\
\hline 20 & 430 & NFR PU foam & cotton $\left(650 \mathrm{~g} / \mathrm{m}^{2}\right)$ \\
\hline 17 & 530 & FR PU foam & cotton $\left(650 \mathrm{~g} / \mathrm{m}^{2}\right)$ \\
\hline 22 & $\sim 0$ & neoprene foam & cotton $\left(650 \mathrm{~g} / \mathrm{m}^{2}\right)$ \\
\hline
\end{tabular}

Table 25. Effect of frame material for specimens with NFR PU padding and polyokfin fabrics [137].

\begin{tabular}{|c|c|c|c|c|}
\hline Specimen & $\begin{array}{c}\text { Mass } \\
(\mathrm{kg})\end{array}$ & $\begin{array}{l}\text { Peak } \dot{q} \\
(k W)\end{array}$ & $\begin{array}{r}\text { Peak } \dot{\mathrm{q}} \\
\div \text { mass }\end{array}$ & Frame \\
\hline F25 & 27.8 & 1990 & 72. & wood \\
\hline F30 & 25.2 & 1060 & 42. & polyurethane \\
\hline F29 & 14.0 & 1950 & 139. & polypropylene \\
\hline
\end{tabular}


Table 26. Effect of specimen mass on the heat release rate of polyurethane foam padded specimens of similar construction [137].

\begin{tabular}{ccccc}
\hline Specimen & $\begin{array}{c}\text { Peak q } \\
(\mathrm{kW})\end{array}$ & $\begin{array}{c}\text { Mass } \\
(\mathrm{kg})\end{array}$ & $\begin{array}{c}\text { Peak } \dot{\mathrm{q}} \\
\div \text { mass }\end{array}$ & Type \\
\hline F26 & 810 & 19.2 & 42 & 70 \\
F21 & 1970 & 28.2 & 72 & minimum weight chair \\
standard chair \\
F31
\end{tabular}

Table 27. Rate of heat release peak values for upholstered chairs-measured and predicted values $[79,102,137,170]$.

\begin{tabular}{|c|c|c|c|c|c|c|c|c|c|}
\hline Specimen & $\begin{array}{c}\text { Mass } \\
\text { factor }\end{array}$ & $\begin{array}{l}\text { Frame } \\
\text { factor }\end{array}$ & $\begin{array}{l}\text { Style } \\
\text { factor }\end{array}$ & $\begin{array}{c}\text { Padding } \\
\text { factor }\end{array}$ & $\begin{array}{l}\text { Fabric } \\
\text { factor }\end{array}$ & $\begin{array}{c}\text { Predicted }^{\mathrm{b}} \\
\dot{\mathrm{q}} \\
(\mathrm{kW}) \\
\end{array}$ & $\begin{array}{c}\text { Bench-scale } \\
\dot{\mathrm{q}}^{\prime \prime} \\
\left(\mathrm{kW} / \mathrm{m}^{2}\right) \\
\end{array}$ & $\begin{array}{c}\text { Predicted }^{3} \\
\dot{q} \\
(\mathrm{~kW}) \\
\end{array}$ & $\begin{array}{c}\text { Actual } \\
\dot{q} \\
(\mathrm{~kW}) \\
\end{array}$ \\
\hline $\mathrm{CO1}$ & 11.7 & 0.30 & 1.2 & 1.0 & 0.4 & 350 & & & 260 \\
\hline $\mathrm{CO} 2$ & 12.2 & 0.30 & 1.2 & 1.0 & 1.0 & 920 & & & 800 \\
\hline $\mathrm{CO} 3$ & 12.7 & 0.30 & 1.2 & 1.0 & 1.0 & 960 & & & 460 \\
\hline $\mathrm{CO} 4$ & 11.3 & 0.30 & 1.2 & 1.0 & 1.0 & 850 & & & 1350 \\
\hline $\mathrm{C} 07$ & 11.2 & 0.58 & 1.3 & 1.0 & 1.0 & 1560 & & & 1000 \\
\hline $\mathrm{C} 08$ & 15.4 & 0.58 & 1.2 & 1.0 & 0.25 & 500 & & & 830 \\
\hline $\mathrm{C} 10$ & 8.6 & 0.18 & 1.3 & 1.0 & 1.0 & 350 & & & 240 \\
\hline $\mathrm{C} 12$ & 17.0 & 0.30 & 1.2 & 0.4 & 1.0 & 510 & & & 290 \\
\hline F21 & 28.3 & 0.30 & 1.0 & 1.0 & 1.0 & 1780 & 326 & 1740 & 1970 \\
\hline F22 & 31.9 & 0.30 & 1.0 & 0.4 & 0.4 & 320 & 83 & 500 & 370 \\
\hline F23 & 31.2 & 0.30 & 1.0 & 0.4 & 1.0 & 790 & 128 & 750 & 700 \\
\hline F24 & 28.3 & 0.30 & 1.0 & 1.0 & 0.4 & 710 & 119 & 640 & 700 \\
\hline F25 & 27.8 & 0.30 & 1.0 & 1.0 & 1.0 & 1950 & 357 & 1880 & 1990 \\
\hline F26 & 19.2 & 0.30 & 1.0 & 1.0 & 1.0 & 1210 & 326 & 1180 & 810 \\
\hline F27 & 29.0 & 0.30 & 1.2 & 1.0 & 0.4 & 880 & 204 & 1340 & 920 \\
\hline F28 & 29.2 & 0.30 & 1.2 & 1.0 & 0.4 & 880 & 99 & 660 & 730 \\
\hline F29 & 14.0 & 0.58 & 1.2 & 1.0 & 1.0 & 1820 & 357 & 1950 & 1950 \\
\hline F30 & 25.2 & 0.18 & 1.2 & 1.0 & 1.0 & 950 & 357 & 1020 & 1060 \\
\hline F31 & 40.0 & 0.30 & 1.0 & 1.0 & 1.0 & 2520 & 326 & 2460 & 2890 \\
\hline F32 & 51.1 & 0.30 & 1.0 & 1.0 & 1.0 & 3220 & 326 & 3150 & 3120 \\
\hline F33 & 39.2 & 0.30 & 1.0 & 1.0 & 0.4 & 990 & NA & NA & 940 \\
\hline T49 & 15.7 & 0.30 & 1.0 & 1.0 & 0.4 & 400 & & & 210 \\
\hline T53 & 1.9 & 1.66 & 1.0 & 1.0 & 0.25 & 170 & & & 270 \\
\hline T54 & 5.8 & 1.66 & 1.0 & 1.0 & 0.25 & 510 & & & 370 \\
\hline T56 & 11.2 & 0.30 & 1.0 & 1.0 & 0.25 & 180 & & & 80 \\
\hline T57 & 54.6 & 0.30 & 1.0 & 1.0 & 0.25 & 860 & & & 1100 \\
\hline T66 & 23.5 & 0.30 & 1.0 & 1.0 & 0.4 & 580 & & & 640 \\
\hline
\end{tabular}

${ }^{a}$ Based on generic factors for padding and fabric.

${ }^{b}$ Based on actual bench-scale measurements.

NA-Not available.

Table 28. Heats of gasification for aircraft seat materials [210].

\begin{tabular}{|c|c|c|c|c|c|}
\hline \multirow[b]{2}{*}{ Padding foanı } & \multirow[b]{2}{*}{ Interliner } & \multirow[b]{2}{*}{ Fabric } & \multicolumn{3}{|c|}{$120 \mathrm{~s}$ average heats of gasification $(\mathrm{kJ} / \mathrm{kg})$ at irradiance of } \\
\hline & & & $25 \mathrm{~kW} / \mathrm{m}^{2}$ & $50 \mathrm{~kW} / \mathrm{m}^{2}$ & $75 \mathrm{~kW} / \mathrm{m}^{2}$ \\
\hline $\overrightarrow{\text { FR PU }}$ & none & none & $4.8 \times 10^{3}$ & NA & NA \\
\hline FR PU & none & wool/nylon & $19 \times 10^{3}$ & $8 \times 10^{3}$ & NA \\
\hline polyimide & none & wool/nylon & $\rightarrow \infty$ & $\rightarrow \infty$ & $\rightarrow \infty$ \\
\hline FR PU & Vonar 3 & wool/nylon & $60 \times 10^{3}$ & $19 \times 10^{3}$ & $27 \times 10^{3}$ \\
\hline NFR PU & Vonar 3 & wool/nylon & $190 \times 10^{3}$ & $19 \times 10^{3}$ & $27 \times 10^{3}$ \\
\hline FR PU & fiberglass & wool/nylon & $63 \times 10^{3}$ & $20 \times 10^{3}$ & N.A. \\
\hline FR PU & Norfab $^{a}$ & wool/nylon & $94 \times 10^{3}$ & $21 \times 10^{3}$ & $11 \times 10^{3}$ \\
\hline NFR PU & Norfab ${ }^{a}$ & wool/nylon & $210 \times 10^{3}$ & $45 \times 10^{3}$ & $38 \times 10^{3}$ \\
\hline
\end{tabular}

a $70 \%$ Kevlar, $25 \%$ Nomex, $5 \%$ Kynol; aluminized layer.

NA-Not available. 
Table 29. Comparison of full-scale and bench-scale heat release rate results for aircraft seats [218].

\begin{tabular}{|c|c|c|c|c|c|c|c|c|c|}
\hline \multirow[b]{2}{*}{$\begin{array}{l}\text { Specimen } \\
\text { number }\end{array}$} & \multirow[b]{2}{*}{$\begin{array}{l}\text { Padding } \\
\text { foam }\end{array}$} & \multirow[b]{2}{*}{ Interliner } & \multirow[b]{2}{*}{ Fabric } & \multicolumn{3}{|c|}{ Full-scale results } & \multicolumn{3}{|c|}{$\begin{array}{l}\text { Bench-scale ignitability (piloted) } \\
\text { ignition time(s) at irradiance of }\end{array}$} \\
\hline & & & & $\begin{array}{l}\text { Total mass } \\
\text { lost }(\mathrm{kg})\end{array}$ & \multicolumn{2}{|c|}{$\begin{array}{l}\text { Fraction mass } \\
\text { lost }(\%)\end{array}$} & $25 \mathrm{~kW} / \mathrm{m}^{2}$ & $50 \mathrm{~kW} / \mathrm{m}^{2}$ & $75 \mathrm{~kW} / \mathrm{m}^{2}$ \\
\hline 1 & FR PU & none & wool/nylon & 1.19 & \multicolumn{2}{|c|}{71.19} & $\infty$ & 12 & 6 \\
\hline 2 & FR PU & Vonar 3 & wool/nylon & 0.11 & \multicolumn{2}{|c|}{4.15} & $\infty$ & 12 & 6 \\
\hline 6 & FR PU & Norfab & wool/nylon & 0.10 & \multicolumn{2}{|c|}{4.11} & 33 & 12 & 6 \\
\hline 9 & NFR PU & Norfab & wool/nylon & 0.13 & \multicolumn{2}{|c|}{5.76} & $\infty$ & 12 & 6 \\
\hline 7 & FR PU & fiberglass & wool/nylon & NA & \multicolumn{2}{|c|}{ NA } & 71 & 12 & 6 \\
\hline 10 & neoprene & none & wool/nylon & 0.10 & \multicolumn{2}{|c|}{2.33} & $\infty$ & 12 & 6 \\
\hline 11 & polyimide & none & wool/nylon & 0.13 & \multicolumn{2}{|c|}{10.85} & $\infty$ & 12 & 6 \\
\hline \multirow{3}{*}{$\begin{array}{l}\text { Specimen } \\
\text { number }\end{array}$} & \multirow{2}{*}{\multicolumn{3}{|c|}{$\begin{array}{l}\frac{\text { FAA Bench-Scale Tests (OSU) }}{180 \mathrm{~s} \text { average heat release }} \\
\text { rates }\left(\mathrm{kW} / \mathrm{m}^{2}\right) \text {, at irradiance of }\end{array}$}} & \multirow{2}{*}{\multicolumn{3}{|c|}{$\begin{array}{l}\text { Boeing Bench-Scale Tests (OSU) } \\
\begin{array}{c}180 \mathrm{~s} \text { average heat release } \\
\text { rates }\left(\mathrm{kW} / \mathrm{m}^{2}\right), \text { at irradiance of }\end{array}\end{array}$}} & \multirow{2}{*}{\multicolumn{3}{|c|}{$\begin{array}{c}\text { Douglas Bench-Scale Tests (OSU) } \\
\begin{array}{c}180 \mathrm{~s} \text { average heat release } \\
\text { rates }\left(\mathrm{kW} / \mathrm{m}^{2}\right) \text {, at irradiance of }\end{array}\end{array}$}} \\
\hline & & & & & & & & & \\
\hline & $25 \mathrm{~kW} / \mathrm{m}^{2}$ & $50 \mathrm{~kW} / \mathrm{m}^{2}$ & $75 \mathrm{~kW} / \mathrm{m}^{2}$ & $25 \mathrm{~kW} / \mathrm{m}^{2}$ & $50 \mathrm{~kW} / \mathrm{m}^{2}$ & $75 \mathrm{~kW} / \mathrm{m}^{2}$ & $25 \mathrm{~kW} / \mathrm{m}^{2}$ & $50 \mathrm{~kW} / \mathrm{m}^{2}$ & $75 \mathrm{~kW} / \mathrm{m}^{2}$ \\
\hline 1 & 3.0 & 86 & 100 & 105 & 100 & 86 & 34 & 38 & NA \\
\hline 2 & 2.7 & 42 & 65 & 35 & 84 & 90 & 11 & 36 & NA \\
\hline 6 & 3.9 & 36 & 69 & 71 & 120 & 102 & 42 & 47 & NA \\
\hline 9 & 3.2 & 40 & 75 & 74 & 96 & 84 & 36 & 42 & NA \\
\hline 7 & 3.8 & 61 & 83 & 86 & 102 & 92 & NA & NA & NA \\
\hline 10 & 2.9 & 35 & 46 & 39 & 61 & 40 & NA & NA & NA \\
\hline 11 & 3.9 & 45 & 59 & 56 & 65 & 49 & NA & NA & NA \\
\hline
\end{tabular}

Table 30. Typical heats of combustion measured in the oxygen bomb calorimeter for upholstered furniture components [124,183].

\begin{tabular}{lcc}
\hline Material & $\begin{array}{c}\text { Heat of combustion, gross (MJ/kg) } \\
\text { Average }\end{array}$ & Range \\
\hline cotton & 18.1 & $17.4-20.4$ \\
cotton/polyester & 21.2 & $19.7-22.3$ \\
jute & 23.4 & \\
latex & 40.6 & \\
neoprene, FR & & \\
$\quad$ black & 25.8 & $24.8-26.8$ \\
$\quad$ buff, bulk & 15.6 & $15.3-15.8$ \\
$\quad$ buff, interliner & 9.7 & \\
polyester & 25.8 & $47.5-49.5$ \\
polypropylene & 48.5 & \\
polyurethane & & $26.1-31.6$ \\
$\quad$ NFR & 30.5 & $24.0-24.3$ \\
$\quad$ FR & 24.2 & $10.1-12.8$ \\
$\quad$ hydrophilic & 11.5 & $22.8-26.0$ \\
polyvinylchloride (PVC) & 25.1 & $17.3-23.6$ \\
PVC-nitrile & 20.5 & $13.6-19.5$ \\
rayon & 16.5 & \\
\hline
\end{tabular}


Table 31. Effective heats of combustion as measured in full-scale or bench-scale tests on furniture and mattresses [124,137,173,183].

\begin{tabular}{|c|c|c|c|c|}
\hline Padding & $\begin{array}{l}\text { Construction } \\
\text { fabric }\end{array}$ & Frame & $\begin{array}{l}\text { Peak effective } \\
\text { heat of combustion } \\
(\mathrm{MJ} / \mathrm{kg})\end{array}$ & $\begin{array}{l}\text { Average effective } \\
\text { heat of combustion } \\
(\mathrm{MJ} / \mathrm{kg})\end{array}$ \\
\hline PU foam & polyolefin & wood & 23.7 & 18.0 \\
\hline PU foam & cotton & wood & 15.1 & 14.6 \\
\hline cotton & polyolefin & wood & 16.8 & 16.1 \\
\hline cotton & cotton & wood & 14.8 & 14.9 \\
\hline PU foam & polyolefin & polyurethane & 26.0 & 20.9 \\
\hline PU foam & polyolefin & polypropylene & - & 35.1 \\
\hline PU foam & polyolefin & (non-combustible) & -- & 30.4 \\
\hline PU foam & acrylic & (non-combustible) & $22.0-24.8$ & $18.4-22.9$ \\
\hline PU foam & cotton & (non-combustible) & -- & 25.2 \\
\hline PU foam & wool & (non-combustible) & 26.7 & 21.7 \\
\hline PU foam & cotton, rayon & - - $^{\prime \prime}$ & -. & $14.4-23.0^{\mathrm{h}}$ \\
\hline PU foam & PVC & $--^{\prime}$ & -- & $12.7-24.9^{\mathrm{h}}$ \\
\hline PU foam & PVC & $--^{a}$ & -- & 8.8 \\
\hline \multicolumn{5}{|l|}{ (hydrophilic) } \\
\hline cotton & cotton & $--^{a}$ & - & 5.7 \\
\hline cotton & PVC & $--^{*}$ & -- & 7.5 \\
\hline latex & PVC & $--^{a}$ & -- & 28.0 \\
\hline neoprene & cotton & $--^{a}$ & -- & 6.7 \\
\hline
\end{tabular}

${ }^{a}$ None (mattress data).

${ }^{\mathrm{b}}$ Lower values for FR grades, higher for non-FR

Table 32. Smoke production for a series of mattresses $[183,267]$.

\begin{tabular}{lccl}
\hline Specimen & $\begin{array}{c}\text { Core } \\
\text { material }\end{array}$ & $\begin{array}{c}\sigma_{\mathrm{m}} \\
\left(\mathrm{m}^{2} / \mathrm{kg}\right)\end{array}$ & $\begin{array}{c}\Gamma_{\mathrm{s}} \\
(-)\end{array}$ \\
\hline M01 & PU foam & 757 & 0.10 \\
M02 & PU foam & 833 & 0.11 \\
M03 & cotton batting & 383 & 0.05 \\
M04 & latex foam & 0.20 \\
M05 & PU foam & 1504 & 0.023 \\
M06 & mixed fibers batting & 176 & 0.040 \\
M07 & cotton batting & 304 & 0.005 \\
M08 & neoprene & 39 & 0.12 \\
M09 & PU foam & 924 & 0.10 \\
M10 & neoprene & 779 & 0.14 \\
M11 & neoprene & 1076 & 0.059 \\
M12 & neoprene & 450 & 0.034 \\
M13 & neoprene & 258 & 0.15 \\
M14 & FR PU foam & 1150 & 0.14 \\
M16 & FR PU foam & 1083 & 0.13 \\
M17 & mixed & 993 & 0.040 \\
M18 & neoprene & 306 & 0.031 \\
M19 & polyester batting & 236 & 0.033 \\
M20 & PU foam & 249 & 0.15 \\
M21 & mixed & 1159 & 0.11 \\
M22 & b5 & 978 & 0.13 \\
M25 & hydrophilic FR PU foam & 385 & 0.05 \\
\hline
\end{tabular}

a PU foam, rayon, cotton batting, scrap felt.

${ }^{b}$ Neoprene interliner, PU foam, cotton batting, jute. 
Table 33. Comparison of smoke production results for upholstered furniture.

\begin{tabular}{|c|c|c|c|c|c|c|}
\hline \multirow[b]{2}{*}{$\begin{array}{l}\text { Specimen } \\
\text { test }\end{array}$} & \multirow[b]{2}{*}{ Padding } & \multirow[b]{2}{*}{ Fabric } & \multirow{2}{*}{$\begin{array}{c}\text { Full-scale } \\
\text { peak } \sigma_{\mathrm{m}} \\
\left(\mathrm{m}^{2} / \mathrm{kg}\right)\end{array}$} & \multicolumn{3}{|c|}{ Bench-scale } \\
\hline & & & & $\begin{array}{c}\text { Peak } \sigma_{\mathrm{m}} \\
\left(\mathrm{m}^{2} / \mathrm{kg}\right)\end{array}$ & $\begin{array}{c}\sigma_{\mathrm{m}} \text { at peak } \\
\left(\mathrm{m}^{2} / \mathrm{kg}\right)\end{array}$ & $\begin{array}{c}\text { Avg. } \sigma_{\mathrm{m}} \\
\left(\mathrm{m}^{2} / \mathrm{kg}\right)\end{array}$ \\
\hline \multicolumn{7}{|c|}{ Upholstered furniture (F21-F33) series [137] } \\
\hline $\mathrm{F} 25$ & NFR PU & LO & 236 & 880 & 420 & 562 \\
\hline $\mathrm{F} 21,26,31,32$ & FR PU & LO & 258 & 770 & 535 & 578 \\
\hline $\mathrm{F} 24$ & FR PU & $\mathrm{HC}$ & 99 & 295 & 43 & 82 \\
\hline $\mathrm{F} 23$ & FR C & LO & 152 & 443 & 393 & 121 \\
\hline $\mathrm{F} 22$ & FR C & $\mathrm{HC}$ & 84 & 222 & NA & 15 \\
\hline \multicolumn{7}{|l|}{ Mockup Series [83] } \\
\hline $12, \mathrm{i} 7$ & NFR PU & LO & 422 & 1050 & 602 & 624 \\
\hline 7,19 & FR PU & LO & 520 & NA & 600 & 706 \\
\hline 14 & FR PU & $\mathrm{HO}$ & 403 & 1360 & 690 & 610 \\
\hline 20 & NFR PU & $\mathrm{HC}$ & 137 & 516 & 111 & 102 \\
\hline 21 & FR PU & LC & 243 & 530 & 530 & 359 \\
\hline 17 & FR PU & $\mathrm{HC}$ & 167 & 487 & 57 & 118 \\
\hline 15 & $\mathrm{NP}$ & LO & 783 & 877 & 733 & 393 \\
\hline 29 & NFR PU & none & 137 & 382 & 367 & 275 \\
\hline 28 & FR PU & none & 296 & 590 & 455 & 510 \\
\hline $\begin{array}{l}\text { NFR PU = } \\
\text { FR PU =fit } \\
\text { NP }=\text { neopr } \\
\text { FR C = fire } \\
\text { LO = light } \\
\text { HO = heavs } \\
\text { LC }=\text { light } \\
\text { HC = heavs }\end{array}$ & $\begin{array}{l}\text { fire retareded } \\
\text { arded polyur } \\
\text { ded cotton b } \\
\text { in } \\
\text { n }\end{array}$ & ane foam & & . & & \\
\hline
\end{tabular}




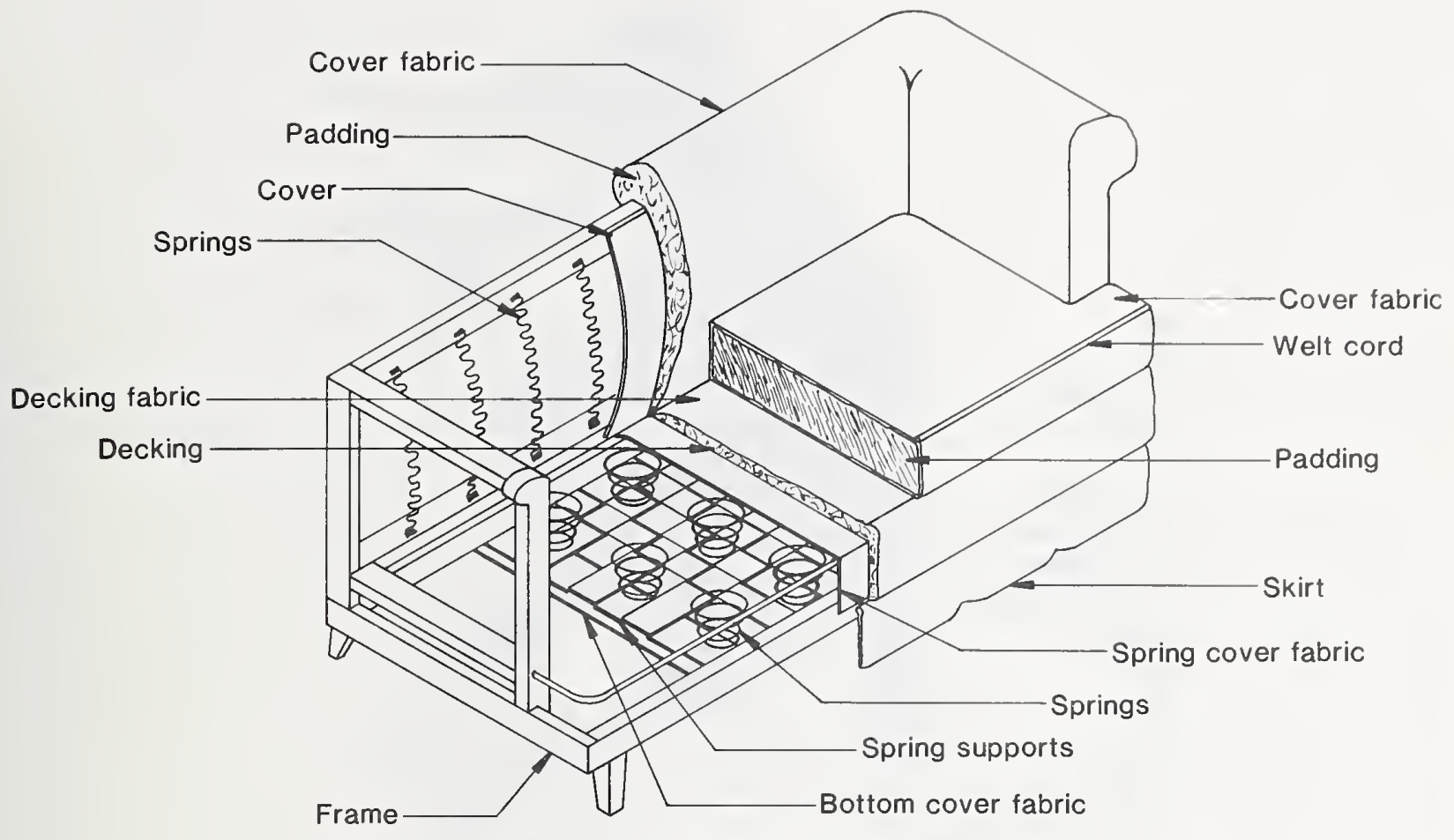

Figure 1. Upholstered furniture construction details.
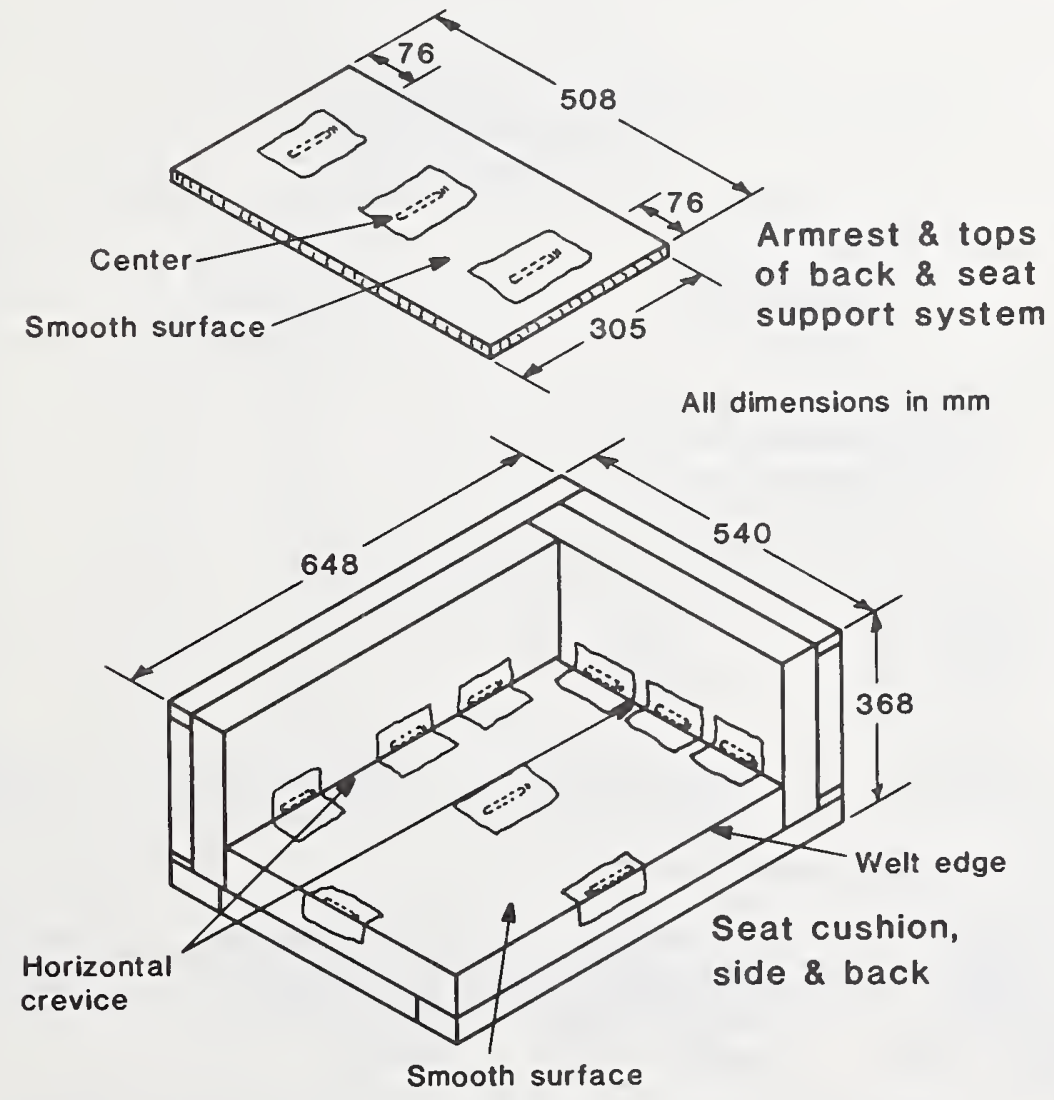

Figure 2. Mockup for testing cigarette ignition resistance of upholstèred furniture. 


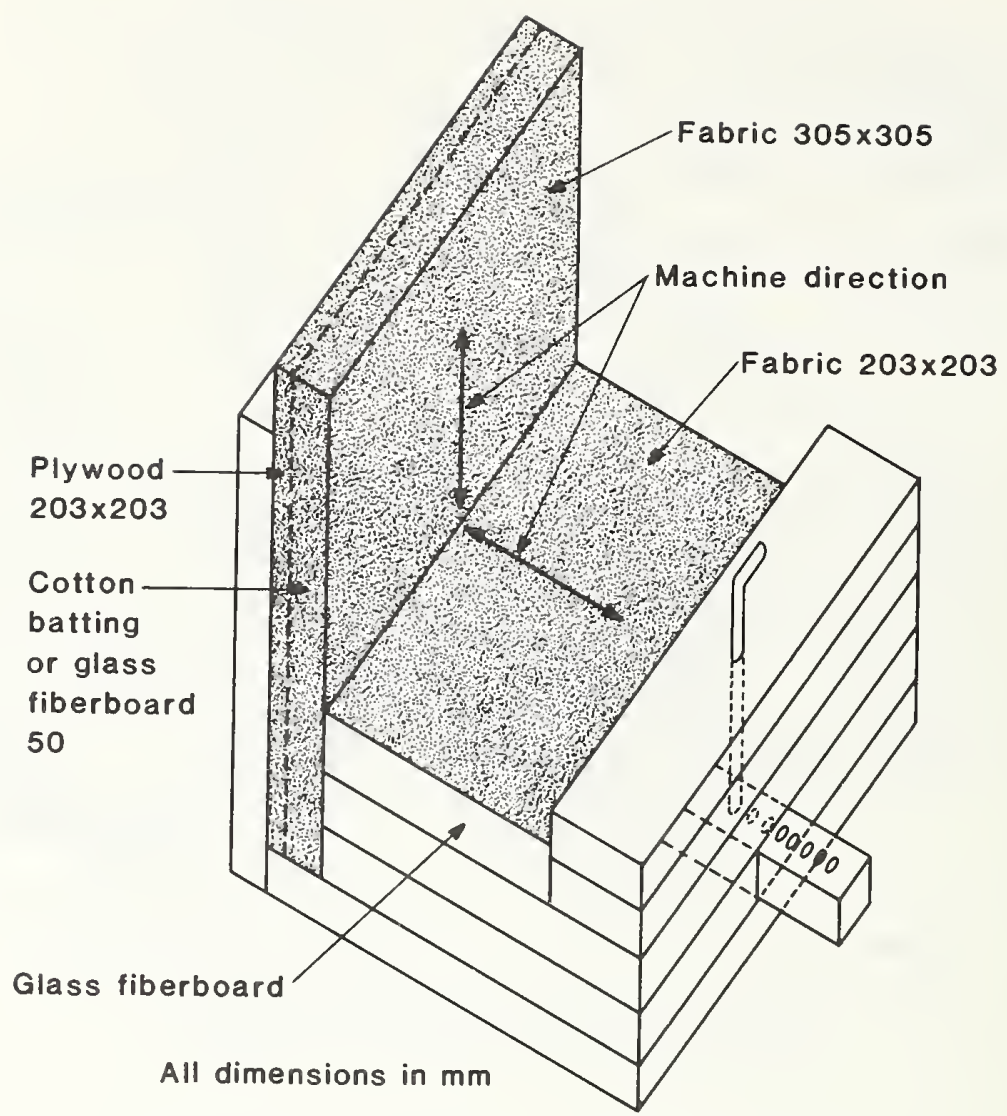

Figure 3. Mini-mockup for determining fabric classification.

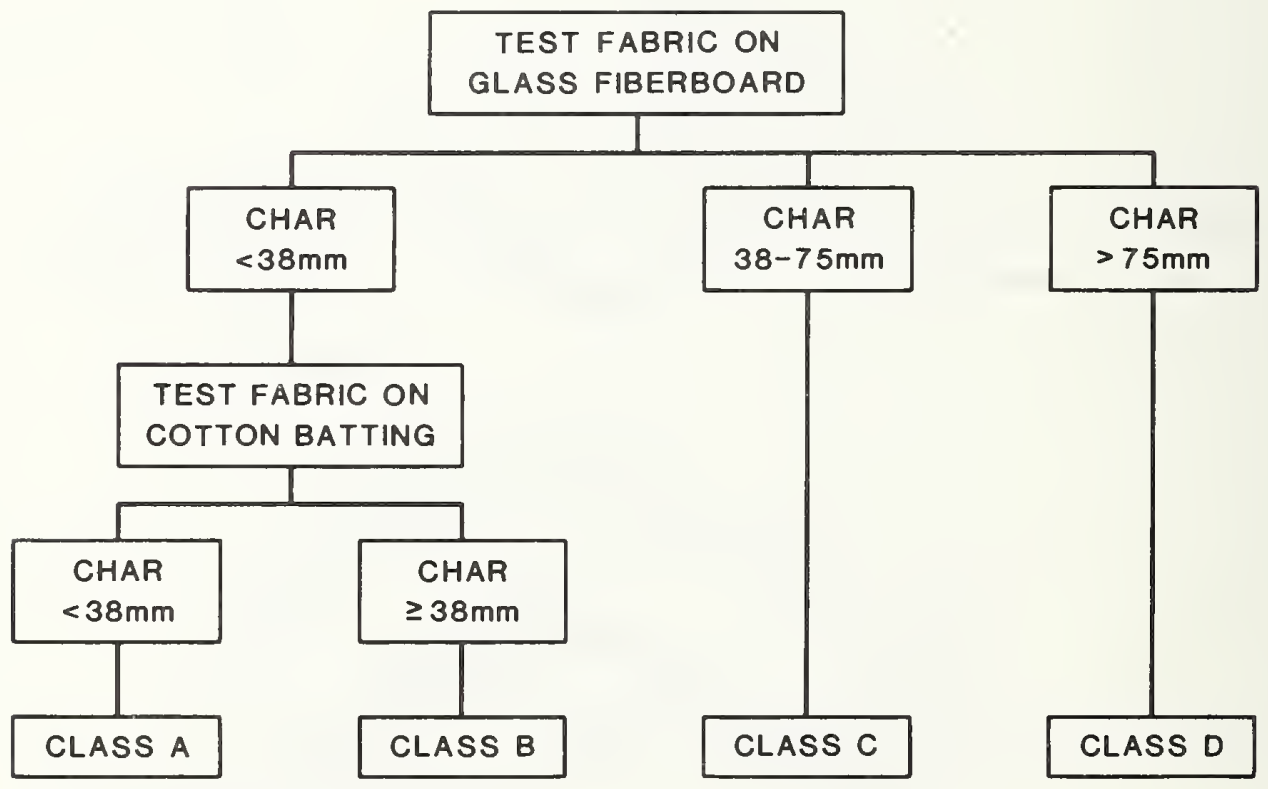

Fabrics generally found in class:

wool, heavy

thermoplastics,

vinyl or poly-

urethane coated

fabrics light weight cellulosics, medium weight thermoplastics medium weight cellulosics, light weight thermoplastics heavy weight cellulosics

Figure 4. Fabric classification scheme. 


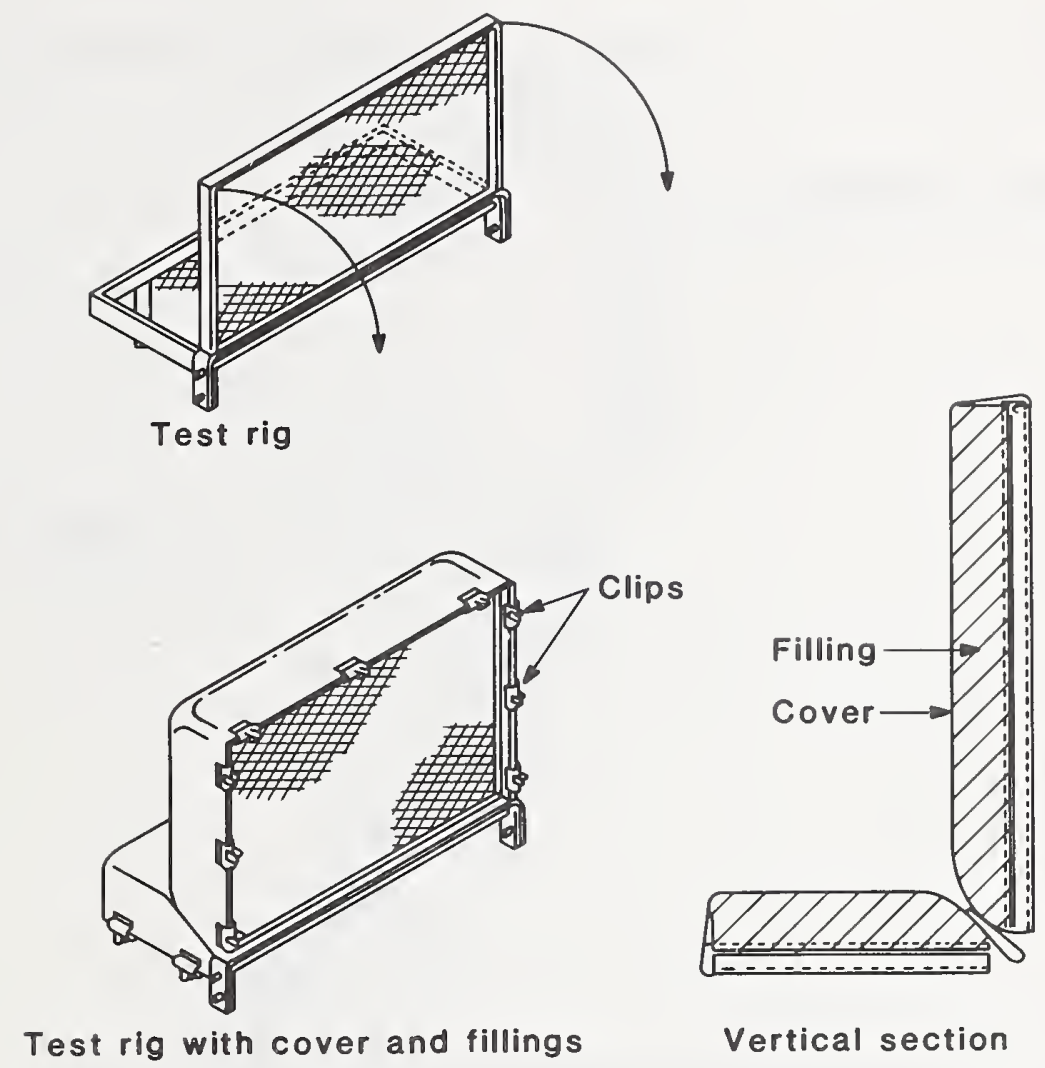

Figure 5. Mockup for BS 5852 tests.

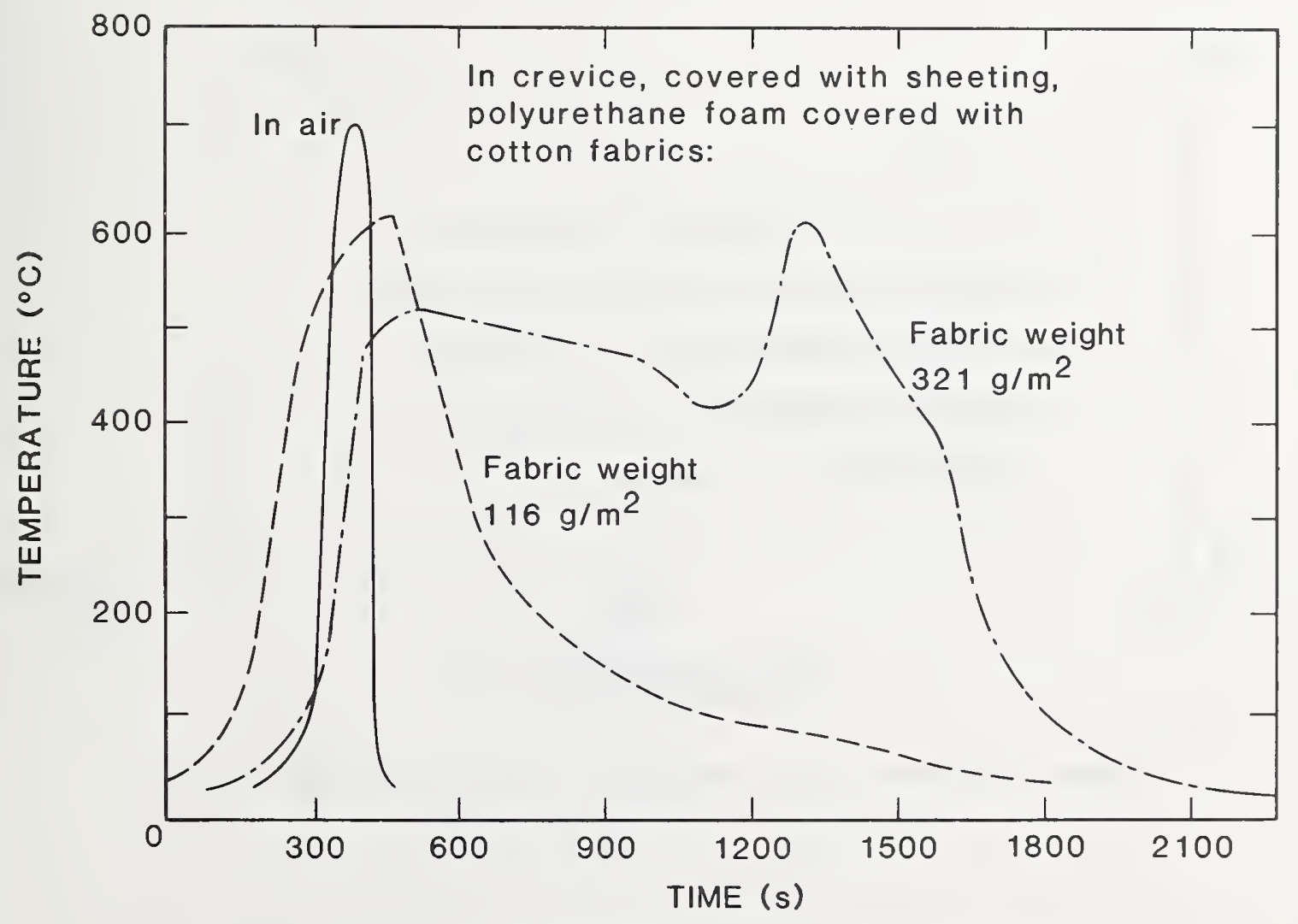

Figure 6. Time-temperature relationships for cigarettes burning on various substrates. 


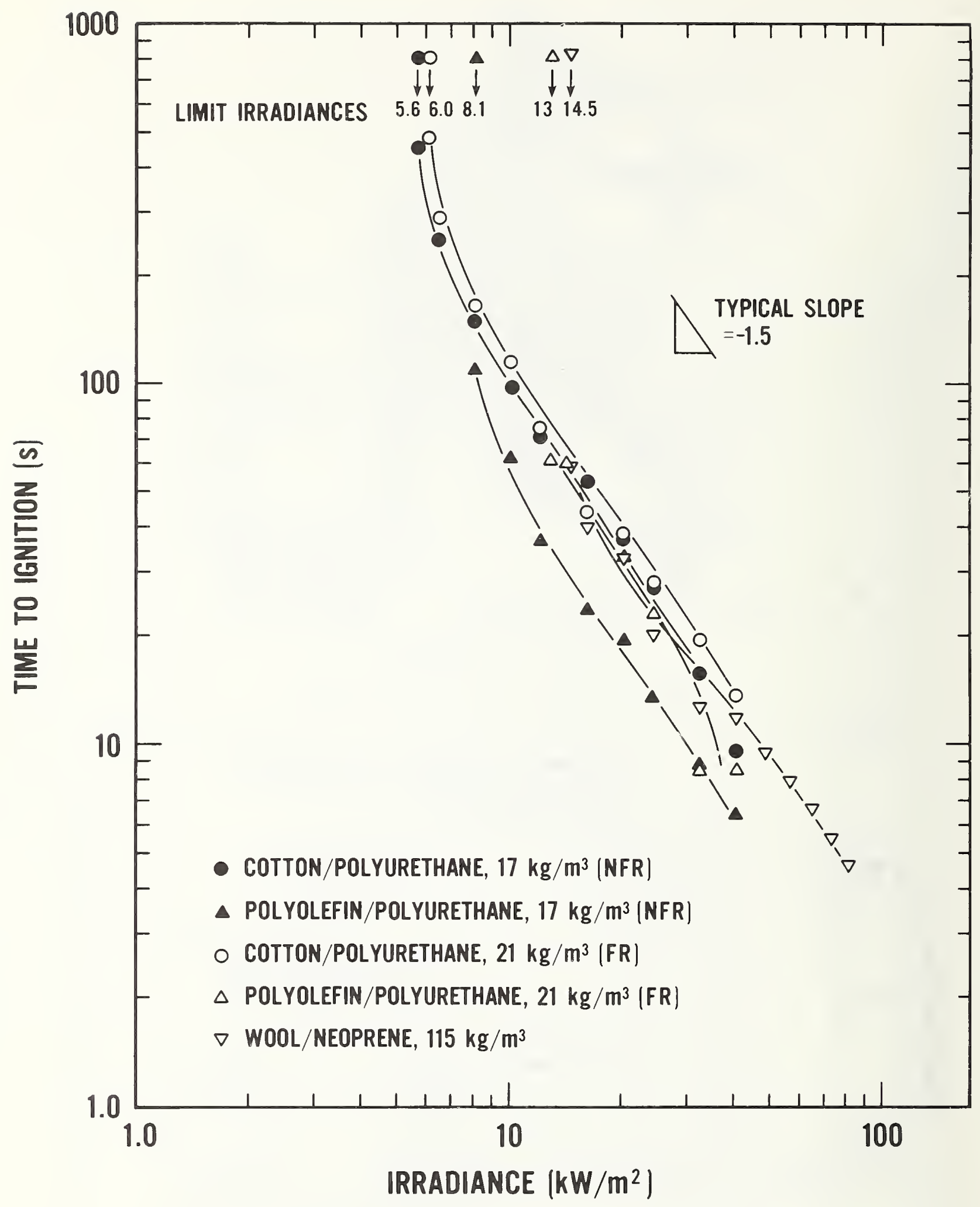

Figure 7. Typical ignition curves for a range of upholstered furniture fabric/padding combinations. 


\section{Heat flux gage}
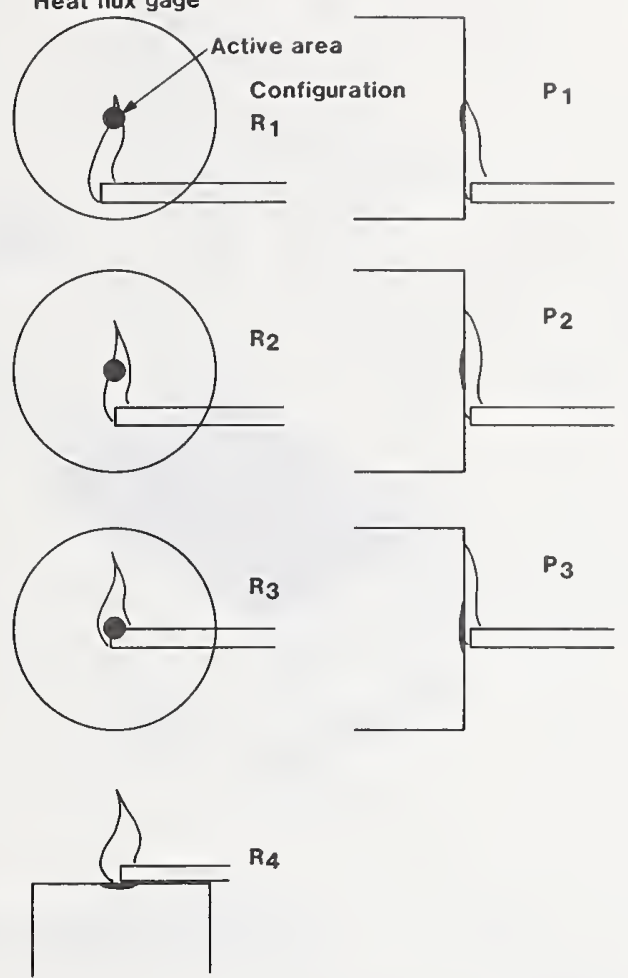

Figure 8. Gage locations for heat flux measurements on ignitability test burners.

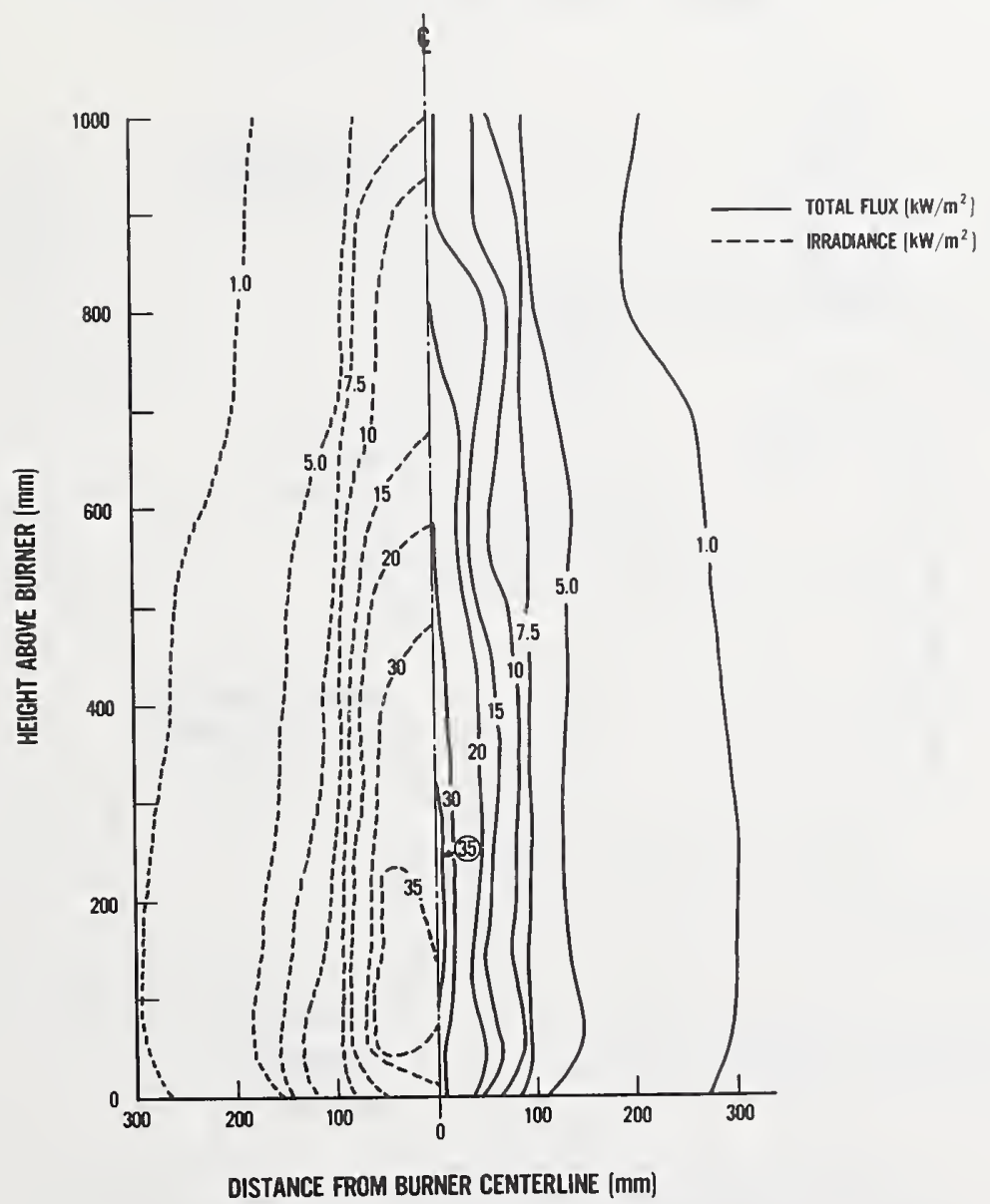

Figure 9. Heat fluxes measured at the wastebasket simulation burner. 


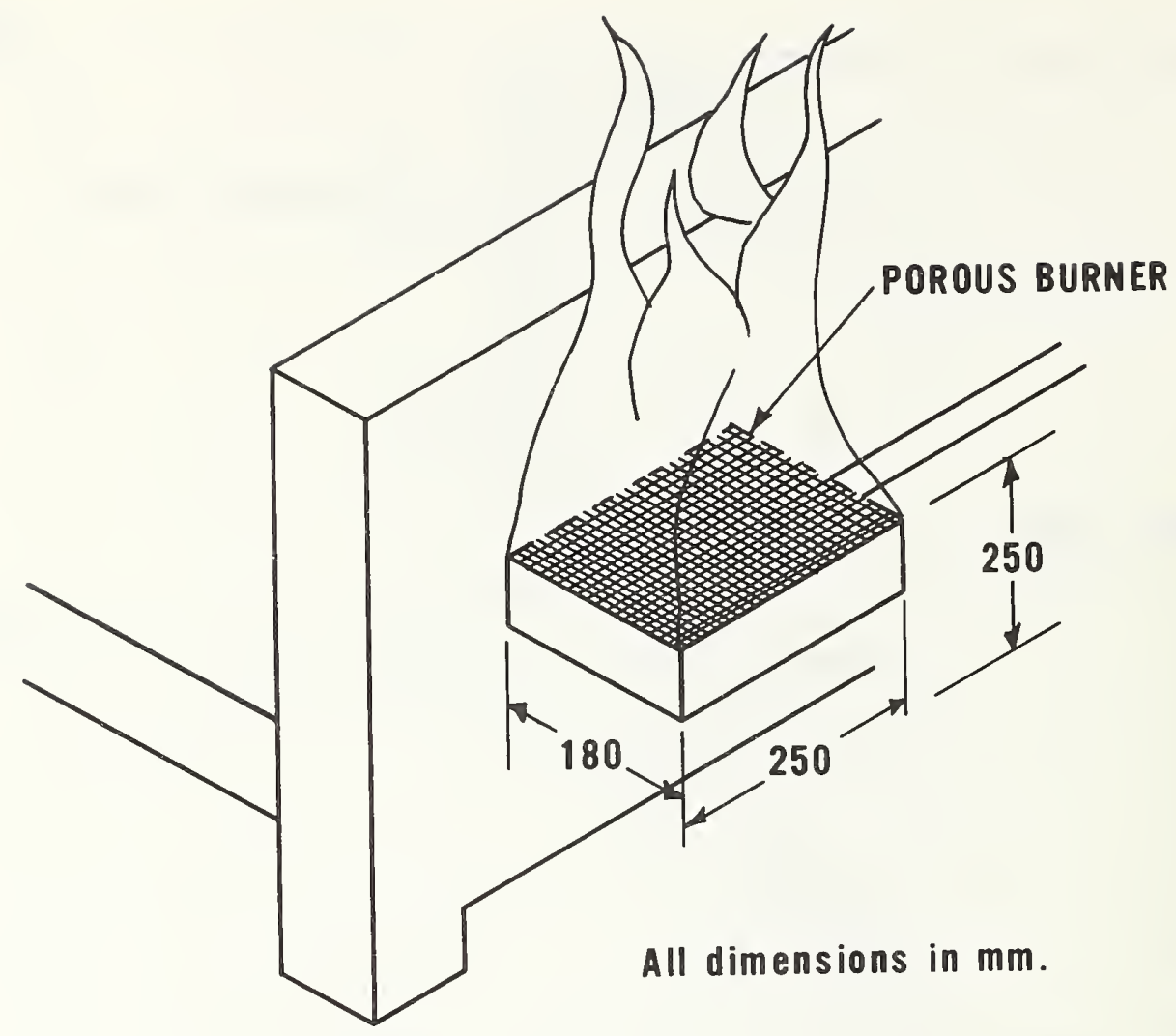

Figure 10. Wastebasket simulation burner, used as ignition source.

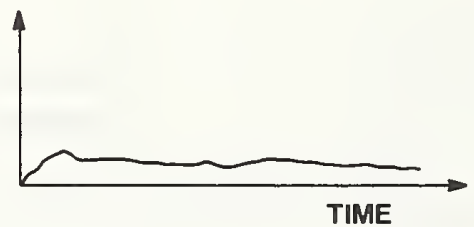

SMOLDERING

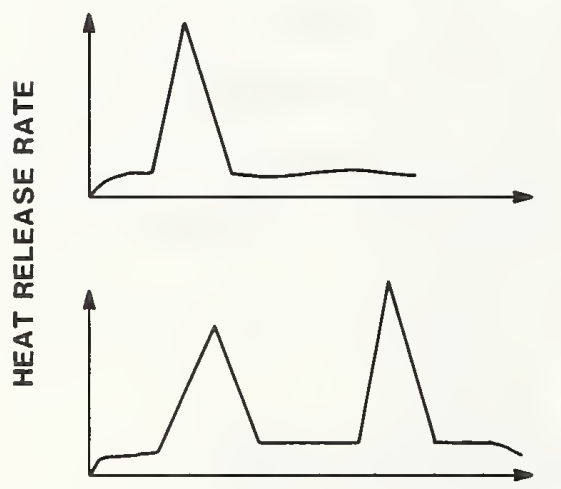

RAPID

BURNING

MORE COMPLEX

FUEL PACKAGES

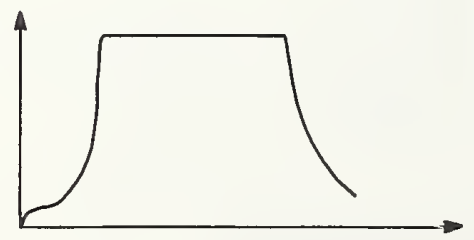

QUASI-STEADY

BURNING

(rarely seen)

Figure 11. Typical curve shapes illustrating rate of heat liberated. 


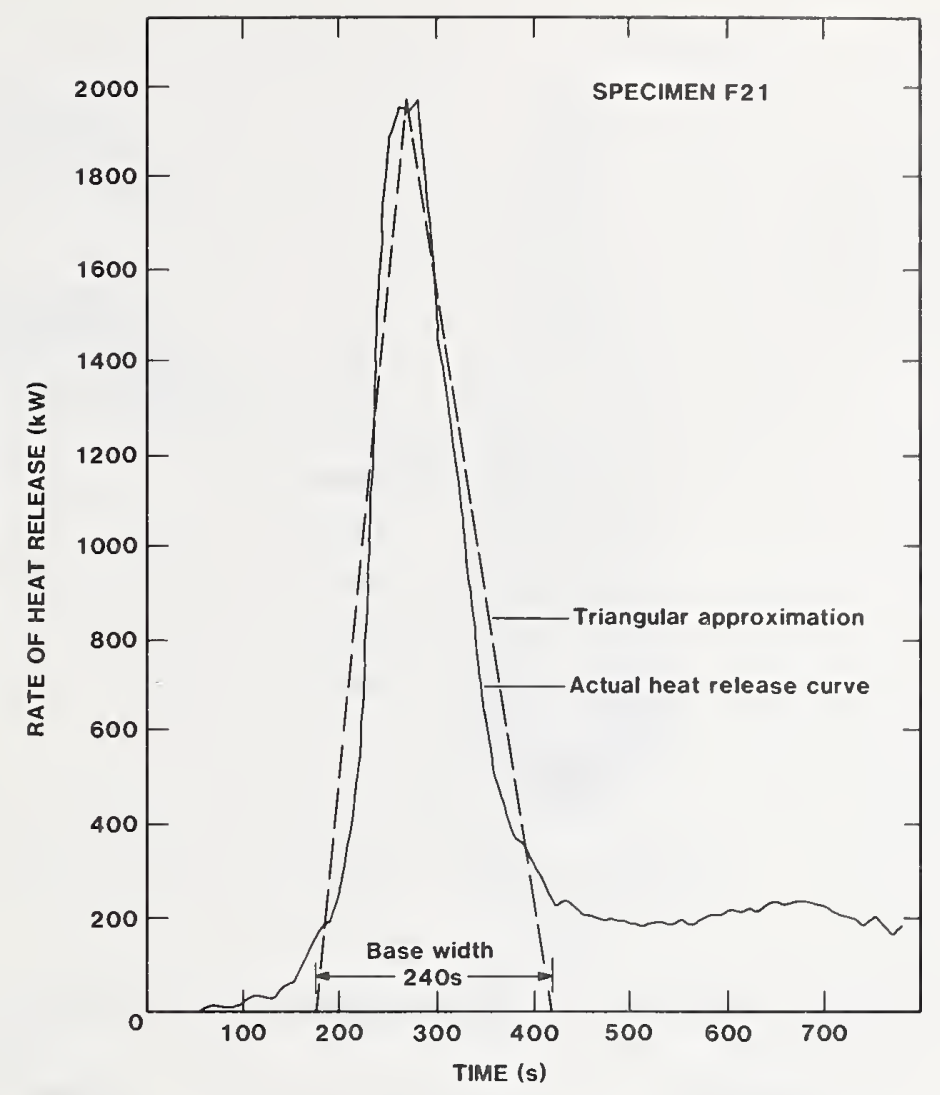

Figure 12. Triangular approximation to an actual heat release rate curve.

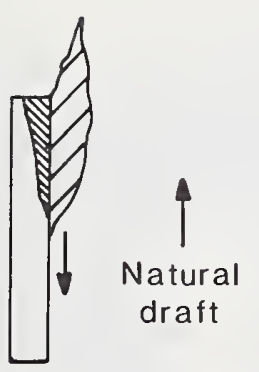

VERTICAL SAMPLE IGNITION AT TOP (edge view)
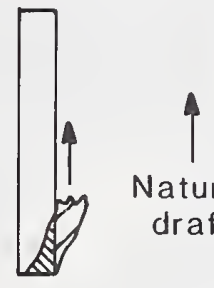

Natural draft

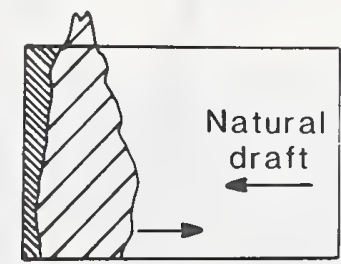

VERTICAL SAMPLE LATERAL SPREAD (front view)

\section{VERTICAL SAMPLE \\ IGNITION AT BOTTOM (edge view)}

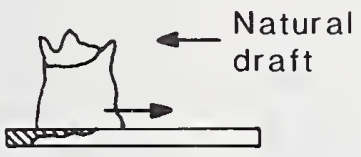

HORIZONTAL SAMPLE (edge view)

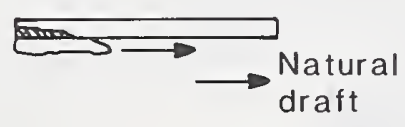

UPSIDE-DOWN HORIZONTAL SAMPLE (edge view)

Figure 13. Geometrical configurations possible for one-dimensional flame spread. 


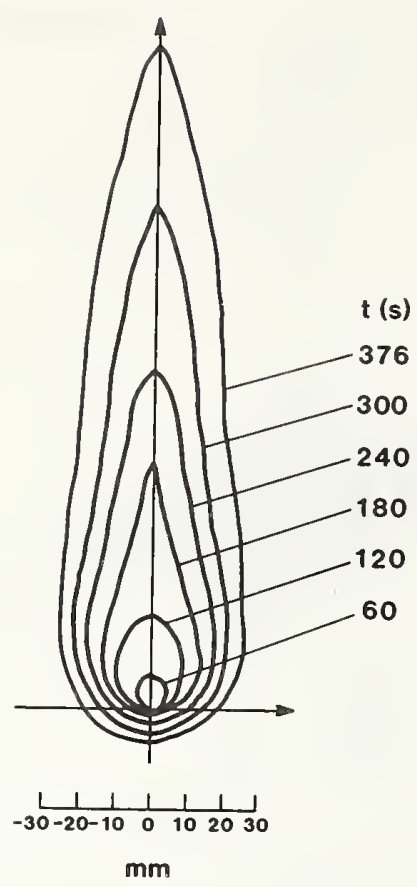

Figure 14. Shape of the pyrolysis area on a vertical slab with point ignition, at different times.
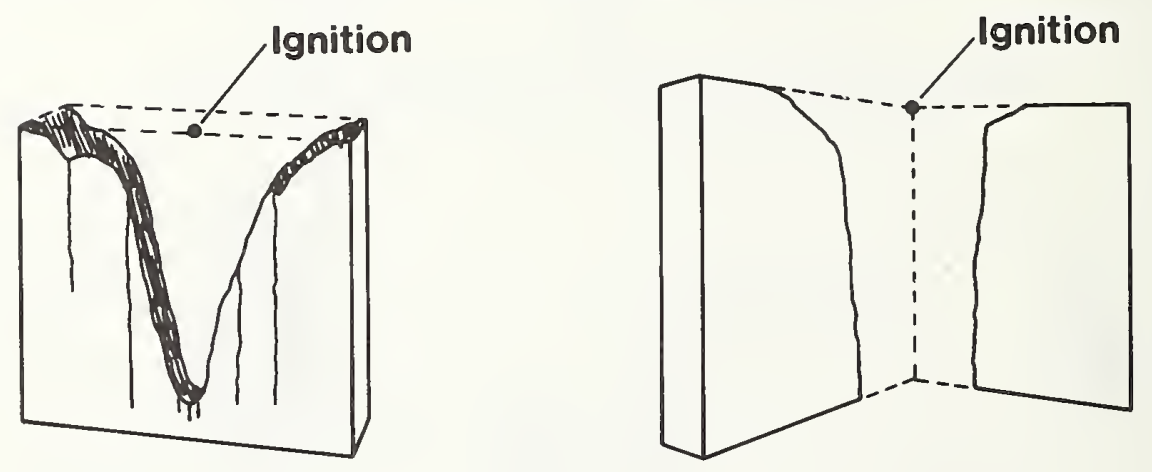

Figure 15. Shapes of pyrolysis zones on polyurethane foam slabs with point ignition.

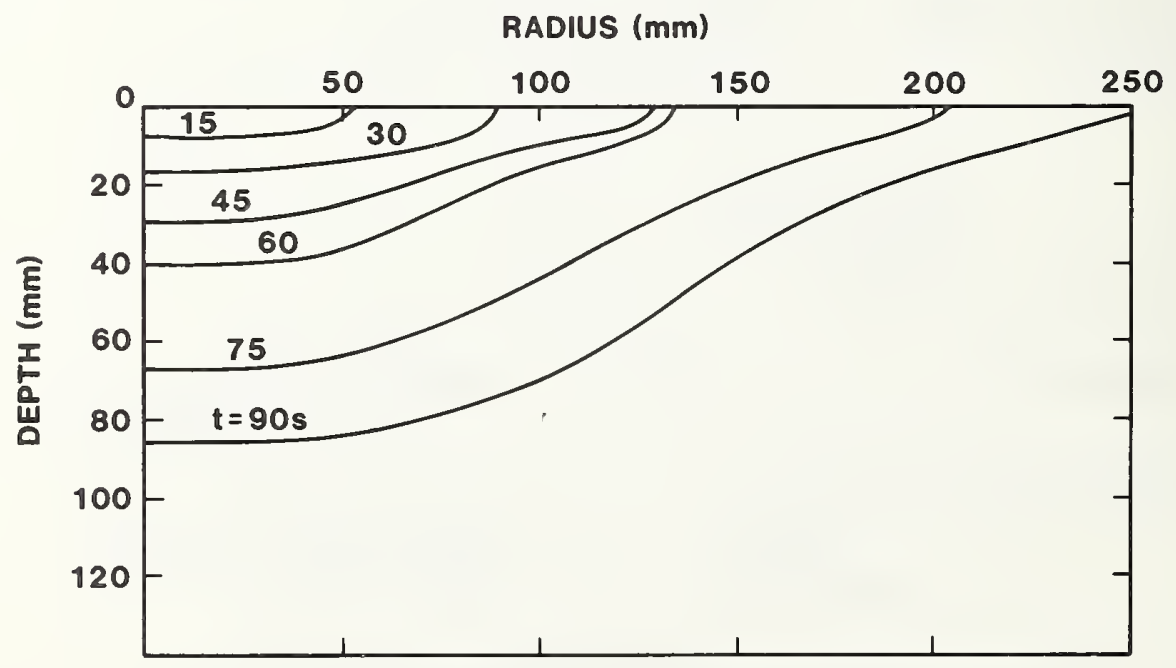

Figure 16. Pyrolysis zone contours for horizontal polyurethane foam slab, ignited at the center, as a function of time. 


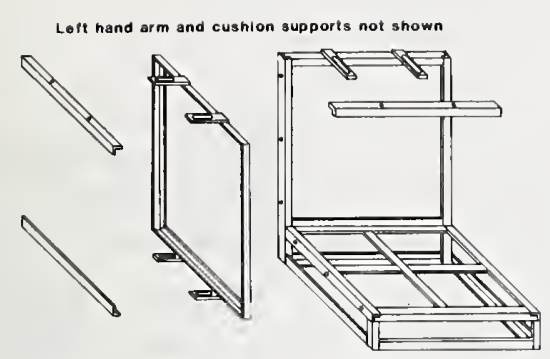

FRAME

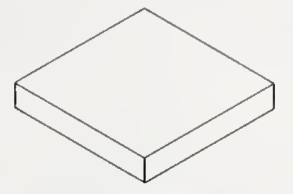

SINGLE CUSHION

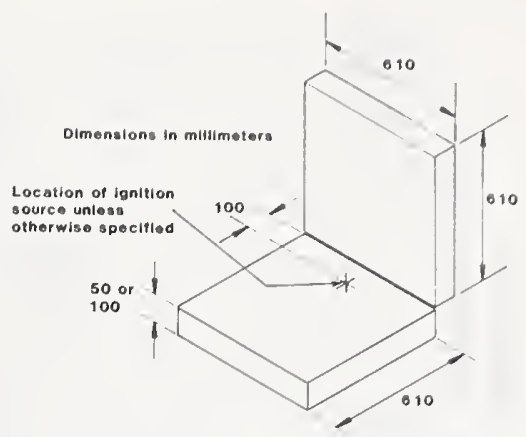

2 CUSHIONS

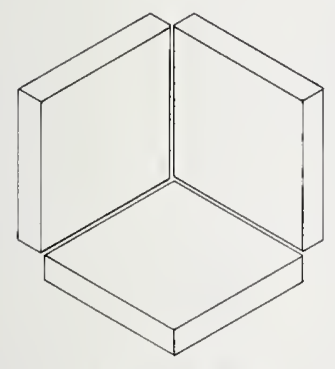

3 CUSHIONS

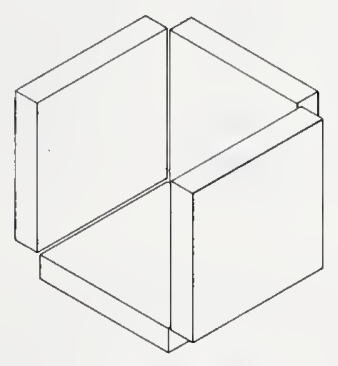

4 CUSHIONS

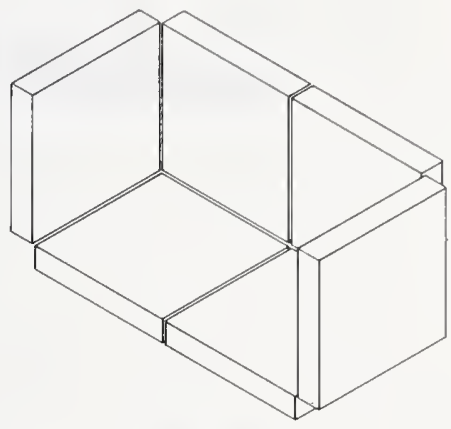

6 CUSHIONS

Figure 17. Mockup frame and cushion arrangements.

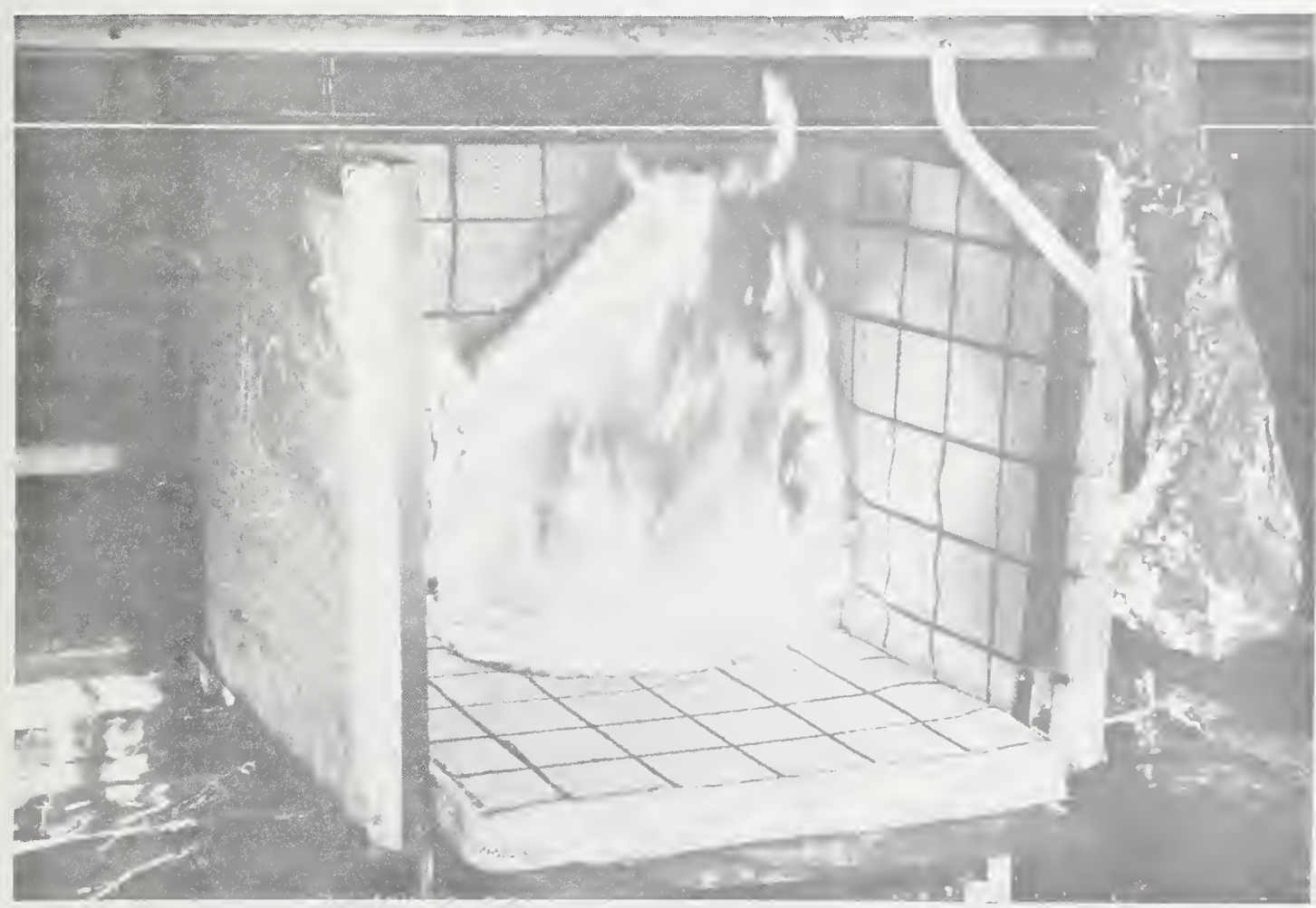

Figure 18. Upholstered chair mockup, four-cushion configuration. 


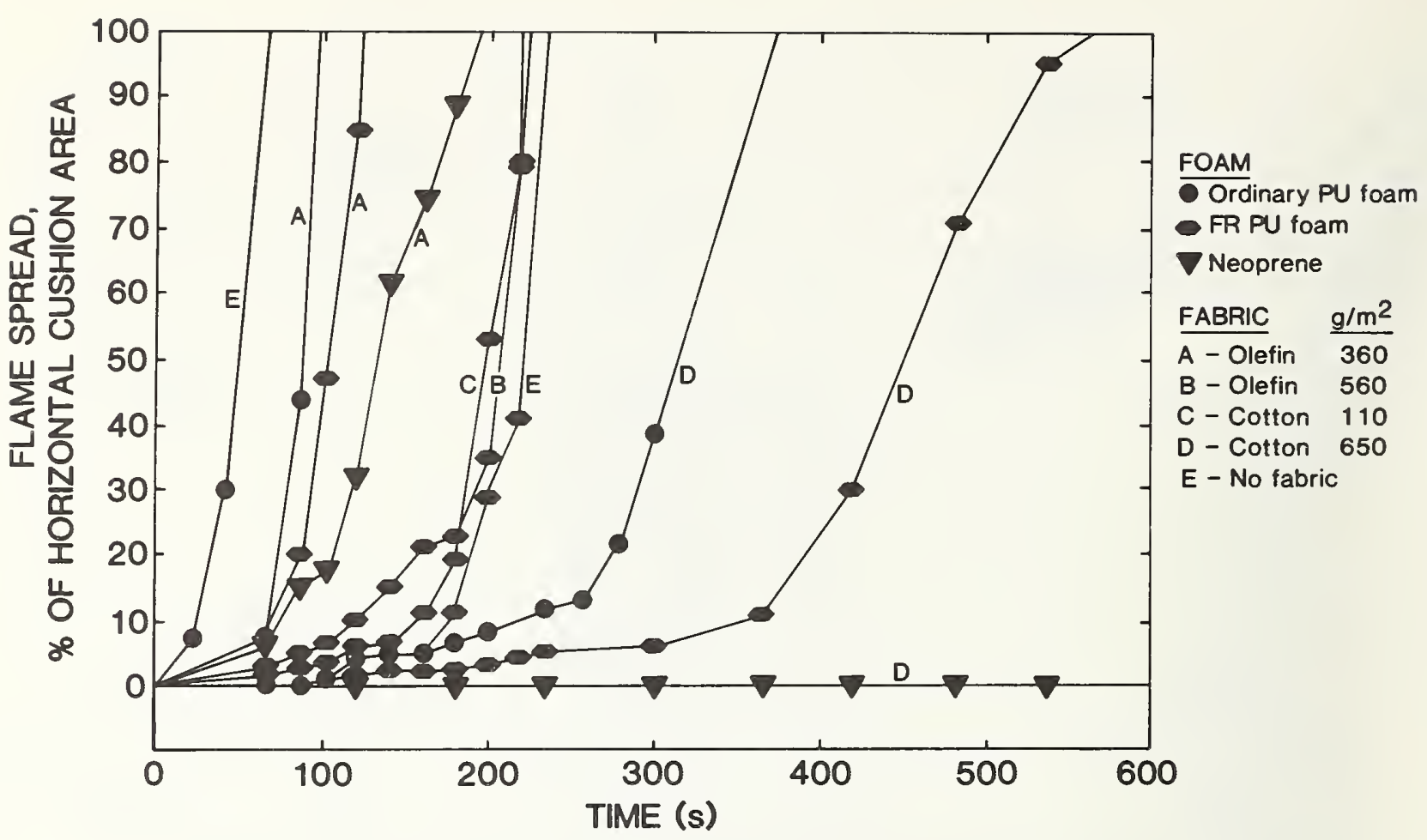

Figure 19. Flame spread over seat cushion surface in four-cushion mockup.

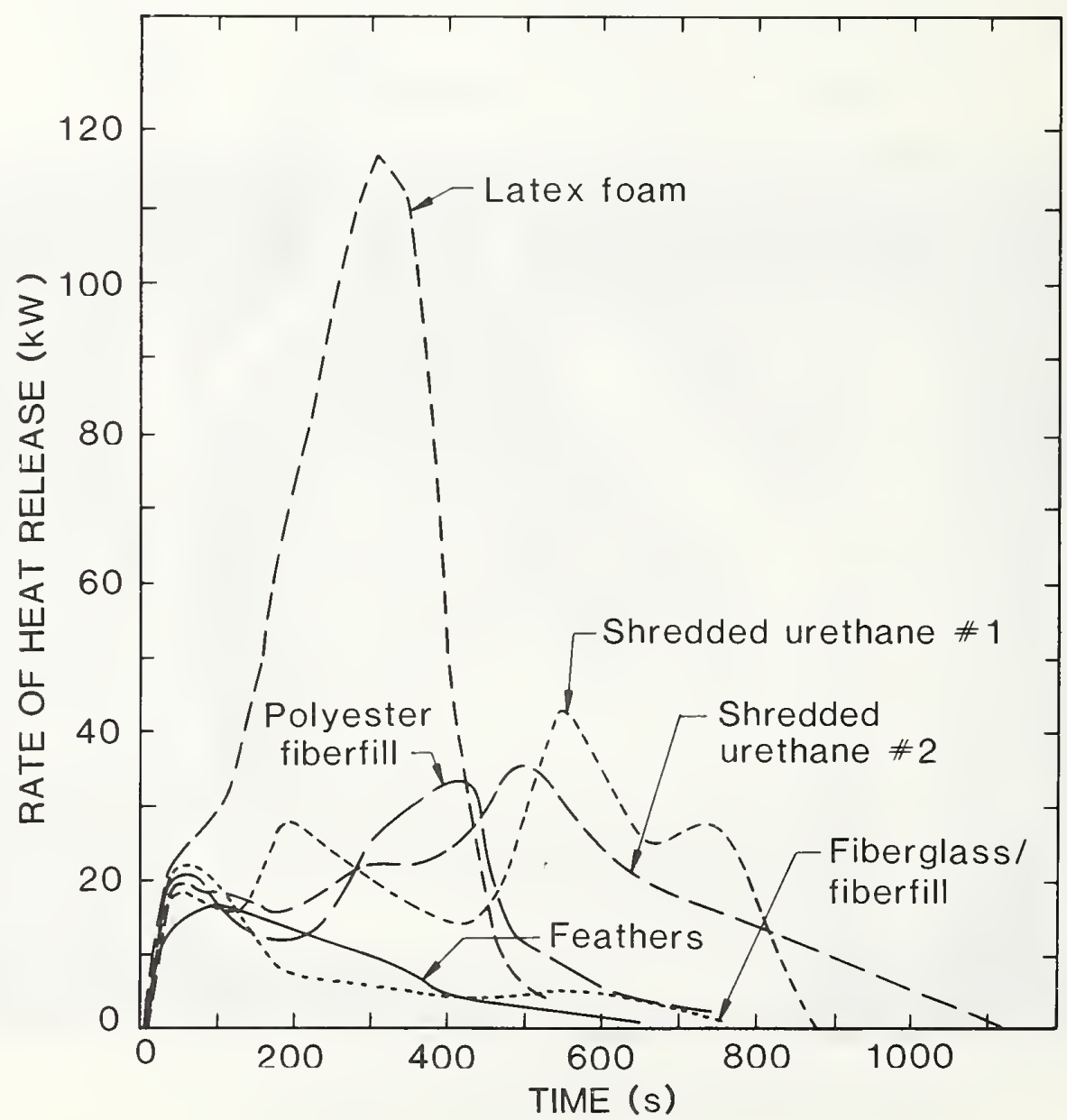

Figure 20. Rates of heat release for standard-size pillows, covered with polyester/cotton pillowcases and ignited at one end. 


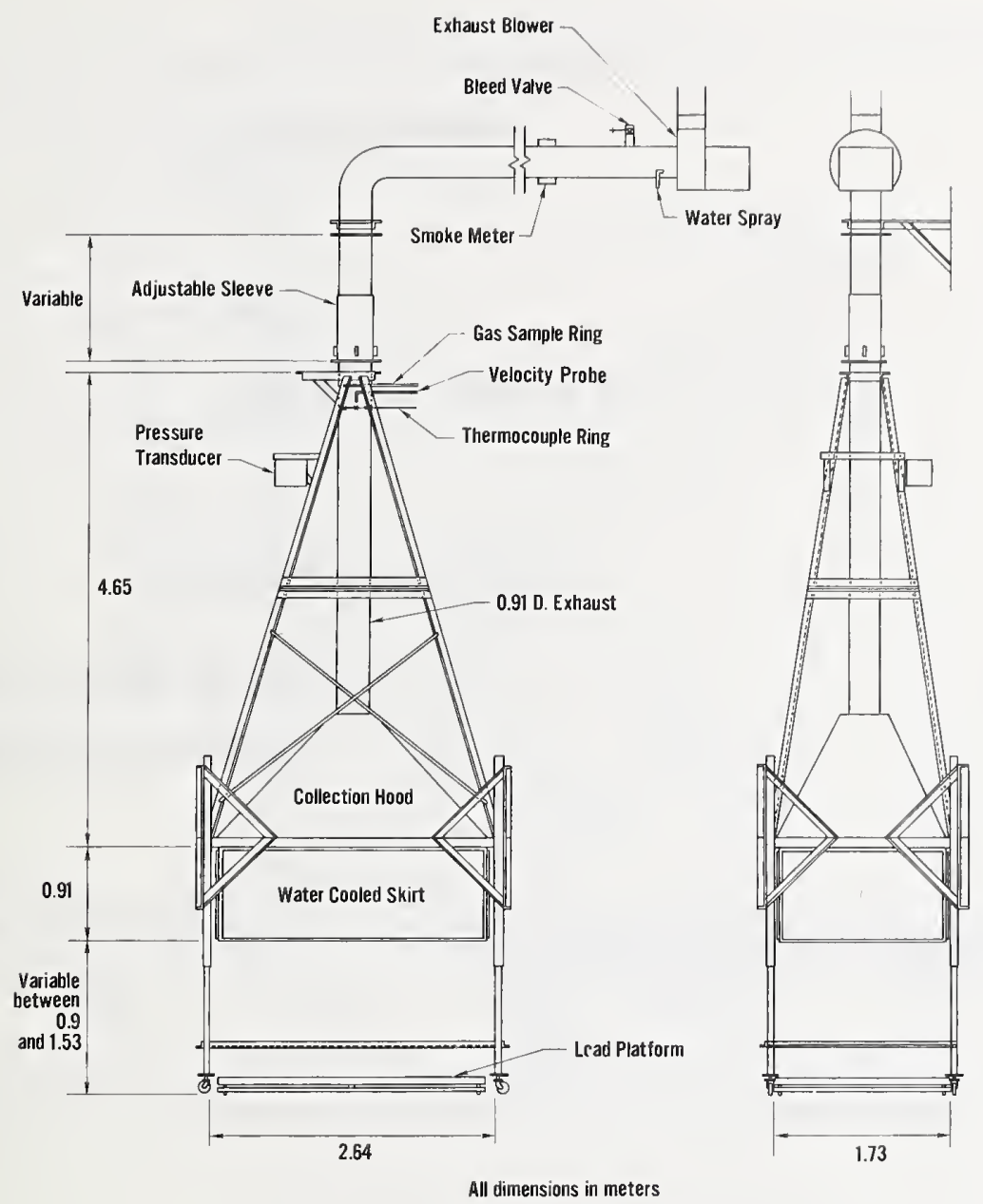

Figure 21. View of furniture calorimeter.

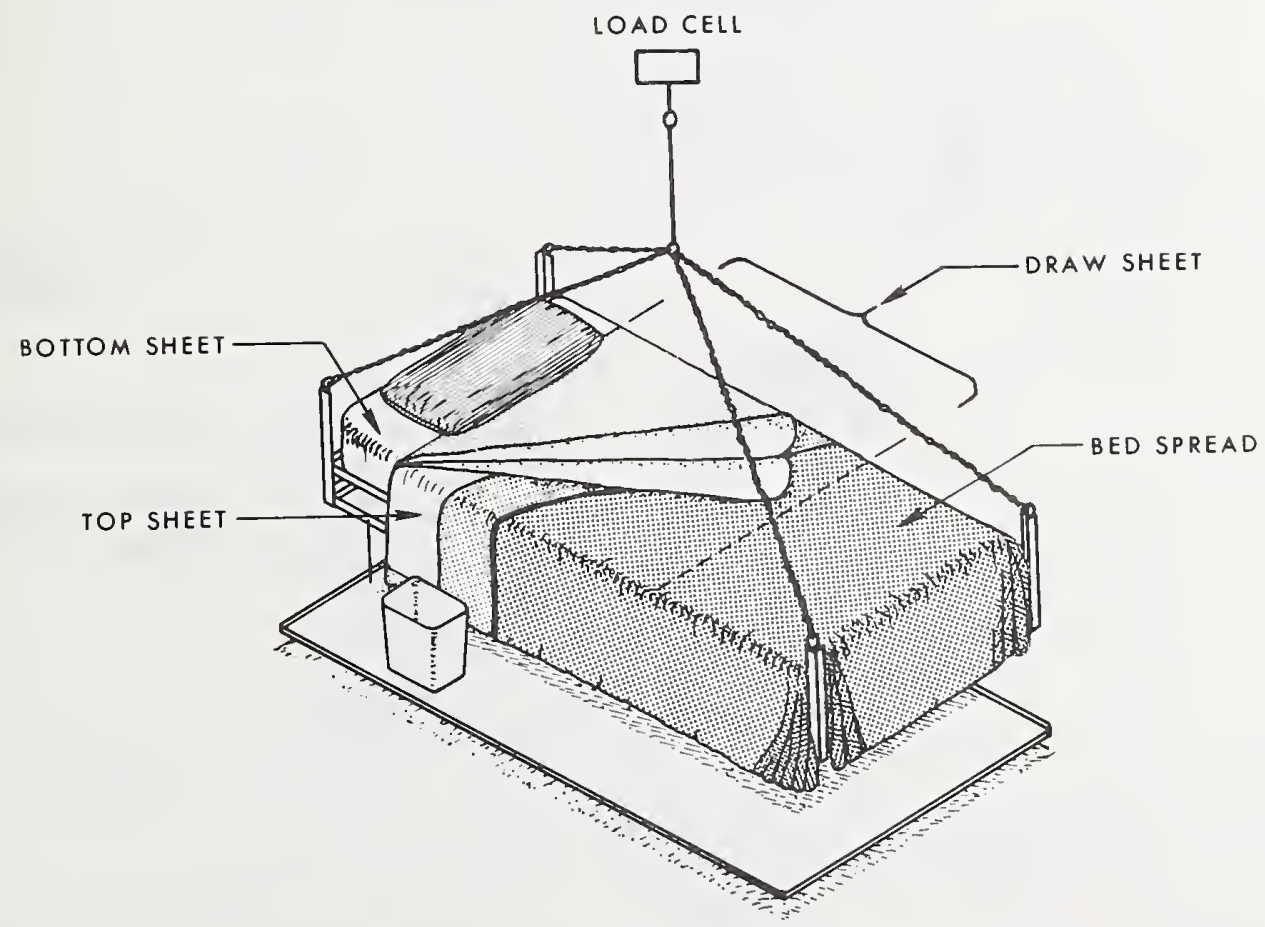

Figure 22. Test bed configuration used for mattress room fire tests. 


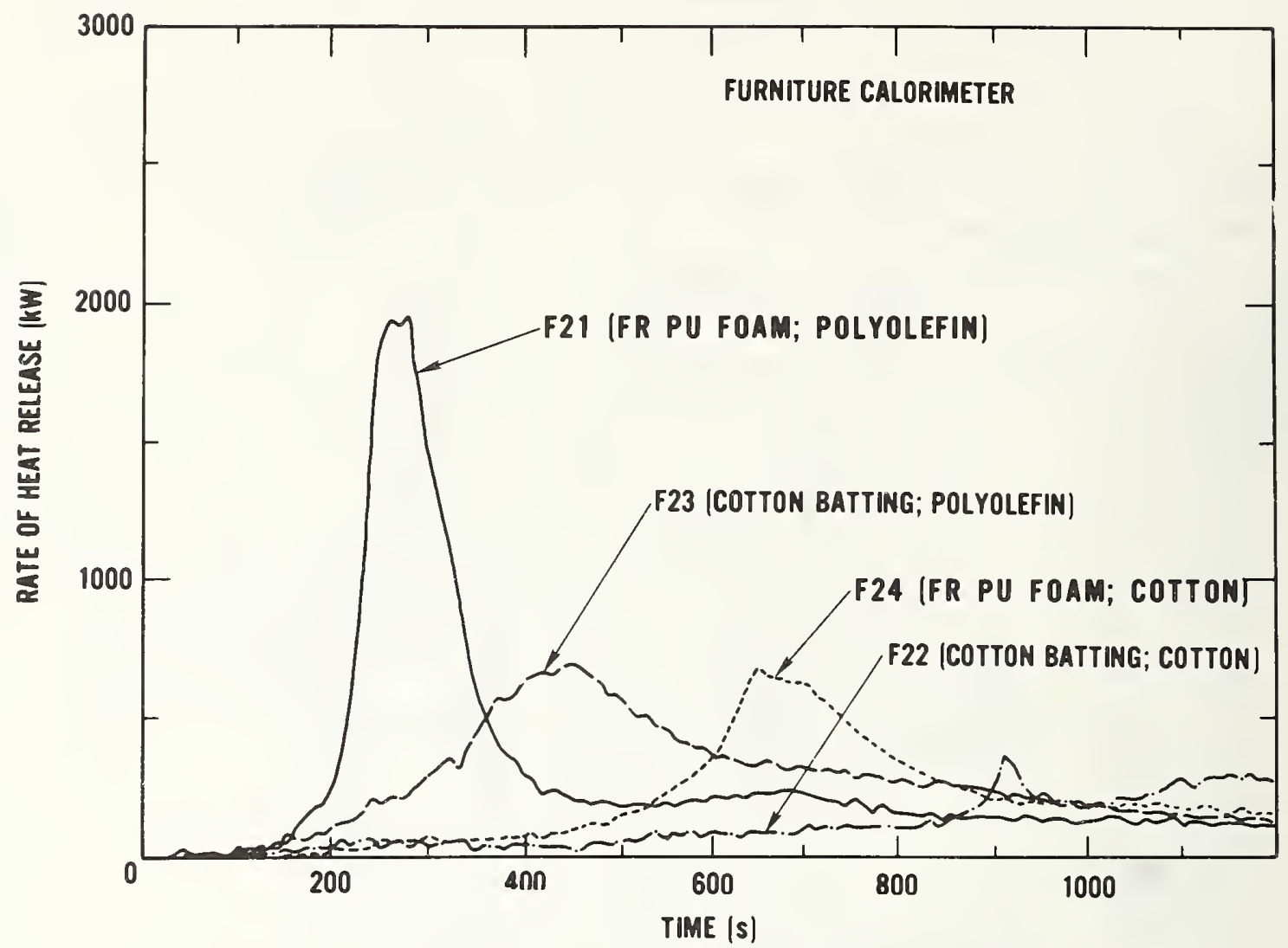

Figure 23. Typical heat release rate results in the furniture calorimeter.

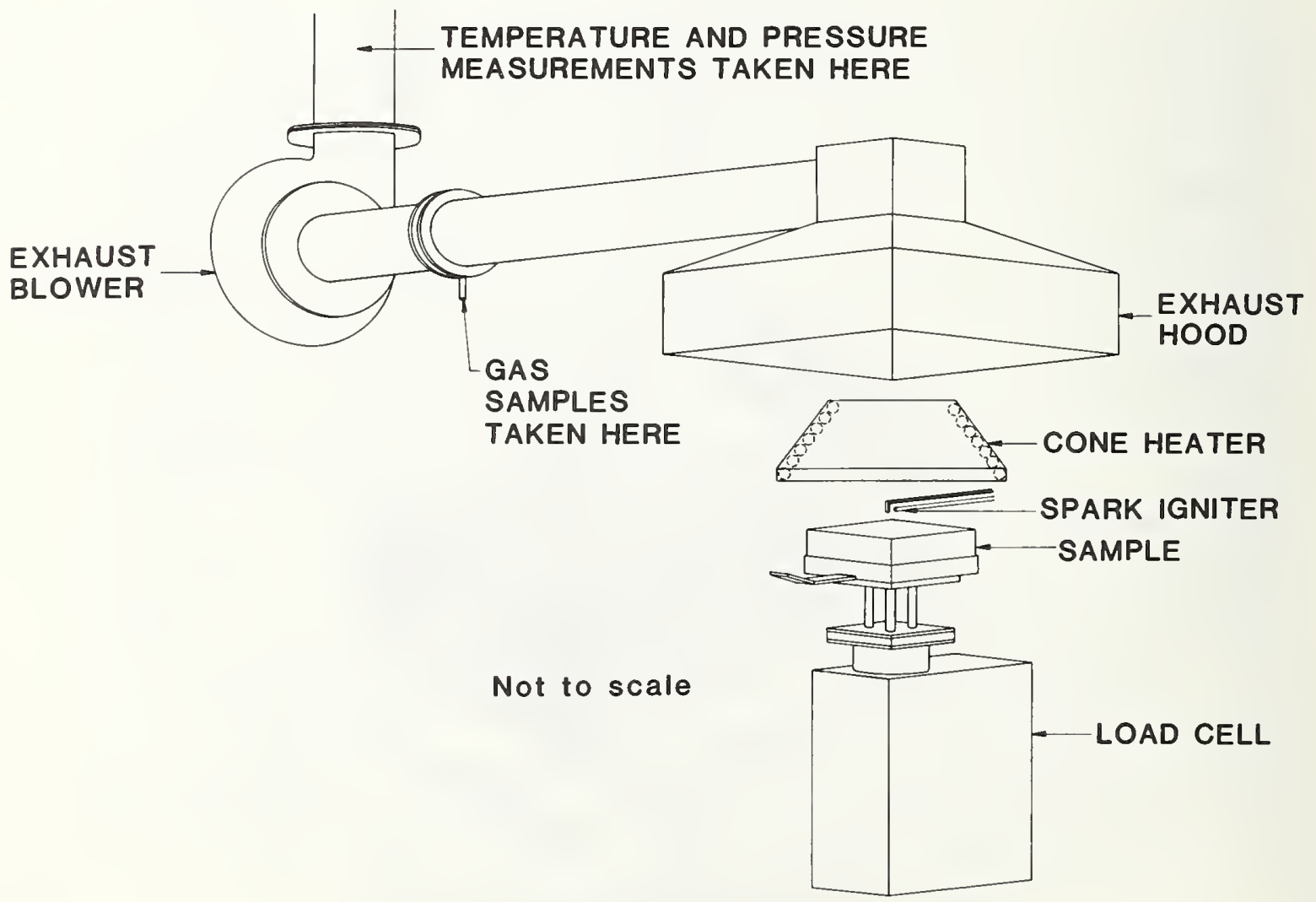

Figure 24. View of cone calorimeter. 


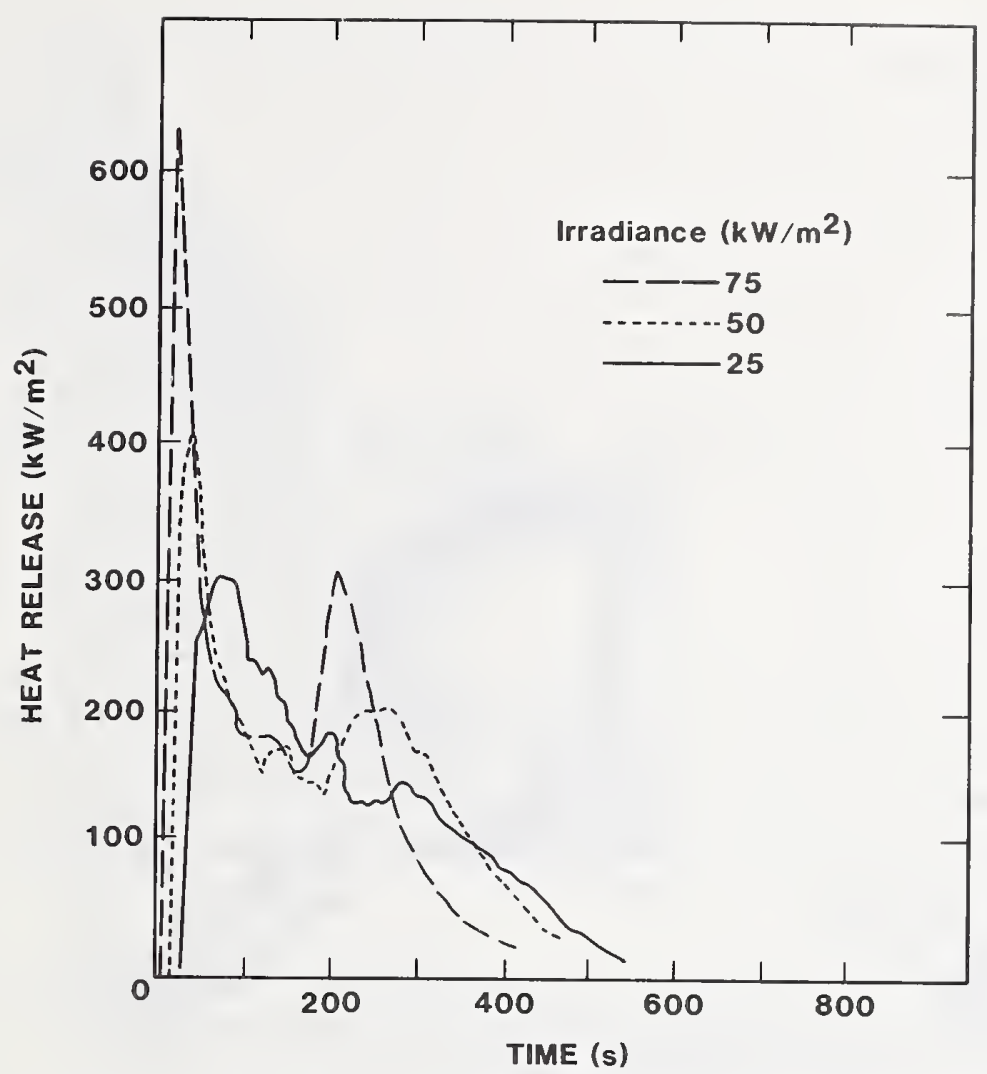

Figure 25. Cone calorimeter measurements of the heat release rate for heavy polyolefin fabric/combustion modified high-resiliency polyurethane foam assemblies.

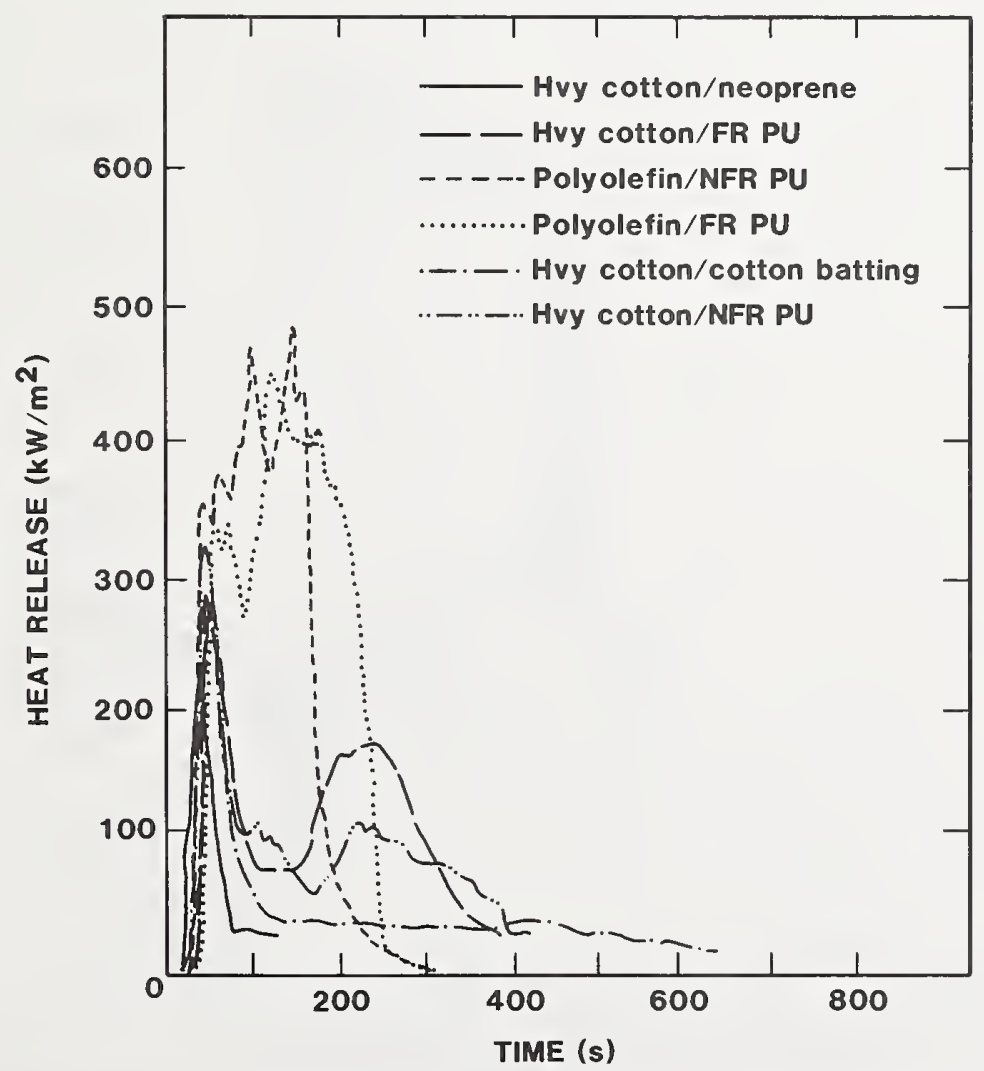

Figure 26. Cone calorimeter measurements of the heat release rate for various fabric/padding combinations, at an irradiance of $25 \mathrm{~kW} / \mathrm{m}^{2}$. 


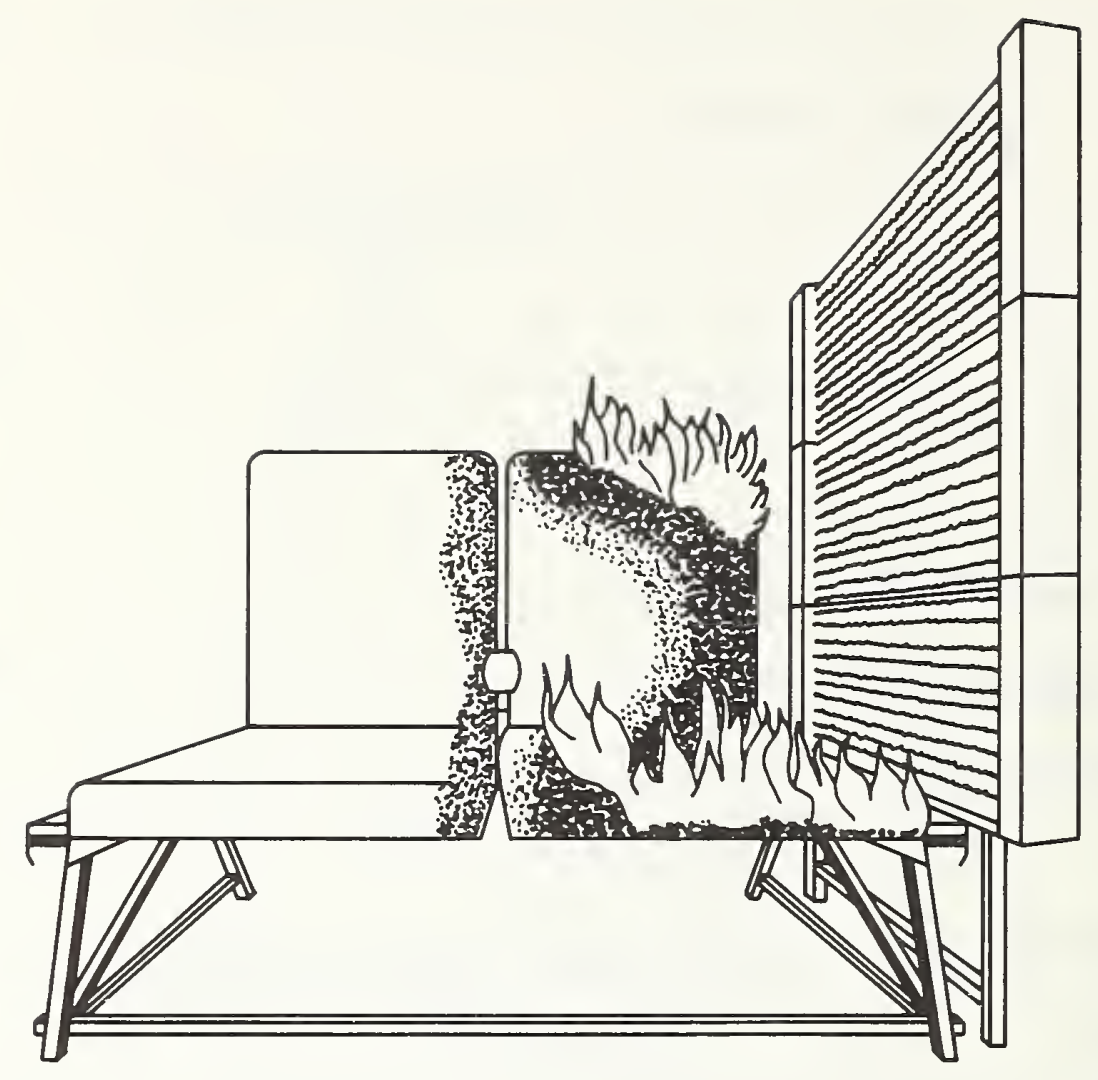

Figure 27. View of cabin fire simulator test.

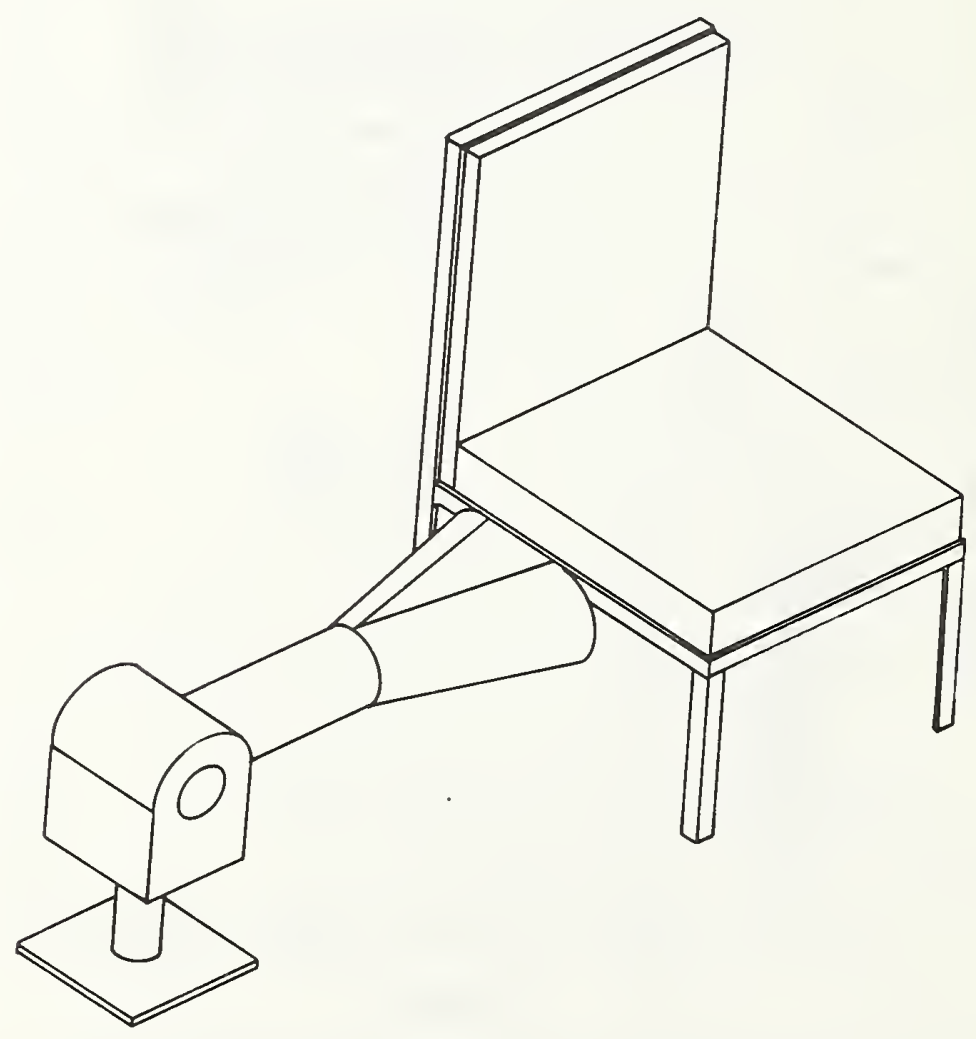

Figure 28. View of FAA "2 gallon/hour burner" test. 


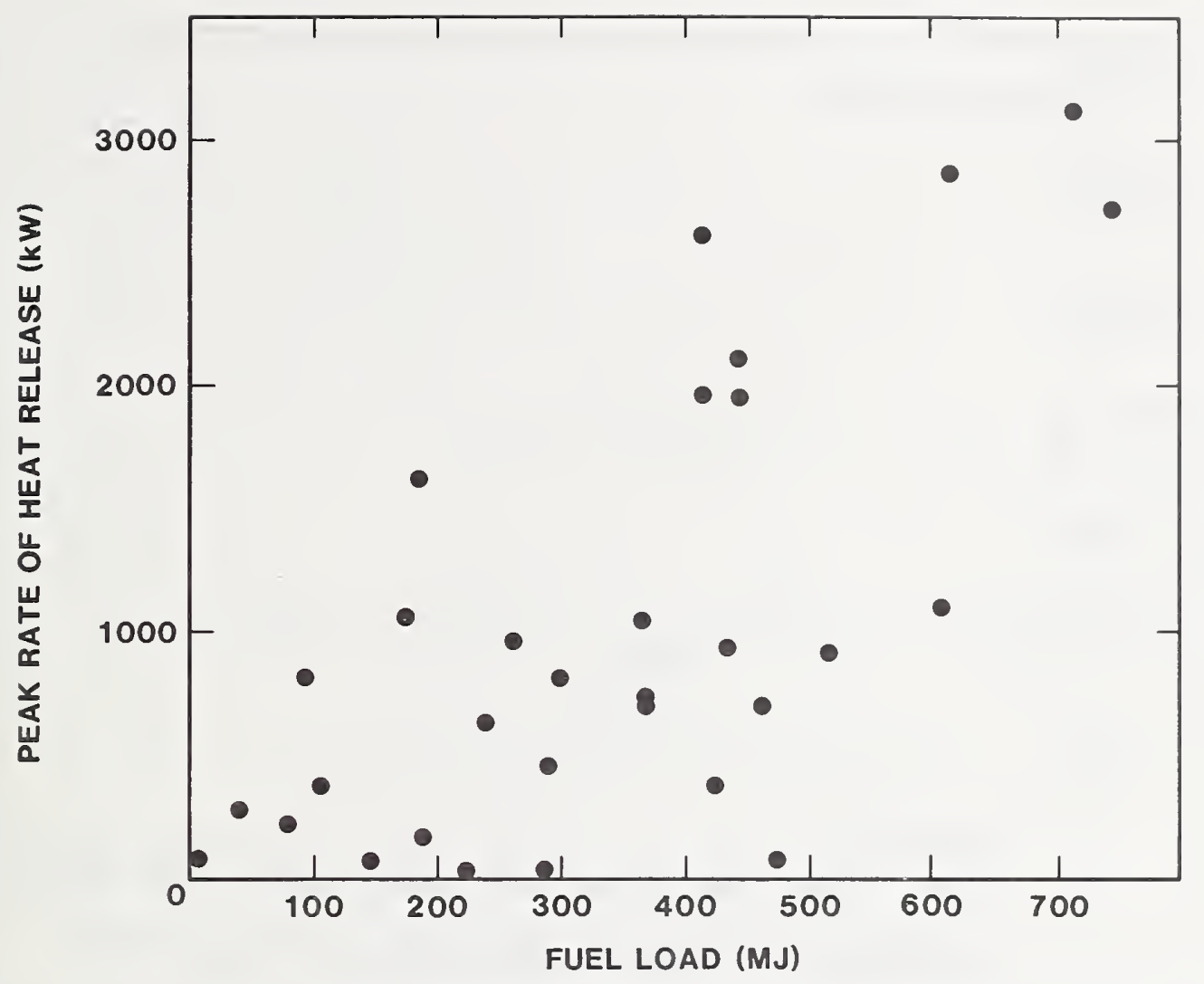

Figure 29. Data for mattresses and upholstered chairs indicating that fuel alone is a poor predictor of the peak heat release rate.

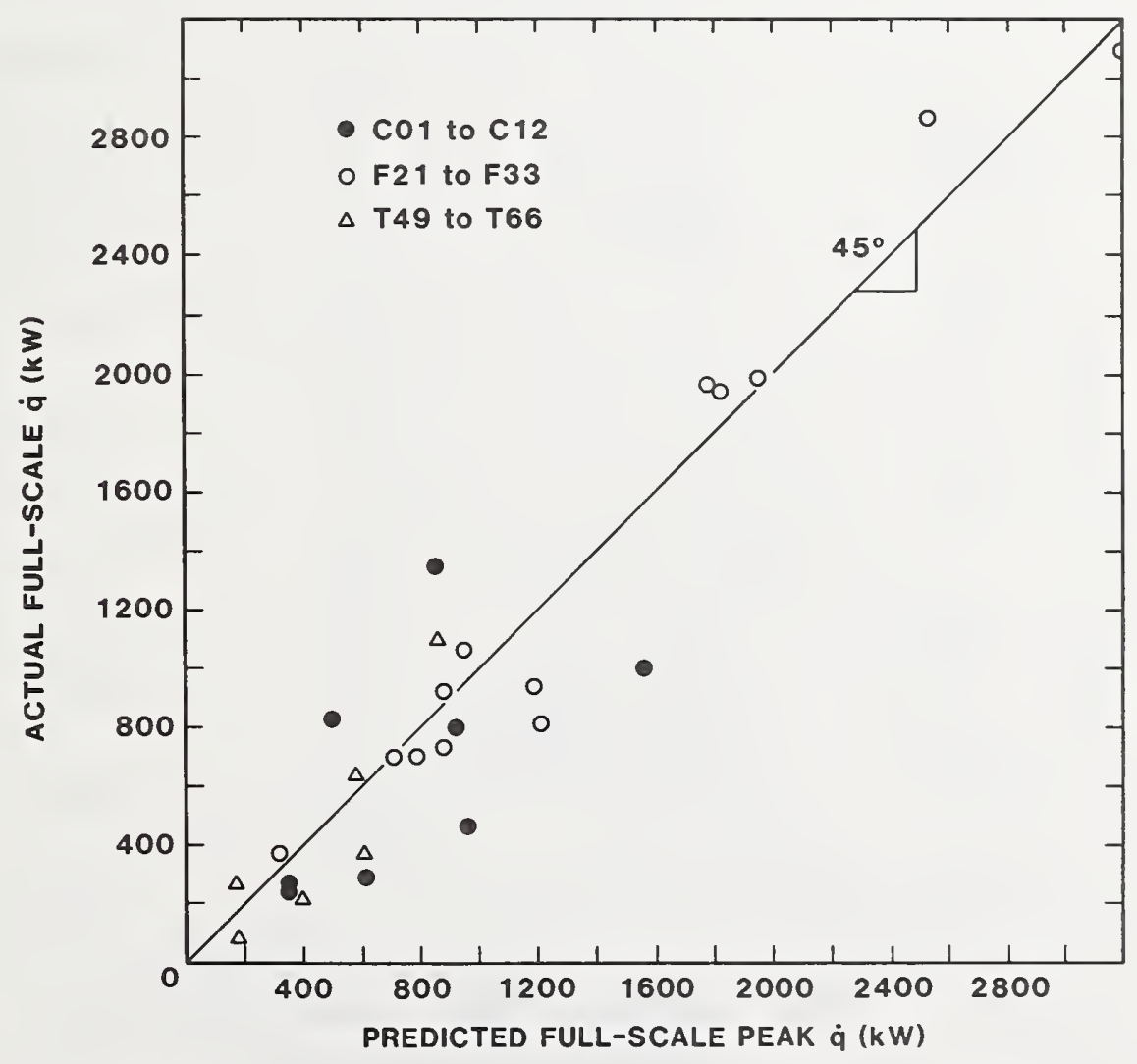

Figure 30. Prediction of full-scale heat release rate based on generic material factors. 


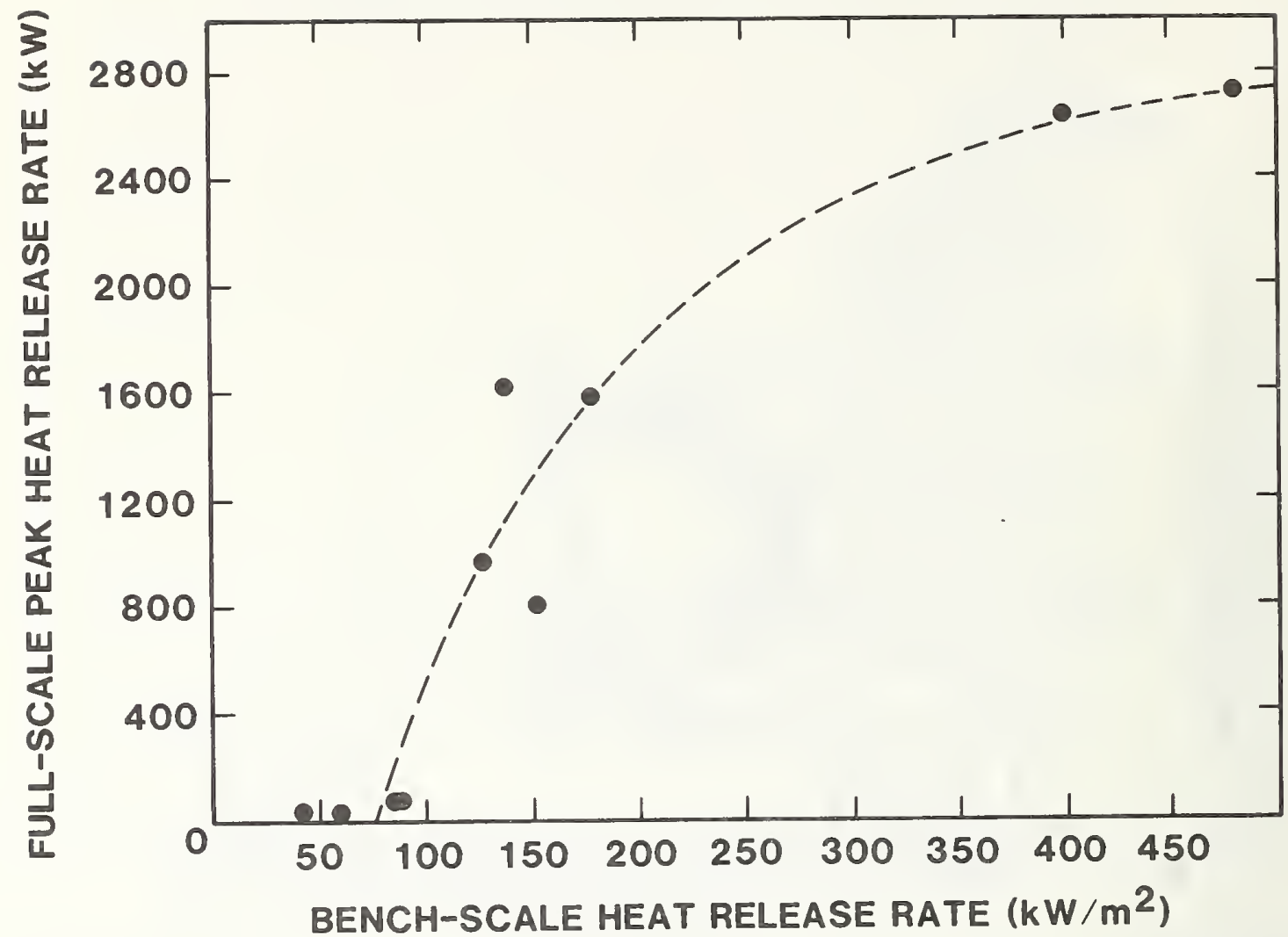

Figure 31. Relationship between full-scale and bench-scale of heat release measurement for mattresses.

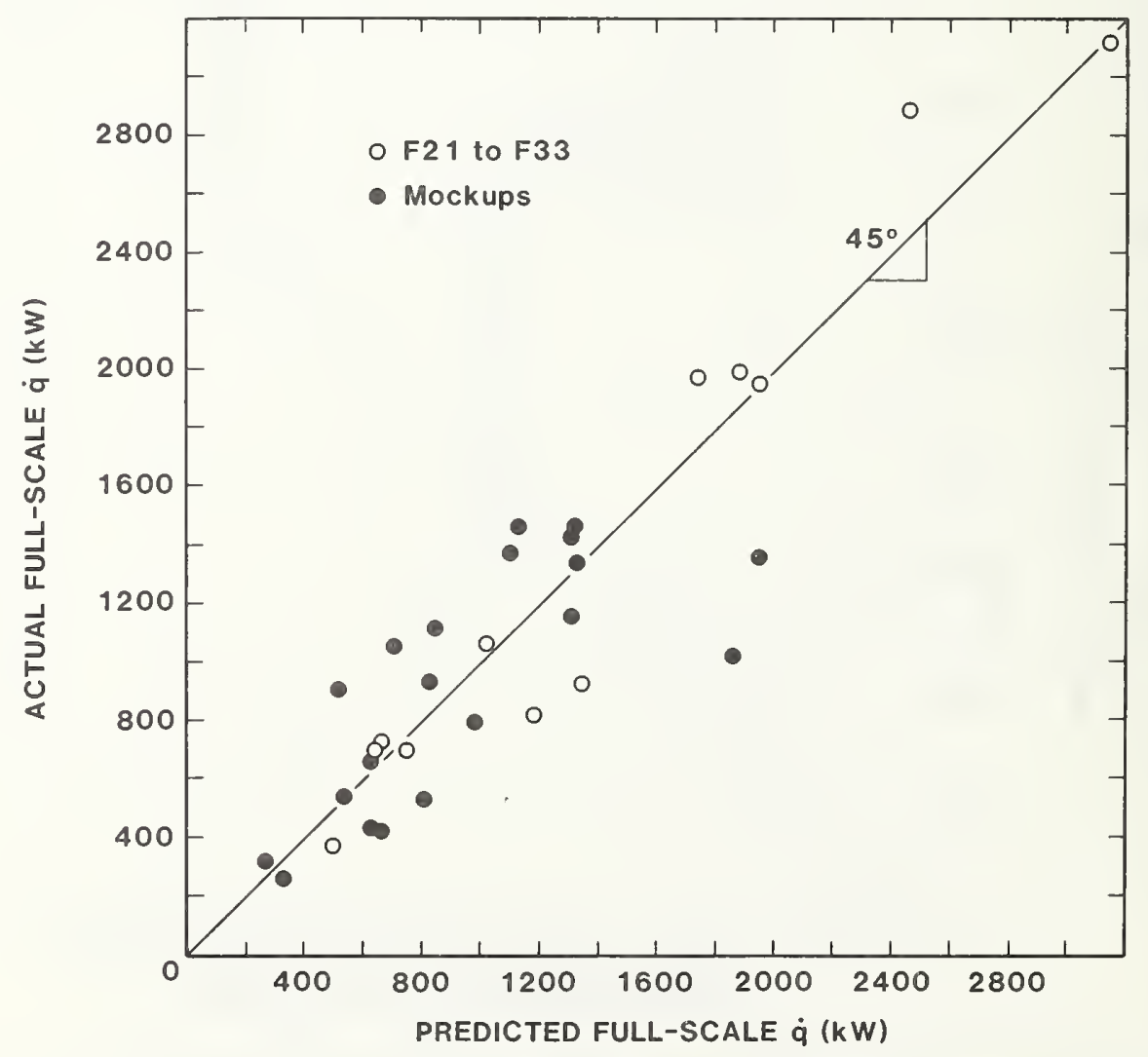

Figure 32. Prediction of full-scale heat release rate based on bench-scale measurements for upholstered furniture. 


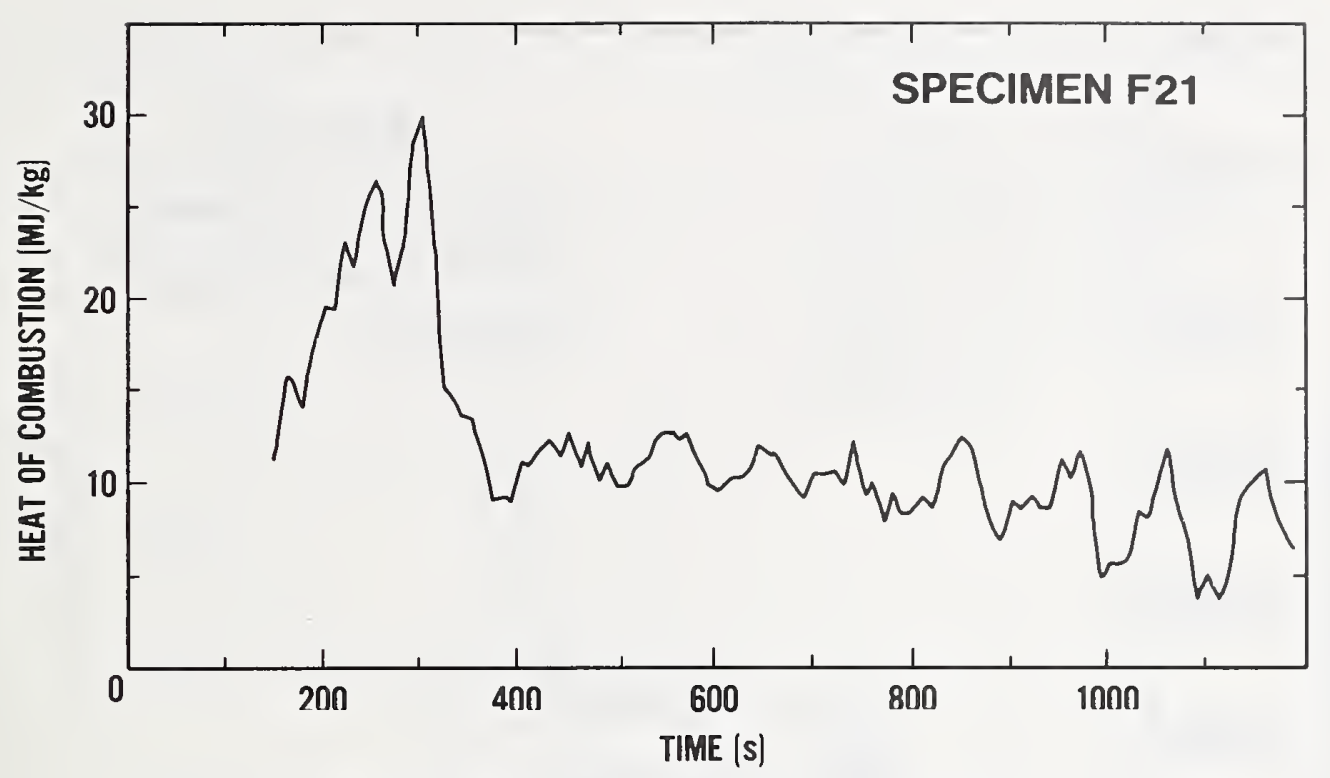

Figure 33. Effective heat of combustion measured for chair F21.

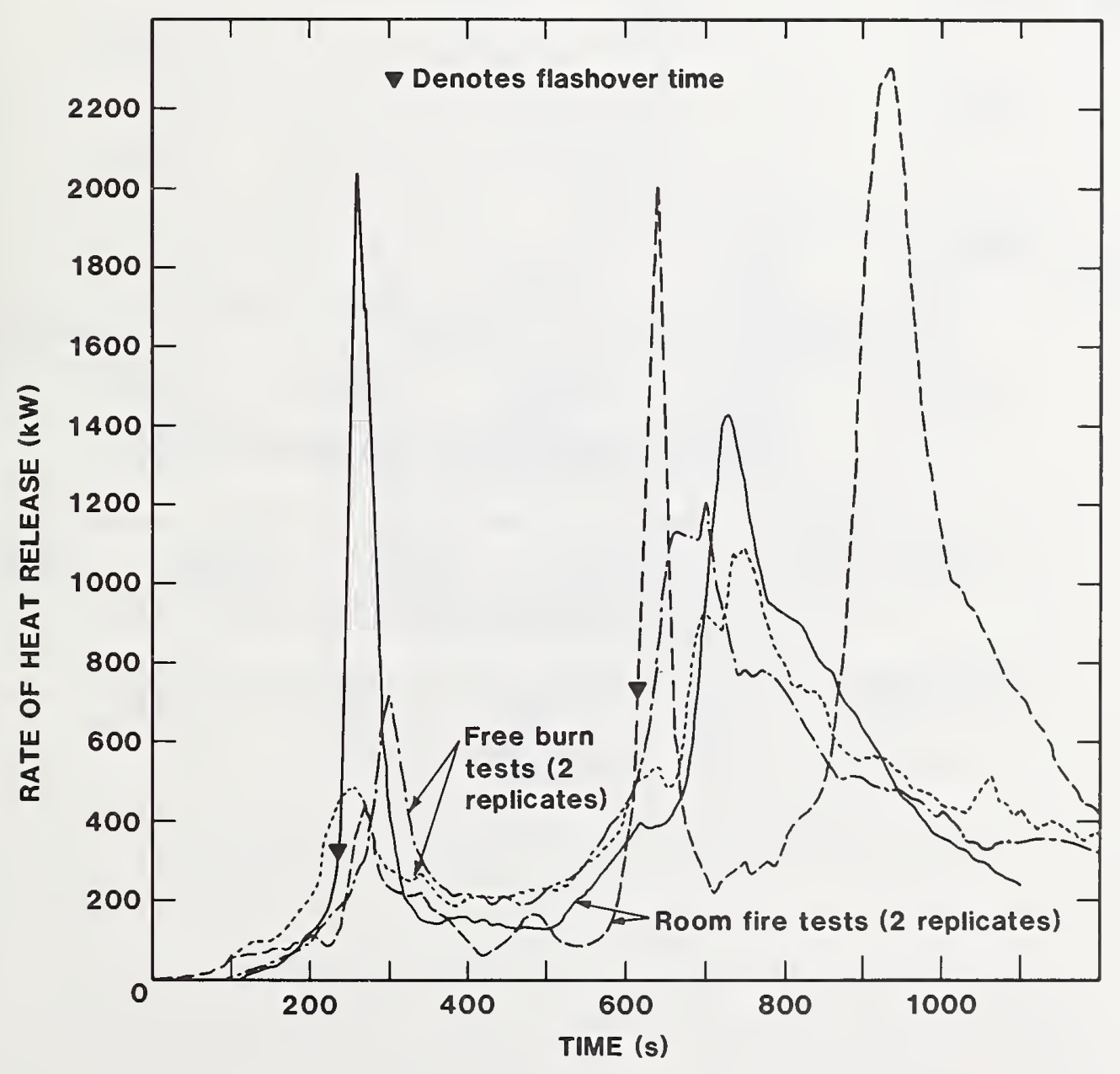

Figure 34. Comparison of free burn and room fire results for beds. 


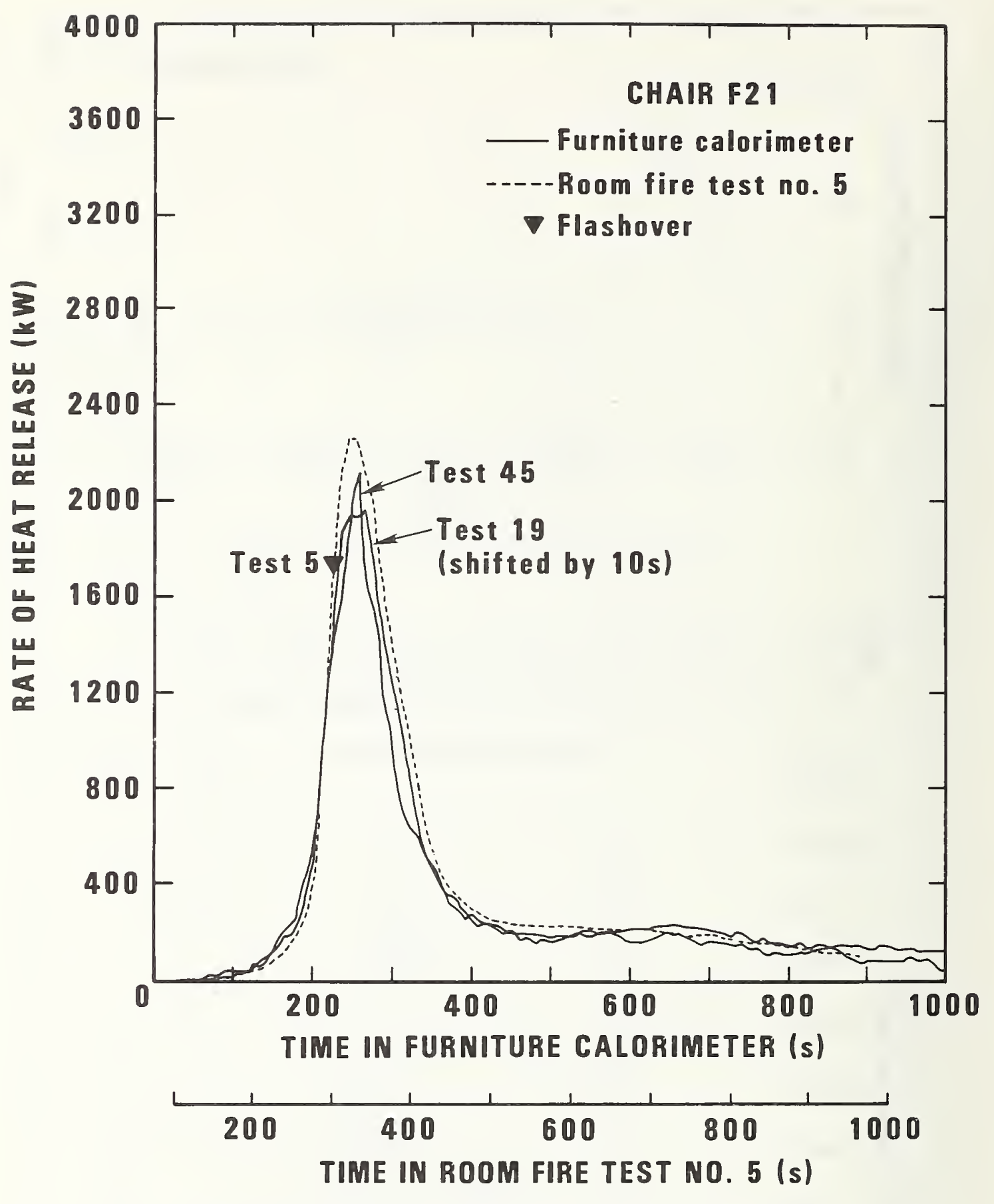

Figure 35. Comparison of furniture calorimeter and room fire results for an upholstered chair. 


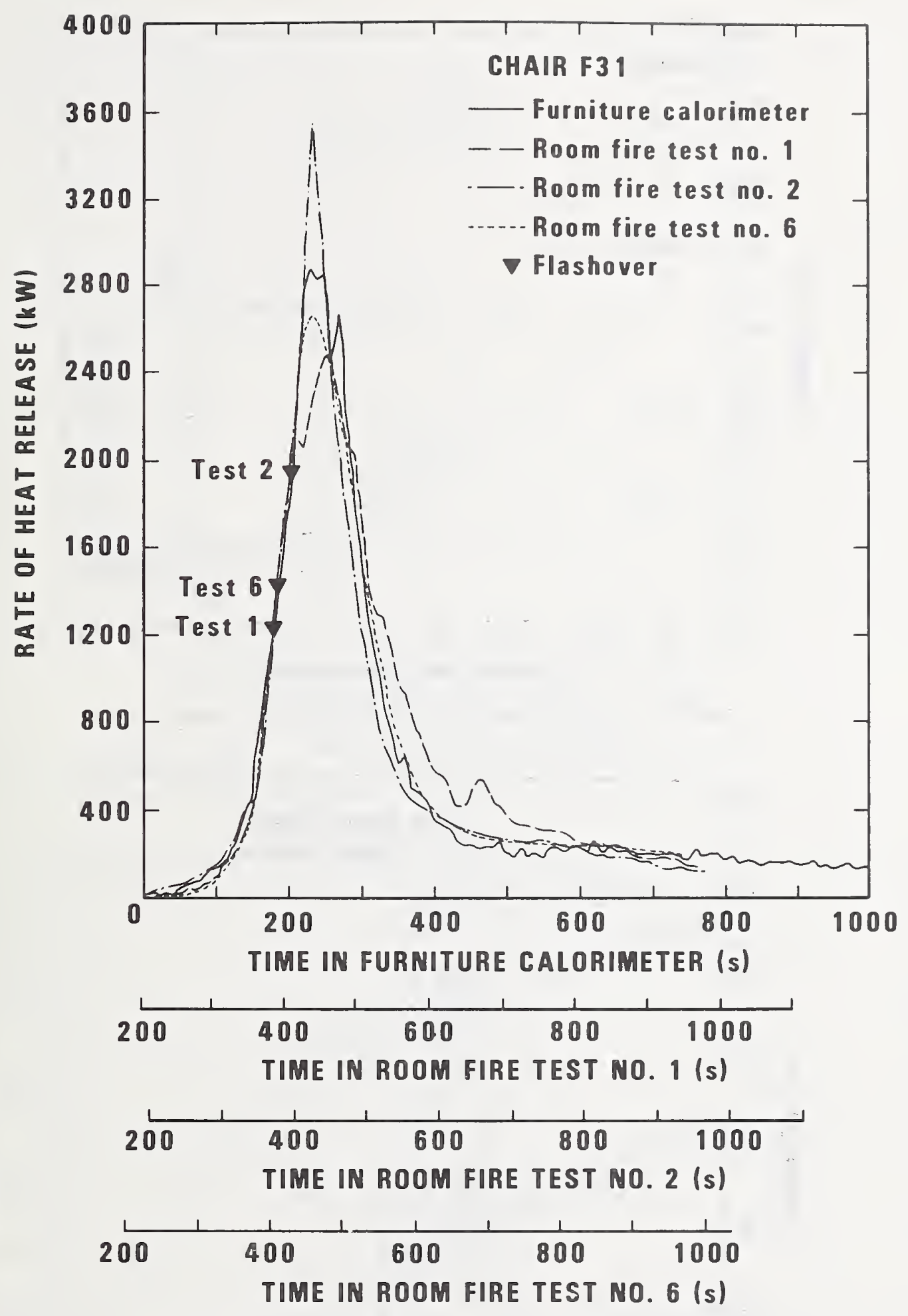

Figure 36. Comparison of furniture calorimeter and room fire results for a loveseat. 


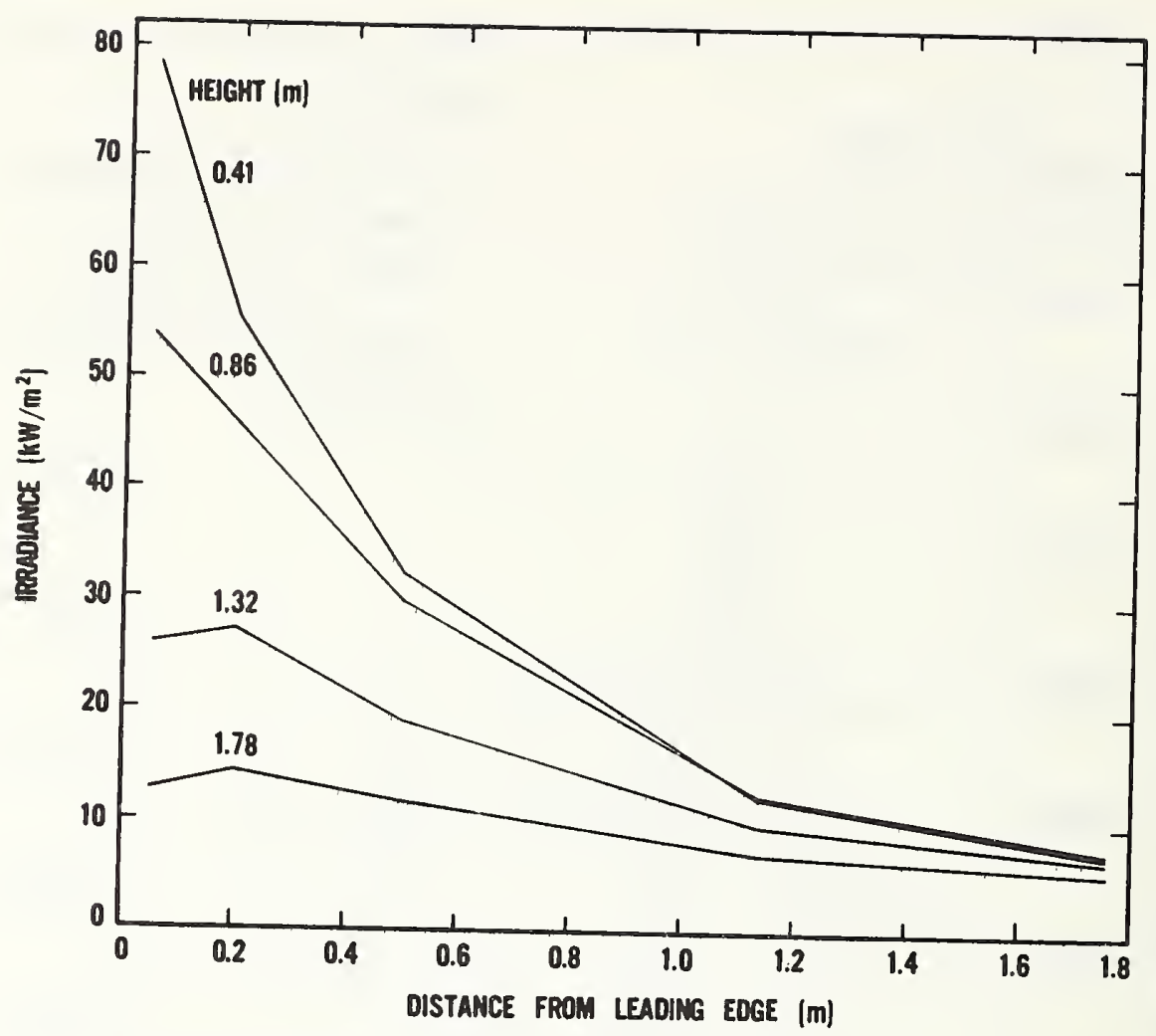

Figure 37. Irradiances for wicker couch (F19) measured at peak burning time.

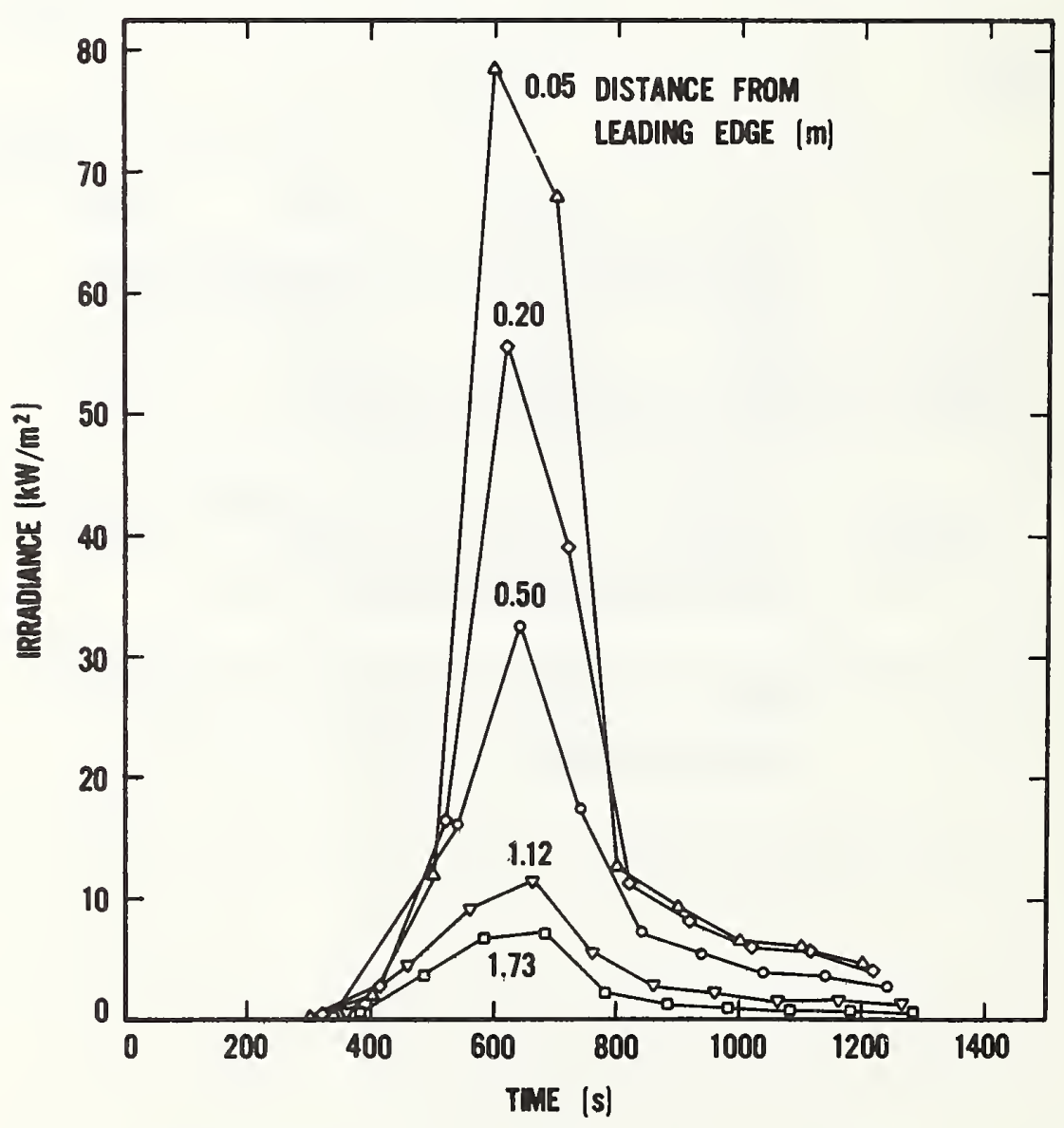

Figure 38. Irradiances for wicker couch (FI9) measured at $0.41 \mathrm{~m}$ height. 


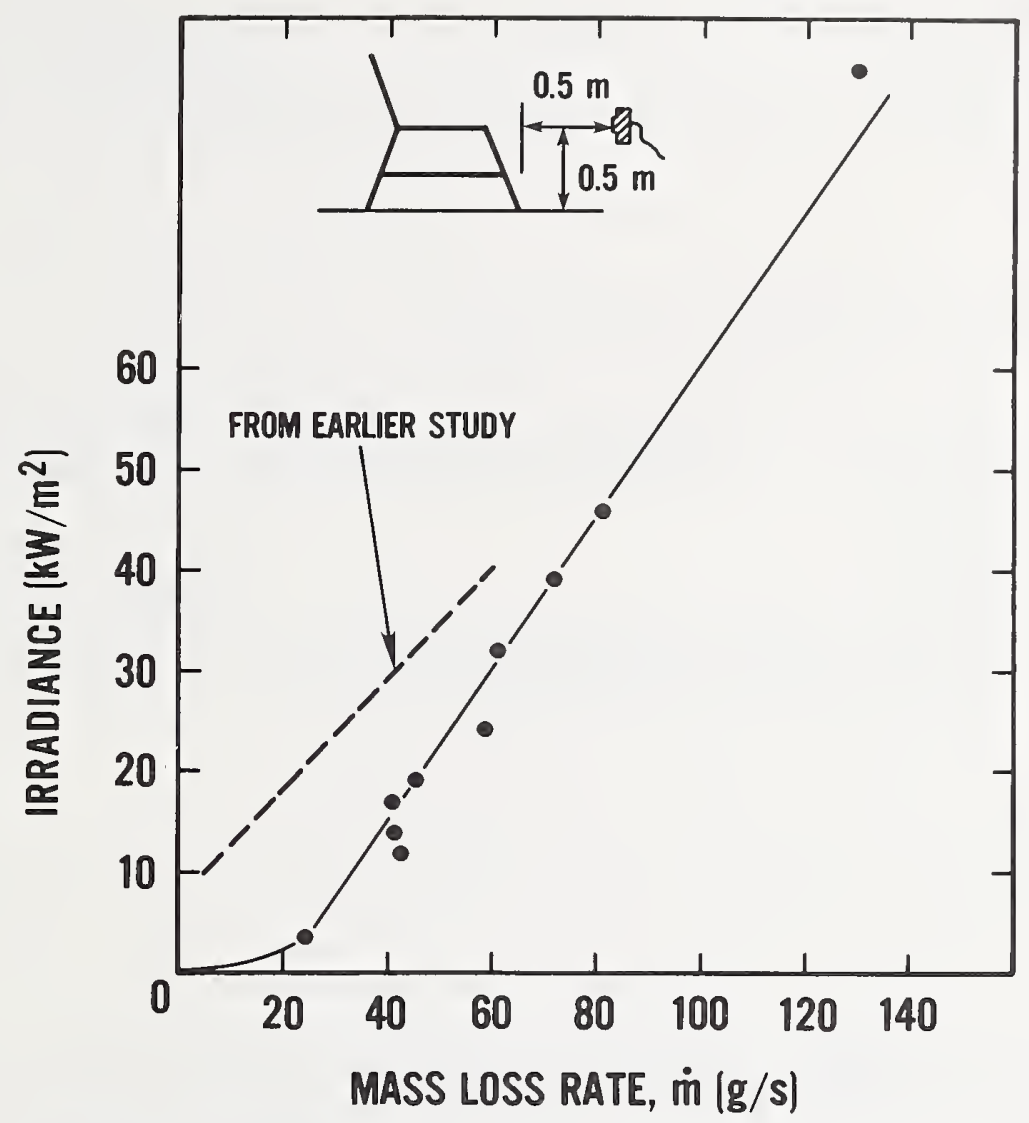

Figure 39. Relationship between mass loss rate of initial item and irradiance to target.

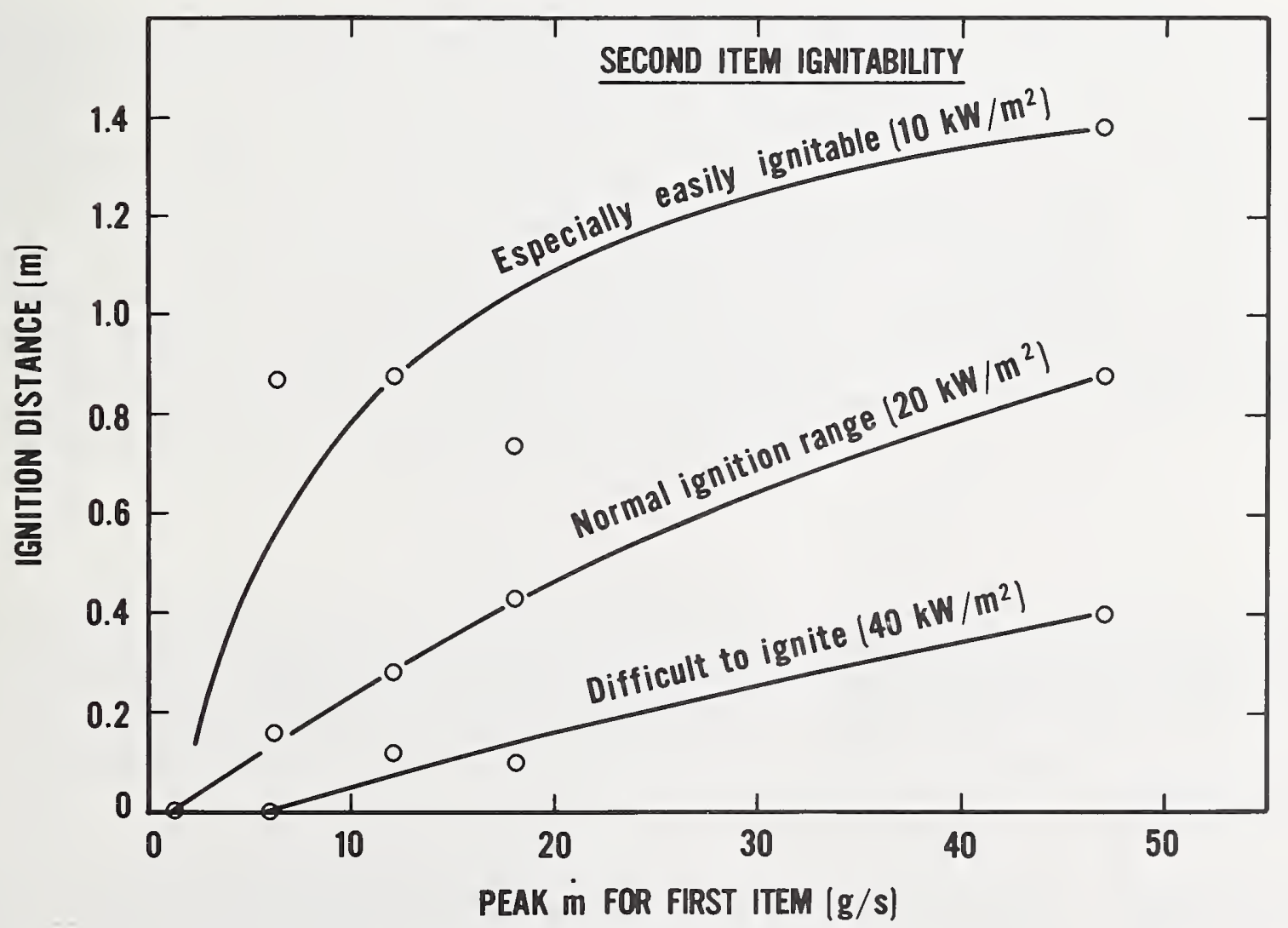

Figure 40. Relationship between mass loss rate of initial item and maximum ignitability distance for second items of varying ignitability. 

NBS-114A (REV, 2-8C)

U.S. DEPT. OF COMM.

BIBLIOGRAPHIC DATA

SHEET (See instructions)

1. PUBLICATION OR
REPORT NO.
NIBS/MONO-1.73

2. Performing Organ. Report No.

3. Publication Date

November 1985

4. TITLE AND SUBTITLE

Fire Behavior of Upholstered Furniture

5. AUTHOR(S)

Vytenis Babrauskas and John F. Krasny

6. PERFORMING ORGANIZATION (If joint or other than NBS, see instructions)

7. Contrack Grant No.

National Bureau of Standards

U.S. Department of Commerce

Gaithersburg, MD 20899

8. Type of Report \& Period Covered Fina1

9. SPONSORING ORGANIZATION NAME AND COMPLETE ADDRESS (Street, City。 Stote, ZIP)

Same as item 6.

10. SUPPLEMENTARY NOTES

Library of Congress Catalog Card Number 85:600620

Document describes a computer program; SF-185, FIPS Software Summary, is attached.

11. ABSTRACT (A 200-word or less foctual summary of most significant information. If document includes a significant bibliography or literature survey. mention it here)

A systematic review is made of engineering data on the major aspects of upholstered furniture flammability: cigarette fgnition, small open flame ignition, radiant ignition, transition from smoldering to flaming, flame spread rates, and heat release and mass loss rates during fully-involved burning. Other areas discussed, but for which less data are available, include smoke production and radiant heat fluxes. Mattresses and transportation vehicle seating are included, along with upholstered chairs, loveseats, and sofas. Appropriate test methods most suitable for measuring each of these properties are discussed. Where available, relationships are presented which permit the quantitative prediction of full-scale furniture behavior from bench-scale tests. Where such relationships are not available, generalizations of qualitative results of empirical tests are given. Areas where substantive work is not available are outlined.

12. KEY WORDS (Six to twelve entries; alphabetical order; capitalize only proper names; and separate key words by semicolons) beds (furniture); cigarettes; fabric flammability; fire tests; flame spread rate; heat release rate; ignition; mattresses; plastics; smoke production; smoldering; upholstered furniture

13. AVAILABILITY

[X] Unlimited

$\square$ For Official Distribution. Do Not Release to NTIS

Order From Superintendent of Documents, U.S. Government Printing Office, Washington, D.C. 20402.

14. NO. OF PRINTED PAGES

101

[ Order From National Technical Information Service (NTIS), Springfield, VA. 22161

15. Price 



\section{Periodical}

Journal of Research-The Journal of Research of the National Bureau of Standards reports NBS research and development in those disciplines of the physical and engineering sciences in which the Bureau is active. These include physics, chemistry, engineering, mathematics, and computer sciences. Papers cover a broad range of subjects, with major emphasis on measurement methodology and the basic technology underlying standardization. Also included from time to time are survey articles on topics closely related to the Bureau's technical and scientific programs. Issued six times a year.

\section{Nonperiodicals}

Monographs-Major contributions to the technical literature on various subjects related to the Bureau's scientific and technical activities.

Handbooks-Recommended codes of engineering and industrial practice (including safety codes) developed in cooperation with interested industries, professional organizations, and regulatory bodies.

Special Publications-Include proceedings of conferences sponsored by NBS, NBS annual reports, and other special publications appropriate to this grouping such as wall charts, pocket cards, and bibliographies.

Applied Mathematics Series-Mathematical tables, manuals, and studies of special interest to physicists, engineers, chemists, biologists, mathematicians, computer programmers, and others engaged in scientific and technical work.

National Standard Reference Data Series-Provides quantitative data on the physical and chemical properties of materials, compiled from the world's literature and critically evaluated. Developed under a worldwide program coordinated by NBS under the authority of the National Standard Data Act (Public Law 90-396).

NOTE: The Journal of Physical and Chemical Reference Data (JPCRD) is published quarterly for NBS by the American Chemical Society (ACS) and the American Institute of Physics (AIP). Subscriptions, reprints, and supplements are available from ACS, 1155 Sixteenth St., NW, Washington, DC 20056.

Building Science Series-Disseminates technical information developed at the Bureau on building materials, components, systems, and whole structures. The series presents research results, test methods, and performance criteria related to the structural and environmental functions and the durability and safety characteristics of building elements and systems.

Technical Notes-Studies or reports which are complete in themselves but restrictive in their treatment of a subject. Analogous to monographs but not so comprehensive in scope or definitive in treatment of the subject area. Often serve as a vehicle for final reports of work performed at NBS under the sponsorship of other government agencies.

Voluntary Product Standards-Developed under procedures published by the Department of Commerce in Part 10, Title 15, of the Code of Federal Regulations. The standards establish nationally recognized requirements for products, and provide all concerned interests with a basis for common understanding of the characteristics of the products. NBS administers this program as a supplement to the activities of the private sector standardizing organizations.

Consumer Information Series-Practical information, based on NBS research and experience, covering areas of interest to the consumer. Easily understandable language and illustrations provide useful background knowledge for shopping in today's technological marketplace.

Order the above NBS publications from: Superintendent of Documents, Government Printing Office, Washington, DC 20402.

Order the following NBS publications-FIPS and NBSIR's-from the National Technical Information Service, Springfield, VA 22161.

Federal Information Processing Standards Publications (FIPS PUB)-Publications in this series collectively constitute the Federal Information Processing Standards Register. The Register serves as the official source of information in the Federal Government regarding standards issued by NBS pursuant to the Federal Property and Administrative Services Act of 1949 as amended, Public Law 89-306 (79 Stat. 1127), and as implemented by Executive Order 11717 (38 FR 12315, dated May 11, 1973) and Part 6 of Title 15 CFR (Code of Federal Regulations).

NBS Interagency Reports (NBSIR)-A special series of interim or final reports on work performed by NBS for outside sponsors (both government and non-government). In general, initial distribution is handled by the sponsor; public distribution is by the National Technical Information Service, Springfield, VA 22161, in paper copy or microfiche form. 
U.S. Department of Commerce National Bureau of Standards

Gaithersburg, MD 20899

Official Business

Penalty for Private Use $\$ 300$ 